\title{
APPLICABILITY OF PERFORMANCE-BASED FUNDING MODELS FOR TERTIARY EDUCATION IN SMALL ISLAND DEVELOPING STATES THE CASE OF MAURITIUS
}

By

Siamah Kaullychurn

\begin{abstract}
A thesis
submitted to the Victoria University of Wellington in fulfilment of the requirements for the degree of Doctor of Philosophy in Public Policy
\end{abstract}

Victoria University of Wellington

May 2009 


\section{ABSTRACT}

Performance-based funding of publicly-provided goods and services is an outputoriented system which is seen by many experts as a better way of improving efficiency and enhancing public accountability than reliance upon an input-based system. From the early 1980s, the goal has shifted in many OECD countries from accounting for expenditures to accounting for results. The shift gained momentum from movements to re-engineer business and reinvent government. Empirical studies of performance-based funding (PBF) systems to date have been largely confined to OECD countries and there is a lack of literature on PBF models with regard to developing countries, including Small Island Developing States (SIDS). This research explores the desirability and applicability of a PBF model for tertiary education in SIDS, with particular reference to Mauritius.

This research adopts a pluralist methodology which is based on a literature review, a substantive assessment of the five OECD countries (Australia, Denmark, Sweden, New Zealand and United Kingdom) where PBF models are currently in use in the tertiary education sector, and qualitative interviewing. Thirty-eight respondents were interviewed involving members of the political elites and representatives of the tertiary education sector in Mauritius. Primary empirical materials were triangulated and cross-validated with secondary data gathered from official documents.

The results indicated some measure of support for performance-based systems among the respondents in order to promote the quality of tertiary education, enhance research capability and increase accountability for the use of public funds. However, SIDS would face difficulties in developing and implementing PBF systems for tertiary education in the short-term because of a lack of human resource capability, the limited capacity of governments to reward performance due to budgetary constraints, the distinctive characteristics of SIDS (e.g. smallness, a limited number of tertiary education institutions, and vulnerability to natural calamities), and high administrative and compliance costs.

An important conclusion from this investigation is that there is no 'perfect' PBF model and unintended consequences are likely from any model adopted. A PBF model for either teaching or research (whether based on peer review, performance indicators or a mix of the two) would not be desirable, feasible or applicable in Mauritius or any other SIDS in the short-term. 
Three other policy options are considered for enhancing research and teaching performance in the tertiary education sector in the short-term, namely better monitoring and reviewing research performance, an improved quality assurance system, a review of outcomes, or some combination of the three options. In the longer-term, there is the possibility of developing a PBF research indicator model, provided some key preconditions are met, such as stable policy settings and political commitment, adequate human resource capacity and capability, and the separation of budgets for research and teaching. 


\section{ACKNOWLEDGEMENTS}

I am grateful to a number of organisations and people who contributed to my goal of writing a PhD thesis. It is virtually impossible to mention all of them here. My appreciation and thanks to the Governments of Mauritius and New Zealand for awarding me the Commonwealth Scholarship and to the management of University of Technology, Mauritius for granting me leave for my studies. My heartfelt thanks to my supervisors Professor Jonathan Boston and Dr Chris Eichbaum. I have learned a lot from you both and have been privileged to have had such dedicated and good supervision. I am particularly grateful to my primary supervisor Jonathan, for keeping me focused through the research process and providing sound advice, wise comments and encouragement for improving the quality of my work. I am especially thankful to Dr Deborah Laurs, Student Learning Support Advisor, for her great assistance, constant support and encouragement for the writing up of my thesis for the past three years. I also wish to acknowledge with gratitude the financial support from the Commonwealth Scholarships Committee, NZAID, and from the School of Government, Victoria University of Wellington, for the conference attendance and fieldwork. I would also like to thank all the staff of the School of Government, especially Dr Amanda Wolf and Dawn Yeabsley, the NZVCC scholarship manager Kiri Manuera, NZAID Student Advisors, the librarian Charlotte Clements and all my Kiwi and overseas PhD colleagues.

In Mauritius, the assistance of the Ministry of Education and Human Resources, Tertiary Education Commission, Mauritius Research Council, and Tertiary Education Institutions is acknowledged. I am very thankful to all the people who kindly accepted to be interviewed for this research.

My sincere appreciation and special thanks to David and Daniele McGee for their continuous support and encouragement, and great hospitality for my stay and study in New Zealand.

Last, but not least, I am grateful to my cousin Prakash, my brother Jatin, my sisters and their families, all my close friends, relatives, colleagues, and loved ones for their immense support for my studies. Above all, I am indebted to my parents for the education they provided me and their infinite encouragement for my achievements in life. My thoughtful appreciation and thanks to them. 


\section{ABBREVIATIONS}

$\begin{array}{ll}\text { ERI } & \text { External Research Income } \\ \text { FTE } & \text { Full Time Equivalent } \\ \text { GTER } & \text { Gross Tertiary Enrolment Rate } \\ \text { HEI } & \text { Higher Education Institution (as used in Denmark, Sweden and the } \\ & \text { United Kingdom) } \\ \text { IGS } & \text { Institutional Grants Scheme } \\ \text { MRC } & \text { Mauritius Research Council } \\ \text { NZ } & \text { New Zealand } \\ \text { OECD } & \text { Organisation for Economic Co-operation and Development } \\ \text { PBF } & \text { Performance-Based Funding } \\ \text { PBRF } & \text { Performance-Based Research Fund } \\ \text { PFI } & \text { Public Funded Institution } \\ \text { RAE } & \text { Research Assessment Exercise } \\ \text { RDC } & \text { Research Degree Completion } \\ \text { RTS } & \text { Research Training Scheme } \\ \text { SIDS } & \text { Small Island Developing States } \\ \text { TEC } & \text { Tertiary Education Commission } \\ \text { TEI } & \text { Tertiary Education Institution (as used in Mauritius) } \\ \text { TEO } & \text { Tertiary Education Organisation (as used in New Zealand) } \\ \text { UK } & \text { United Kingdom } \\ \text { UoM } & \text { University of Mauritius } \\ \text { UTM } & \text { University of Technology Mauritius } \\ \end{array}$


TABLES

Table 1.1: Positioning Mauritius among other SIDS ..................... 12

Table 2.1: Conventional and Naturalistic Methods to ensure Quality and Trustworthiness ........................................... $\quad 30$

Table 3.1: Country Comparisons - GDP Per Capita (PPP) and HDI... 35

Table 3.2: Total Enrolment in Tertiary Education for 1997/98, $2000 / 01,2003 / 04$, and $2007 / 08 \ldots \ldots \ldots \ldots \ldots \ldots \ldots \ldots \ldots . . . \ldots \ldots$

Table 3.3: Research Grant Schemes for the Financial Years 2000,

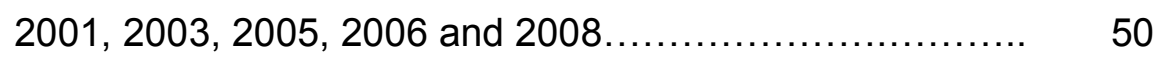

Table 5.1: Tertiary Education Reforms in New Zealand .................. $\quad 90$

Table 5.2: $\quad$ Summary of Reviews and Research Studies .................... $\quad 95$

Table 5.3: RAE Ratings and Corresponding Funding Weights for

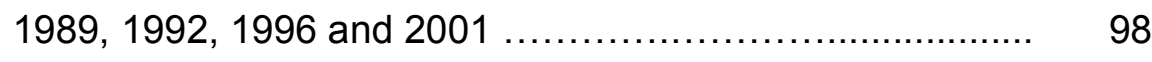

Table 6.1: $\quad$ Phases of Thematic Analysis ................................. 136

Table 7.1: $\quad$ Themes and Findings from Stakeholder Interviews.......... 180

Table 7.2: Mauritius Education Budget for Tertiary Sector................ 185

Table 7.3: $\quad$ Allocation of Funds to Tertiary Education Institutions........ 186

Table 7.4: $\quad$ UoM Publications by Faculties................................. 191 


\section{FIGURES}

Figure 3.1 Total Enrolment in Tertiary Education from 1998 to

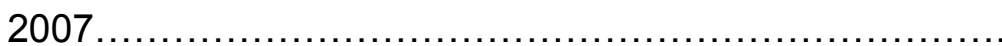

Figure 3.2 Distribution of Total Tertiary Enrolment by Source, 2007

Figure 3.3 Evolution of Tertiary Education Enrolment by

Source.

Figure 3.4 Government Funding for Tertiary Education Sector for the Financial Years $1999 / 2000$ to $2007 / 2008$.

Figure 5.1 Program Outcome Model for Tertiary Education.

Figure 7.1 Tertiary Education Budget as a Percentage of Total Education Budget.

Figure 7.2 Budget Allocations for TEls

Figure 7.3 Outputs (Graduates) from the Publicly-Funded Institutions 1995/96 - 2006/07

Figure 7.4 Faculty-Wise Distribution of Students Registered for MPhil or a PhD Degree. 


\section{TABLE OF CONTENTS}

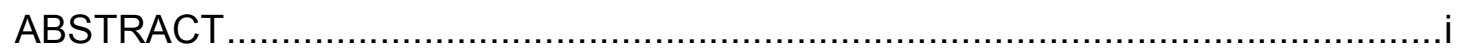

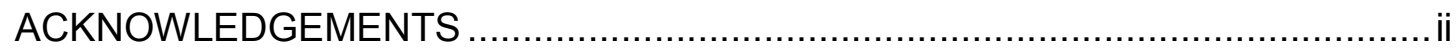

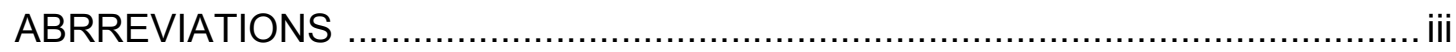

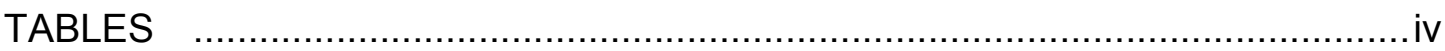

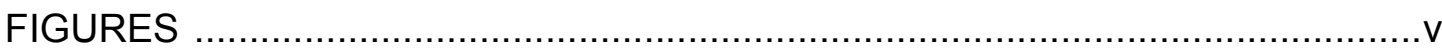

CHAPTER ONE: INTRODUCTION ............................................................ 1

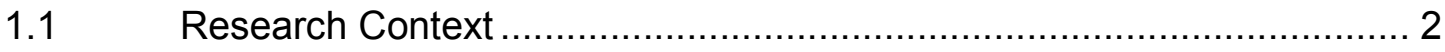

$1.2 \quad$ Specific Issues and Challenges for SIDS ...................................... 3

1.2.1 Political Instability and Lack of Good Governance ...................................... 4

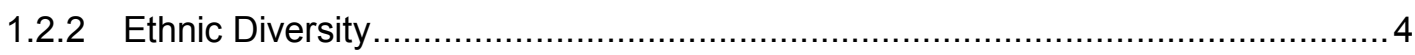

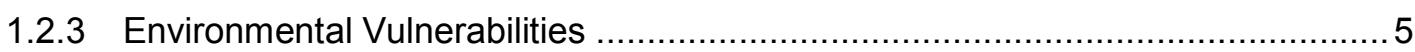

1.2.4 Trade Development and Economic Performance .......................................... 5

1.2.5 Human Resource Development............................................................... 6

1.2.5.1 Educational Research Challenges for Small Island States............................ 7

1.2.5.2 Quantity versus Quality Educational Issues ........................................... 7

1.2.5.3 Education for Sustainable Development in African, Caribbean and Pacific

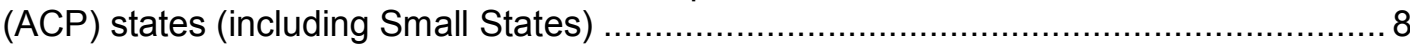

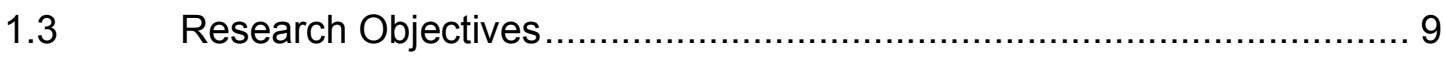

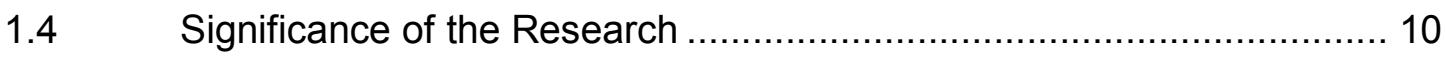

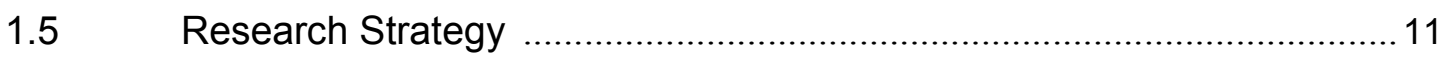

1.5.1 Case Study - Mauritius …............................................................... 11

1.5.2 Criteria for Evaluation of the Models ........................................................ 13

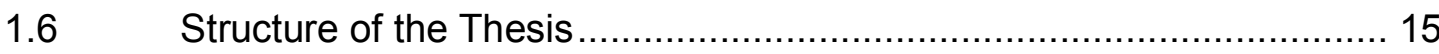

CHAPTER TWO: RESEARCH METHODOLOGY......................................... 19

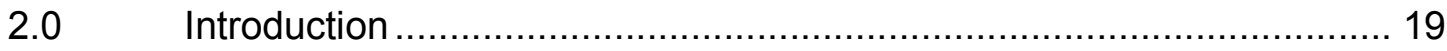

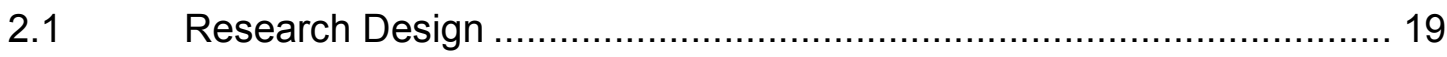

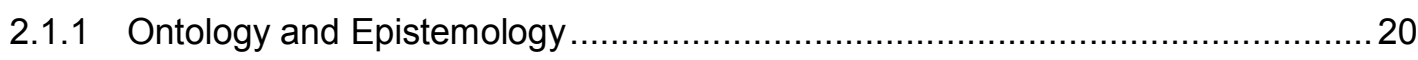

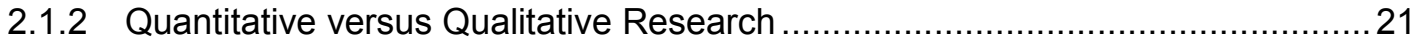

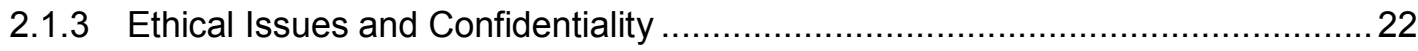




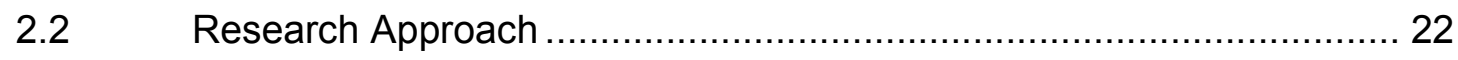

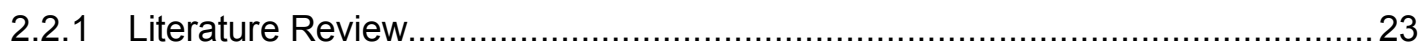

2.2.2 Empirical Materials Collection.............................................................. 23

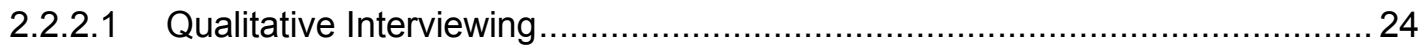

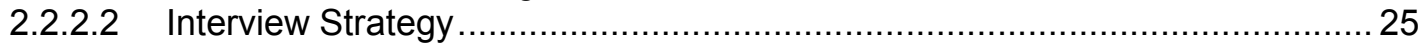

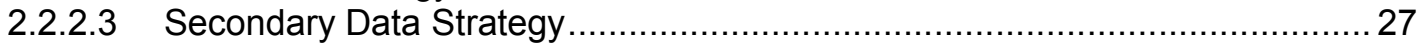

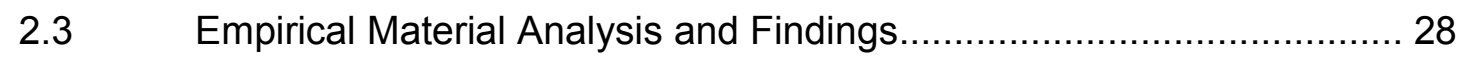

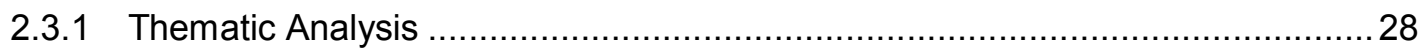

2.3.2 Evaluative Criteria for Qualitative Research....................................... 29

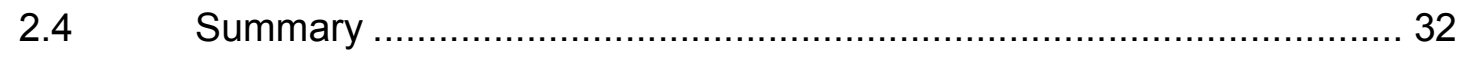

CHAPTER THREE: TERTIARY EDUCATION SYSTEM IN MAURITIUS ............ 33

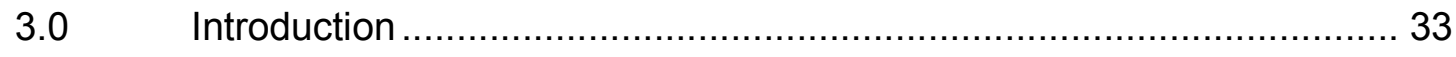

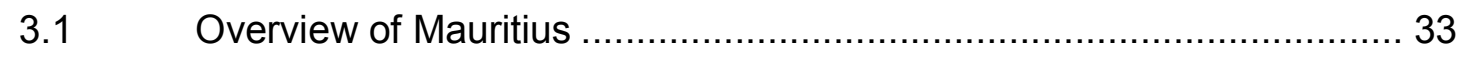

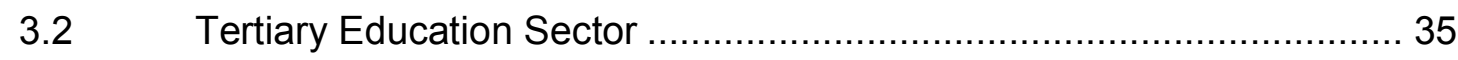

3.3 Tertiary Education Institutions ............................................... 36

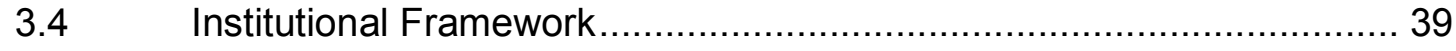

3.5 Participation in Tertiary Education ......................................... 42

3.6 Tertiary Education Funding ...................................................... 45

3.7 Current Issues for Tertiary Education in Mauritius ............................ 50

3.7.1 Encouraging Private and Overseas Institutions ............................................. 51

3.7.2 Open and Distance Learning Education .................................................... 52

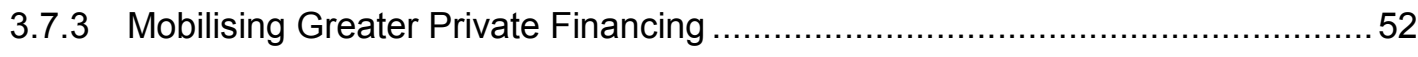

3.7.4 Financial Student Support and Loan Schemes ......................................... 53

3.7.5 Increased autonomy for Public-Funded Institutions .................................. 54

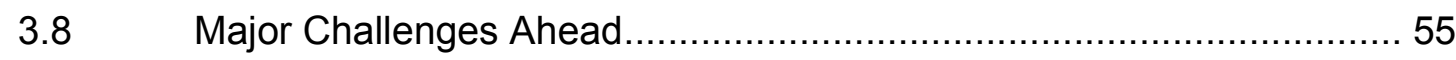

3.8.1 Developing Mauritius into a Knowledge Hub and a Centre of Higher

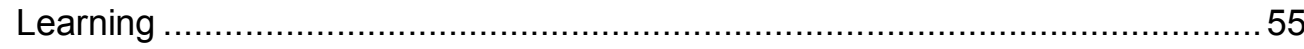

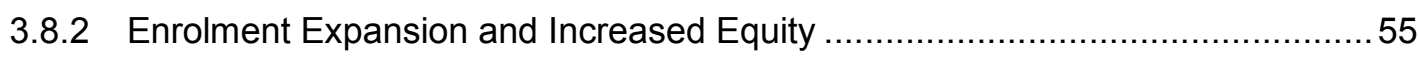

3.8.3 Incentives for Efficient Resource Allocation and Utilisation ............................56 
3.8.4 Ensure Quality Standards of all Tertiary Education Provisions.........................56

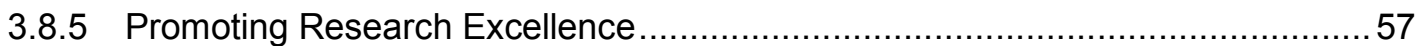

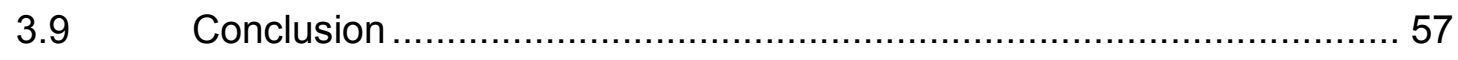

CHAPTER FOUR: HISTORICAL AND CURRENT FUNDING MECHANISMS... 59

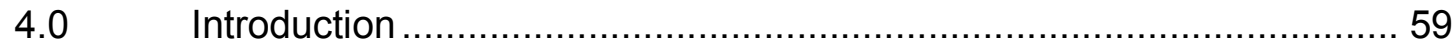

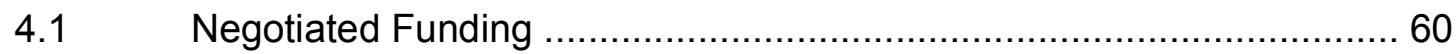

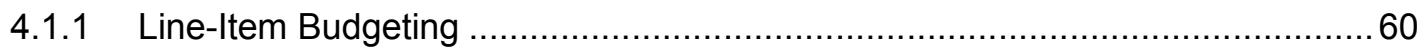

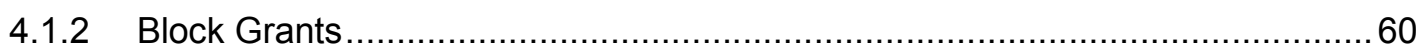

4.2 Strengths and Weaknesses of Negotiated funding ......................... 61

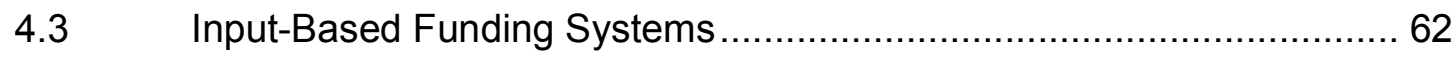

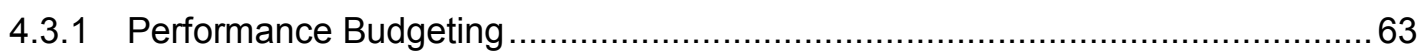

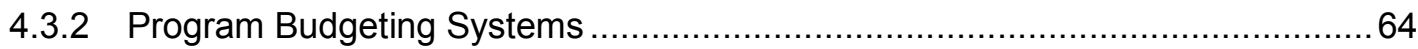

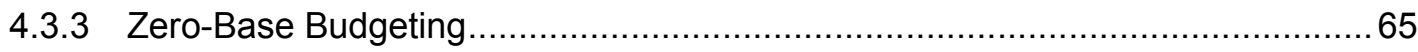

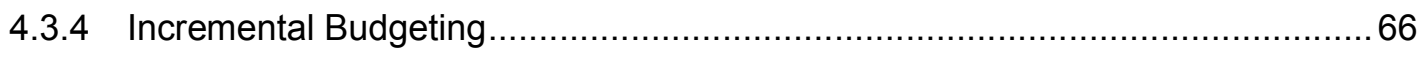

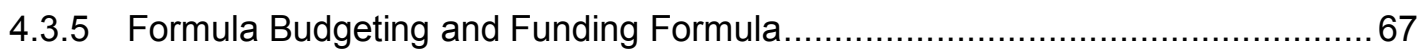

4.4 Problems with Input-Based Funding Systems ...............................69

4.5 Strengths and Weaknesses of Formula Budgeting and Funding .............

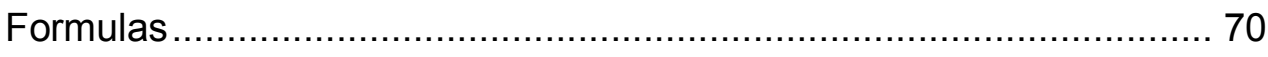

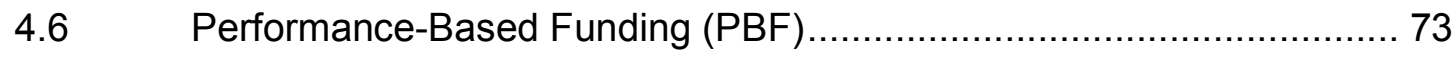

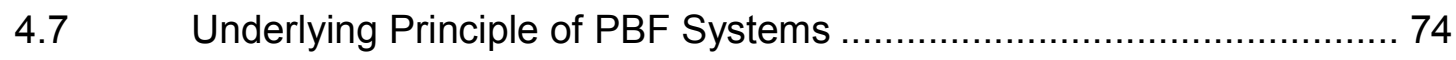

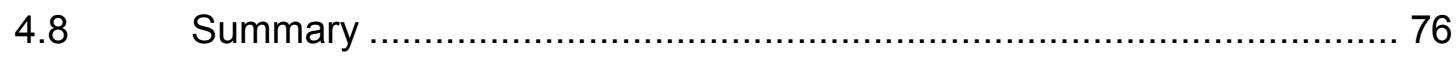

CHAPTER FIVE: REVIEW OF PERFORMANCE BASED FUNDING MODELS 78

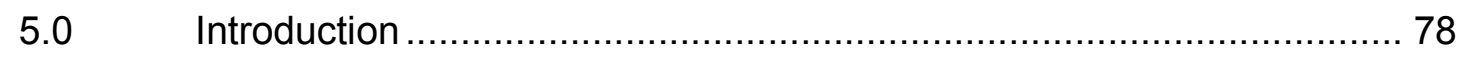

5.1 Background to the Developments of PBF Mechanisms ..................... 78

$5.2 \quad$ Programme Outcome Model for Tertiary Education............................ 81

5.3 Performance-Based Funding Models for Research .......................... 83

5.3.1 Higher Education System, Reforms and Funding (United Kingdom, Australia, ..... New Zealand) ................................................................................ 84 
5.3.2 United Kingdom - Peer Review Model 92

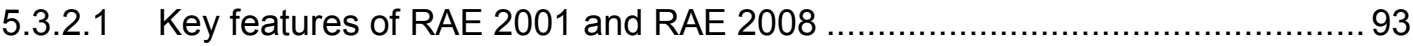

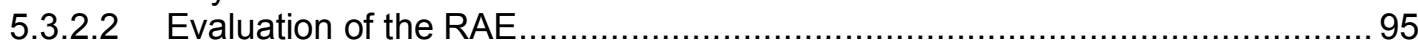

5.3.2.3 Significant Changes for the RAE 2008............................................ 102

5.3.2.4 Post 2008 RAE- Research Excellence Framework ............................... 102

5.3.3 Australia - Performance Indicator Model................................................ 104

5.3.3.1 Evaluation of the Performance Indicators Model.................................... 106

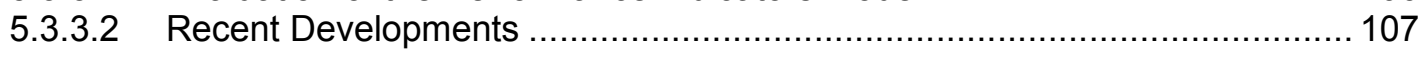

5.3.4 New Zealand - Mixed Model ...................................................................... 109

5.3.4.1 Key features of PBRF - Phase one (2003) ........................................... 110

5.3.4.2 Points of Similarity and Difference with the UK Performance-Based ................

System .......................................................................................... 111

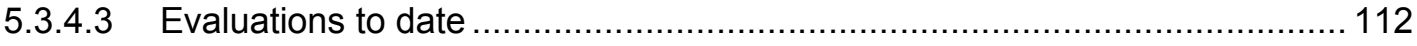

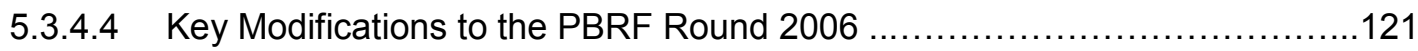

5.4 Performance-Based Funding Models for Teaching ......................... 122

5.4.1 Higher Education System, Reforms and Funding (Denmark and weden) ........ 122

5.4 .2 Denmark Taximeter Model ............................................................... 125

5.4.3 Sweden FTE (Students) and FTE Study Results .................................... 126

5.4.4 Significant differences between Denmark and Sweden Funding Models ......... 127

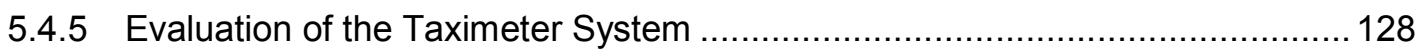

5.4.5.1 Future Direction of the Taximeter System .......................................... 130

5.4.6 Evaluation of the FTE (students) and FTE study results ............................ 131

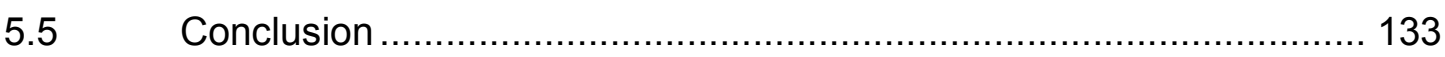

CHAPTER SIX: NECESSARY CONDITIONS FOR PBF SYSTEMS ................ 135

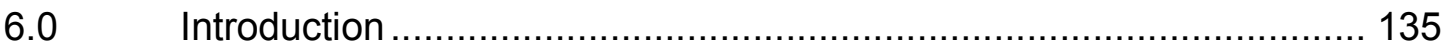

6.1 Process of Empirical Materials Analysis .................................... 135

6.2 Policy Objectives and Outcomes for Tertiary Education in Mauritius .. 137

6.2.1 Access, Equity and Quality Improvement .......................................... 137

6.2.1.1 Quality as Relevance and Employability ............................................ 138

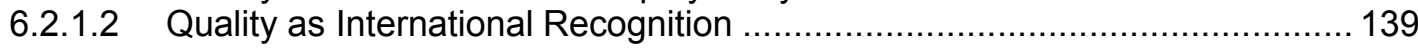

6.2.1.3 Responsible Citizens and Brain Drain............................................... 140

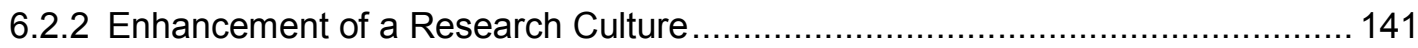

6.2.3 Development of Alternative Sources of Funding ........................................ 142

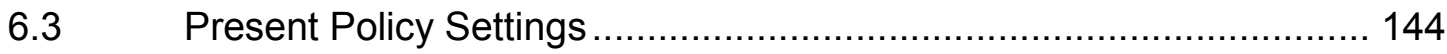

6.4 Understanding and Comprehension of PBF Systems ..................... 148 


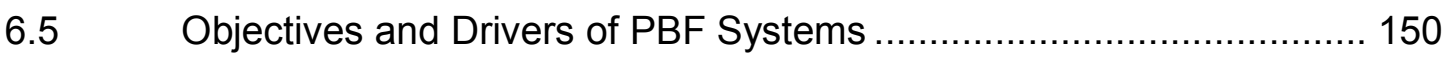

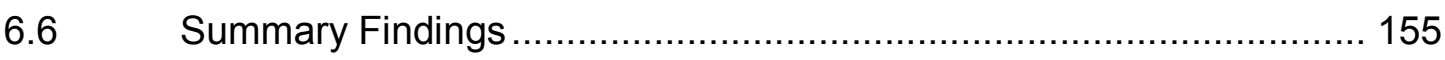

CHAPTER SEVEN: OPPORTUNITIES AND CHALLENGES FOR PBF SYSTEMS 159

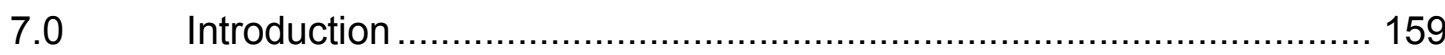

7.1 Applicability and Desirability of PBF Systems ........................... 160

7.2 Capacity Constraints and Opportunities for PBF Systems................. 164

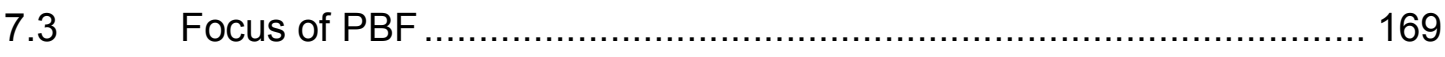

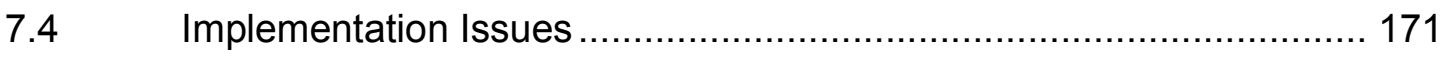

7.5 Political Acceptability and Administrative Feasibility of PBF Systems 176

Secondary Data Analysis ........................................................ 184

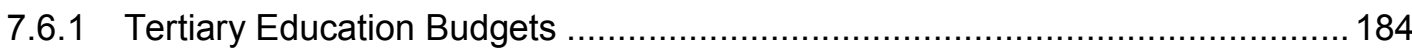

7.6.2 Number of Researchers (Academic Staff) ........................................... 187

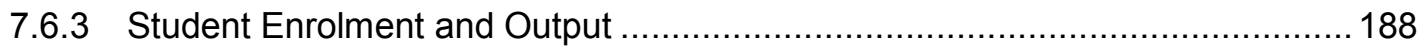

7.6.4 Higher Degree Research Student Enrolments .......................................... 189

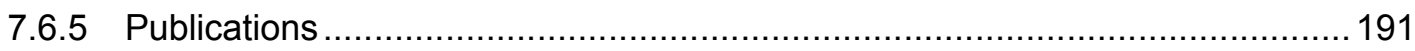

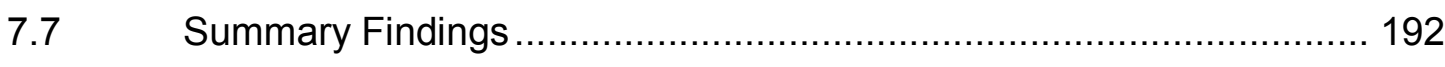

CHAPTER EIGHT: DISCUSSIONS AND IMPLICATIONS FOR SMALL ISLAND

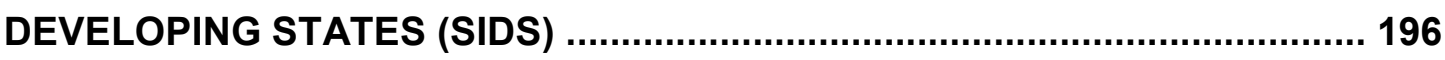

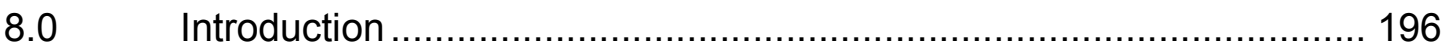

8.1 Discussions of Research Findings ......................................... 197

8.2 Key Lessons from Overseas Experience for SIDS .......................... 203

8.2.1 Political Acceptability and Commitment ............................................... 203

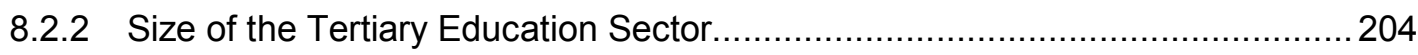

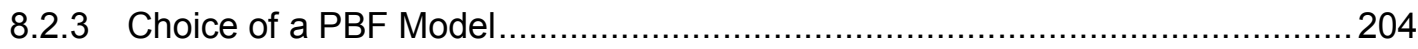

8.2.4 Transaction Costs associated with PBF systems ....................................... 205

8.2.5 Adequacy of Tertiary Education Budget................................................. 206 
8.2.6 Technical Capability at Government and TEI Levels................................. 207

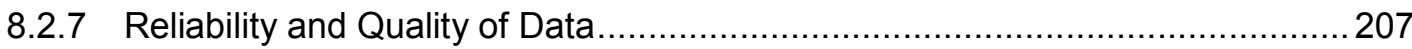

8.2.8 Leadership from TEls and Staff Association Participation............................. 208

8.3 Applicability of PBF Models for SIDS ..................................... 208

8.3.1 PBF for Teaching - Why Not Applicable? .......................................... 209

8.3.2 PBF for Research (Peer Review or Mixed Model) - Not Applicable.................211

8.3.2.1 Choice of Performance Indicators for Research........................................ 211

8.3.2.2 Peer Reviewers and Composition of Panel Members ................................ 213

8.3.2.3 Affordability (Administrative and Compliance Costs) ................................. 213

8.3.3 PBF for Research (Indicator Model) - Possibly applicable in the long-term ...........

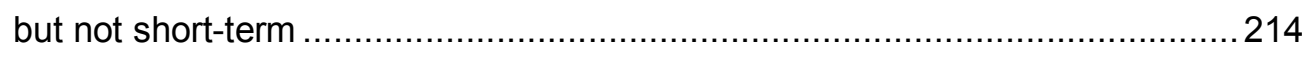

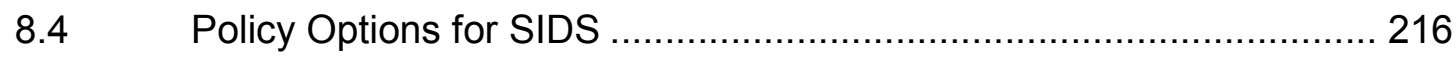

8.4.1 Monitor and Review Research Performance of TEls ................................ 217

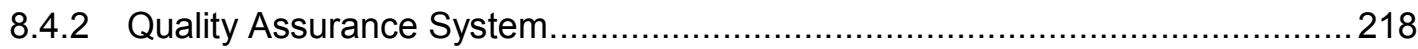

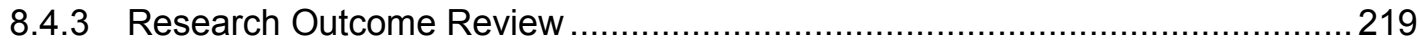

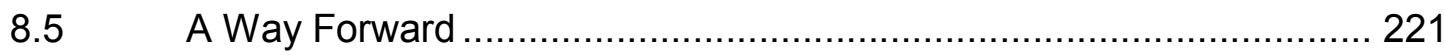

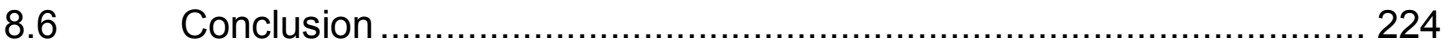

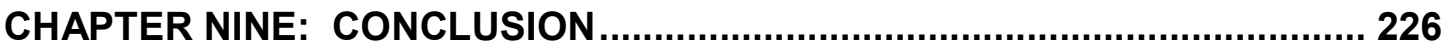

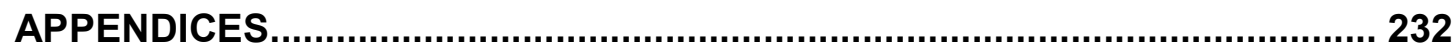

Appendix A: List of Small Island Developing States (UN Members) .................. 232

Appendix B: Number of Interviewees from Different Organisations and

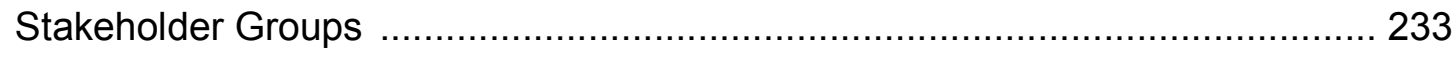

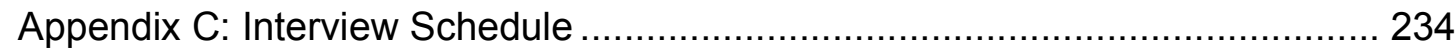

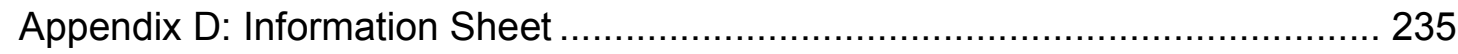

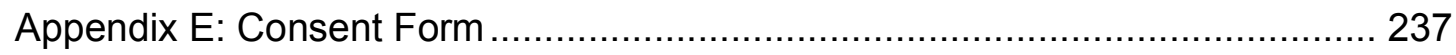

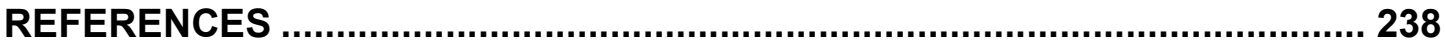




\section{CHAPTER ONE: INTRODUCTION}

Tertiary education exercises a direct influence on national productivity, which largely determines living standards and a country's ability to compete in the global economy (World Bank, 2002, p.20)

Investment in tertiary education is an essential pillar of development strategies, which emphasise the construction of democratic, knowledge-based economies and societies (World Bank, 2002). In the era of globalisation, as knowledge becomes more important, so does tertiary education. Government support for tertiary education is justified by two important factors: the existence of market failures and the desire for greater equity for educational opportunity (World Bank, 2002).

Improving the performance of the public sector has been an ongoing objective of many governments. Most governments in developed and developing countries have become increasingly concerned about the funding systems in their respective tertiary sectors. They want tertiary education institutions (TEIs) to be effective and efficient and also to maximise their performance with regard to the money provided to them. They want to know whether the funds allocated to tertiary education have been spent appropriately and have achieved their intended results. All these issues have led governments to review the funding mechanisms and accountability for teaching and research activities in the tertiary sector.

During the 1980s and the early 1990s, governments of developed industrialised countries sought ways of making tertiary education more efficient in order to maintain the valued investment in tertiary education. In many countries (Australia, Belgium, Germany, Netherlands, New Zealand, United Kingdom and United States) tighter funding regimes have led to a situation in which TEls have become more dependent on tuition fees and research income from private sources for their funding rather than public money. As part of the drive for greater efficiency there was significant reform of the financing and management of the tertiary education sector.

A major transformation from completely input-based funding systems to more competitive outcome-based approaches took place over this period (Barnett and Bjarnason, 1999; Layzell, 1998). 
These system changes were designed to improve tertiary education funding in developed countries. It is even more important for developing countries with more limited resources to ensure that money invested in the tertiary education sector is used efficiently and effectively so as to increase national productivity, improve human resource capability and meet the needs of the knowledge society.

\subsection{Research Context}

The challenging tasks for developing countries, particularly Small Island Developing States (SIDS), are expanding their tertiary education systems, improving quality within continuing budgetary constraints, and having "more consistent and productive public funding mechanisms" (World Bank, 2000, p. 11). The World Bank Report (2000) Higher Education in Developing Countries (in collaboration with UNESCO) concludes that longstanding problems and new realities (such as insufficient resources and autonomy, greater demands on public budgets, expansion of higher education, knowledge-based society, accountability and efficiency, and good governance) mean that traditional ways of organising and funding tertiary education are becoming less relevant (World Bank, 2000).

In most SIDS, the funding mechanism adopted for allocating resources to TEls is negotiated funding or input-based funding (line-item budgeting or formula budgeting). Input-based funding systems largely compensate institutions for costs incurred for salaries and physical needs. However, this mechanism has five major problems in terms of allocating resources. The first problem is a lack of incentives for efficient use of resources. Under input-based funding systems resources are provided on the basis of average rather than marginal costs. Second, there is inadequate accountability. Funding formulas are based on enrolment figures, unit costs and weights to reflect the differential costs but do not focus on results, outputs and outcomes.

Third, there is a lack of institutional performance and quality assessment. This is because input-based funding mechanisms do not really establish cost norms per output; neither do they provide incentives for institutions to lower their costs nor to improve the quality of their programmes. Fourth, there are not enough incentives for tertiary providers to seek external sources of funding since input-based funding formulas do not incorporate any measure to attract external income. 
Finally, there is the problem of uncertainties regarding future funding as such mechanisms do not motivate tertiary education institutions to plan their future funding (Kaiser, Vossensteyn, and Koelman, 2001; McKeown-Moak Mary, 1999; Ziderman and Douglas, 1992, 1995).

The challenge for SIDS governments as they seek to fund tertiary education is to develop new funding strategies that allow TEls to operate efficiently, to account for the use of their funds, and to enable them to focus on outcomes and performance. This points to increased attention to funding regimes that enhance efficiency, the quality of education and sustain funding at socially desirable levels.

\subsection{Specific Issues and Challenges for SIDS}

SIDS are small island nations that share similar sustainable development challenges, including small populations, a lack of resources, remoteness, susceptibility to natural disasters, excessive dependence on international trade and vulnerability to global developments (United Nations Report, 2003). The literature on SIDS tends to focus on their vulnerabilities to disaster, state fragility and the resulting environmental, economic and social consequences (Carment, Prest, and Samy, 2004; Pillay and Elliott, 2005). The United Nations and other international organisations, such as the World Bank, the Commonwealth Secretariat and the World Trade Organisation, have recognised the unique difficulties confronting SIDS. Of the current 52 SIDS, 38 are UN members (see Appendix A). SIDS are not just different due to their small size; in their characteristics they are also qualitatively different from developed and other developing countries. Both size and qualities of SIDS bear on the choice of funding regime.

Among issues frequently observed about SIDS, political instability and lack of good governance, ethnic diversity, environmental vulnerabilities, and economic performance and trade development are discussed briefly in this section. These four sets of factors are interrelated. Together, the set of a particular challenge for human resource development and the objectives of the tertiary sector are highlighted in section 1.2.5. 


\subsubsection{Political Instability and Lack of Good Governance}

Political instability is possibly the most significant issue currently hindering development prospects in SIDS. In most of the SIDS the political environment is unstable because the political parties have remained in power for only short periods or too long, and extensive corruption of political elites has resulted in a loss of societal confidence and trust of state institutions (Carment, et al., 2004). Political volatility in the Pacific small island states appears common (Asian Development Bank, 2000). Furthermore, democracy tends to be limited in the sense that there are restrictions on civil and political rights, such as the rights of expression and freedom of the media (Carment, et al., 2004).

Political stability, however, is essential for good governance. Good governance has eight major characteristics. It is participatory, accountable, consensus oriented, transparent, responsive, effective and efficient, equitable and inclusive and follows the rule of law (UNESCAP, 2009). Further, it assures that corruption is minimised, the voices of the most vulnerable in society are heard in decisionmaking, and that the views of minorities are taken into consideration. It is also responsive to the present and future needs of society. Good governance is imperative for the achievement of the development goals and objectives of SIDS.

However, the lack of good governance practices in SIDS is endemic.

Accountability and transparency, which are the key attributes of good governance, are not greatly encouraged. Governments of these countries face challenges and difficulties in participating in global financial markets. These difficulties can feed into instability, starting a downward spiral with adverse effects on their economies (Asian Development Bank, 2000).

\subsubsection{Ethnic Diversity}

Another specific issue is that many SIDS are highly homogeneous in terms of social and cultural characteristics. There is likely to be ethnic or religious diversity creating political tensions. The political or economic inequalities between different ethnic groups can give rise to communities mobilising against each other and worsening the risk of conflict. The greater the strength of a group's identity, the greater is its potential for ethnic rebellion. 
Therefore, the challenges to good governance may be further complicated by various group demands and expectations (Carment, et al., 2004). Ethnic diversity may pose a greater problem for SIDS than for larger states. In some SIDS, one ethnic group, even though itself small, can either achieve undue influence quite readily in the policy-making process or immobilise government from taking action.

\subsubsection{Environmental Vulnerabilities}

Environmental vulnerabilities are another important challenge for SIDS. Many SIDS are extremely vulnerable to environmental threats and natural disasters Climate change may increase the frequency and severity of drought and floods (Tigerstrom, 2005). Frequency and intensity of storms and cyclones combined with a rise in sea level may even threaten the existence of some small island states. $A$ high island is, in geology, an island of volcanic origin, whereas a low island is an island of coral origin. Low islands were formed as a result of sedimentation or uplifting of coral reefs and are the kind of islands which ring the lagoons of atoll. The two types of islands are often found in proximity to each other, especially among the islands of the South Pacific Ocean, where low islands are found on the fringing reefs that surround most high islands. The Pacific and Indian Ocean islands, in particular, are generally low-lying and most are at risk from sea-level rise (Pelling and Uitto, 2001).

Moreover, disasters and environmental degradation often affect the physical environment and the entire population, with potentially devastating consequences. Environmental goals, such as natural resource conservation, waste management, and pollution prevention are becoming increasingly important priorities for SIDS governments in order to reduce their vulnerability (Asian Development Bank, 2000).

\subsubsection{Trade Development and Economic Performance}

SIDS generally face formidable challenges regarding trade liberalisation, globalisation, and economic diversification. The main issue is that the production of goods and provision of services for export are costly in SIDS, and economies of scale cannot be realised. The principal elements of SIDS' economic vulnerability are their small domestic markets, limited resources, high local transport costs, and susceptibility to external shocks (Campling, 2006). 
Therefore, small economies are restricted in their ability to export products.

Natural disasters and other hazards, to which SIDS are prone, regularly disrupt production and divert resources. As a result, it can be difficult or even impossible to compete in a liberalised global market (Tigerstrom, 2005).

Even though the island states are signatories to many international agreements regulating international trade - potentially the most important is the World Trade Organisation - market access on equal terms with other countries is unlikely to be enough to enable them to increase exports (Tigerstrom, 2005).

Changes to the international trading regime have had significant impacts on island states. The disappointing economic performance of many island economies and the significant reduction in SIDS' global market share in recent years has been attributed to the loss of trade preferences. This is because the global trading regime has successively reduced protectionist and preferred trade measures as part of a comprehensive liberalisation. However, the phasing of preferential trade agreements including the Cotonou Agreement between EU and ACP countries began after 2000. Over the last two decades, while SIDS' share of global trade in services remained stable, their share of global commodities trade diminished by half (from $0.4 \%$ of world exports of goods in 1980 to $0.2 \%$ in 2000) (United Nations, 2005).

In a situation of economic decline, measured by lower Gross Domestic Product (GDP) per capita, unfavourable exchange rates, low levels of foreign direct investment, the living standards of most people in SIDS suffer. A common result is growing dissatisfaction with government performance.

\subsubsection{Human Resource Development}

States that are small in area tend to have a restricted variety of physical resources, which makes their human resources correspondingly more important in economic development. The smallness and vulnerability of SIDS to global trends necessitate paying special attention to education and training for effective human resource development and the need to invest more in human capital growth. Investment in education, research and training is thus a key strategy for these nations' development. Knowledge itself may become the basic economic resource of the $21^{\text {st }}$ century. 
The problems caused by global economic, social and cultural changes have led to more pressures for small island states to reconceptualise their education policies and management practices (Pillay and Elliott, 2005). Among these, an effective research capacity is paramount.

\subsubsection{Educational Research Challenges for Small Island States}

The strengthening of research capacity is essential so that SIDS can identify their own needs and priorities in and beyond education and become more able to negotiate effectively with external parties. Moreover, educational research can help to focus on relevant and general issues for the improvement of learning and teaching (Crossley and Holmes, 2001, 2004).

However, policies for strengthening research capacity in these contexts have yet to be fully and critically explored. The current thinking is that care should be taken not to imitate fashionable models of educational research but to give attention to the distinctive features and social ecology of the small island states themselves. One study concludes that "the mutually reinforcing development activities of research partnerships and capacity building could provide a powerful means for St Lucia and other small states to gain greater control over the nature and direction of educational development" (Crossley and Holmes, 2001, p. 405). SIDS can use strategies for their own benefit and also to make a valuable contribution to international development research.

In doing so, SIDS need to consider both the quality and quantity of tertiary education provided, undertake to train and retain researchers, and adopt appropriate educational management practices.

\subsubsection{Quantity versus Quality Educational Issues}

Many small island developing states have set up their own institutions of higher education to tackle the problem of brain drain or outward migration. These institutions are under pressure to recruit staff locally but states with small populations have limited pools of expertise. Small states have to confront issues of quality as well as the problems of economies of scale (Bray and Kwo, 2003). 
In most of the SIDS, education policy is focused on the philosophy of Education for All (UNESCO, 2005). According to the EFA Global Monitoring Report 2005, the quantitative aspects of education have become the main focus of attention in recent years for policy makers. However, quantity alone is not enough. There is evidence that the benefits of education to individuals and society are enhanced when the quality of education is high.

The quality of the labour force seems to be an important determinant for economic growth and the ability of government to alleviate and eradicate poverty. Therefore, quantity and quality in education are complements rather than alternatives (UNESCO, 2005).

\subsubsection{Education for Sustainable Development in African, Caribbean and Pacific (ACP) states (including Small States)}

At the first meeting of ACP Ministers of Education on 5 May 2006 held in Brussels, important issues concerning tertiary education were specified in the declaration on Education for Sustainable Development. In summary, the Ministers agreed to:

- Undertake to improve the quality of tertiary education, including the establishment and support of national regulatory frameworks and quality assurance systems.

- Pursue policy reforms in the education sector and introduce measures in development assistance that will address the problem of the brain drain.

- Undertake to establish and promote frameworks that encourage tertiary education institutions to be more responsive to a globally competitive knowledge economy.

- Support and maintain postgraduate training, research and development (ACP/83/012/06, 2006).

This agreement evidently demonstrates that governments of the ACP countries, including small island states are committed to achieve the tertiary education objectives and meet the key challenges for human resource development, knowledge-based society, and quality enhancement. 


\subsection{Research Objectives}

As part of efforts to improve the quality of tertiary education, enhance technical efficiency, promote research culture, and increase accountability PerformanceBased Funding (PBF) systems have been introduced over the past two decades in a number of jurisdictions such as Australia, Denmark, Hong Kong, Israel, the Netherlands, New Zealand, Sweden, the United Kingdom and the United States. According to Thorn, Holm-Nielsen, and Jeppesen (2004), performance funding ties public funding directly and tightly to the performance of tertiary institutions on one or more predefined indicators. A PBF system is not so much a measure to distribute funds equitably, but rather an instrument used to steer and manage higher education systems or institutions.

Some of the jurisdictions have implemented research funding models, while others have introduced models for teaching. Most of the studies to date on PBF systems have been largely undertaken for developed countries. There are no studies that consider the applicability of PBF models in SIDS or other developing countries. Accordingly, there is a lack of literature on PBF models with regard to tertiary education in developing countries, including SIDS.

The primary objective of this research is to generate knowledge about the applicability and desirability of PBF systems for tertiary education in SIDS. To this end, the research questions for this study are:

- What are the main forms of PBF systems for tertiary education, as implemented thus far in developed countries? What are their respective strengths and weaknesses? And why have such systems been viewed by some policymakers as possible mechanisms for enhancing the performance of tertiary education systems in developing countries, including SIDS?

- Under what conditions, if any, might a PBF system be applicable and desirable in SIDS and do such conditions apply currently in Mauritius?

- More specifically, of the various PBF systems, is there a particular model (e.g. peer review, indicator or mixed) that is likely to be more appropriate in the context of a SIDS like Mauritius, and if so which model? 
- To the extent that the necessary conditions for the successful implementation of a PBF system do not currently exist in a SIDS like Mauritius, what other policy options are available to improve the performance of tertiary education?

This research will contribute to the understanding of PBF models, consider the implications for SIDS, and lead to recommendations concerning the application of PBF models for tertiary education in SIDS as a means of promoting excellence, enhancing greater accountability and improving efficiency.

\subsection{Significance of the Research}

The concept, application and impacts of PBF models in tertiary education have been researched for over two decades. Most of the studies have focused on American states ${ }^{1}$ and OECD countries. ${ }^{2}$ Some of the studies are either comparative analyses or country-specific surveys designed to describe and assess the trends and future prospects of PBF in different jurisdictions. Others have concentrated on the implementation, impacts and implications of PBF models for teaching and research activities.

However, there is a lack of empirical evidence on PBF models in developing countries, including SIDS, because there are not any PBF systems operating in such countries. Moreover, available research suggests that the applicability of PBF models to developing countries is unclear. Therefore, this research attempts to overcome the knowledge gap, and contribute to both scholarly debates and policy deliberations.

SIDS have been chosen as the particular focus because they are developing states which have specific features of smallness, limited population, low gross domestic product, and a small tertiary education sector, making them suitable for a case study.

\footnotetext{
${ }^{1}$ Ashworth, 1994; Burke, 1998; Burke and Minassians, 2001, 2002, 2003; Burke and Modarressi, 2000; Burke, Rosen, Minassians, and Lessard, 2000; Burke and Shahpar, 1999; Layzell and Caruthers, 1995; Serban, 1997, 1998, 2000

${ }^{2}$ Adams and Smith, 2006; Boston, 2002, 2004; Boston, Mischewski, and Smyth, 2005; Canton and van der Meer, 2001; Goldfinch, 2003; Hare, 2002; Hazeldine and Kurniawan, 2006; Johansson, 2004; Jongbloed and Vossensteyn, 2001; Kaiser, et al., 2001; Klemming, 2005; Koelman and Venniker, 2001; Maassen, 2000; 
If a PBF model is feasible for such states, it should also be possible to introduce PBF in developing countries as they are likely to have even better underlying conditions and opportunities than SIDS in terms of financial and human resource capabilities and size of the tertiary education sector.

\subsection{Research Strategy}

This research adopts a pluralist strategy. It includes a literature review of primary and secondary sources designed to assess the strengths and weaknesses of PBF systems for various countries, including Australia, Denmark, New Zealand, Sweden and the United Kingdom. The literature study then explores the applicability and desirability of PBF models for tertiary education in SIDS, with particular reference to Mauritius.

From this review, the theoretical underpinnings behind funding approaches in tertiary education are clarified so as to establish the rationale for and potential benefits of PBF systems.

\subsubsection{Case Study - Mauritius}

Mauritius was selected as a case study. Like other SIDS, it faces challenges in terms of its tertiary education objectives, including the challenge of adjusting to the rapid growth in tertiary education while maintaining quality, a vigorous research culture, efficiency, and accountability. In several developed countries, the funding approaches have changed from input-based funding systems to performancebased funding systems over the past decades. Accordingly, it is a general practice for developing countries or SIDS to explore the policy strategies adopted by developed countries and consider whether these strategies are workable and desirable in their own circumstances.

Table 1.1 illustrates data on the land area, population, education expenditures as a percentage of GDP, GDP per capita (Purchasing Power Parity), the Human Development Index (HDI), and the number of public universities for a sample of 15 SIDS so as to demonstrate how Mauritius compares with states of a broadly similar nature. 
Table 1.1: Positioning Mauritius among other SIDS

\begin{tabular}{|c|c|c|c|c|c|c|}
\hline SIDS & $\begin{array}{l}\text { Land } \\
\text { Area }\end{array}$ & $\begin{array}{l}\text { Population } \\
\text { (2009 est.) }\end{array}$ & $\begin{array}{l}\text { Education } \\
\text { Expenditure } \\
(\% \text { GDP) }\end{array}$ & $\begin{array}{l}\text { GDP per } \\
\text { Capita } \\
\left(\text { PPP* }^{*}\right) \\
(2008 \\
\text { est. in } \\
\text { US\$) }\end{array}$ & $\begin{array}{l}\text { HDI } \\
2007\end{array}$ & $\begin{array}{l}\text { Number of } \\
\text { public } \\
\text { universities }\end{array}$ \\
\hline $\begin{array}{l}\text { Antigua and } \\
\text { Barbuda }\end{array}$ & 442.6 & 85,632 & $3.9 \%$ of GDP (2002) & $\$ 19,100$ & 0.868 & 0 \\
\hline Barbados & 431 & 284,589 & $6.9 \%$ of GDP (2005) & $\$ 20,200$ & 0.903 & 1 \\
\hline Cuba & 110,860 & $11,451,652$ & $9.1 \%$ of GDP (2006) & $\$ 12,700$ & 0.863 & 7 \\
\hline Dominica & 754 & 72,660 & $5 \%$ of GDP (1999) & $\$ 9,500$ & 0.814 & 1 \\
\hline Fiji & 18,270 & 944,720 & $6.5 \%$ of GDP (2004) & $\$ 3,700$ & 0.741 & 2 \\
\hline Maldives & 300 & 396,334 & $8 \%$ of GDP (2006) & $\$ 4,500$ & 0.771 & 1 \\
\hline $\begin{array}{l}\text { Marshall } \\
\text { Islands* }\end{array}$ & 181.3 & 64,522 & $11.8 \%$ of GDP (2004) & $\$ 2,500$ & $\begin{array}{l}\text { Data not } \\
\text { available }\end{array}$ & 1 \\
\hline Mauritius & 2,030 & $1,284,264$ & $3.9 \%$ of GDP (2006) & $\$ 12,400$ & 0.804 & 2 \\
\hline Nauru & 21 & 14,019 & Not Available & $\$ 5,000$ & & 0 \\
\hline $\begin{array}{l}\text { Papua New } \\
\text { Guinea }\end{array}$ & 452,860 & $6,057,263$ & Not Available & $\$ 2,300$ & 0.541 & 4 \\
\hline Saint Lucia & 606 & 160,267 & $6.6 \%$ of GDP (2006) & $\$ 11,300$ & 0.821 & 0 \\
\hline Seychelles & 455 & 87,476 & $6.5 \%$ of GDP (2006) & $\$ 18,700$ & 0.845 & 0 \\
\hline Tonga & 718 & 120,898 & $5 \%$ of GDP $(2004)$ & $\$ 4,400$ & 0.768 & 0 \\
\hline $\begin{array}{l}\text { Trinidad and } \\
\text { Tobago }\end{array}$ & 5,128 & $1,229,953$ & $4.2 \%$ of GDP (2000) & $\$ 18,600$ & 0.837 & 2 \\
\hline
\end{tabular}

Source: Catalogue of Universities, 2009; Central Intelligence Agency, 2009; Human Development Report, 2009

* The Marshall Islands have a university centre and is one of the 12 countries that own the University of South Pacific.

First, Mauritius was chosen because it is the researcher's home country. Second, the researcher has a particular interest in exploring PBF models and their applicability to SIDS as she has worked as an accountant in a tertiary education institution for more than six years and this has included involvement in the management of the institution's funds and financial policies. Third, unlike other SIDS, which are typically unstable politically and have poor economic performance, Mauritius has more political stability and experiences relatively favourable socio-economic conditions. 
Fourth, the possible introduction of performance-based measurements for the public sector in Mauritius is a policy objective of the government. As Mauritius is not the best or the worst among SIDS, it serves as a "good test case" judged ex ante for adopting a policy strategy in use in many developed countries. Therefore, knowledge about the applicability and desirability of PBF systems in the case of Mauritius can serve as a benchmark for other SIDS and countries on a development path.

If PBF systems are applicable and desirable in this relatively well-positioned SIDS, or even if the reasons for lack of workability can be well understood, then other countries can learn from this case analysis. Certainly, if a PBF system is not workable in Mauritius, it will not be desirable for other SIDS which have features not as good as the case study country.

Using Mauritius as a case study, the researcher has combined several different sources of information, including interviews, archival information, and official documents. It is thus possible to substantiate information gained from one source with information gathered from another source (O'Sullivan, Rassel, and Berner, 2008).

\subsubsection{Criteria for Evaluation of the Models}

Following the literature review and critical assessment of the strengths and weaknesses of the three different PBF models for research funding (peer review, indicator and mixed model) and those for teaching (taximeter and Full Time Equivalent (FTE) study result), a set of criteria were derived to facilitate interpretation of the case study data to draw conclusions regarding the suitability of the PBF models as applied for SIDS.

Seven main criteria were selected: (i) the political acceptability and commitment; (ii) the size of the tertiary education sector and especially the number of TEls; (iii) the fiscal and human capabilities at the government and TEls levels; (iv) the transaction costs that will be involved; $(v)$ the reliability of quantitative measures; (vi) the potential of quantitative measures to reward good performance; and (vii) management style and commitment from TEls and staff association participation in the implementation process. 
Political acceptability and commitment over a medium-term time-frame are essential for considering the applicability and desirability of PBF models for research and teaching for SIDS, including Mauritius. In most SIDS there is a lack of good governance, and greater political instability and corruption than in developed countries. Given this situation, governments of SIDS may face difficulties developing and implementing a PBF scheme for tertiary education. Hence, for a PBF policy to be feasible it must first be politically acceptable and second the political situation should be relatively stable.

Second, apart from political commitment, in most of the developed countries (Australia, Denmark, NZ, Sweden, and the UK) where PBF models have been adopted for teaching or research, the tertiary education sector is characterised by a relatively large number of institutions, a high number of student enrolments, and a reasonable number of academics. In the case of SIDS, the number and size of the TEls vary but are typically small both in number and size compared with the other democracies which have adopted PBF systems. Further, the number of researchers is very low, and some SIDS do not even have any tertiary institutions. Thus, the size of the tertiary sector matters for the development and implementation of PBF systems in SIDS.

Third, the fiscal and human resource capabilities at government and TEls levels are another crucial criterion in determining whether PBF systems are appropriate and desirable for SIDS. The application of PBF models requires a high-level of sufficient number of technically knowledgeable and capable people at the governmental and institutional levels.

In terms of fiscal capability, the adequacy of the tertiary education budget to implement PBF funding models is critical. For instance, the developed countries (Australia, Denmark, NZ, Sweden and the UK) have disbursed a significant amount of money in the tertiary sector over the past decades. Funding might be an issue for many SIDS, including Mauritius, because of their limited financial resources and state priorities for development needs. PBF models require a significant level of funding so as to provide incentives to enhance performance and reward improvements in performance. This clearly indicates that the quantity of public funds available for the tertiary education sector is as important as the other criteria highlighted earlier. 
Fourth, the overall transaction costs associated with PBF systems are an essential factor that needs to be considered as a criterion for evaluating any kind of PBF model in SIDS. If the total funds allocated are already limited, the costs of implementing PBF models, which tend to be high, will prove an added burden for governments and TEls. On the basis of international literature, in the UK, transaction costs associated with the RAE represent about $0.8 \%$ of the total money allocated over seven years while for NZ the transaction costs of the PBRF are predicted to range from $1.5 \%$ to $2 \%$ for 2007-2012 (WEB Research, 2004) . Therefore, potential transaction costs are an important consideration for policymakers in order to develop and implement any particular PBF scheme.

Fifth, the reliability of potential quantitative measures is also another important criterion for assessing any PBF models as data are subject to potential errors and manipulation.

Sixth, the impact of using particular measures to reward good performance is an equally significant criterion. Given the way data are collected in tertiary education, it is important that SIDS have the necessary expertise and processes to prevent the possibility of distorting information.

Finally, commitment from TEls and union participation are also vital so as to ensure a successful development and implementation process for PBF systems in SIDS.

\subsection{Structure of the Thesis}

This thesis is divided into nine chapters. This chapter, as will be evident, sets out the research context, highlights the specific issues and challenges for SIDS, and outlines the research objectives, significance of the research, and the research strategy adopted.

Chapter two describes the methodology used in this thesis. First, the chapter starts with the research design as defined by Denzin and Lincoln (2005). The chapter continues by explaining the choice of research method, including how the literature review was conducted, the criteria for evaluating the PBF models, and the choice of Mauritius as a case study to collect empirical materials (primary and secondary). 
This chapter also describes how the data have been analysed thematically and the qualitative evaluative criteria adopted to ensure quality and trustworthiness of the research (Lincoln and Guba, 1985).

Chapter three focuses on the tertiary education system in Mauritius. A general overview of Mauritius, including the geographical, political and economic aspects, is presented. The chapter then describes the main TEls, the institutional framework that has been established and the legislation under which the tertiary education sector is administered.

Next, an analysis of the pattern, level and structure of participation at the tertiary education level is undertaken and the tertiary funding systems for teaching and research are summarised. The chapter then highlights the current issues and the major challenges for tertiary education in Mauritius. Finally, it concludes by highlighting the need for tertiary education reforms and the strong drive by policymakers to ensure quality standards, promote research excellence and enhance efficiency.

Chapter four examines the historical development of funding mechanisms for TEls in the developed and developing worlds. It identifies the problems that earlier funding systems have presented for TEls and explains the concepts of efficiency and effectiveness, which are widely used in the literature. The chapter further analyses the strengths and weaknesses of negotiated funding systems (line-item budgeting and block grants) and input-based funding systems (performance budgeting, program budgeting system, zero-base budgeting, incremental budgeting and formula budgeting). Finally, the chapter defines the PBF concept and continues by discussing the underlying principle of PBF systems.

An in-depth review of the different PBF models for research and teaching implemented by a number of countries (Australia, Denmark New Zealand, Sweden and the United Kingdom) is carried out in chapter five, which is divided into two parts. The first part provides a backdrop to the developments of PBF mechanisms for countries under review and presents a programme outcome model for tertiary education. Then, it examines various PBF models for research - namely the United Kingdom's Research Assessment Exercise (RAE), the Australian Institutional Grants Scheme (IGS) and Research Training Scheme (RTS), and New Zealand's Performance-Based Research Fund (PBRF). 
The higher education systems, recent reforms and funding mechanisms for these countries are highlighted. Next, the key features of the models currently used are enumerated and critically assessed, by identifying their strengths and weaknesses. The second part focuses on the Danish and Swedish PBF models for teaching. The key elements of the Danish taximeter and Swedish FTE study results models are outlined. The significant differences between the two teaching funding models are highlighted, and an assessment of the two models is undertaken.

Finally, this chapter provides a broader perspective of the different PBF models for research and teaching adopted in the various jurisdictions, so as to determine their desirability and applicability to SIDS.

Chapter six describes the different phases of thematic analysis (Boyatzis, 1998; Braun and Clarke, 2006) for the empirical materials generated by the 38 interviews undertaken for this research. Then, the chapter presents the key themes that emerged from the empirical analysis and the substantive assessment of the PBF models carried out in the literature review. These themes are considered as the underlying conditions affecting the introduction of a PBF system in Mauritius. These include: (i) policy objectives and outcomes for tertiary education in Mauritius; (ii) the present policy settings; (iii) the level of comprehension of PBF systems amongst the stakeholders; and (iv) the objectives and drivers of PBF systems.

Chapter seven continues with the interpretation of the empirical analysis and exploration of the applicability and desirability of PBF systems in Mauritius. It highlights the capacity constraints and challenges facing SIDS, giving rise to the potential difficulties of developing and implementing PBF systems, and the likely political acceptability and administrative feasibility of PBF systems. Respondents' quotes are included to substantiate the empirical findings and analysis.

The secondary data, such as tertiary education budgets, number of researchers, student completion rates, research student enrolments, and number of publications collected from the official documents of Mauritius, are analysed graphically to supplement and triangulate the primary data. Finally, the findings from the various stakeholder groups are summarised in a matrix form at the end of this chapter. 
Chapter eight moves to a discussion of the research findings, and implications for SIDS. This chapter is divided into five main parts. The first part presents the overall importance of the study results and relevant issues linked with the literature review. Next, the key lessons and issues that are drawn from the overseas experience of PBF models are summarised. The third part assesses the applicability of PBF models for SIDS and explains why PBF models for teaching or research would not be desirable or feasible for SIDS in the short-term.

Then, policy options to improve performance and promote quality in tertiary education for Mauritius and other SIDS are recommended. These include monitoring and reviewing the research performance of TEls, establishing a quality assurance system, and reviewing the impact of the research outcomes on the economic and social development of the country. The final part suggests, as a way forward, that SIDS that have more than two TEls should move towards a performance indicator model for funding research in the long-term provided certain preconditions are met.

Chapter nine summarises the contribution of this research with an examination of the implications of PBF systems for the tertiary education sectors in SIDS, and proposes areas for further research. 


\section{CHAPTER TWO: RESEARCH METHODOLOGY}

\subsection{Introduction}

This chapter outlines the research design employed in this thesis, with an emphasis on the researcher's ontological (what is the nature of reality) and epistemological (theory of knowledge) positions, the differences between quantitative and qualitative research, the ethical issues and confidentiality required for this study, and a brief description of how the literature review was conducted. This is followed by a discussion of the methods used to collect and analyse empirical materials. Both primary (qualitative interviewing) and secondary (government and TEls official documents) data were collected for this research. The empirical materials were analysed thematically. Finally, the chapter ends with a review of the evaluative criteria for qualitative research that were employed to assure the quality and dependability of the research.

\subsection{Research Design}

According to Denzin and Lincoln (2005, 2008):

Research design describes a flexible set of guidelines that connect theoretical paradigms first to strategies of inquiry and second to methods for collecting empirical materials. A research design situates the researcher in the empirical world and connects him or her to specific sites, persons, groups, institutions, and bodies of relevant interpretive materials, including documents and archives. A research design also specifies how the investigator will address the two critical issues of representation and legitimation (Denzin and Lincoln, 2005, p. 25).

A research design is the detailed blueprint for the entire research used to direct a study towards its objectives. For the purpose of this study, qualitative research has been employed. Qualitative research deals with interpreting social realities and involves an interpretive and natural approach to the world (Bauer and Gaskell, 2002; Denzin and Lincoln, 2005). 
The qualitative researcher may be seen as a "bricoleur, as maker of quilts, or as in film making" and such researchers emphasise "the value-laden nature of inquiry" (Denzin and Lincoln, 2005, p. 4 \&10). These principles mingle beliefs about ontology (what is the nature of knowledge or reality?), epistemology (what is the relationship between the researcher and knowledge?), and methodology (how should the inquirer go about finding out knowledge?) and shape how the qualitative researcher sees the world and acts in it (Bailey, 1997; Denzin and Lincoln, 2008).

\subsubsection{Ontology and Epistemology}

Ontology is that part of "philosophy that concerns itself with the kinds of entities that exist and the features they possess" (Howe, 1998, p. 16). Ontology specifies "the nature of reality" that is to be studied, and what can be known about it, whereas epistemology describes "the relationship of knower to known" (Lincoln and Guba, 1985, p. 37). Ontology is the framework; it refers to the what of the research, whereas epistemology is a set of questions based on a framework and refers to the how of research ( $\mathrm{Nel}$ and Com, 2007). Epistemology is the theory of knowledge. It includes the methods, validity and scope of knowledge that is employed in research and provides evidence for conclusions ( $\mathrm{Nel}$ and Com, 2007).

A paradigm or an interpretative framework comprises a researcher's ontological, epistemological, and methodological principles. Interpretive research is guided by the researcher's set of beliefs about the world and how it should be studied. Different interpretive paradigms make different specific demands on the researcher, including the questions the researcher asks and the interpretations brought to them (Denzin and Lincoln, 2005). All interpretive paradigms, however, suggest that social actors are different from natural phenomena and research needs to interpret their behaviour from their perspectives (Bryman, 2001; Silverman, 2001).

There are four major interpretive paradigm structures for qualitative research: "positivist and post-positivist, critical (Marxist emancipatory), feminist-post structural and constructivist-interpretive" (Denzin and Lincoln, 2008, p. 31). 


\subsubsection{Quantitative versus Qualitative Research}

Quantitative and qualitative research approaches can be seen as merely different ways of doing research (Blaikie, 2000) yet qualitative research leads to hypothesis-generating research (Auerbach and Silverstein, 2003) whereas Quantitative research typically tests hypotheses.

Quantitative research deals with numbers, uses statistical models to explain the data, and is considered as hard research (Bauer and Gaskell, 2002). The epistemology of the quantitative research is positivist. Qualitative research tends to be more constructionist (Gubrium and Holstein, 2002). According to Rubin and Rubin (2005, pp. 23-27) "positivists assume that objects and events that researchers study exist independently of people's perceptions while constructionists expect people to see somewhat different things, examine through distinct lenses and come to different conclusions".

The qualitative approach to research design leads to studies that are quite different from those designed using the more traditional approach. Qualitative research is conducted through an intense and/or prolonged contact with a "field" or life situation, reflective of the everyday life of individuals, groups, societies, and organisations (Miles and Huberman, 1994, p. 6).

The researcher's role in a qualitative study is to gain a holistic overview of the context under study, and attempt to capture data on the perceptions of local actors. It is primarily descriptive and interpretative, concentrating on a few selected individuals or phenomena in some detail (Borland, 2001). Also, qualitative research provides theories, models and descriptions of human experiences and perceptions within particular contexts. Qualitative research, with its emphasis on people's "lived experience, is fundamentally well suited: for locating meanings that people place on the events, processes, and structures of their lives; their perceptions, assumptions, prejudgments, presuppositions; and for connecting these meanings to the social world around them" (Miles and Huberman, 1994, p. 10).

The constructivist paradigm that assumes "a relativist ontology (there are multiple realities), a subjectivist epistemology, and a naturalistic (in the natural world) set of methodological procedures" (Denzin and Lincoln, 2005, p. 24) is most appropriate for this research. 
First, the entities considered by this research are TEls whose status is created by stakeholders' perceptions of the values they achieve. Stakeholders construct distinct realities of an institution's identity. Second, the perceptions of different stakeholder groups, such as policymakers, TEl chief executives, senior state officials, and academics, are the focus of this research.

Therefore, their thoughts about PBF and related matters are subject to interpretation for what they reveal about the social realities for the development and implementation of PBF models in SIDS. Hence, adopting this qualitative approach provides an opportunity to gather rich data and a much deeper understanding.

\subsubsection{Ethical Issues and Confidentiality}

As the research involved human participants, and interviews have been conducted, ethical approval was sought from and granted by Victoria University of Wellington's Human Ethics Committee. A sample of the covering letter, an information sheet (purpose and benefits of the project, ethical approval, procedures and duration, confidentiality) and an informed consent form were submitted for ethical approval. Ethical considerations were also taken into account for those interviewees who may speak negatively about organisations on which their institution relies for funding. These interviewees were handled with care: they were interviewed on the basis of informed consent and made fully aware of how the information provided would be used. Confidentiality was assured by ensuring that those interviewed were not identified. Code names were used and identifying information avoided.

\subsection{Research Approach}

As noted in chapter one, this research investigates the applicability and desirability of PBF models for tertiary education in SIDS, with particular reference to one SID state, Mauritius. Given its exploratory nature, the study adopts a 'pluralist methodology' which was based on a literature review, and a substantive assessment from selected jurisdictions, specifically Australia, Denmark, New Zealand, Sweden and the United Kingdom. Further, primary and secondary data were collected in the case study country, Mauritius. 


\subsubsection{Literature Review}

An extensive literature review was undertaken through the University library databases, bibliographies in the literature, journal articles, on-line searches on the Web, electronic sources (on-line articles, official documents), reports on higher education, and books. The review covered: (i) theoretical reasons for funding approaches in tertiary education systems; (ii) the rationale and application of different PBF models for research and teaching activities; and (iii) existing evaluations of the PBF models for research (UK, Australia and NZ) and for teaching (Denmark and Sweden).

This review was the basis for a critical assessment of the strengths and weaknesses of each PBF model. In light of the literature review and research objectives, the interview schedule (see Appendix C) was designed for use in the Mauritius case study.

\subsubsection{Empirical Materials Collection}

Qualitative researchers employ several methods for collecting empirical materials ${ }^{3}$ and these include interviewing, direct observation, analysis of artifacts, and the use of visual materials (Denzin and Lincoln, 2005). The empirical materials collection method for this research included the use of one-to-one interviews, and an analysis of secondary data of historical figures accessed from official documents and reports. Every interview was taped (digital recording) and transcribed for analysis purposes. In addition to taping the interviews, notes were taken to capture important points made by the respondents.

Qualitative research yields valuable knowledge for decision makers. It provides theories, models and descriptions of human experiences and perceptions within particular contexts. Qualitative inquiry, which is inductive, is often labeled as "subjective" (Mayan, 2001, p. 6). In this study, a qualitative approach was employed to address the main research questions.

A qualitative interviewing method was used for collecting the empirical materials and investigating the opinions and perceptions of various stakeholders in Mauritius.

\footnotetext{
${ }^{3}$ Denzin and Lincoln (2005 p. 28), "empirical materials" is the preferred term for what traditionally have been described as data
} 
Semi-structured interviews were undertaken with two samples of respondents. One sample comprised members of political elites and the other sample was representatives of the tertiary education sector. In addition, secondary data were retrieved from published reports and official documents. They are important in order to compare, triangulate and cross-validate the primary empirical materials.

\subsubsection{Qualitative Interviewing}

As May (2001, p. 120) points out, "interviews yield rich insights into people's biographies, experiences, opinions, values, aspirations, attitudes and feelings". Similarly, Lilleker (2003) concurs that interviews should be used if individual insights and rich depth are required, as they can open the way for expanding upon data and will add greater depth to the analysis of a phenomenon. Qualitative interviewing refers to in-depth, semi-structured forms of interviewing and may involve one-to-one interactions, larger group interviews or focus groups (Mason, 2002). Interviews can give enormous amounts of information that could not be gathered from published documents.

In the empirical social sciences, qualitative interviewing is widely used for empirical materials collection. Semi-structured interviews lie between formal (structured) and unstructured interviews. In this research semi-structured interviews were adopted for two reasons. First, the possible introduction of PBF models for Mauritius is a public policy objective of the government. Therefore, the views and opinions of policy makers and chief executives in the tertiary education sector with respect to a common set of themes or criteria are crucial.

Second, semi-structured interviews are one of the most commonly recognised forms of qualitative methods used by the studies undertaken thus far on PBF models (Boston, 2002; Burke and Minassians, 2001, 2002, 2003; House of Commons Select Committee on Science and Technology, 2002; Jenkins, 1995; Layzell and Caruthers, 1995; Middleton, 2005; WEB Research, 2004). Continuing in the same vein contributes to developing scholarship. According to Gubrium and Holstein (2002), interviews played a central role in educational research throughout the $20^{\text {th }}$ century. They state that researchers have utilised interviews in attempting to learn how policies function. 
Therefore, it is regarded as necessary to obtain the views of those who are involved in the educational community, such as TEI chief executives, directors, heads of schools, academics, and staff association representatives. Semistructured interviews which drew on the experiences of OECD countries which have already implemented PBF models for tertiary education allowed participants to answer in their own terms.

The interview schedule covered questions on background, experience and behaviour, opinions and values, and knowledge (Patton, 2002). In conducting each interview, the standard set of questions was augmented by additional probing.

\subsubsection{Interview Strategy}

The aim in qualitative sampling is to achieve the best possible understanding of phenomenon of interest and to enable one to focus on specific issues. In qualitative enquiry, "samples are generally small" (Mayan, 2001, p. 33) and in the $3^{\text {rd }}$ edition on Qualitative Research and Methods, Patton states "there are no rules for sample size in qualitative inquiry" (Patton, 2002, p. 244). According to Patton (2002), snowball sampling is an effective approach for locating information-rich, key informants.

The sampling for this research was not random. Using snowball sampling, also called chain sampling, respondents were selected on the basis of their influence in the tertiary education sector and involvement in the funding system for tertiary education in Mauritius. Only respondents with a sufficient level of knowledge and experience were selected for interview.

The sample for this research had two types of respondents. One sample comprised political elites - those who are involved in the policy-making process at two central agencies namely, the Ministry of Education and Human Resources (MOEHR) and the Ministry of Finance and Economic Development (MOFED) in Mauritius. The other sample comprised those people engaged in a TEI, or agencies that accredit and coordinate public tertiary education. The views and perceptions of these two sets of stakeholders are vital, as they provide the impetus for policy formulation, and the development and implementation of PBF models for tertiary education. 
Using this interview strategy, in this research a total of 38 respondents was the actual sample size for the interviews. Eleven people were interviewed from the political elites (MOEHR, MOFED, a Member of Parliament, policy advisors, chief executives, chairmen of TEls and private providers) and 17 from the tertiary educational sector (TEls chief executives, senior academics, and representatives of the TEls associations), and 10 senior officials in government ministries and agencies responsible for tertiary education and TEls.

For this research, interviewees were sent a letter signed by the researcher, which outlined the purpose of the study. An information sheet and informed consent form were also enclosed (see Appendices $C$ and D). The letters were addressed in person to the interviewees and follow-up contact was made to arrange an interview. The informed consent forms which were duly completed and signed by all respondents involved in this study were collected by the researcher at the time of interview. A pre-determined interview schedule, including the set of questions to meet the research objectives, was also provided (see Appendix E).

According to McEvoy (2006), there is an abundance of literature on interviewing techniques but only some on interviewing political elites. Elites can be defined as those individuals and groups who occupy the top echelons of society (Gubrium and Holstein, 2002) or "those with close proximity to power or policymaking" (Lilleker, 2003, p. 207).

Likewise, Desmond (2004) views elites as those exercising the major share of authority, or control within society, organisations and institutions. For the purpose of this research, political elites comprise the Minister of Education and Human Resources, Members of Parliament, policy advisors, chief executives and chairpersons of TEls. The literature on elite interviewing recommends a number of strategies for effective empirical materials collection. The interview schedule should move from non-threatening, general questions at the beginning to the more substantial aspects of the interview (McEvoy, 2006). Furthermore, the literature notes that in elite interviewing there is a power differential between the interviewer and the interviewee which can affect access and cooperation (Desmond, 2004; McEvoy, 2006). 
The researcher was successful in gaining access, and sought to apply the basic laws of elite interviewing. Efforts were made to be tactful for interviews when seeking an interviewee's cooperation, well-prepared, confident, neutral, ethical and professional.

\subsubsection{Secondary Data Strategy}

The secondary data were collected from various sources, such as TEls, TEC, Ministry of Education and Human Resources [Mauritius], and Central Statistical Office [Mauritius] official documents, and also reports (annual, budget and statistics digest) and websites. The TEls secondary data were gathered mainly from annual reports.

Such documents assisted the researcher to be aware of potential for bias in the interview transcripts. The various reports were used to triangulate the primary interview data. Further, these data were used to go beyond the spoken word and to cross-validate the primary data. The secondary data for tertiary education budgets (including allocation of funds to TEls), student enrolment and output, and publications were tabulated and graphically interpreted (see chapter eight) to show the changes and trends over the past years.

The strength of qualitative interviewing is the opportunity it provides to collect and rigorously examine narrative accounts of social worlds (Silverman, 2004). Further, it allows interviewers to probe for more details and gives flexibility for them to use their own knowledge and expertise to explore interesting themes raised by the interviewees. Nevertheless, qualitative interviewing does have weaknesses, such as being subjective, expensive, time-consuming for analysing and interpreting and reactive to personalities, moods, and interpersonal dynamics between the interviewer and interviewee (Sewell, 2002). This means that it cannot be relied upon as the sole methodology.

The data collected must be reinforced by other forms of empirical materials or based upon a broad sample of interviews, all conducted with those who enjoyed equal access to the activity under focus (Lilleker, 2003). Empirical materials need to be reliable and valid. A triangulation technique is one solution to ensure reliability and avoid errors. 
The use of multiple methods, or triangulation, reflects an attempt to secure indepth understanding of the phenomenon in question (Denzin and Lincoln, 2005). Triangulation means cross-referencing materials collected from primary sources (interviews, published first-hand accounts and documentary sources) with available published secondary source material (P. Davies, 2001; Lilleker, 2003; McEvoy, 2006). This reduces the likelihood of misinterpretation of data, thus increasing the reliability and validity of the research. Respondents from different stakeholder groups (political elites, tertiary education agencies, academics and senior officials) can offer different perspectives from those of others in their own and other institutions. Triangulation with published documentary reports and secondary evidence guides the substantiation of views.

\subsection{Empirical Material Analysis and Findings}

Empirical materials analysis is "the process of moving from raw interviews to evidence-based interpretations that are the foundation of published reports" (Rubin and Rubin, 2005, p. 201). Miles and Huberman (1994, p. 12) advocate "an interactive model of analysis consisting of three types of activities: data reduction, data display, and conclusion drawing/verification". Boyatzis (1998) and Braun and Clarke (2006) state that a widely used qualitative analytic method is thematic analysis.

The method of thematic analysis chosen for this study is the data-driven inductive approach (Boyatzis, 1998). An inductive approach means the themes identified are strongly linked to the data themselves. Inductive analysis is therefore a method of coding the data without trying to fit it into a pre-existing code frame, or the researcher's analytic preconceptions. An inductive method has been used for all themes apart from those easily identified in the direct nature of the question put to the interviewees.

\subsubsection{Thematic Analysis}

Thematic analysis is a process that involves the identification of themes through careful reading of the data. It is a form of "pattern recognition within the data, where emerging themes become categories for analysis" (Fereday and MuirCochrane, 2006, p. 4). 
Braun and Clarke (2006, p. 82) state that a theme "captures something important about the data in relation to the research question, and represents some level of patterned response or meaning within the data set".

In the case of this research project, data were transcribed verbatim. Each of the transcribed interviews was read through more than once, without coding. For each of the transcripts, the raw data were reduced by highlighting the relevant materials, coding of common ideas, discarding, and organising the data into relevant text and transferring to a data reduction Excel sheet. Each relevant text from the transcripts was then coded and summarised into a theme (group of repeating ideas that had something in common) according to the strengths and weaknesses of PBF models for teaching and research activities.

The primary data findings have been presented in a narrative and displayed in a matrix form, while the secondary data were analysed and interpreted graphically. In the presentation of the primary findings, direct quotes are used as outlined by Miles and Huberman (1994) to allow the reader to confirm the conclusions. The respondents from the various stakeholder groups were designated as " $R$ " and allocated numerical figures 1 to 38 (R1, R2....R38) when illustrating their quotes in order to maintain confidentiality. A matrix display has been used to summarise the findings (see chapter eight). The rows include the themes emerging from the findings as discussed in the narrative form and the columns comprise the various stakeholders, namely, academics, representatives of TEls associations, senior state officials, TEI chief executives, and policymakers. Moreover, the secondary data collection has been analysed and interpreted mainly by charts and graphs so as to validate the primary data.

Finally, qualitative criteria, such as credibility, transferability, dependability and confirmability have been used to ensure the trustworthiness of this research.

\subsubsection{Evaluative Criteria for Qualitative Research}

One of the important challenges confronting qualitative researchers is how to assure the quality and trustworthiness of the research. The use of quantitative criteria such as validity and reliability is largely irrelevant to substantiate the findings in the case of qualitative research. It is crucial "to use qualitative evaluation criteria to assess qualitative methods within the qualitative paradigm" (Leininger, 1994, p. 96). 
Leininger (1994) identifies and defines six important criteria to evaluate qualitative paradigm studies, namely: (i) credibility; (ii) confirmability; (iii) meaning-in-context; (iv) recurrent patterning; (v) saturation; and (vi) transferability. These criteria can be used with all qualitative research methods to assess research findings.

Lincoln and Guba (1985) suggest four criteria for 'naturalistic' (qualitative inquiry) research. The four terms, "credibility, transferability, dependability and confirmability are, then, the naturalist's equivalents for the conventional paradigms [quantitative inquiry] termed as internal validity, external validity, reliability and objectivity" (Lincoln and Guba, 1985, p. 300). The methods adopted by the naturalist to meet trustworthiness criteria are tabulated in Table 2.1.

Table 2.1: Conventional and Naturalistic Methods to ensure Quality and Trustworthiness

\begin{tabular}{|c|c|c|}
\hline $\begin{array}{l}\text { Conventional } \\
\text { Paradigm }\end{array}$ & Naturalistic Paradigm & $\begin{array}{l}\text { Methods to ensure quality and } \\
\text { trustworthiness }\end{array}$ \\
\hline Internal validity & Credibility & $\begin{array}{l}\text { Prolonged engagement in the } \\
\text { field; persistent observation; } \\
\text { data triangulation (use of } \\
\text { multiple and different } \\
\text { sources, methods, } \\
\text { investigators, and theories); } \\
\text { respondents' checks }\end{array}$ \\
\hline External validity & Transferability & $\begin{array}{l}\text { Thick description of setting } \\
\text { and/or participants }\end{array}$ \\
\hline Reliability & Dependability & $\begin{array}{l}\text { Audit - researcher's } \\
\text { documentation of data and } \\
\text { triangulation }\end{array}$ \\
\hline Objectivity & Confirmability & $\begin{array}{l}\text { Audit trail (raw data, data } \\
\text { reduction and analysis, } \\
\text { process notes) and reflexive } \\
\text { journal }\end{array}$ \\
\hline
\end{tabular}

Source: Adapted from (Lincoln and Guba, 1985)

In order to evaluate the qualitative inquiry and to ensure trustworthiness, this research uses a combination of Lincoln and Guba's (1985) and Leininger's (1994) criteria: 
(i) Credibility refers to the "truth", value, or "believability" of the findings that have been established by the researcher: truth as known, experienced, and interpreted from the findings with co-respondent evidence as the "real world", or the truth in reality (Leininger, 1994, p. 105). Data triangulation and respondents' validation (as described by Lincoln and Guba, 1985) are the two techniques utilised to ensure credibility. In this research, the secondary sources from official documents were used to triangulate and cross-validate the data.

(ii) Confirmability signifies obtaining direct and often repeated affirmations of what the researcher has heard, seen or experienced with respect to the phenomena under study. It includes getting evidence from informants about findings or interpretations by the researcher. Confirmability, replacing the concept of objectivity, also uses auditing as a means to demonstrate quality. Audit trails (Lincoln and Guba, 1985) or "periodic confirmed informant checks" and feedback sessions (Leininger, 1994, p. 105) obtained directly from the people involved are important means to establish confirmability of the data. As there was not any feedback to informants and no direct efforts were made to confirm the data and interpretations in this research, a partial way to meet this criterion is the use of direct quotes from the respondents which allows the reader to judge the researcher's conclusions.

(iii) Dependability replaces the notion of reliability. The researcher provides a complete record of all phases of the research process or an audit trail (the documentation of data, methods and results of the research) which can be made available for external scrutiny.

(iv) Transferability refers to whether specific findings from "a qualitative study can be transferred to another similar context or situation and still preserve the particular meanings, interpretations, and inferences from the completed study" (Leininger, 1994, p. 106).

The transferability criterion focuses on general similarities of findings under similar environmental conditions, contexts, or circumstances. For instance, this research aims to give readers enough information to judge the applicability of the findings to other similar settings and can contribute to extending knowledge to other SIDS or larger developing states. 


\subsection{Summary}

As this study explores the perceptions and opinions of different stakeholder groups in Mauritius and uses these as a basis for its conclusions, it employs a qualitative (constructivist-interpretive) approach to address the key research questions. Therefore, ethical and confidentiality issues have been considered. To assist with data collection and interpretation, a comprehensive literature review was carried out, focussing on an evaluation of the strengths and weaknesses of PBF systems. Mauritius, being a SIDS, is used as a case study to collect empirical materials (primary and secondary data). Qualitative interviewing (semi-structured) has been applied to collect the primary data. A snowball sampling technique was employed to identify two groups of respondents and there were two groups of people involved: political elites and representatives of the tertiary education sector. Additionally, secondary data were extracted from the relevant official documents to triangulate and cross-validate the primary data. In order to analyse and interpret the findings, a thematic analysis using an inductive approach was employed.

Every study has biases and particular threats to validity. All methods have limitations. Criteria, such as credibility, transferability, dependability and confirmability become important in qualitative research. In order to evaluate the quality or trustworthiness of this study, these qualitative criteria have been applied. 


\section{CHAPTER THREE: TERTIARY EDUCATION SYSTEM IN MAURITIUS}

\subsection{Introduction}

The first part of the chapter gives an overview of Mauritius: the geography, the climate, a brief history of the government, political and legal system, and the economy. Then, the core of the chapter outlines the tertiary education systems' provisions. It describes the main TEls and other providers offering tertiary-level programmes, the institutional arrangements which have been set up and the legislation introduced to oversee the tertiary education sector. Next, the chapter analyses the pattern, level and structure of participation at the tertiary level, followed by a detailed summary of tertiary education funding. The allocation of public resources for teaching and research activities is input-based funding, using the Full-Time Equivalent (FTE) funding formula. Finally, the chapter focuses on current issues such as encouraging the expansion of private and overseas institutions, distance education, mobilisation of greater private financing and student support schemes for tertiary education in Mauritius, as well as the major challenges to becoming a knowledge hub or centre of higher learning and excellence.

\subsection{Overview of Mauritius}

Mauritius, an island of volcanic origin in the Indian Ocean and covering 1,865 square kilometres, is situated some 2,000 kilometres off the south east coast of Africa. It was colonised by the Dutch, French and English in turn, with a history influenced by India, Africa and China. Mauritius has a maritime climate, tropical during summer and sub-tropical during winter. The average yearly temperature is $25^{\circ} \mathrm{C}$ during the day and around $13^{\circ} \mathrm{C}$ at night. It has a multi-cultural population of approximately 1.2 million and an income per capita of US\$5,250 as of July 2005. There are two dominant languages which are fluently spoken and written, namely English, the official language, and French, mainly used in daily conversations. Other languages include Creole, Hindi, Urdu, Chinese, Tamil, Telegu and Marathi (Mauritius Chamber of Commerce and Industry, 2006; ORCA [Mauritius], 2006). 
The island became independent on 12 March 1968 and adopted a constitution based on the British Parliamentary system. On 12 March 1992, Mauritius became a Republic. It still remains a member of the Commonwealth and the right of appeal to the Privy Council is preserved (ORCA [Mauritius], 2006). The President is the head of state, while the Prime Minister has full executive power and is the head of Government. Mauritius has a multi-party system, with two strong parties, namely Alliance Sociale (which includes the Labour Party and the Mauritian Party) and Alliance MSM-MMM (Militant Socialist Movement and Mauritian Militant Movement). The National Assembly is made up of seventy members of whom sixty-two are directly elected on a first-past-the-post basis in 21 constituencies every five years by universal adult suffrage (National Assembly [Mauritius], 2006). After a general election, the Electoral Supervisory Commission may nominate up to a maximum of 8 additional members in accordance with section 5 of the First Schedule of the Constitution with a view to correct any imbalance in community representation in Parliament.

The Republic of Mauritius may now be described as a presidential democracy modelled on the British system of parliamentary democracy. There are guarantees of the separation of the legislative, executive and judicial powers. The legal system is a hybrid of English Common Law, the Code Napoléon and the 1968 Constitution. The Constitution provides for the independence of the judiciary (S. Moore, 2006). Since independence, Mauritius has developed from a low-income, monocrop (sugar)-based economy to a middle-income diversified economy. This has been due to an export-led manufacturing sector, an upmarket-tourism sector, expanding financial services, and information and communication technology sectors.

The GDP growth rate was 5.1\% in 2006/07. The GDP per capita (PPP) for Mauritius is US $\$ 12,400$ (2008 est.) and the human development index (HDI) 2007 is 0.804 . Table 3.1 shows a couple of comparable countries' GDP per capita, HDI and their ranking. 
Table 3.1 Country Comparisons - GDP Per Capita (PPP) and HDI

\begin{tabular}{|l|l|l|l|l|}
\hline $\begin{array}{l}\text { GDP } \\
\text { Ranking } \\
\text { (out of 229 } \\
\text { countries) }\end{array}$ & Country & $\begin{array}{l}\text { GDP Per Capita } \\
\mathbf{( 2 0 0 8} \text { est. US\$) }\end{array}$ & $\begin{array}{l}\text { HDI } \\
\text { Ranking } \\
\text { (out of 182 } \\
\text { countries) }\end{array}$ & $\begin{array}{l}\text { Human } \\
\text { Development } \\
\text { Index (2007) }\end{array}$ \\
\hline 90 & Cuba & $\$ 12,700$ & 51 & 0.863 \\
\hline 91 & $\begin{array}{l}\text { Northern } \\
\text { Mariana Islands }\end{array}$ & $\$ 12,500$ & $\begin{array}{l}\text { Data not } \\
\text { available }\end{array}$ & $\begin{array}{l}\text { Data not } \\
\text { available }\end{array}$ \\
\hline 92 & Romania & $\$ 12,500$ & 63 & 0.837 \\
\hline 93 & Mauritius & $\$ 12,400$ & 81 & 0.804 \\
\hline 94 & Uruguay & $\$ 12,300$ & 50 & 0.865 \\
\hline 95 & Belarus & $\$ 12,000$ & 68 & 0.826 \\
\hline & Kazakhstan & $\$ 12,000$ & 82 & 0.804 \\
\hline 97 & Costa Rica & $\$ 11,900$ & 54 & 0.854 \\
\hline
\end{tabular}

Source: Central Intelligence Agency, 2009; Human Development Report 2009

\subsection{Tertiary Education Sector}

The tertiary education sector currently encompasses a range of public, private, regional and overseas institutions (Tertiary Education Commission [Mauritius], 2006d). The first TEI College of Agriculture was established in 1924. Other TEls offer not only undergraduate and postgraduate degrees, but also diploma and certificate programmes. The institutions, especially those not offering degree programmes, are also referred to as post-secondary institutions (Mohamedbhai, 2006). Some provide tertiary education in a variety of disciplines and levels, while others concentrate their activities on only one or two areas, at certain levels.

Tertiary education in Mauritius is characterised by a wide range of institutions. Within the public sector, there are two universities, namely the University of Mauritius (UoM) and the University of Technology, Mauritius (UTM), and four institutes: the Mauritius Institute of Education (MIE), the Mahatma Gandhi Institute (MGI), the Mauritius Institute of Health (MIH) and the Rabindranath Tagore Institute (RTI). There is also the Mauritius College of the Air which is a distancelearning college. In addition, there are three remaining publicly-funded institutions, two of which are polytechnics, namely the Swami Dayanand Institute of Management (SDIM) and the Institut Supérieur de Technologie (IST), which are managed by Technical School Management Trust Fund. 
Furthermore, there is the Industrial and Vocational Training Board (IVTB) which offers some post-secondary education (Mohamedbhai, 2006; Tertiary Education Commission [Mauritius], 2006a).

Altogether, as at 2006/07 there were $10 \mathrm{PFIs}, 34$ private institutions and 4 regional institutions (Tertiary Education Commission [Mauritius], 2006a, 2008b). Private institutions offer programmes through franchise agreements with overseas institutions. The four regional TEls are the University of the Indian Ocean, Institut de la Francophonie Pour L'Entrepreneuriat, the Sir Seewoosagur Ramgoolam Medical College, and the Mauras School of Dentistry. The activities of these institutions are geared towards programmes in specific disciplines which are not offered by the other TEls (Tertiary Education Commission [Mauritius], 2006d).

Finally, the provision of tertiary education extends beyond the local frontier given that a significant number of Mauritian students study in overseas institutions mostly in Australia, France, India, South Africa, Russia, and the UK. Some register for distance education programmes directly with foreign institutions to obtain tertiary education.

\subsection{Tertiary Education Institutions}

This section provides a brief look at the TEls. There are six TEls falling under the purview of the Tertiary Education Commission (TEC): University of Mauritius (UoM), University of Technology, Mauritius (UTM), Mahatma Gandhi Institute (MGI), Mauritius Institute of Education (MIE), Rabindranath Tagore Institute (RTI), and Mauritius College of the Air (MCA). They are categorised into two universities, three institutes, and a distance education college.

These six public funded TEls are the only ones which offer tertiary-level programmes from postgraduate degrees to Bachelor, diploma and certificate level, with the exception of Rabindranath Tagore Institute, which has not yet started delivering courses. Further, all of them are under the responsibility of the Ministry of Education and Human Resources. The other post-secondary institutions (Swami Dayanand Institute of Management, Institut Supérieur de Technologie and Industrial Vocational Training Board) provide courses up to diploma level only. 
(i) The University of Mauritius

The University of Mauritius, established in 1965, originally had three schools, namely, Agriculture, Administration, and Industrial Technology. It has since expanded to include five faculties: Agriculture, Engineering, Law and Management, Science, and Social Studies and Humanities. It has also a Centre for Medical Research and Studies, a Centre for Distance Education, a Centre for Information Technology and Systems, and a Consultancy Centre.

The University of Mauritius, with its rapid expansion, dominates the tertiary education sector. The level of study has changed from certificate/diploma only to Bachelor and post-graduate degrees including research degrees.

\section{(ii) The University of Technology, Mauritius}

University of Technology, Mauritius was set up in June 2000 to provide multi-level tertiary education including continuing professional education to meet the needs of Mauritius, with emphasis on information technology, sustainable development science and public sector policy and management. It started operations in September 2000 with two Schools, namely Business Informatics and Software Engineering, and Public Sector Policy and Management. UTM works closely with government, business and industry.

\section{(iii) The Mahatma Gandhi Institute}

The Mahatma Gandhi Institute was established in 1970 as a joint Government of Mauritius/Government of India venture for the promotion of education and culture. It has three main Schools operating at the tertiary level, namely Indian Studies, Music and Fine Arts, and Mauritian and Area Studies (Tertiary Education Commission [Mauritius], 2006d). For the last few years it has been running Bachelor programmes in Languages, Fine Arts and Performing Arts in collaboration with University of Mauritius, in addition to diploma and certificatelevel programmes.

\section{(iv) The Mauritius Institute of Education}

The Mauritius Institute of Education was founded in 1973 and was responsible for teacher education, educational research and curriculum development. Since 1993, it has been predominately confined to teacher training and educational research. 
There are currently five Schools, namely Applied Sciences, Education, Science and Mathematics, Arts and Humanities, and Distance Education. The programmes delivered by the institute have diversified over the years and range over certificate level, diploma level and the post graduate certificate of education. Presently, it also offers Bachelor of Education and Master of Education.

\section{(v) Rabindranath Tagore Institute}

The Rabindranath Tagore Institute was set up in December 2002. It has a cultural vocation and operates under the aegis of the Mahatma Gandhi Institute. It is still in an early phase of development and has yet to become operational in terms of student enrolment (Tertiary Education Commission [Mauritius], 2008b) .

\section{(vi) The Mauritius College of the Air}

The Mauritius College of the Air was established in 1971 to promote tertiary education, arts, and science and culture in Mauritius through mass media. When the Mauritius College of the Air statute was re-enacted in 1985, distance education was maintained as a major strategy to meet these objectives. In 1986, it merged with the Audio-Visual Centre of the Ministry of Education and Science and also began delivering primary and secondary educational programmes for broadcast on radio and television.

Since the beginning of 1995, the Mauritius College of the Air has been involved in providing tertiary-level programmes in collaboration with overseas institutions through the distance mode (Tertiary Education Commission [Mauritius], 2006d). There has been a recent policy decision announced in the 2005/2006 Budget Speech for the transformation of the Mauritius College of the Air into The Open University Mauritius.

In sum, as outlined earlier, the institutes focus their programmes mostly on specialised disciplines (Music, Fine Arts, Languages, and Education). They undertake programmes which are jointly awarded by the University of Mauritius or overseas universities. The two universities offer a variety of degree courses in different disciplines such as sciences, engineering, social studies and humanities, and law and management, and lately have begun to undertake research projects more than previously. 


\subsection{Institutional Framework}

The main government institutions with a responsibility for tertiary education in Mauritius are the Ministry of Education and Human Resources, the TEC, the National Accreditation and Equivalence Council, the Mauritius Qualifications Authority, the Technical School Management Trust Fund, and the Industrial Vocational Training Board.

\section{(i) Ministry of Education and Human Resources}

The Ministry of Education and Human Resources is the government department responsible for developing the policy framework for primary, secondary and tertiary education.

It advises the Minister how education policy might be moulded to improve the educational outcomes for life-long learning. The Ministry is also responsible for monitoring the development and implementation of educational strategies and the financial performance of the TEls. Moreover, the Ministry oversees the funding system for the sector.

\section{(ii) Tertiary Education Commission}

The Tertiary Education Commission was created in 1988 by an Act of Parliament as a parastatal body under the Ministry of Education and Human Resources. The Commission is made up of a Board with a chairman and six other members appointed by the Prime Minister. The TEC is responsible for developing, planning and coordinating post-secondary education in Mauritius. Furthermore, it allocates public funds to those institutions falling under its purview and ensures their accountability and the optimum use of resources within those institutions. The TEC also has a mandate to ensure the quality of post-secondary education, and to determine the recognition and equivalence of post-secondary qualifications. The TEC Act was amended in 2005 and additional responsibilities were assigned to the TEC. The major additional responsibilities were:

- to register and accredit private universities and other institutions offering post-secondary education in Mauritius, 
- to promote and maintain high quality standards in post-secondary education institutions through appropriate quality assurance and accreditation mechanisms, and

- to determine the recognition of an equivalence of academic or professional qualification in the post-secondary education obtained within or outside Mauritius (Education and Training (Miscellaneous Provisions) Act, 2005).

In 1997, the government established the National Accreditation and Equivalence Council (NAEC) under the Ministry of Education and Scientific Research. The foremost purpose of the council was to ensure the provision of quality education in Mauritius. It was responsible not only for establishing equivalence of qualifications awarded by institutions both within and outside Mauritius, but also with undertaking academic audits and accreditation of institutions. It was meant to serve as the external quality assurance agency in Mauritius. The NAEC was abolished in 2005 and its responsibilities absorbed by the Mauritius Qualifications Authority.

\section{(iv) Mauritius Qualifications Authority}

The Mauritius Qualifications Authority was set up in 2001 to evaluate and recognise qualifications awarded mainly by training institutions running technical and vocational courses, and post-secondary qualifications. It was set up, not under the Ministry of Education, but under the Ministry which is responsible for Training and Human Resource Development.

The Mauritius Qualifications Authority's (MQA) objectives are developing, implementing and maintaining a National Qualifications Framework for an effective certification system and ascertaining that standards and registered qualifications are internationally comparable (Ministry of Education and Scientific Research [Mauritius], 2004). As a consequence of the MQA's establishment, there was an overlapping of responsibilities between MQA and NAEC with respect to recognition of qualifications, and between MQA and TEC with regard to public post-secondary education institutions. Thus, on 4 May 2005, important amendments were made. 
The Education and Training Act, the Mauritius Qualifications Authority Act and the Tertiary Education Commission Act were amended in order to make better provisions for the recognition and equivalence of qualifications in the tertiary sectors, for regulating the establishment and operation of private post-secondary educational institutions, and for matters related thereto (Education and Training (Miscellaneous Provisions) Act, 2005).

The MQA Act was amended so as to remove all post-secondary institutions from its purview. The MQA would be responsible for only technical and vocational qualifications. The NAEC was dismantled and the Act repealed and all its responsibilities were transferred to TEC.

\section{(v) Technical School Management Trust Fund School}

The Technical School Management Trust Fund School was created in 1990 to manage the Polytechnics. It is administered by a Board. Industry Advisory Committees, which include representatives from both the public and private sectors, are appointed. These committees have responsibilities for establishing programme objectives, curriculum content and delivery modes, establishing terminal standards and certification, prescribing training equipment and training facilities, advising on industrial training attachments, reviewing programme results and diploma holders' employment performance, and monitoring and reviewing market demand.

\section{(vi) Industrial Vocational Training Board}

The Industrial Vocational Training Board was set up by government in 1988 to promote vocational education and training with the aim of ensuring the ready supply of a skilled and trained workforce for the industrial, services and domestic sectors. It is partly financed by a training levy paid by employers. Most of the programmes that are being run are of a vocational nature leading to the National Trade Certification (levels 3 and 2). However, as from 1998 it has also started running tertiary-level programmes at the levels of certificate and diploma in selected areas, including hotel management, automation, and information technology. Lately, the roles of the Industrial Vocation Training Board have been reviewed, making it an enhanced provider of training and skills development for employability. 
It is obvious that, for a small island developing state like Mauritius with 10 public funded institutions, there are too many independent organisations attempting to oversee the sector where, despite recent changes, many roles and responsibilities still overlap.

\subsection{Participation in Tertiary Education}

The tertiary sector has registered significant growth between 1997/98 and 2003/04 with participation rates for tertiary education more than doubling. The annual student intake for tertiary education providers increased from fewer than 3,000 in 1997/98 to 7,585 in 2003/04 (Tertiary Education Commission [Mauritius], 2006d). The total enrolment of tertiary students from the publicly funded institutions, distance education/private providers and overseas institutions grew from 9,488 in $1997 / 98$ to 26,074 in December 2004. Overall, the tertiary student population was 34,332 as at December 2007 (Central Statistical Office [Mauritius], 2008). The total tertiary education enrolment expanded by $3.3 \%$ in 2007 compared with $15.1 \%$ in 2006.

The Gross Tertiary Enrolment Rate, calculated as the percentage share of total enrolment in the population aged 20 to 24 years, registered a significant increase from $10 \%$ in $1997 / 98$ to $36.6 \%$ in $2007 / 08$ (Tertiary Education Commission [Mauritius], 2006c, 2008b). The total enrolment in tertiary education by the publicfunded institutions, overseas institutions and private providers and distance education for the period from 1998 to 2007 is illustrated in Figure 3.1. 
Figure 3.1: Total Enrolment in Tertiary Education from 1998 to 2007

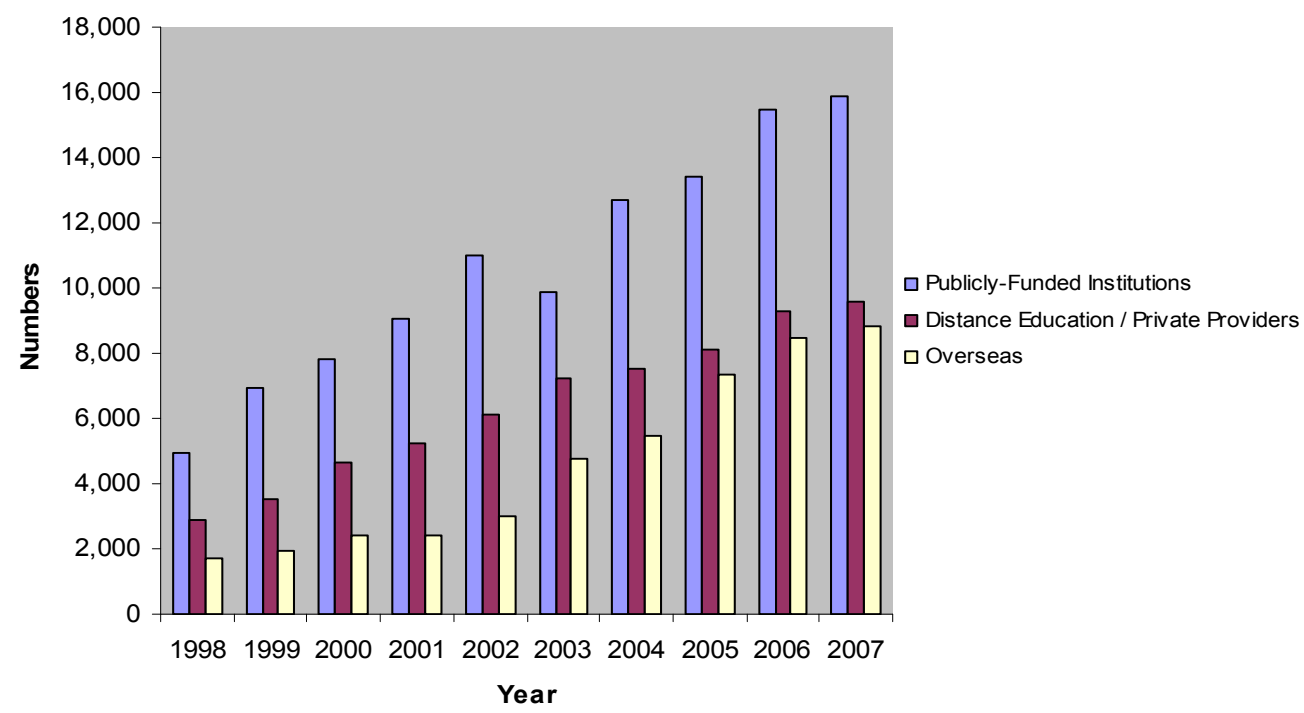

Source: Tertiary Education Commission [Mauritius], 2006c, 2008b

As shown in Figure 3.1, the participation rate in the tertiary education sector has steadily increased over the ten years. This may be because of government policies and strategies adopted to meet the needs of an increasingly competitive, knowledge-based and globalised economy. Mauritian students want to upgrade their qualifications to meet the labour market requirements and secure a better job in the future. Moreover, the rapid increase in participation has emanated from greater enrolment capacity locally, arising from the expansion of existing institutions, both public and private, the establishment of a second university, new private providers and the provision of open and distance learning education.

Figure 3.2 summarises the percentage of total tertiary enrolment in 2007 and the distribution among the public-funded institutions, private providers and overseas institutions. 
Figure 3.2: Distribution of Total Tertiary Enrolment by Source, 2007

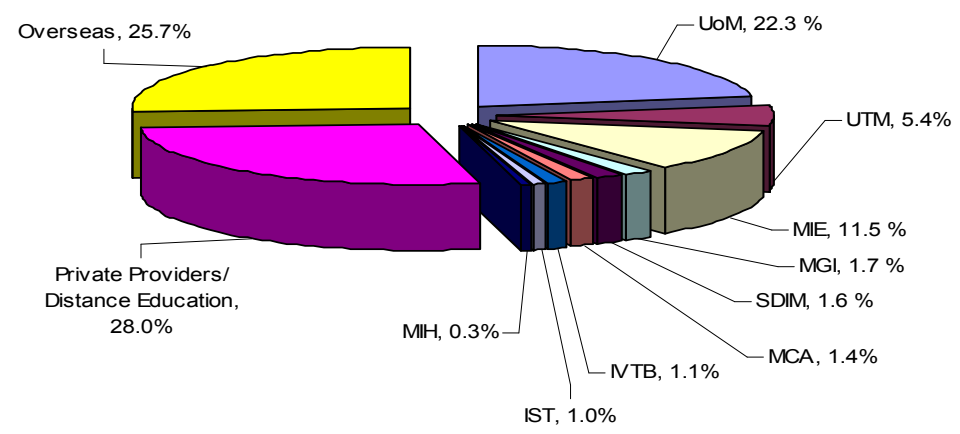

Source: Central Statistical Office [Mauritius], 2008; Tertiary Education Commission [Mauritius], 2008b

In 2007 , the public-funded institutions made up $46.3 \%$ of total tertiary education enrolment or approximately 15,880 students, while private providers/distance education and overseas institutions accounted for $28 \%(9,612)$ and $25.7 \%(8,840)$, respectively (Tertiary Education Commission [Mauritius], 2008b). Within the publicfunded institutions, the UoM obtained $22.3 \%$ of the total enrolment, followed by MIE, UTM, MGI, SDIM, MCA ,IVTB, IST and MIH as illustrated in Figure 2.2.

Table 3.2: Total Enrolment in Tertiary Education for 1997/98, 2000/01, 2003/04, and $2007 / 08$

\begin{tabular}{|l|l|l|l|l|}
\hline & $\mathbf{1 9 9 7 / 9 8}$ & $\mathbf{2 0 0 0 / 0 1}$ & $\mathbf{2 0 0 3 / 0 4}$ & $\mathbf{2 0 0 7 / 0 8}$ \\
\hline Public-Funded Institutions & 4,928 & 9,057 & 12,710 & 15,880 \\
\hline Private institutions/distance education & 2,860 & 5,255 & 7,507 & 9,612 \\
\hline Overseas Institutions & 1,700 & 2,423 & 5,468 & 8,840 \\
\hline
\end{tabular}

Source: Tertiary Education Commission [Mauritius], 2006c, 2008b

Figure 3.3 shows the evolution and growth of tertiary education enrolment over the years 1997/98, 2000/01, 2003/04, and 2007/08. 
Figure 3.3: Evolution of Tertiary Education Enrolment By Source

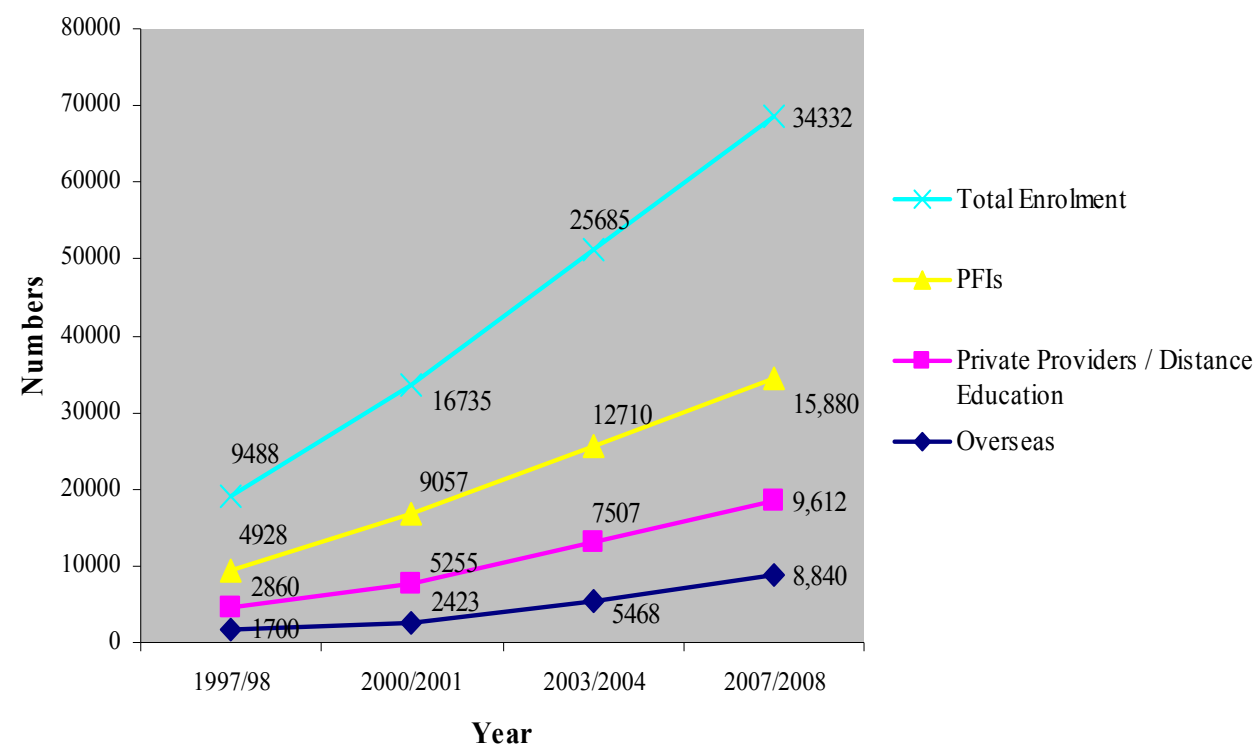

As exhibited in Table 3.2 and illustrated in Figure 3.3, in 1997/98 the publicfunded institutions enrolled a total of 4,928 students representing $51.9 \%$ of all enrolments. Private institutions/distance education and overseas institutions accounted for $30.1 \%(2,860)$ and $17.9 \%(1,700)$ respectively. By $2007 / 08$ there was a decrease of $5.7 \%$ of all enrolments for PFIs and $2.1 \%$ private institutions and distance education but an increase of $7.8 \%$ for overseas institutions compared to $1997 / 98$.

In general, the rates for change show variations at the level of the tertiary education providers. These will be discussed in section 3.7 under the current issues for tertiary education.

\subsection{Tertiary Education Funding}

The tertiary education sector is funded by government grants as well as tuition fees charged by TEls to cover both research and teaching activities. The funding for teaching and research activities for public-funded institutions is integrated, based on the FTE funding formula. For some specific research projects, funds are provided by the Mauritius Research Council. Budgeting systems for preceding years were based on line-items but in the financial year 2008/2009, the government introduced a programme-based budgeting system as part of the financial management reforms. 
Funding by government is carried out under various principles and procedures set by the Ministry of Finance and Economic Development (MOFED) which is solely responsible for the preparation of the annual budget. On the basis of the macroeconomic fiscal framework, ceilings are issued to all Ministries in a Budget Circular issued by the MOFED that sets out overall government objectives as well as detailed instructions for recurrent and capital budgets. MOFED requests line ministries to submit their expenditure proposals for the forthcoming fiscal year (July to June), given the expenditure ceilings. The line ministries communicate the budget circular to departments concerned.

The TEC requests budgetary proposals from the TEls in December every year for the next financial year and provides guidelines on the basis of which the budgets are to be prepared. The budgets are examined in the light of the long-term plans of the institutions, and the needs and government priorities for the sector. The examination of the budget covers all aspects, including staffing, enrolment, courses and programmes delivered by the institutions, once the approval of the TEC Board is obtained; the budget for the sector is submitted to the Ministry of Education and Human Resource (MOEHR) with all justifications.

The budget is once again examined at the level of the MOEHR and submitted at the MOFED. The MOEHR submission is then reviewed by MOFED staff. Since expenditure is generally well above the notional expenditure envelopes indicated by MOFED, formal meetings are held until a consensus is reached and the amount to be allocated to the sector is finally decided upon by the MOFED. Then the budget for all ministries is published in a document which is presented to the House on the budget day.

The budget is discussed by the Estimate Committee, then once it is cleared by the committee, it moves to Parliament for approval and then is published as an official document. The budgetary allocation for the public-funded institutions is provided by the MOFED in the form of a one-line item to TEC and to the Technical School Management Trust Fund. Funds received are allocated to the institutions on the basis of the budgetary submissions. With the implementation of the budget reform in Mauritius (Programme Based Budget 2008/09), the funds for the tertiary education sector and the technical and vocational sector are allocated under the programme code 425 and 426 correspondingly. 
By contrast, the Mauritius Institute of Health budget is borne by the Ministry of Health and allocated under the programme code 581(Ministry of Finance and Economic Development, 2008b). Funding of the tertiary education sector is managed by TEC, while that of the technical and vocational sector is managed by Technical School Management Trust Fund and Industrial Vocational Training Board respectively.

In 2003/04, the Government recurrent grant to tertiary education represented $0.41 \%$ of the GDP at market prices compared to $0.44 \%$ in $2000 / 01$. For the 2007/08 financial year, an amount of MUR 785.4 $\mathrm{m}$ has been provided as a recurrent grant for the tertiary education sector. This is an increase of $14.7 \%$ compared to the actual expenditure on post secondary education (MUR 684.7) in 2005/06. This increase is partly due to the coming into operation of the Rabindranath Tagore Institute , the setting up of an Open University of Mauritius and the rise in student enrolment for the years 2005/06 and 2006/07 (Ministry of Education and Human Resources [Mauritius], 2008; Tertiary Education Commission [Mauritius], 2006d). 
Figure 3.4: Government Funding for Tertiary Education Sector for the Financial Years $1999 / 2000$ to $2007 / 2008$

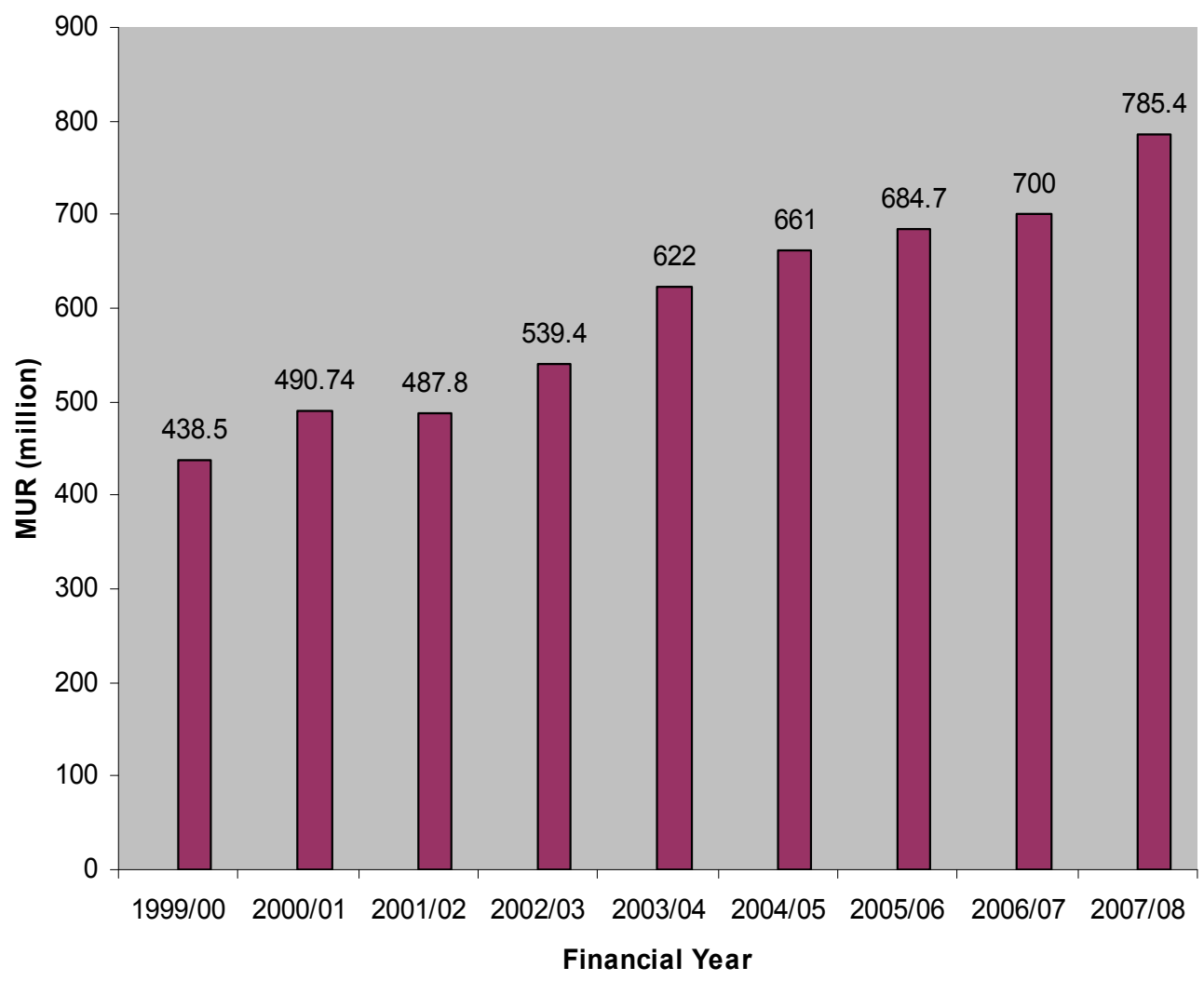

Source: Ministry of Education and Human Resources [Mauritius], 2008; Tertiary Education Commission [Mauritius], 2008b

TEls receive teaching and research funds in the form of grants from the TEC, which has responsibility for allocating public funds and tuition fees generated by the TEls. Budgets for teaching and research are integrated. The funding for teaching and research activities for TEls is based on a funding formula, using the FTE system. Tuition fees charged by TEls are used to cover recurrent expenditure and to balance the total grants that will be provided by government.

The funding rates are differentiated by subject area, mode (full-time, part-time and distance education), and qualification type (post graduate degree, Bachelors degree, diploma and certificate). Generally, the unit cost per FTE student ranged between MUR ${ }^{4} 49,900$ and MUR 211,000 in 2003/04. Agriculture is the most expensive field compared with science and social studies, and humanities is the least (Tertiary Education Commission [Mauritius], 2006d).

${ }^{4}$ Exchange rate one US dollar is equivalent to MUR 34.050 as at 24 March 2009. 
Public research funds are provided under a dual support system, with funds coming from the TEC and the Mauritius Research Council. Aside from the public funding allocated to TEls which covers academic staff costs, administrative expenses, and some research costs, the TEC provides additional funds for ongoing research by $\mathrm{PhD}$ students registered with TEls, mainly the UoM and UTM, under the TEC MPhil / PhD Support Scheme. The Mauritius Research Council was set up in May 1992 (Act no. 10 of 1992) as an apex body to promote and coordinate Government's investment in research. The MRC acts as a central body to advise Government on science and technology issues and to influence the direction of technological innovation by funding research projects in areas of national priority and encouraging strategic partnerships (Mauritius Research Council, 2006a; Ministry of Education and Scientific Research [Mauritius], 2004) .

The MRC currently provides funds under six funding schemes:

- Under the Solicited Research Grant Scheme's (SRGS) top-down approach, the Council defines and selects the areas of research that are of national priority. Researchers are then invited to bid, on a competitive basis, to undertake research.

- $\quad$ The Unsolicited Research Grant Scheme (URGS) is a bottom-up approach to the promotion of research and development, whereby researchers and research institutions submit proposals in their own areas of interest. Funds are then made available for those proposals that satisfy the criteria set up by the Council.

- The Small Scale Research Grant Scheme (SSRGS) is for the public in general who have no expertise in research and development. This scheme is available to all those not covered by the existing research grant schemes of the MRC namely the URGS and PSCRGS.

- $\quad$ The Private Sector Collaborative Research Grant Scheme (PSCRGS) aims at encouraging the private sector, in collaboration with a local academic institution, to undertake research designed to develop new processes, techniques or products with a view to increasing productivity, competitiveness and efficiency. Special emphasis is placed on those research opportunities that have commercial potential.

- The Public Sector Collaborative Research Grant Scheme (PuSCRGS) is intended for employees working in the public sector and parastatal bodies. Promoters invite researchers and research institutions in the public sector to submit proposals in pre-identified areas of interest. 
Proposals that are multi-disciplinary and involve inter-institutional or interdepartmental collaboration are encouraged. Proposals are selected for funding based on their potential research value, their strategic importance and the contribution they would make to improve the efficiency and effectiveness of the public sector.

- A Post Graduate Research Award provides funding on a merit basis for postgraduate research-based projects in line with national priorities. This initiative is expected to develop knowledge and to further promote science and technology research at the national level through increased human capacity building (Mauritius Research Council, 2006a)

These grants are allocated according to the national research priorities. The council funded 140 research projects in 2000/01 compared to 248 projects in $2004 / 05$ in the fields of science and technology, information and communication technology, social, and economics. The allocation of funds by schemes in June 2005 was $1 \%$ small scale, $7 \%$ private sector, $30 \%$ solicited, and $62 \%$ unsolicited (see Table 3.3 which gives a representative sample of research grant schemes over the past few years).

Table 3.3: Research Grant Schemes for the Financial Years 2000, 2001, 2003, 2005, 2006 and 2008.

\begin{tabular}{|c|c|c|c|c|c|c|}
\hline Research Grant Schemes & $\begin{array}{l}2000 \\
\text { MUR } \\
(\mathrm{m})\end{array}$ & $\begin{array}{l}2001 \\
\text { MUR } \\
(\mathrm{m})\end{array}$ & $\begin{array}{l}2003 \\
\text { MUR } \\
(\mathrm{m})\end{array}$ & $\begin{array}{l}2005 \\
\text { MUR } \\
(\mathrm{m})\end{array}$ & $\begin{array}{l}2006 \\
\text { MUR } \\
(\mathrm{m})\end{array}$ & $\begin{array}{l}2008 \\
\text { MUR } \\
(\mathrm{m})\end{array}$ \\
\hline Unsolicited Research Grant Scheme (URGS) & 30.36 & 36.13 & 42.25 & 57.80 & 61.9 & 18.9 \\
\hline $\begin{array}{l}\text { Solicited Research Grant Scheme (SRGS) } \\
\text { Private Sector Collaborative Research Grant }\end{array}$ & 9.68 & 0.10 & 16.25 & 28.30 & 32.0 & 25.0 \\
\hline Scheme (PSCRGS) & 3.96 & 5.15 & 5.85 & 6.90 & 6.93 & 2.83 \\
\hline Small Scale Research Grant Scheme (SSRGS) & 0.00 & 12.17 & 0.65 & 1.00 & 0.976 & 0.568 \\
\hline Total Project Values & 44.00 & 53.55 & 65.00 & 94.00 & 101.806 & 47.298 \\
\hline Total Funds Spent & 30.70 & 38.10 & 49.60 & 68.38 & 76.398 & 33.483 \\
\hline
\end{tabular}

Source: Mauritius Research Council, 2002, 2004, 2005, 2006b, 2008

\subsection{Current Issues for Tertiary Education in Mauritius}

The overwhelming fiscal reality in Mauritius, like most SIDS, is such that quality improvement and enrolment expansion in tertiary education will have to be achieved with little or no increase in public expenditure. In Mauritius, the Government has decided that knowledge-based industries will be an increasing source of added value for the economy and a significant component of the new economic model. 
To that end, it is promoting a knowledge-hub agenda in which tertiary education will be given greater importance. To position itself as a key player in the subregion, the tertiary education sector will have to attain world-class status (Ministry of Education and Scientific Research [Mauritius], 2005). To consolidate the tertiary education sector, it will be essential to increase expenditure for tertiary education, including research and development.

Given the fiscal and budgetary constraints affecting SIDS governmental capacity to finance tertiary education, the government goals are to encourage private and overseas institutions and promote open distance education. The means for achieving these goals are mobilising greater private financing, introducing financial student support and loan schemes and increasing the autonomy of public institutions.

Thus, the current issues which prevail in the tertiary education sector in Mauritius are: (i) encouraging private and overseas institutions; (ii) promoting open and distance learning education; (iii) mobilising greater private financing; (iv) introducing financial student support and loan schemes; and (v) increasing the autonomy of public institutions.

\subsubsection{Encouraging Private and Overseas Institutions}

Encouraging private and overseas institutions can help meet the growing demand for tertiary education and make the tertiary education systems more responsive to changing labour market requirements. The Government of Mauritius is supporting the development of private institutions to complement public institutions as a means of managing the costs of expanding tertiary education enrolments and broadening participation in tertiary education. For instance, an Investment Certificate (Education and Training) Scheme has been introduced, providing a series of incentives to enhance the participation of the private sector in tertiary education and training, and encourage the establishment of branches of overseas institutions, such as the University of Birmingham which opened a branch in Mauritius (Ministry of Education and Scientific Research [Mauritius], 2005). 


\subsubsection{Open and Distance Learning Education}

The open and distance learning mode is recognised as having enormous capability in fostering educational development. The provisions of tertiary education for domestic students through open and distance learning have expanded significantly during the past ten years. In 2003/04, the Mauritius College of the Air ran 10 tertiary-level programmes through the distance education mode. This is two more than in 2000/01 (Tertiary Education Commission [Mauritius], 2006d).

The enactment of the Open University of Mauritius legislation reflects the enormous potential of open distance learning for Mauritius. However, it is essential to point out that the public funding level for the Open University of Mauritius is lower compared than the other public-funded institutions because it requires little investment in infrastructures. The distance mode of tertiary education is expected to increase. It will widen access and reduce the dependence on state funding because the unit cost per FTE student will be low.

\subsubsection{Mobilising Greater Private Financing}

The financial base of public tertiary education can be strengthened by mobilising a greater share of the financing from students. Until recently, only private institutions charged fees; now public institutions are increasingly as well. The introduction of tuition fees also gives incentives for students to complete their studies more quickly. The tuition fees policy for part-time students in the PFIs was introduced in Mauritius in the mid 1990s. With the set up of the second public university (UTM) in 2000, the government also established fees for full-time students. Unlike the other PFIs which relied heavily on the government to finance their budgets, the UTM raised more than $75 \%$ of its recurrent expenditure from non-government sources (tuition fees) in 2003/04 (Tertiary Education Commission [Mauritius], 2006d). Furthermore, public TEls are encouraged to pursue incomegenerating activities such as short-term courses, research contracts from industry, and consultancy services from African countries in the region.

In sum, increased private financial support for tertiary education, through the introduction of fees and the undertaking of income-generating activities, can provide institutions with a more diversified and probably more stable funding base. 
Nevertheless, this strategy may be incompatible with the goal of increasing and widening access to education. It may be detrimental to disadvantaged and vulnerable groups.

\subsubsection{Financial Student Support and Loan Schemes}

To implement the cost-sharing approach equitably, student support in the form of educational loans and student scholarship schemes have been provided by the government. The Human Resource, Knowledge and Arts Development Fund has been established in 2008 under the aegis of Ministry of Education, Culture and Human Resources, to provide scholarships. The objective of the Scholarship Scheme is to provide access to qualified students from families with household income not exceeding MUR 10,000 per month and who face severe hardship following death or serious incapacity of a wage earner. Further, there is the Sir Seewoosagur Ramgoolam Foundation Fund Loan Scheme which provides interest-free loans to students following full-time programmes at the University. The student-loan schemes are administered by various organisations, such as Employees Welfare Fund (EWF), Mauritius Mutual Aid Association (MMAA), Trust Fund for Social Integration of Vulnerable Groups, and the financial institutions (commercial banks), (Mohadeb, 2006). The EWF, MMAA, and the Trust Fund for Social Integration of Vulnerable Groups are public institutions which grant student loans at an annual rate of interest of $8 \%$ (with the exception of MMAA at $12 \%$ ). The bank educational loan schemes are mostly used by those who are not entitled to loans from the public institutions. The educational loans offered by the private financial institutions, (mainly commercial banks) carry an annual interest rate in the range of $11 \%$ to $12.75 \%$.

In the National Budget Speech 2008, the Hon. Rama Sithanen, the Minister of Finance and Economic Development, launched a "Government guaranteed student loan scheme of up to MUR 150,000 per year to allow commercial banks to make loans to all students with an offer from a TEC recognised tertiary institution in Mauritius" (Ministry of Finance and Economic Development, 2008a, 2008b, p. 12). This guaranteed loan is aimed at students whose families cannot afford to secure such a loan. Students will pay back the loan, both capital and interest (prevailing interest rates), only after acquiring a job at the completion of their studies. 
In addition to the loan schemes, there are scholarship programmes (Sugar Labour Welfare Fund, UoM and UTM Scholarship Schemes) that guarantee necessary financial support to academically qualified needy students to meet the costs of tertiary education. Moreover, there are a wide variety of scholarships offered by OECD jurisdictions such as Australia, Canada, France, New Zealand and the United Kingdom as well as China, India, Malaysia, Pakistan and Russia.

A Tertiary Education Interest Support Scheme has been put in place to allow any Mauritian who is able and willing to undertake tertiary education in priority areas (agriculture, social science, applied sciences, medical and health studies, financial services, and information communication and technology), within acceptable Government budgetary constraints (Ministry of Education and Scientific Research [Mauritius], 2005). In sum, financial student support and loans enable needy students to make the same choices as those with more financial resources and stimulates competition among educational institutions to offer programmes in line with student demand. In 2002/03, the total loans provided in Mauritius amounted to MUR 174.72 million (Mohadeb, 2006). There is no data available for the percentage of students taking loans.

\subsubsection{Increased autonomy for Public-Funded Institutions}

The Government of Mauritius has promoted greater autonomy at the institutional level, allowing universities and other TEls more freedom to manage their resources by introducing market mechanisms and developing income-generation policies. The decentralisation of all key management roles to TEls is a sine qua non for successful reforms. TEls have the power to set fees, recruit their personnel, provide incentives for undertaking research activities, grant sabbatical leave and use budgetary allocations flexibly across expenditure categories. This has mitigated the need for universities and other TEls to seek government approval for management actions. Along with increased autonomy and flexibility, however, TEls need to be held accountable for their management and academic performance. 


\subsection{Major Challenges Ahead}

Although major innovations have been introduced into the system, there are still a number of challenges facing the educational system at the beginning of the $21 \mathrm{st}$ century. Developing countries, transition economies and SIDS alike face both the old challenge of promoting quality, equity and efficiency and the new challenge of supporting knowledge-based economies and coping with the impacts of globalisation and information technology development.

\subsubsection{Developing Mauritius into a Knowledge Hub and a Centre of Higher Learning}

In the context of a globally articulated knowledge-based economy, initiatives have been undertaken to develop Mauritius into a Knowledge Hub and Centre of Higher Learning at the national level as set out in a recent road map (Ministry of Education and Scientific Research [Mauritius], 2005).

To promote this agenda, consideration has been given to the development of a coherent policy framework, and the provision of an enabling regulatory environment and appropriate financial incentives, such as mechanisms that steer institutions towards efficiency and quality improvement, and formulae linking resources to institutional performance.

\subsubsection{Enrolment Expansion and Increased Equity}

The report entitled Participation in Tertiary Education 2005 issued in June 2006 by the TEC presents statistics on enrolment expansion and indicates that the trend will continue in future. The gross tertiary enrolment rate has maintained its upward rising trend from $15.1 \%$ in 2000, 19.7\% in 2003, 24.2\% in 2004 to $28.4 \%$ in 2005 and to $34.1 \%$ in 2006 (Tertiary Education Commission [Mauritius], 2006a, 2006c). It is worth noting that a majority of the students are enrolled at universities rather than technical institutes.

In addition, it is the goal of government to enhance equity for students' access in the tertiary education system, recognising the need for greater representation from the under-privileged and the disadvantaged subgroups of the population. Thus, to meet the demands for tertiary education and achieve greater equity, it is a prerequisite for government to respond to funding constraints by introducing policies aimed at increasing efficiency and stimulating greater private funding. 


\subsubsection{Incentives for Efficient Resource Allocation and Utilisation}

The distribution of public resources to tertiary institutions in most SIDS is based on negotiated budgets or input-based funding systems. Such systems have been noted to fail to provide incentives for efficient operation, accountability and quality improvement. Alternative mechanisms that link funding to performance measures are therefore of interest in SIDS, including Mauritius. PBF mechanisms are being used increasingly by OECD countries and the assessment of such mechanisms has demonstrated greater incentives for efficient use of resources and quality enhancement. Mauritius has taken note of these developments.

With the foremost goals of developing Mauritius into a knowledge hub and expanding enrolment, an acknowledged need is to explore the opportunities and challenges for the development and implementation of PBF mechanisms. This could possibly help to mobilise efficient resource allocation by TEls, enhance quality of tertiary education and promote more accountability.

\subsubsection{Ensure Quality Standards of all Tertiary Education Provisions}

A growing number of countries ${ }^{5}$ have adopted a common approach of establishing of a national evaluation or independent accreditation body to promote higherquality teaching and learning over both public and private TEls (Steier, 2003). In Mauritius, any institution engaged in the provision of tertiary level programmes is subject to quality assurance procedures set out by the regulating agency.

The TEC has been active in promoting quality assurance in the public tertiary sector since 1997 (Mohamedbhai, 2006). It has set up a Quality Assurance and Accreditation Division and also a Quality Assurance Committee, chaired by the Director of the TEC and consisting of a representative from each of the public institutions under its purview.

In October 1999, the TEC published the document Framework for Quality Assurance in Tertiary Education Sector in Mauritius in order to assist TEls to put in place quality assurance systems in their respective institutions. In May 2004 the TEC published a comprehensive Quality Audit Handbook which outlined the detailed procedures to be used in the external quality auditing of an institution.

\footnotetext{
5 Argentina, Asia, Colombia, Ghana, Indonesia, El Salvador, Europe, Hungary (see Steier, 2003 World
} Bank ) 
With regard to private tertiary institutions, the TEC has published two documents, one entitled Programme Accreditation, and the other Guidelines Programme Accreditation. With effect from July 2005, any private institution that wishes to operate in Mauritius has to register with the TEC, which then accredits its academic programmes.

\subsubsection{Promoting Research Excellence}

The advancement of knowledge through education and research is an underlying function of the tertiary education sector. The sector is a significant producer of research and new knowledge. Therefore it has the responsibility for training most of the researchers and producing research degree graduates. The TEC Annual Report 2003/04 claims that "Research in the PFIs, though progressed satisfactorily between 1997/98 and 2003/04, still remained inadequate" (Tertiary Education Commission [Mauritius], 2006d, p. 129). Among the TEls, UoM accounted for $82 \%$ of research performed in the sector.

Thus, a challenge for the state is to develop mechanisms that will promote research excellence across all the TEls. Furthermore, the government has to send the right signal to encourage concentration in strategic areas to facilitate their mergence as Centres of Excellence.

\subsection{Conclusion}

The first challenge to the government of Mauritius and TEls is that of developing Mauritius into a knowledge hub. With the emerging challenges of globalisation, the economy is knowledge-intensive and requires human capital with high-level skills. There is thus an overall pressure on tertiary education in Mauritius to produce high-level skilled personnel to be more responsive to development needs. Due to budgetary constraints, government has been unable to meet this demand for access by expanding the existing infrastructure for tertiary education. In this regard, there are numerous changes observed in the system of tertiary education in Mauritius. 
The government of Mauritius has opted for policies to open the market to both private and foreign providers of tertiary education within the country so as to meet the needs of a knowledge-based economy. It has also aimed to increase students' access and participation at the tertiary level in terms of gross tertiary enrolment rate (45\% in 2015). In 2008 the government implemented a budget reform, with a change from line-item budgeting to programme-based budgeting.

The increased competition for scarce financial resources has led to pressure on institutions to use scarce resources more efficiently and effectively. There is a strong drive by policymakers to provide incentives for efficient resource allocation, ensure quality standards of all tertiary education provisions, promote research excellence and develop alternative sources of funding. The need for tertiary education reforms is a priority for government in the future. In order to address the current issues and key challenges, the development and implementation of a funding mechanism based on performance could be the means by which government can achieve its ambitious goals. Experiences from OECD countries can be used to explore the applicability of the models to Mauritius and the SIDS. 


\section{CHAPTER FOUR: HISTORICAL AND CURRENT FUNDING MECHANISMS}

\subsection{Introduction}

This chapter examines the funding mechanisms for tertiary education institutions (TEls) from the $19^{\text {th }}$ century up until the end of the $20^{\text {th }}$ century and the problems earlier funding systems have presented for tertiary institutions. It is not the intent of this chapter to provide a full account of all the funding mechanisms or budgeting systems, but to focus on those most commonly used in various states.

"Budgeting is an annual event but it is an event that contributes to the realisation of a strategy or goals that have a longer-term operation than one year" (McGee, 2007, p. 26). Budgeting in most countries was characterised by weak executive power and little central control prior to the late $19^{\text {th }}$ century (World Bank, 1998). Budget reformers of the late $19^{\text {th }}$ and early $20^{\text {th }}$ century advocated funding mechanisms that would promote accountability for the detailed use of resources (World Bank, 1998). There is a body of literature that has addressed the budgeting process in North American university systems but the literature is scarcer for the developing world. In most parts of the world, tertiary education is at least partly publicly funded. Governments use a number of different approaches to help TEls pay for their expenses related to teaching, research, and the maintenance of infrastructure.

According to Ziderman and Douglas (1992, 1995, p. 115), "the mechanisms through which governments transfer funds to higher education institutions have an important effect on the way in which these funds are used". Countries have traditionally used a mix of allocation mechanisms to fund TEls. Only a few studies have examined the allocation mechanisms and these studies have focused mainly on the allocations mechanisms of developed countries. ${ }^{6}$ These include negotiated funding by line-item, or block grants and input-based funding systems, such as program budgeting, zero-based budgeting, incremental budgeting, and formula budgeting.

${ }^{6}$ The United Kingdom and the Netherlands have both made allocation mechanisms a central part of higher education reform over the last decade. See Barnes and Barr 1988; Shattock and Rigby 1983 and; Hansen and Van Vught 1989. 


\subsection{Negotiated Funding}

Negotiation between tertiary education providers and the government, or other appropriate funding bodies, is the traditional way in which funds have been allocated to individual institutions (Salmi and Hauptman, 2006). The fundamental characteristic of negotiated budgets is that there is little relationship between the level of funding and the activities carried out by institutions. As a result, a key factor in allocating the funds is the political skill of the negotiators. Negotiated funding remains pervasive in the developing world (Ziderman and Douglas, 1995) and is mainly based on historical financial data. By and large funding is distributed to institutions in one of the two ways: line-item budgeting or block grants (Salmi and Hauptman, 2006; World Bank, 1998).

\subsubsection{Line-Item Budgeting}

With line-item budgeting, institutions require government approval for each expenditure item, based on expenditure norms. TEls usually include cost parameters such as student-teacher ratios, administrative staff-student ratios and space allocations to assess their line-item funding requests (Ziderman and Douglas, 1992, 1995). Expenditures for the next year are listed according to line items, indicating how much money a particular institution will be permitted for staff costs, equipment and other overheads. Under this mechanism, governments focus most on specifying the line-item ceilings so as to ensure that institutions do not spend in excess of their budget allocations (World Bank, 1998). Line-item budgets may be very detailed.

Weiler (2000) states that line-item budgets, which may specify in advance detailed institutional purposes such as purchase of computers, are a key way to control an institution through the specification of inputs.

\subsubsection{Block Grants}

Another way that negotiated budgets have been implemented is by giving a single block grant to each TEI. Fixed revenue agreements are adopted in many countries with less-developed higher education systems and only one university. Some governments reach agreements with institutions to allocate a fixed percentage of the total government revenue or expenditure to them. 
Central American and Andean nations, for example, specify that public universities should receive $5 \%$ to $7 \%$ of the national budget every year (Salmi and Hauptman, 2006). In Honduras, for instance, the government allocates $6 \%$ of total expenditures to the National University. Other states employ different measures for funding tertiary education. Thus, in Costa Rica, the allocation for tertiary education is determined as a percentage of GDP, whereas in Jordan, the universities are funded on the basis of a fixed percentage of revenue generated from a stamp tax (World Bank, 1998).

\subsection{Strengths and Weaknesses of Negotiated funding}

These funding models, namely line-item budgeting and block grants have been developed to give TEls more autonomy and flexibility. The strengths of such funding mechanisms are their relative simplicity, lack of ambiguity, and potential for control of expenditures through easy comparison with prior years (World Bank, 1998). Although their use is widespread in various developing countries, such funding methods have their limitations and do pose some problems for TEls. One of these is that line-item budgets give no information about why money has been spent or on the efficiency and effectiveness of programs (World Bank, 1998). Another problem is that the extent to which TEls can switch or reallocate between budget headings is controlled centrally (Salmi and Hauptman, 2006). According to the World Bank (1998), line-item systems have been associated with a short time horizon, leading to failure to take longer-term costs into account.

Additionally, detailed line-item control has tended to lead to micromanagement of agency budget implementation by central budget offices (World Bank, 1998).

Ziderman and Douglas $(1992,1995)$ note that negotiated funding has not been an effective mechanism for allocating tertiary education resources. With negotiated funding, there is no system put in place to ensure that the courses which universities and other tertiary institutions offer meet local labour market requirements.

Subsequent budget reforms have attempted to remedy these deficiencies by focusing on management through input-based funding systems. These include performance budgeting, program budgeting, zero-based budgeting, incremental budgeting and formula budgeting and funding formula. 


\subsection{Input-Based Funding Systems}

According to Ziderman and Douglas (1992, 1995), in most industrial countries and some developing countries in Asia and Africa, funding is allocated on the basis of estimates of costs for educational inputs. Input-based funding establishes a relationship between costs and efficiency. The general approach starts with enrolment data and applies cost multipliers. Cost settings take into account student-teacher ratios, space allocation, and various other services such as libraries, laboratories, and accommodation. The implications of various inputbased funding systems are discussed below. But first, the differences between efficiency and effectiveness are explained, as these concepts are key criteria for assessing funding mechanisms.

In economics, efficiency is sometimes referred to as cost or non-allocative efficiency or technical efficiency. Technical efficiency is attained when outputs make the best use of a given set of inputs or, from a financial perspective, when the cost of production per unit is minimised (Leathers, 1979). Technical efficiency is closely linked to the term productivity where the latter is basically the ratio of units of outputs to units of inputs. Thus, if output per unit of input is maximised, technical efficiency is achieved and productivity is maximised.

Moreover, a political scientist affirms that efficiency refers to the conversion of inputs into outputs with the least amount of organisational effort in terms of processing cost. In contrast, effectiveness refers to the ability to convert inputs into desired outputs (Leathers, 1979). Another definition of the two concepts introduces an element of conflict between efficiency and effectiveness in policymaking. In this definition, "efficiency is the elimination of waste without any consideration given to priorities and/or relative worth of the activities or programs. Effectiveness is consideration of relative worth and priorities" (Leathers, 1979, p. 66).

Cowan (1985) states that the theories of efficiency and effectiveness are regularly discussed as if they were synonymous: "Efficiency is the ratio of output to input; effectiveness is the ratio of the actual outcome to the possible or ideal outcome" (Cowan, 1985, p. 236). For instance, the efficiency of $80 \%$ signifies that only $20 \%$ of the input has not been used productively whereas effectiveness of $40 \%$ indicates that $60 \%$ of the potential has not been realised. 
Hoenack (1982, p. 403) defines efficiency as "the achievement of maximum total benefits to society from the resources employed in higher education, such as faculty, staff and student time, equipment, and physical facilities". According to Sadlak (1978), UNESCO affirms that efficiency may be assessed at two levels: external efficiency is related to the success of the educational system in meeting the cultural, social and economic objectives, whereas internal efficiency of a tertiary education institution is a measure of its success in meeting operational targets with the resources made available to it.

Further, an OECD study on the development of education in Argentina states that internal efficiency refers to what happens inside the educational system; it is concerned with the optimal use of teachers and buildings, with dropout rates and with what might be called the "productivity" of the education system. By contrast, effectiveness means the relation between the expected or achieved result: the sacrifices involved therein viewed against an overall goal.

Measuring efficiency in higher education is of increasing importance because of changes in socio-economic conditions and most notably the rising enrolment rate and financial constraints (Sadlak, 1978). Effectiveness has, as a result, been of secondary concern.

\subsubsection{Performance Budgeting}

Performance budgeting is an input-based system and is defined as a "vehicle for directing the work of agencies in order to fulfil government's service delivery responsibilities" (Friedman, 1979). It was designed to allow managers to develop institutional measures of workload and unit cost and focuses on the processes of work (such as organisation and structure). The budget can then be built on the basis of anticipated workload.

The emphasis is on gauging the workload of an agency instead of making government-wide budgetary trade-offs. While managers have more control, governments have not favoured such a mechanism. Although it emphasises the integration of activity information and budgeting, it is not often accepted as a government-wide budgetary process (World Bank, 1998). 
The major weakness with performance budgeting is that efficiency, "an important goal in budgeting", is an inadequate criterion for allocation because it is difficult to measure (World Bank, 1998, p. 12). With some difficulty, the goals of TEls can usually be defined, but measuring the institution's effective and efficient achievement of these goals is another matter. Therefore, a method of budgeting that would also take into account the effectiveness of expenditures is needed. Another weakness is that performance budgeting diverts attention from policy outcomes, which require a perspective beyond the annual budget (World Bank, 1998). These considerations have led to program budgeting.

\subsubsection{Program Budgeting Systems}

Program budgeting is most closely associated with the efforts to introduce a planning-programming-budgeting system. The Planning and Program Budgeting System (PPBS) is an integrated and comprehensive system. It was designed for long-range planning and budgeting, and was developed to cover multi-year periods (Temple and Riggs, 1978). During the 1960s, many US state higher education systems replaced line-item budgeting with planning program budgeting systems (Ziderman and Douglas, 1992, 1995).

Contrary to performance budgeting, program budgeting is explicitly a resource allocation system but not a management system (World Bank, 1998). The key to program budgeting is the program - a public policy objective also identifying the steps necessary to achieve it. It attempts to link program costs with the results of public programs (World Bank, 1998). It implies monitoring program achievement as well as controlling expenditures. It measures the performance of a program in terms of its outputs and outcomes and introduces a degree of competition designed to attain greater effectiveness (Temple and Riggs, 1978).

Program budgeting is the primary budget reform that has been exported to developing countries, but it has not been conspicuously successful in either developed or developing countries (World Bank, 1998). Indeed, there are people who believe that program budgeting is so flawed in concept that it is inapplicable in any setting. This is because the prerequisites that would be necessary for its success in developing countries are not currently present. 
For instance, Sri Lanka engaged in budget reform in 1969, which ultimately led to the widespread adoption of a system closely parallel to program budgeting. By 1974 , the entire government was presenting the budget in a program-budget format. However, program budgeting was unsuccessful in Sri Lanka because there was a lack of skilled workforce to carry out the necessary analyses (World Bank, 1998). With program budgeting, it is impossible to compare programs on the basis of effectiveness since there is no common index for measuring the worth or value of public programs. The most important problems are the lack of consistent political commitment to allow the system to be fully implemented and stability in developing countries to enable longer-term budgetary forecasts (World Bank, 1998). Commitment and stability are crucial factors in implementing program budgeting fully.

\subsubsection{Zero-Base Budgeting}

Another budgetary system was developed to overcome the shortcomings of Program Planning Budgeting Systems. In 1961 the United States Department of Agriculture began an experiment in budgeting which was called zero-base budgeting (ZBB). Georgia was the first state to establish ZBB, spurred by then Governor of Georgia, Jimmy Carter's enthusiasm (Boyd, 1982; Lauth, 1978). ZBB involves management at all organisational levels, concentrates on priorities, and tries to make the best use of available resources (Boyd, 1982). This technique assumes nothing about prior budgets. Budget decisions are made by starting from zero each year to build a new budget. The main advantage of ZBB is that it could improve both the quality and quantity of information available to managers about agency operations.

However, a key problem associated with ZBB is that increases or decreases called for in the ZBB approach cannot always be achieved easily and sometimes not at all. This arises because institutions cannot change their costs easily. It is extremely difficult to relocate or reduce personnel in a short period of time. This system does not guarantee the academic excellence of the university. When quality and excellence are important considerations, quantitative factors alone will not always suffice (Boyd, 1982). 
Moreover, Lauth (1978, p. 421) notes that zero-based is a myth: "budget makers in Georgia rely heavily on past experience. Even in ZBB the base is the historic base, not zero base". Unfortunately, the theory has failed to achieve the expectations that accompanied its implementation and this gave rise to yet another approach for the funding requirements of public higher education.

\subsubsection{Incremental Budgeting}

Incremental models have been applied to budgeting in the United States federal government, in central and local budgeting in other countries, and in international organisations. Layzell and Caruthers (1995, p. 2) state that "the traditional and dominant form of governmental budgeting is the incremental budget". It has been relatively common in Latin America, South Asia and Africa (Ziderman and Douglas, 1992). In the budgeting process the current budget base provides the starting point and annual changes result from increasing or decreasing appropriate items as resource needs and other considerations dictate (Temple and Riggs, 1978; Tucker, 1982). The common practice in developing countries is for organisations to receive a flat percentage increment on their previous budget, in other words, institutions receive the same funding as in the previous year, plus a certain increase based on their requests, and funds available, and adjustments for inflation.

The main criticism of incremental budgeting is that, because the focus tends to be on a percentage increase, the majority of the budget is not reviewed during the budget process, and the increment may be vulnerable to political whim. The validity of the incremental approach has been questioned by institutions, as the method tends to ignore changes in program and institutional emphasis and actual costs or needs. Under this system expenditure patterns become rigid and fixed and internal expenditures do not relate effectively to long-range plans or performance (Temple and Riggs, 1978).

According to Tucker (1982) the points of disagreement between proponents and critics of incremental budgeting models have been numerous, complex and often quite technical. Among the problems, Cermáková et al. (1994) identified ineffectiveness and lack of transparency and flexibility. 
This scheme can lead to waste of resources because institutions try to use up the current year's budget, thus providing grounds for receiving the largest possible amount of funding for the following year. Within the whole system, there are no incentives for better performance of tertiary education institutions.

With many influences and subjective decisions, the whole budget lacks transparency. As a budget is based on the previous year's position, it can not respond to developments both inside and outside the institution (labour market conditions, the changing needs of the economy, the changing pattern and level of student demand etc). The incremental budgeting scheme is unable to reflect major differences caused by changes in the number of students. It further encourages tertiary education providers to operate inefficiently.

\subsubsection{Formula Budgeting and Funding Formula}

For many, the main challenge for funding in higher education is to create and implement a financial system that will enhance the viability and effectiveness of scholars and students, rather than focusing excessively on the relationships between activities and costs. Formula budgeting was devised to address this need. Formula budgeting was largely adopted in the United States in the sixties during a period of rapidly increasing enrolments for tertiary education. Its use intensified during the seventies, particularly in the Southern and Midwestern states where funds were limited and competition for these funds was vigorous (Moss and Gaither, 1976). The use of formula budgeting in systems of higher education became widespread, and appears to be increasing (Turner, 1994).

The first significant work, "State Budgeting for Higher Education: The Use of Formulas and Cost Analysis" was produced by James Miller at the University of Michigan in the early 1960 s.

Miller (1964, p. 6) defines formula budgeting as:

....an objective procedure for estimating the future budgetary requirements of a college or university through the manipulation of objective (quantitative ) data about future programs, and relationships between programs and costs, in such a way as to derive an estimate of future costs. 
According to Rourke and Brooks (1966), a budget formula is a set of program cost relationships used to forecast future budgetary requirements for HEls. The principal reasons for the development and implementation of modern budget formulas can be generally classified as: (i) political complexities; (ii) inadequate revenues; and (iii) increased demands for accountability (Moss and Gaither, 1976). The problems of distributing available resources equitably and the increased public demand for demonstrating efficiency and effectiveness also play important roles in the choice of formula funding methods. In higher education funding, formulas are based on the concept of forecasting future requirements by multiplying estimated FTE (students) or credit hours and estimated unit costs (rates).

According to Moss and Gaither (1976), formulas can be classified according to the following three basic computational methods:

(i) The rate-per-base-factor-unit method starts with an estimate of a given base factor, such as credit hours or FTE enrolment. The estimated base factor is subsequently multiplied by a specific unit rate established through cost studies of previous periods. The end result of this computation becomes the forecasted future budgeting requirements for the particular operating unit.

(ii) The base-factor-position-ratio works with salary rates and ratios (faculty salary/student, faculty salary/support staff salary) to determine the justified employee numbers which are multiplied by given salary rates to estimate the resource requirements.

An example would be to divide the FTE enrolment by a faculty/student ratio of 30 to obtain the number of FTE faculty positions justified at each salary level, and then multiply the ratio by the salary rate for that level to get the total faculty salaries.

(iii) The percentage-of-base-factor method assumes a relationship between an established base factor, such as total faculty salaries, and certain other factors. In such circumstances, the budget required for student services, for instance, may be determined to be a percentage of the total budget for faculty salaries (Moss and Gaither, 1976). 
Formulas may differentiate among academic disciplines (engineering, science, business and education), levels of enrolment (graduate and postgraduate), and types of institutions. Differentiation is used to recognise the valid differences in certain costs of operation.

In sum, there are two basic approaches used in the application of budget formulas: the all-inclusive approach, where the total entitlement or allocation for the program is determined by one calculation; and the itemised approach, where two or more separate calculations are used to arrive at the total budget of a particular area (Mckeown Mary P, 1996).

\subsection{Problems with Input-Based Funding Systems}

According to Ziderman and Douglas $(1992,1995)$, one of the main problems with an input funding system is how it relates to access policy. The government's commitment is theoretically open ended if there are no fixed limits on enrolments to the system. The government has a choice either to increase the overall budget or to reduce its payment per student. The latter has been used very often as governments face budget constraints. Some countries have responded to this problem by setting a price which the government will pay per student, but for a fixed number of students only. Above this number other students are admitted on a full fee-paying basis.

Another problem that has been encountered is that most input funding mechanisms fail to provide efficiency incentives. While input funding largely compensates institutions for costs incurred for salaries and physical needs, it does not readily establish cost norms per output, nor does it provide incentives for institutions to lower their costs.

The study by Kaiser, Vossensteyn and Koelman (2001), affirms that input-based funding contains few incentives for an efficient operation of higher education. As resources are provided at average rather than marginal cost, funding formulas may give universities an incentive to expand inefficiently but that has not actually happened. As a result of this problem, in the 1980s in many countries efficiency became the leading principle in discussions regarding funding. The main goal of changes became to increase the efficiency of the system. 
Further, input funding systems promote excessive homogeneity among institutions. The use of indicators presumes a standard for institutions on which they should converge. In fact, most input funding techniques actually provide disincentives to diversifying activities and sources of funding. This is because many funding formulas either deduct or limit the amount of external funds institutions may generate, particularly through fees. They are also prevented from competing on the basis of price and quality because of a lack of fee differentiation. Governments in some developing countries must be careful in the choice of the indicators they use to create a funding mechanism because of the inaccuracy of reported statistics. In Ecuador, for example, institutions have been identified as making false claims while in Mexico institutions have been said to include as many people as possible in their enrolment counts in order to maximise their funding (Ziderman and Douglas, 1992). Since governments often lack the capacity to verify enrolment numbers they are unable to determine whether these are simply shadow enrolments. Lack of accurate information to verify actual enrolment undermines the funding mechanisms. In some countries, the lack of reliable institutional information limits the possibility of using such funding techniques.

The concerns with input-based funding systems have occurred as a result of experience that they fail to encourage efficiency and also prevent the process of institutional differentiation that becomes critical as tertiary education systems grow in size. Differentiation is desirable to the extent that each university has a clear strategic view of its strengths and its overall positioning in the system.

\subsection{Strengths and Weaknesses of Formula Budgeting and Funding}

\section{Formulas}

A number of reviews ${ }^{7}$ have commented that formula budgeting or funding formulas have a long history of use. Although the focus of this chapter is on the problems associated with various mechanisms, it is also important to summarise the strengths of formula funding because it has operated for more than 50 years. The following strengths are seen as the main reasons for the widespread use of formula funding:

\footnotetext{
${ }^{7}$ Cross and Valley, 1974; Layzell and Mckeown, 1992; McKeown-Moak Mary, 1999; Mckeown
} Mary P, 1996; Miller, 1964; Moss and Gaither, 1976; Rourke and Brooks, 1966 
- Formulas provide an objective approach to determine institutional needs equitably. The equitable distribution of funds minimises institutional conflicts between state officials and institutions.

- Formulas reduce political competition and lobbying by tertiary institutions.

- Formulas provide government officials with a reasonably simple and understandable basis for measuring expenditure and revenue requirements of tertiary institutions and determining the adequacy of support.

- Formulas provide a balance between state control over each item in a budget and total institutional autonomy in fiscal matters.

- Formulas provide uniformity and ease budget preparation and presentation

- Formulas provide a cost productivity measure for comparison between institutions and between activities within institutions.

- Formulas reduce the tension and bickering among TEls.

Despite these strengths, formula budgeting for tertiary education in its current form is being increasingly questioned as an acceptable mechanism for allocating government resources. Experts agree that there is "no perfect formula" (Mckeown Mary P, 1996, p. 1).

Some of the weaknesses of formula funding faced by TEls are discussed in the literature (Mckeown Mary P, 1996; Moss and Gaither, 1976). The main weakness identified is the linear approach to funding. Formulas were developed and implemented during the 1950 s and 1960s when tertiary education was experiencing a massive enrolment increase. "Most formulas were based on mathematical relationships such as, one teacher per twenty students or one administrator per ten teachers" (Moss and Gaither, 1976, pp. 555-556). The linear nature of formulas may not account for rapid shifts in enrolments and costs. Such practices fail to recognise economies of scale. The greater the level of production (up to a certain point), the lower the unit costs will be. 
Formulas are considered to be enrolment-driven, since they are based on credit hours, students or faculty members. In formula budgeting, resources follow students to institutions. During periods when enrolments are steady or in decline, funding for HEls is reduced because formulas generate proportionately fewer funds and, as a result, unit costs probably increase, but not in every case. A decrease in numbers of students means resource reductions, both from government grants and from tuition fees. But there are major obligations that are not reduced when enrolments decrease. This aspect of formulas has raised concern in many TEls. It may influence institutions to limit new programs development, to eliminate existing programs or to reduce costs by decreasing personnel and other overheads (Mckeown Mary P, 1996; Moss and Gaither, 1976), even if such choices are not in their best interests.

There is a growing concern that formulas may be used to reduce all academic programs to a common level by funding each one on the same basis. This is because quantitative measures cannot assess the quality of a program.

Furthermore, formulas may perpetuate inequities in funding that existed before their adoption since they often start with historical data. Further, formulas are only as accurate as the data on which they are based.

Finally, another weakness of formula funding is the "leveling effect" it has upon the quality of major state institutions and programs (Moss and Gaither, 1976, p. 555). Under formula funding the average expenditure rates apply to all TEls. In order to reach the average rate, cost studies are conducted, generally by program and level, within each institution involved. The unit costs for all institutions are then averaged to arrive at the rates to be used for all institutions, regardless of the institutional size, differences in program costs, and complexity. The resulting average rates will be higher than the actual unit costs for some institutions and lower for others; some institutions will benefit from these rates while others will be at a disadvantage. But much depends on the complexity of the formula and the accuracy of the costings. Therefore, the result is a levelling of quality along with funds. 
In addition, according to Cermáková et al. (1994) there are other weaknesses which have been raised by TEls. For instance, the key rule of formula funding has been criticised for using the number of students as a criterion for outputs. There have been suggestions of alternative solutions such as measuring the outputs by the number of degrees awarded. Moreover, resources allocated through formula funding may not fully correspond to financial requirements and the volume and quality of research activities.

Although formula funding has been widely used as an input-based funding system, the concerns and problems associated with negotiated and input-based funding, and the 1980s and 1990s developments in tertiary education systems, have led governments in various jurisdictions to review the funding mechanisms they employ. In this era of change, government, policy makers and the public at large are more insistent on TEls being more effective and efficient. Thus, to complement or replace other funding mechanisms, such as negotiated and input- based funding, PBF emerged as a budgetary method so as to enhance efficiency, promote quality and increase greater accountability.

\subsection{Performance-Based Funding (PBF)}

More recently, the goal has shifted in many OECD countries from accounting for expenditures to accounting for results. The shift gained momentum from the movements to re-engineer business and re-invent government ${ }^{8}$. There is no universally accepted definition of PBF. However, the following definitions describe the key ideas surrounding the PBF concepts.

According to Burke and Minassians (2001, p. 4), PBF in the tertiary education sector is defined as follows:

\footnotetext{
Performance funding ties specified state funding directly and tightly to the performance of public college and university on individual indicators. Performance funding focuses on the distribution phase of the budget process.
}

Serban (2000, p. 3) claims that PBF is embodied in six critical components: "purpose, performance indicators, success criteria, indicator weights, allocation methods, and funding levels".

\footnotetext{
${ }^{8}$ Hammer, Michael \& Champy (1993) Reengineering the Corporation - A Manifesto for Business Revolution. New York: Harper Press and Osborne, D \& Gaebler, T. (1992) How the Entrepreneurial Spirit is Transforming the Public Sector, Reading: Addison-Wesley Publishing Company
} 
Salmi and Hauptman (2006, p. 16) state that "performance-based allocation mechanisms differ from most other allocation approaches in that they tend to use performance indicators that reflect public policy objectives rather than institutional needs. They include incentives for institutional improvement".

Performance indicators are standardised, numerical ways of measuring inputs, activities, outputs or outcomes.

\subsection{Underlying Principle of PBF Systems}

Researchers agree that the major policy concerns in tertiary education in recent years have been ensuring equitable access to lifelong learning, promoting educational quality, improving efficiency, and enhancing greater accountability (Boaden and Cilliers, 2001; Boston, 2006; Burke and Modarressi, 2000; Evans and Quigley, 2006; Guena and Martin, 2003; Serban, 1998). PBF emerged as a budgetary method for complementing or replacing other funding mechanisms so as to promote and respond to these policy concerns more effectively. A further key argument that has been used in favour of PBF is the increased differentiation within the tertiary education sector (Gerristen, 2008).

\section{(i) Promote excellence}

PBF seeks to strengthen initiatives that serve to promote excellence in teaching, learning and research. The rewards for research activities at national and international excellence levels establish strong incentives for TEOs to concentrate their research around areas of excellence. For instance, in New Zealand, the Centres of Research Excellence initiative was a parallel development to the PBRF. High-quality research cultures underpin and enhance the teaching and learning environments, particularly at the post-graduate level.

Under PBF systems, qualitative and quantitative performance indicators are used to measure the research or teaching quality of tertiary institutions. Indicators include the assessment of research quality by external peer review panels, and evaluation of teaching activities by independent bodies, and the system of external examiners. Improving and measuring performance and access to high-quality information enhance the ability of potential students to make decisions about appropriate courses of study. 
This available information on TEls' performance further assists learners to enrol in programmes compatible with their abilities and desires.

(ii) Improve efficiency

Improving the efficiency and effectiveness of public institutions was a central objective of the reforms for developed countries (e.g. Australia, Denmark, Sweden, New Zealand, and the United Kingdom) from mid-1980s to 1990s. An institution's efficiency is measured by the relationship between inputs and outputs, while its effectiveness is measured by the extent to which it accomplishes its objectives. The rationale for PBF systems is mainly to improve technical efficiency. The link between funding and performance is intended to promote efficiency by encouraging institutions to reduce costs and eliminate low priority expenditures (Orr, 2003). Institutions are motivated to deliver outputs specified by the funding agency, since they lose income when they fail to do so. Introducing output criteria, such as the number of graduates and the number of study-credits obtained, has been noted as a way to increase the incentives for efficient production (Canton and van der Meer, 2001).

Moreover, the allocation of research funds between research units (universities, departments, research groups) on the basis of performance, strengthens the incentive to provide research effort thereby raising researchers' productivity and eventually their aggregate research output (Koelman and Venniker, 2001).

\section{(iii) Enhance greater accountability}

PBF has been viewed by many scholars as an 'accountability mechanism' or 'managerial accountability' (Banta, Rudolph, Dyke, and Fisher, 1996; Burke and Minassians, 2003; Codd, 2005; Layzell and Caruthers, 1995; Peters, 1992). The goal of accountability changed dramatically in the mid-1980s in American states and moved from accounting for expenditures to demonstrating performance (Burke and Modarressi, 2000). In order to hold universities accountable for producing measurable results in teaching, research and public service, many American states presently support performance-based accountability measures (Serban, 2000). 
Thus, a performance-based mechanism provides a transparent means of reporting on performance outcomes to the public at large, and rewarding TEls that demonstrate success and continued improvement in key areas related to quality and efficiency, student achievement, and excellence.

\section{(iv) Increase differentiation within the tertiary education sector}

A key issue for universities is differentiation, particularly in terms of quality and by subject area. PBF has been considered as a means of enhancing differentiation at both the institutional and sectoral levels within the tertiary education sector (Gerristen, 2008). Ranking the performance of TEls enables the government to have a clear indication of which subject areas to invest in to meet the long term strategic objectives of the country. Maintaining differentiation of the various types of tertiary education providers is in the interests of greater specialisation and better overall performance for government's investment.

\subsection{Summary}

Negotiated and input-based funding systems for higher education have a long history. From the 1950s and up to the early 1980s these funding mechanisms have been used in most public systems of higher education in American states, and in both developed and developing countries. The major failures which have been identified in the literature about negotiated funding (line-item budgeting and block grants) are: (i) a lack of incentives for efficiency; (ii) uncertainties regarding future funding; and (iii) no incentives for tertiary providers to seek external funding. To remedy these shortcomings input-based funding systems were introduced. Among the various input-based funding systems which have been discussed in section 4.3, program budgeting is the major mechanism which has been adapted to developing countries. But unfortunately, it fails in both the developed and developing countries mainly because of its inapplicability in all settings, and the lack of skilled and trained manpower to implement it.

At the beginning of the 1960s the concept of zero-base budgeting emerged. Although it has improved both the quality and quantity of information available for managers, it ultimately fails because its base is not actually zero but relies on historic data. 
An alternative approach to this budgeting system is incremental budgeting. However, this latter system also has some weaknesses. It is easily influenced by political factors and lacks transparency.

Additionally, formula budgeting, which has been in use for more than 50 years, has also been seen as having a number of disadvantages. It has been criticised for being too student-numbers driven and because it creates inequities in funding. Many jurisdictions have introduced far-reaching reforms in the structure and operation of government agencies. Tertiary institutions are not exempt from these developments. The new forms of management and culture in the public sector have been a useful tool in the drive to increase efficiency of public expenditures and accountability and as a result, PBF materialised as a new mechanism in many developed democracies. 


\section{CHAPTER FIVE: REVIEW OF PERFORMANCE BASED FUNDING MODELS}

\subsection{Introduction}

This chapter reviews the different PBF models for research and teaching adopted in various jurisdictions for determining their desirability and applicability to SIDS. The first part of the chapter provides a background to the developments of PBF mechanisms in the countries under review and introduces a programme outcome model for tertiary education. It then outlines the PBF models for research in the UK, Australia, and NZ and the justification for choosing these countries. Thus, it highlights the higher education systems and reforms that took place and funding mechanisms in these jurisdictions. The chapter presents a detailed description of the models that are currently being used in the UK (RAE), Australia (IGS and Research Training Scheme) and NZ (Performance-Based Research Fund (PBRF)) and evaluates the different models. Further, it critically examines the strengths and weaknesses emerging from the evaluation of the PBF models for research. Finally, the first part summarises significant changes for the RAE 2008, the development of the new Excellence in Research for Australia (ERA) scheme, the similarities and differences between the UK RAE and the NZ PBRF, and the key modifications to the PBRF round in 2006.

The second part of the chapter deals with PBF models for teaching in Denmark and Sweden. It covers similar aspects as the PBF models for research and enumerates the key features of the Danish taximeter model and the Swedish FTE study results. Subsequently, this part highlights the significant differences between the Danish and Swedish teaching funding models. Lastly, it assesses both systems identifying their strengths and weaknesses.

\subsection{Background to the Developments of PBF Mechanisms}

Changes in the political and ideological context were powerful factors for reforms in some Western countries. For instance, the New Right ideas found favour in the Conservative government that came to power in the United Kingdom in 1979, and in the three subsequent Conservative governments. 
In analysing the United States case, Reagan's election in 1980 provided some impetus for market-oriented reforms in the public sector, which was already under pressure to reform. Similar changes in the political context took place in Australia and New Zealand, which both brought in pro-reform governments. However, in the case of New Zealand, it was a Labour government that embraced new management reforms in response to the fiscal pressures on the state to cut back expenditure and for public services to be more efficient.

The ideas that were behind the development of PBF mechanisms in the countries under examination were derived to some extent from an approach called New Public Management (NPM). The key components of NPM suggest that the ideas and themes may be put in two broad strands. On the one hand are ideas and themes that emphasise managerial improvement and organisational restructuring, i.e. managerialism in the public sector. Decentralising management, disaggregating and downsizing of public services are strands of NPM derived from managerialism. According to Hood (1991), NPM consists of a number of different doctrines. These include emphasis on the introduction of explicit standards and measures of performance, a focus on outputs and results, professional management, private sector styles of management practice, and greater competition in the public sector.

On the other hand, the second strand of NPM derives from the new institutional economics, which has its theoretical foundation in public choice, transaction cost and principal-agent theories. These generated public sector reform themes based on ideas of market competition into the public service, contracting, transparency and emphasis on incentive structures as a way of giving more choice to service users and promoting efficiency in public service delivery.

The structures of government agencies have been examined, revised and changed in various countries, such as Australia, New Zealand, the United Kingdom and the United States. Barzelay and Gallego (2006, p. 544) consider the United Kingdom, Australia and New Zealand as the "NPM benchmark countries and cases of comprehensive public management policy change". New Zealand's public management reforms in particular are largely based on the concepts, principles and practices of 'new public management' and are an example of a NPM theoretical model. The key principles underpinning the new model have influenced New Zealand's policies. 
Among others, the main policies include: (i) a strong emphasis on the use of incentives both at the institutional and individual levels to improve performance; (ii) an extensive use of contracts (e.g. performance agreements between ministers and departments); (iii) institutional separation of commercial and non-commercial functions; (iv) decentralisation; and (v) implementation of financial management systems.

Further, in Sweden, "the NPM principles of management and measurement, and with an emphasis on accountability, which are experienced throughout when university systems change their modus operandi, have been particularly visible in the funding mechanisms" (Sorlin, 2007, p. 420). In Denmark, the Ministry of Finance's most effective tools were budgetary mechanisms - notably output budgeting and contract steering (Jensen, 1998). Accordingly, Danish education policy reforms have adopted a NPM view and introduced an output-based funding system.

Most of the efforts at governmental restructuring and reinventing have shared similar goals, "to improve the effectiveness and efficiency of the public sector, enhance the responsiveness of public agencies to their clients and customers, reduce public expenditure, and improve managerial accountability" (Boston, Martin, Pallot, and Walsh, 1996, p. 2). Similar policy instruments were chosen in the different countries: commercialisation, corporatisation, and privatisation; the devolution of management responsibilities; a shift from input controls to output and outcome measures; and extensive contracting out.

According to De Boer (2000), 'reinventing government' is described as a shift of paradigm from the state-control model to the state-supervisory model, noted for steering at arm's length and an emphasis on assuring quality and accountability. The focus has changed from administration to a manageralist style and the NPM mantra is "let the managers manage" in Australia and Sweden and "making the managers manage" in New Zealand and the UK (Kettl, 1997, pp. 447-448).

Despite various countries having embarked on public sector reforms since the 1980s, which have been guided to some extent by the doctrines of NPM, it is acknowledged in the literature that NPM has some weaknesses. 
As noted by Boston, et al. (1996, p. 36), among others, "NPM has been criticised for "its constitutional illiteracy, its insensitivity to varying organisational cultures and political constraints, and its potential for reducing the capacity of governments to deal with catastrophes". Further, the authors pointed out that not all the tasks of public management are identical to those in the private sector. Osborne and Gaebler (1992, pp. 21-22) likewise believe that "government cannot be run like a business" due to the basic differences between the two sectors. Business theory is not enough in government.

Thus, the government approach to increased institutional self-regulation is linked with a greater demand for accountability on how resources are being used and the outcomes achieved. The link between the state and tertiary institutions is characterised by the two aspects of control and finance. Accordingly, most of the recent government reforms include principles and mechanisms, such as PBF models for financial allocation and the control of public funds.

\subsection{Programme Outcome Model for Tertiary Education}

One such mechanism is an outcome model which can be adapted to demonstrate the activities which lead to a PBF system. Figure 5.1 illustrates a program outcome model for tertiary education.

The model involves inputs that lead to certain types of activities which achieve immediate program or project objectives (outputs), as well as broader development objectives (outcomes) (Vos, 1996). 
Figure 5.1 Programme Outcome Model for Tertiary Education

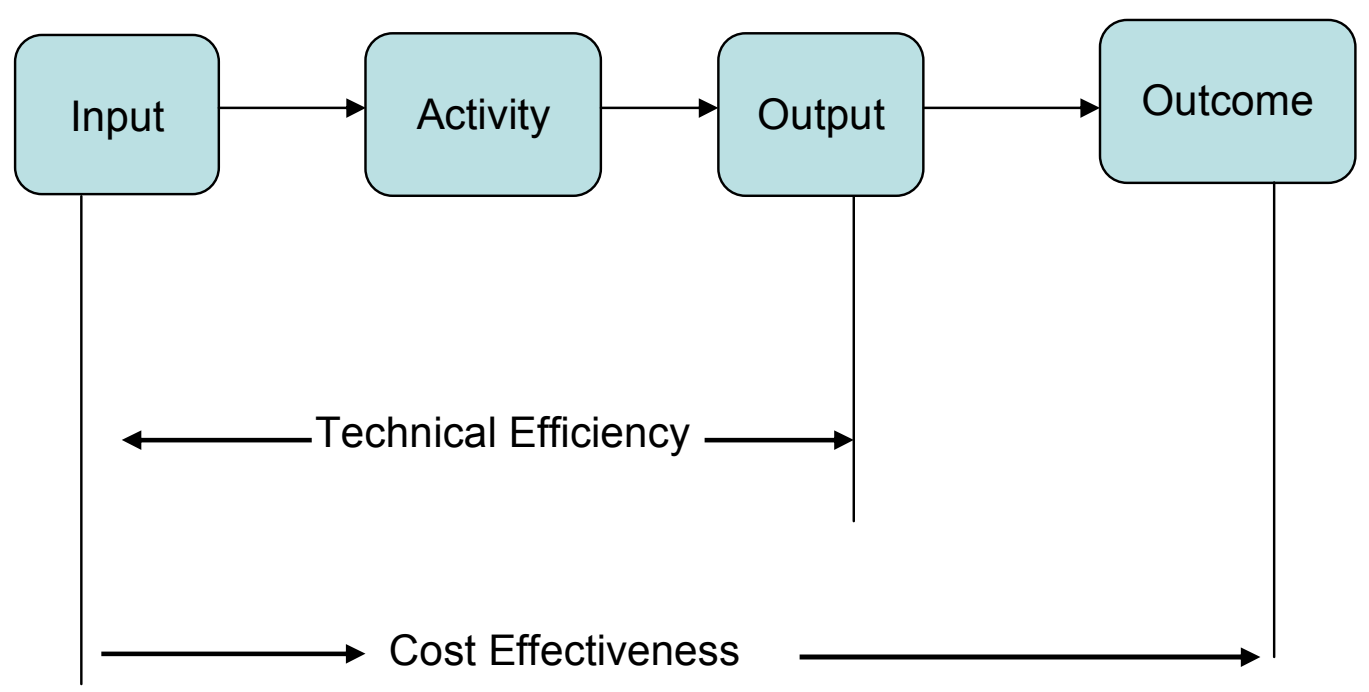

Source Adapted: Cohen, 2006

- Inputs are the resources employed to produce outputs and outcomes. For instance, inputs for tertiary education would include financial and human resources, such as the number of academic staff, buildings, teaching materials, and equipment, or the expenditures incurred to acquire them.

- Activities, or processes, specify how inputs become products or outputs and outcomes (e.g. teaching)

- Outputs are aggregate products of a system and refer to the immediate objective of educational policies, such as improving internal efficiency, raising the skills and expanding the knowledge of graduates.

- Outcomes are the effects of outputs in society, for instance higher labour productivity and enhanced capabilities of individuals in society.

According to Vos (1996, p. 3), "indicators tend to be classified depending on whether they reflect the means, the process, or the end in achieving the objective of a particular set of development policies, programs or projects". 
Input indicators measure the resources allocated to undertake an activity without regard to levels or measures of achievement, such as student/teacher ratios, average cost per student, or unit costs per student.

Output indicators measure to what extent immediate objectives are achieved. For instance, in a university where a PBF mechanism is adopted, the output indicators which are used include the number of credits accumulated by students, degrees awarded, students' completion rates, research publications generated, and doctoral theses completed. Other examples of output indicators are participation or drop out rates at various levels of the education system.

Performance indicators are policy instruments used to measure the level of attainment of an activity or policy. By linking funding with measures of outcomes rather than inputs, PBF focuses on an entirely new perspective.

\subsection{Performance-Based Funding Models for Research}

As part of the efforts for the implementation of the NPM principles, many governments have sought to improve the accountability of public sector institutions, reduce the level of government expenditure and the size of the core public sector, and improve the efficiency and quality of goods and services produced by public agencies. This has led to a number of reforms in various jurisdictions, including higher education reforms.

Over the past few decades, various countries have introduced PBF models in their tertiary education sectors either for research or for teaching activities. The tendency has been towards the greater use of PBF models for research activities. PBF models were primarily introduced for research activities in Australia, Hong Kong, NZ, and the UK whereas Denmark, Sweden and the United States of America employed PBF models for teaching activities.

The UK, Australia and NZ have been selected for this study for two main reasons. First, there is a growing body of literature and empirical evidence on which to assess the strengths and weaknesses of these countries' PBF models. Second, performance-based research funding models which have been adopted by the UK and Australia have tended to be relatively durable (and the NZ model is the most recent one). Until 2008, none had been abolished; instead, there have been continual design changes to improve the models. 


\subsubsection{Higher Education System, Reforms and Funding (United Kingdom,} Australia, New Zealand)

In the UK, universities are diverse and numerous. The older universities were established by Royal Charter or Act of Parliament. With the passing of the Higher Education Act 1992, former polytechnics were given the status of universities and are sometimes called 'new universities' (Higher Education Funding Council for England, 2005). There were 169 Higher Education Institutions (HEIs) in UK as at August 2008, of which 109 are universities, and there are a number of furthereducation colleges which are funded separately (Higher Education Statistics Agency, 2008). In 1994/95 the total number of higher education students (full-time and part-time) at UK HEls was 1,567,313, whereas, in 2006/07, it had increased to approximately 2,362,815 (Higher Education Statistics Agency, 2008).

Among other causes, the expansion of higher education, budget constraints and a demand for greater efficiency and quality have led to a series of reforms in the UK. The Education Reform Act in 1988 eliminated the University Grants Committee which was perceived as a mediating institution between central government control and institutional autonomy. With the election of 'New Labour' in 1997, further reform came following the 1997 Dearing Report. The report argued for the introduction of tuition fees at all HEls in England. The tuition fees - capped at $£ 1,000$ plus inflation - were not applicable to low income students and unfortunately failed to generate significant increases in funding.

Therefore, further reforms were undertaken to improve higher education funding. $A$ White Paper entitled The Future of Higher Education issued in early 2003 by the Department of Education and Skills promised important reforms (Douglass, 2004). The 2004 UK reforms of higher education drew lessons from other countries' experiences, such as Australia and NZ, for tuition fees (Barr, 2004).

The Higher Education Act 2004 aimed to widen access to HEls and help them to remain competitive in the world economy. The 2004 reforms have improved the system of student finance by extending loans to cover tuition fees and living costs. From 2006, the reforms have replaced the upfront flat fee with a variable fee of between zero and $£ 3,000$ per year until at least 2010 . The loan repayments started from 2006; graduates will repay $9 \%$ of earnings above $£ 15,000$ (Barr, 2004; Douglass, 2004; Higher Education Funding Council for England, 2005). 
Grants to cover at least part of the living costs, abolished in 1998, have been reintroduced. Since 2006, students from poor backgrounds entitled to a grant of $£ 2,700$ per year in addition to a loan, and all universities charging fees of $£ 3,000$ expected to provide poor students with bursaries of at least $£ 300$ per year to help with fees. The reform also brought in an Access Regulator, whose tasks are to ensure that institutions have satisfactory provisions which include scholarships. In 1992, the Higher Education Funding Councils (England, Wales, Scotland and Northern Ireland) were established, replacing the Universities Funding Council and the Polytechnics and Colleges Funding Council: "The changes of 1992 created a single system and the establishment of a unified system of higher education, with a unified funding structure separating funding councils for England, Scotland and Wales" (Theisens, 2003, p. 13).

The mission of the higher education funding councils was not only to assume the roles of a buffer organisation, but to promote the quality and quantity of learning and research in HEls and to encourage good management practices and ensure accountability (Higher Education Funding Council for England, 2000). With the exception of the University of Buckingham which is a private institution, all universities are publicly funded institutions.

The expenditure on tertiary education institutions was 1\% of GDP in 2000 and increased to $1.3 \%$ of GDP in 2005, but this is below the OECD average of $1.5 \%$ (Organisation for Economic Co-operation and Development [OECD], 2008). The total recurrent grant available for the $2008 / 09$ academic year is $£ 7,476$ million. This represents an overall increase of 3.3\% compared with the figure for 2007-08. The total includes funding of $£ 4,632$ million for teaching, $£ 1,460$ million for research, $£ 120$ million for business and community engagement, £902 million for earmarked capital grants, $£ 337$ million for special funding, and $£ 25$ million for vulnerable science subjects (Higher Education Funding Council for England, 2008a).

The Higher Education Funding Council for England (HEFCE) funds are divided between teaching, research and special funding but the performance-based model is applied for research activities only. The public funding is provided through the 'dual support system'. 
One stream flows via HEFCE to support the research activities in HEls (academics' salaries and costs of research infrastructure). The other stream flows via the eight Research Councils to provide funding for specific research projects (Higher Education Funding Council for England, 2006): "Most HEFCE research funds are distributed selectively to HEls that have demonstrated their strength in research by reference to national and international standards" (Theisens, 2003, p. 33). This quality is measured in a periodic RAE.

The Australian higher education system plays an important role in developing knowledge and is making a fundamental contribution to social, cultural and economic development (Department of Education Science and Training [Australia], 2007).

The Higher Education Support Act 2003 is the legislative framework for Australian Government funding of higher education. The main objects of the Act are:

- to support a higher education system that is characterised by quality, diversity and equity of access and contribute to the development of cultural and intellectual life in Australia;

- to encourage the distinctive purposes of universities, which are the education of persons and the creation, advancement and application of knowledge;

- to strengthen Australia's knowledge base and promote Australia's research capabilities to national economic development; and

- to support students undertaking higher education (Department of Education Science and Training [Australia], 2007).

The higher education sector in Australia is made up of universities and other HEls - or higher education providers. A higher education provider is a body that is set up or recognised by or under the law of the Australian Government, State, or Territory. The provider has to be approved by the Australian Government Minister for Education, Science and Training before it can obtain grants or its students can receive assistance from the Australian Government under the HESA. 
In 2007, the Australian higher education system comprised 37 public and two private universities, one approved Australian branch of an overseas university, four other self-accrediting HEls, and more than 150 non-self-accrediting higher education providers (Department of Education Science and Training [Australia], 2007). These providers offer a range of programmes to students, including undergraduate and postgraduate awards and various shorter courses. There were 733,352 domestic students and 250,794 international students undertaking higher education in 2006 (Department of Education Science and Training [Australia], 2007).

Australian Government funding support for higher education is by and large provided through the Commonwealth Grant Scheme and the Higher Education Loan Programme arrangements for financial assistance to students. Further, there is a variety of grants for particular purposes, such as quality, learning and teaching, research and research training programmes. The Australian Commonwealth Grant Scheme was set up in 2003 to replace a system of block grants which were determined largely on a historical basis. The funding reforms were undertaken because of a number of problems which had been identified. These problems include: (i) increased resources would be required in the long term; (ii) a large number of students were not completing their studies (30\% at universities); (iii) there was a substantial duplication in some university activities; and (iv) many institutions were over-enrolling students which affected quality (Mahoney, 2006).

The Commonwealth Grant Scheme and Higher Education Loan Programme arose from these reforms. The reforms were constructed on four key policy principles:

- quality - incentives to promote performance and greater accountability;

- equity - increased number of student places, incentives to improve participation and outcomes for disadvantaged groups;

- $\quad$ sustainability - improved governance and greater pricing flexibility for universities; and

- diversity - PBF for teaching and research, support for restructuring and collaboration for regional institutions (Department of Education Science and Training [Australia], 2007). 
The Australian Government gives loans to domestic students through the Higher Education Loan Programme. In 2006, the government assisted higher education providers in supporting around 630,000 students in meeting the costs of their higher education (student contributions or tuition fees). During 2006-07, 18 additional non-self-accrediting higher education providers were given approval to offer a higher education loan programme to their students, bringing the total number of approved providers to 60 at the end of the period.

In 2006-07, the Australian Government provided A\$ 8.3 billion in funding to the higher education sector. The aim is to reform the sector, promote excellence and specialisation and encourage the emergence of more world-class universities (Department of Education Science and Training [Australia], 2007).

The Australian Government monitors accountability, quality, and financial viability of HEls and the sector through the Institutional Assessment Framework. This is undertaken to ensure that the institutions deliver the outputs for which they are funded, that their outcomes are of a high quality and that they comply with their legal obligations. The appraisal of higher education providers is based on quantitative and qualitative data from universities and external sources. In addition, the Australian Universities Quality Agency conducts audits of the universities on a five-yearly cycle. The audits scrutinise the claims of institutions against their own missions and objectives. The process involves a selfassessment and a site visit. Further, the audit reports are made publicly available. In NZ, tertiary education consists of public TEls, private training establishments, industry training organisations, adult and community education providers, and others. Throughout New Zealand, there are 8 universities, 20 institutes of technology and polytechnics, and 3 wānanga (Ministry of Education [New Zealand], 2007). The wānanga - Māori centres of tertiary learning - were officially recognised as TEls in the last decade. They offer study from foundation education to postgraduate study and research. Māori traditions and customs are an integral part of their programmes.

Tertiary participation grew from $10.6 \%$ of New Zealanders aged 15 and over in 2000 to $14.2 \%$ in 2005. Public tertiary institutions' enrolments increased from 278,001 in 2000 to 420,878 in 2005, a growth of $51.4 \%$ (Cinlar and Dowse, 2008). 
In 2006, all the universities enrolled 166,000 students, institutes of technology and polytechnics had 214,000 students, the colleges had 6,910 students before the latest mergers and wānanga had 48,800 students. The total enrolments represented 228,460 equivalent full-time students (Ministry of Education [New Zealand], 2007).

Like the UK, a number of tertiary education reforms took place in NZ in the last two decades. With regard to tertiary reforms in NZ, the main reviews and reports from the mid 1980s to 2002 are as follows: (i) Labour Government's Tertiary Review, 1987-1988; (ii) the Hawke Working Group Learning for Life, 1988; (iii) National Government's Tertiary Review, 1991; (iv) Todd Task Force, 1994; (v) the Coalition Government's Review, 1997-1998; and (vi) Tertiary Education Advisory Commission, 2000-2001. The tertiary education reforms in NZ can be categorised in four time periods and summarised as follows (McLaughlin, 2003): 
Table 5.1: Tertiary Education Reforms in New Zealand

Before the mid-1980s: An Elite System

- Government subsidised all tertiary education students until late 1980s

- Relatively low participation rates and low student fees

- Universities funded through University Grants Committee

Mid-to-Late-1980s: Moving towards broader participation through more competition

The Labour Government appointed a Working Group on Post Compulsory Education and Training (PCET), chaired by Professor Gary Hawke. The Hawke Report 1988 recommended major changes.

- Increase student tuition fees and allow institution to set fee levels

- Increase participation through increased private contributions

- Treat funding of all public tertiary institutions as similarly as possible

- Base funding of tertiary education institutions on the number of Equivalent Full Time Students (EFTS)

- Help disadvantaged students by paying fees rather than providing loans

- Establish student loan scheme with income-contingent repayment

1990-1999 Reforms: Further move to the competitive market-based model

- Set public funds at $80 \%$ of costs and private contributions $20 \%$ but institutions allowed to set their own fees.

- Introduce student loan to relieve students from increased fees payment and living allowances

- Abolish Labour's tuition fees of $\$ 1300$

- Maintain funding based on EFTS

- Target allowances for needy students under 25 years of age based on parental income

- Restrict government costs and increase private contribution

- Expand Private Training Establishments funding

- Establish Wānanga - Māori centres of tertiary education - as public Institutions

2000 to date: Continued emphasis on competitive market-based model - Deciding how to move to more central steering

- Lower student loan borrowing costs and create tertiary education strategy

- Maintain competitive model but move towards more centrally-steered system based on national needs

- Separate funding of tuition and research and create a new performance-based funding system for research (PBRF)

- Create Tertiary Education Commission as a Crown entity to regulate, fund and monitor the performance of tertiary system

- Use new regulatory instruments, institutional charters and profiles to help steer the system towards the goals of strategy

Source: Adapted from (McLaughlin, 2003) 
The Education (Tertiary Reform) Amendment Act 2002 incorporates the changes to education legislation needed to implement the Government's tertiary education reforms (Ministry of Education [New Zealand], 2006; Ministry of Education and Transitory Tertiary Education Commission [New Zealand], 2002). Prior to the establishment of a Transition Tertiary Education Commission in April 2002, the Tertiary Resourcing Unit of the Ministry of Education was responsible for funding tertiary education providers. The Transition Tertiary Education Commission was established to provide a smooth transition for the Tertiary Education Commission. On 1 January 2003, the TEC was established incorporating Skill New Zealand and the Tertiary Resourcing Division of the Ministry of Education. The key functions of the Commission are giving effect to the Statement of Tertiary Education Priorities, negotiating charters and profiles with tertiary providers, building the capability of tertiary providers and Industry Training Organisations and allocating funds to them (Ministry of Education and Transitory Tertiary Education Commission [New Zealand], 2002). The tertiary education system has an integrated funding framework which is intended to resource and steer the tertiary education system. The framework has three broad elements: (i) funding for teaching and learning of domestic students, through the student component and the Industry Training Fund; (ii) funding for research, through Centres of Research Excellence funding and the PBRF; and (iii) targeted funding, through a Strategic Development Component.

In 1991, the New Zealand's government funding of tertiary education amounted to NZ\$993 million, rising to NZ\$1,181 million in 1999, an increase of 19\%. Between 1999/2000 and 2004/05, government operating expenditure on tertiary education increased from $N Z \$ 1,887$ million to $N Z \$ 2,721$ million, representing a rise of $44 \%$ in nominal terms. However, the real operating expenditure increased by only $27 \%$.

Total government spending on tertiary education, including operational costs and capital expenditure, was NZ\$4.2 billion in 2007 . Total tertiary education expenditure (student loans included) represented $2.7 \%$ of GDP while operating expenditure accounted for $1.9 \%$. The student loan scheme was treated as a capital expense (Ministry of Education [New Zealand], 2007). NZ now devotes $42 \%$ of government funding for tertiary education to financial aid to students against an OECD average of $18 \%$. 
Government funding per university EFTS has fallen from NZ\$10,932 in 1991 to NZ\$ 9,098 in 2006, adjusted for the consumer price index in constant 2006 dollars (Field, 2008).

Having outlined the context of higher education systems in the jurisdictions that have implemented PBF models for research, the following section will now describe and critically evaluate the different models.

\subsubsection{United Kingdom - Peer Review Model}

Regular Research Assessment Exercises (RAEs) were introduced by the UK funding council for higher education, the University Grants Commission, in the mid 1980 s in response to claims by members of the Conservative Government that there was no system of accountability for the large sums of money given to the universities to support research. The government wanted to see its money concentrated on institutions that were centres of research excellence delivering value for money. To meet that desire, the University Grants Commission created the RAE in 1986, putting its own system of evaluation and rewards in place.

In 1992, the Higher Education Funding Councils (HEFC England, Northern Ireland, Scotland and Wales) were established to support the research activities in HEls (Higher Education Funding Council for England, 2006). The four UK higher education funding bodies assess the quality of research for universities and higher education colleges by undertaking RAE (Adams and Smith, 2006; Elkin, 2002). The RAE provides quality ratings of academic units in all subjects in which research is carried out, and these ratings are used to determine funding. The RAE can be described as an 'ex post evaluation' based on 'informed peer review' (Guena and Martin, 2003, p. 281).

The UK Research Assessment Exercise (RAE) system is the most developed version of a performance-based research funding model, with the longest track record (Hare, 2002). The RAE, a peer review model, was introduced in 1986 as a way of selectively funding research according to defined standards. The RAE is conducted every four to seven years by the Higher Education Funding Councils. RAE has been modified continuously since 1986 in response to criticisms and concerns about the conduct of the previous assessment. 
Since the middle of the 1980s the UK has had six series of RAEs - 1986, 1989, 1992, 1996, 2001 and 2008. The latest RAE was completed and results published on 18 December 2008. However, the Government announced in March 2006 its intention to replace the RAE after 2008 with an assessment system based on metrics. Higher Education Funding Council for England (HEFCE) is working to develop the new arrangements - the Research Excellence Framework (REF) - for the assessment and funding of research (Higher Education Funding Council for England, 2008b)

Every publicly funded $\mathrm{HEI}$ in the UK is invited to submit information about their research activity for assessment. All research activities within a $\mathrm{HEI}$ are categorised into so-called 'units of assessment' (UoA) and every department is assigned to a UoA. Each department is required to submit information on research performance to the relevant UoA in a standard format, containing various core data. For the 2001 RAE the data required included:

- Overall staff summary (RAO)

- Research active individuals' details (RA1)

- Research output (RA2) up to four items per individual

- Number of research students (RA3a)

- Research studentships (RA3b)

- External research income (RA4)

- Textual description (RA5), including information about the environment, structure, policies and strategies within which research is undertaken and developed

- General observations and additional information (RA6), including information about indicators of research excellence and peer esteem, which could not be given elsewhere in the submission (Elkin, 2002; HERO, 2001).

\subsubsection{Key features of RAE 2001 and RAE 2008}

The RAE has various purposes. The primary purpose of the RAE is "to produce ratings of research quality which will be used by the higher education funding bodies in determining the main grant for research to the institutions they fund" (McNay, 2003, p. 2). 
The other purposes are to promote greater research quality and to provide benchmarks which can be used by institutions for developing and managing their research strategies (Boaden and Cilliers, 2001; HERO, 2001).

By contrast, the RAE 2008 sought to produce quality profiles for each submission of research activity made by institutions. The four higher education funding bodies (England, Northern Ireland, Scotland and Wales) will use the RAE 2008 results to distribute funding for research to the institutions from 2009-10 (Research Assessment Exercise 2008: the outcome, 2008).

The key features of the RAE 2001 and 2008 are summarised as follows:

\begin{tabular}{|c|c|}
\hline RAE 2001 & RAE 2008 \\
\hline $\begin{array}{l}\text { - } 68 \text { units of assessment (Guena and } \\
\text { Martin, 2003; HERO, 2001). }\end{array}$ & $\begin{array}{l}67 \text { units of assessment (RAE 2008: } \\
\text { Research Assessment Exercise, } \\
\text { 2008) }\end{array}$ \\
\hline $\begin{array}{l}\text { Panel members were nominated by a } \\
\text { wide range of organisations and } \\
\text { selected after consultation with } \\
\text { representatives of institutions, learned } \\
\text { societies, research funders, and } \\
\text { research users, among others. } \\
\text { - For each UoA, a panel of } 10 \text { to15 } \\
\text { experts was chosen. }\end{array}$ & $\begin{array}{l}\text { Panel members were nominated by } \\
\text { appropriate nominating bodies, } \\
\text { including learned societies, and } \\
\text { subject groups. Where appropriate, } \\
\text { non-academic users of research, } \\
\text { including those from industry, the } \\
\text { healthcare, the professions and } \\
\text { Government. } \\
67 \text { sub-panels conducted a detailed } \\
\text { assessment of submissions and } \\
\text { worked under the guidance of } 15 \\
\text { main panels. }\end{array}$ \\
\hline $\begin{array}{l}\text { Panels used a seven-point scale for } \\
\text { the quality ratings, denoted } 1,2,3 a \text {, } \\
3 b, 4,5 \text { and } 5^{*} \text {. }\end{array}$ & $\begin{array}{l}\text { Results are presented as quality } \\
\text { profiles. There are four quality levels } \\
4^{*}, 3^{*}, 2^{*}, 1^{*} \text { and unclassified. }\end{array}$ \\
\hline $\begin{array}{l}\text { 2,598 submissions were received from } \\
173 \text { HEls, listing the work of almost } \\
50,000 \text { researchers (HERO, 2001) }\end{array}$ & $\begin{array}{l}\text { 2,344 submissions were received } \\
\text { from } 159 \mathrm{HEls} \text {, listing the work of } \\
\text { more than 50,000 researchers }\end{array}$ \\
\hline
\end{tabular}




\subsubsection{Evaluation of the RAE}

Since the RAE was developed during the mid-to-late-1980s, evaluation and reviews have continuously taken place in one form or another and these are summarised in Table 5.2.

Table 5.2: Summary of Reviews and Research Studies

\begin{tabular}{|c|c|}
\hline Author & Title \\
\hline HECFE (1993) & $\begin{array}{l}\text { - Report for the Universities Funding Council on the } \\
\text { Conduct of the } 1992 \text { RAE }\end{array}$ \\
\hline Jenkins (1995) & $\begin{array}{l}\text { - The Research Assessment Exercise, Funding and } \\
\text { Teaching Quality. }\end{array}$ \\
\hline Mc Nay $(1997,2003)$ & $\begin{array}{l}\text { - Impact of the } 1992 \text { RAE in English Universities } \\
\text { - Assessing the Assessment: An analysis of the UK RAE } \\
2001 \text { and its outcomes }\end{array}$ \\
\hline Elton (2000) & - The UK RAE: Unintended consequences \\
\hline $\begin{array}{l}\text { Evidence Ltd (2000; 2002; } \\
\text { 2003a; 2005a; 2005c) }\end{array}$ & $\begin{array}{l}\text { - The Role of selectivity and the characteristics of } \\
\text { excellence } \\
\text { - Maintaining Research Excellence and Volume } \\
\text { - Funding Research Diversity: The Impact of Further } \\
\text { Concentration on University Research Performance } \\
\text { and Regional Research Capacity } \\
\text { - Impact of Selective Funding of Research in England } \\
\text { - Researchers in Higher Education Institutions }\end{array}$ \\
\hline Koelman \& Venniker (2001) & $\begin{array}{l}\text { - Public Funding of Academic research: The Research } \\
\text { Assessment of UK }\end{array}$ \\
\hline Hare (2002) & $\begin{array}{l}\text { - The UK's RAE: Impact on Institutions, Departments } \\
\text { and Individuals }\end{array}$ \\
\hline $\begin{array}{l}\text { House of Commons Select } \\
\text { Committee on Science and } \\
\text { Technology (2002) }\end{array}$ & - Merits of the RAE \\
\hline Guena and Martin (2003) & $\begin{array}{l}\text { - University Research Evaluation and Funding: An } \\
\text { International Comparison }\end{array}$ \\
\hline Roberts (2003) & - Review of Research Assessment \\
\hline Ball and Butler (2004) & - The Implicit Use of Business Concepts in the UK RAE \\
\hline $\begin{array}{l}\text { Bence and Oppenheim } \\
(2004)\end{array}$ & - The Influence of Peer Review on the RAE \\
\hline Sharp and Coleman (2005) & $\begin{array}{l}\text { - Ratings in the RAE 2001- The Patterns of University } \\
\text { Status and Panel Membership }\end{array}$ \\
\hline Adams and Smith (2006) & - Evaluation of the British RAE \\
\hline Henkel (2006) & $\begin{array}{l}\text { - The Modernisation of Research Evaluation: The Case } \\
\text { of the UK }\end{array}$ \\
\hline
\end{tabular}


These evaluations indicate various strengths and weaknesses of the RAE system from the first in 1986 to 2001. The RAEs have been subject to some criticisms. Some of the concerns, such as criteria used and process issues, prioritisation of research at the expense of teaching, funding bias against new researchers and women and mobility of academic staff, have been addressed by the previous RAEs.

After the RAE 2001, concerns have been expressed that the exercise favours established disciplines over new and interdisciplinary work, places undue administrative burden on the higher education sector, and does not deal well with applied and practice-based research in particular. There was also a great concern about the grading and funding systems, and effect of RAE upon the financial sustainability of research. Further, HEls and departments manage their research strategies, and shape their RAE submissions, in order to achieve the maximum possible ratings (game-playing) (Research Assessment Exercise 2008: the outcome, 2008; Roberts, 2003).

The RAE's evaluation focuses primarily on the main strengths, and the key weaknesses of RAE 2001 which have led to significant changes for the RAE 2008. These are classified as follows : (i) research output; (ii) quality evaluation-peer review system; (iii) grading and funding systems; (iv) administrative burden and cost; (v) game-playing; and (vi) multi-disciplinary research. Each of these is discussed in detail in turn.

\section{(i) Research Output}

One of the main strengths of the RAE is that the system has had a positive and beneficial effect on research in the UK. Various studies (Ball and Butler, 2004; HERO, 2001; Koelman and Venniker, 2001; J. W. Moore, Newman, Sloane, and Steely, 2002; Roberts, 2003) reported that the results of the 2001 RAE and other evidence indicated that there had been a genuine improvement in the quality of research being conducted by the UK HEls since the initial RAEs.

The productivity and effectiveness of the UK research base has considerably increased (Adams, et al., 2000). The output of the most active research universities revealed a relative improvement as funds became more concentrated and they delivered better research. The volume of research in UK universities has also increased per FTE staff member. 
From 1989 to $1992,50 \%$ of the HEls making submissions improved their rating, whereas from 1992 to $1996,51.7 \%$ improved their rating and $31.1 \%$ received the same rating in both years (Koelman and Venniker, 2001). Furthermore, in the RAE 1996, 573 departments received 5 or $5^{*}$ ratings. This compares with the $2001 \mathrm{RAE}$ when 1,081 departments were rated 5 or $5^{*}$ (Ball and Butler, 2004; HERO, 2001). Research at the lower end of the scale (rated 1 or 2) for RAE 2001 accounted for $6 \%$ of submissions compared with nearly one quarter in 1996, but one reason for this is that weak departments are no longer putting in submissions for assessment (Ball and Butler, 2004). Furthermore, the UK's share of world citations has grown faster than its world share of publications and the UK's research impact has therefore also increased (Adams and Smith, 2006). The results of the RAE 2008 "provide evidence of the continuing high quality and international standing of research carried out in higher education institutions (HEls) in the UK" (Research Assessment Exercise 2008: the outcome (2008), p. 3).

Further studies also examined different aspects of the RAE and confirmed evidence of improvements in research management, transparent planning and monitoring of research. According to Hare (2002), individual academics face greater pressure to deliver research output than formerly. Therefore, the RAE has motivated universities into managing their research and has ensured that funds have been targeted at areas of research excellence. A study by J.W. Moore et al (2002) found that, for a sample of academic economists, the RAE system had led to improvements in individual research productivity during the 1990 s.

The general improvement of RAE grades over the years has arisen from an increase in research productivity, demands from tertiary education organisations for academics to perform, and knowledge and experience with the system of assessment.

Moreover, studies suggest that there is a high risk that departments choose to submit the best research output of researchers who have attained the levels of national and international excellence, so as to secure a top grading. In practice, the strategies may be to shift staff who cannot produce high quality research outputs into non-research contracts, making them non-participants in the RAE. The real risk is that taking only the best researchers will reduce the overall volume measure and lead to a decrease in the funding allocation to the HEI. 


\section{(ii) Quality Evaluation - Peer Review System}

Another strength of the RAE is to provide a common framework for quality assessment across academic disciplines. All UoAs have to submit their research outputs under the required formats to peer review panels. "The use of peer review panels gives legitimacy to the RAEs" (Willmott, 2003, p. 131). Some advantages of the peer review system are: "validation of the author's work, quality assurance for the journal's standards, protection from plagiarism and improved scholarship by ensuring the citing of relevant literature" (Bence and Oppenheim, 2004, p. 350). The peer review system provides incentives to improve individual research performance.

However, the composition and recruitment of panel members were considered by institutions to be one of the less transparent aspects of the exercise (Roberts, 2003). A number of panels appeared to have been weighted in favour of particular sub-disciplinary areas, and those involved in recommending the rating of specific departments were often from institutions that were in direct competition with these departments (Boston, 2002). In addition, HEls which were represented on panels tended to award each other better ratings than HEls not on the panel (Sharp and Coleman, 2005). This may simply reflect the fact that the best HEls are represented disproportionately on the panels.

\section{(iii) Grading and Funding Systems}

The grading and funding systems have been seen as one of the main weaknesses of the RAE. Since the introduction of the first RAE in 1986, the number of quality categories, quality ratings and funding weights has been changed several times, as illustrated in Table 5.3.

Table 5.3: RAE Ratings and Corresponding Funding Weights for 1989, 1992, 1996 and 2001

\begin{tabular}{llllllll}
\hline RAE Rating (1989 \& 1992) & 1 & 2 & 3 & 4 & 5 & & \\
1989 Funding Weight & 0.5 & 1.5 & 2.5 & 3.5 & 4.5 & & \\
1992 Funding Weight & 0 & 1 & 2 & 3 & 4 & & \\
\hline RAE Rating (1996 \& 2001) & 1 & 2 & $3 \mathrm{~b}$ & $3 \mathrm{a}$ & 4 & 5 & $5^{*}$ \\
1996 Funding Weight & 0 & 0 & 1 & 1.5 & 2.25 & 3.375 & 4.05 \\
2001 Funding Weight* & 0 & 0 & 0 & 0 & 1 & 3.1198 & 3.9478 \\
& & & & & & & \\
\hline
\end{tabular}


* The 2001 funding weight is for England. Scotland had a different approach in 2001.

Through the years the HEFCE has continually evaluated and reviewed the research evaluation process and the funding system. The first change from 1989 to 1992 (see Table 5.3) mainly introduced a category of institutions receiving no quality-related research funding. In 1996 the scale used for assessment was enlarged from five to seven points. Basically, both the old categories 3 and 5 were split in two (3a and $3 b)$ and $5\left(5^{*}\right)$. According to Ball and Butler (2004) this has widened the gap between top performing and lower ranking university departments. Those departments with assessment ratings 1 and 2 did not receive any funding from 1996 onward. Furthermore, in the $2001 \mathrm{RAE}$, the ratings of 1, 2, $3 b$ and $3 a$ attracted no funding. These changes occurred in response to the general rise in quality rating. However, "there is a risk that grade improvement seen in 2001 RAE may create an expectation of improvement from one exercise to the next, which might drive grade inflation" (Roberts, 2003, p. 10).

Another weakness in England is that the enhanced grades could not be fully funded (McNay, 2003). The funding councils' inability to 'fund the results' of the 2001 RAE shows how this can create a gap between expectation and reality (Roberts, 2003).

The RAE 2001 results generated funding problems requiring about $£ 206$ million extra if the existing funding formulas were to be used, yet the Department for Education and Skills came up with only $£ 30$ million (House of Commons Select Committee on Science and Technology, 2002).

To deal with this problem: "the Higher Education Funding Council for England (HEFCE) decided to maintain funding in real terms for the highest rated $5^{*}$ departments, cutting funding to grade 5 departments by $15 \%$, grade 4 by $30 \%$ and grade 3a by 70\%" (Ball and Butler, 2004). As a result, the RAE was reviewed and the rating scale used in 1996 and 2001 has been dropped. The seven point scale $\left(1,2,3 b, 3 a, 4,5\right.$, and $\left.5^{*}\right)$ has been replaced by quality profiles which will be highlighted under significant changes of the RAE 2008. 


\section{(v) Administrative Burden and Cost}

There are criticisms that the RAE has imposed large burdens in terms of the financial cost and human effort. The 1996 RAE costs were estimated to be between $£ 27$ to $£ 37$ million (Ball and Butler, 2004; House of Commons Select Committee on Science and Technology, 2002). The peer review process is also expensive and time consuming. In the RAE 1996, the administrative costs to the funding councils were about $£ 3$ million and rose to about $£ 5$ million in 2001 (Boston, 2002).

The increase was mainly due to the payment of overseas experts and other changes that took place in 2001. The 2001 RAE Manager estimated that the compliance costs for HEls were likely to be 50\% higher than in 1996 (an estimate of $£ 67$ million) due to inflation and increased requirements on HEls. Additional compliance costs of $£ 5$ million and an administrative cost estimate of $£ 5.1$ million bring the total costs to $£ 77$ million (WEB Research, 2004). This represents approximately $0.8 \%$ of the total funds allocated over seven years (WEB Research, 2004 para 425).

Concerns have been expressed that the RAE places an undue administrative burden on HEls. As a result of the review process, large numbers of senior academics will be involved in the preparation of submissions and also serve on the assessment panels while support staff (non academics) will assist in the administrative process.

\section{(vi) Game-Playing}

Another fundamental criticism which has been raised by researchers (Ball and Butler, 2004; Boston, 2002; Hare, 2002; Henkel, 2006) is that the allocation of funding under the RAE has introduced uncertainty and significant scope for gaming.

HEls will certainly take strategic positions and play the game (Talib and Steele, 2000). This may occur where a department (UoA) has researchers with varying levels of performance. If they are rated as achieving national or international standards of excellence, the department will want to include them in their submissions; but if the researchers are rated below national excellence, the department may decide to exclude them in order to improve their ratings. 
In recent years institutions are forced to 'play games' because the consequences of gaining or losing a grade are so enormous (Roberts, 2003). However, under the RAE the funding formula does not depend only on quality ratings but also on the volume of research-active staff included in their submission. Thus, excluding certain academics may improve the quality ratings but it may also reduce the volume measure (i.e. overall staff in a unit), and vice versa. It is clear that under the RAE system, HEls face a quality versus volume trade-off.

\section{(vi) Multi-Disciplinary Research}

The continuing critique focuses on the RAE's structural inadequacy to embrace multi-disciplinary research. Recent research confirms that academics' commitments remain primarily with their subject or discipline (Henkel, 2006). McNay (1997) reported a bias of review panels towards less interdisciplinary research. Conversely, the HEFCE found no relationship between the percentage of time researchers spend on interdisciplinary research and the rating of their 1996 RAE submission, which indicates that the problem may not be large. It is important to note that the RAE 2008 round will include multidisciplinary panels and a much stronger moderation process.

In light of the key weaknesses of the 2001 RAE, the UK funding bodies commissioned a review led by Sir Gareth Roberts, to consider how to assess research in the future. This was followed by a widespread consultation with the public, informal meetings with stakeholders, open public meetings in HEls, reviews and reports. There was overwhelming support for an assessment process based upon expert review by discipline-based panels, and make better use of relevant quantitative indicators (RAE 2008: Initial Decisions by the UK Funding Bodies, 2004).

Further, among others, a need was identified for a continuous rating scale, greater transparency (especially panel selection), consistency of practice across panels, and clear link between assessment outcomes and funding (Roberts, 2003). This has led to significant changes for the RAE 2008. 


\subsubsection{Significant Changes for the RAE 2008}

The 2008 RAE used the same main principles of peer assessment as previous

RAEs. However, a few significant changes were introduced:

- The rating scale used in 1996 and 2001 was dropped. The seven point scale $\left(1,2,3 b, 3 a, 4,5\right.$, and $\left.5^{*}\right)$ was replaced by quality profiles where the unit of analysis is individual pieces of research, not departments. This allows the funding bodies to identify pockets of excellence wherever these might be found and reduces the 'cliff edge' effect where fine judgements at the grade boundaries can have significant funding impacts (Research Assessment Exercise 2008: the outcome, 2008).

- A formal two-tiered panel structure was introduced in RAE 2008, to ensure greater consistency and international calibration (Research Assessment Exercise 2008: the outcome, 2008).

The quality levels in 2008 are defined as:

\begin{tabular}{|l|l|}
\hline $4^{*}$ & $\begin{array}{l}\text { Quality that is world-leading in terms of originality, } \\
\text { significance and rigour }\end{array}$ \\
\hline $3^{*}$ & $\begin{array}{l}\text { Quality that is internationally excellent in terms of } \\
\text { originality, significance and rigour but which nonetheless } \\
\text { falls short of the highest standards of excellence }\end{array}$ \\
\hline $2^{*}$ & $\begin{array}{l}\text { Quality that is recognised internationally in terms of } \\
\text { originality, significance and rigour }\end{array}$ \\
\hline $1^{*}$ & $\begin{array}{l}\text { Quality that is recognised nationally in terms of originality, } \\
\text { significance and rigour }\end{array}$ \\
\hline Unclassified & $\begin{array}{l}\text { Quality that falls below the standard of nationally } \\
\text { recognised work. Or work which does not meet the } \\
\text { published definition of research for the purposes of this } \\
\text { assessment }\end{array}$ \\
\hline
\end{tabular}

Source: RAE 2008: Quality Profiles

\subsubsection{Post 2008 RAE- Research Excellence Framework}

The British Government announced in March 2006 its intention to replace the RAE after 2008 with an assessment system based on metrics. HEFCE is working to develop the new arrangements - the Research Excellence Framework (REF) - for the assessment and funding of research. The REF will be the successor to the RAE. 
The REF is being piloted in approximately 20+ institutions (Adams, 2008a). Aspects of the framework will be phased in gradually starting in 2011-12, and it will be fully introduced for research funding for all disciplines from 2014 (Higher Education Funding Council for England, 2008b).

The RAE assessed a body of research activity in terms of quality of outputs, research environment and esteem, whereas in the REF the priorities are to capture the quality of outputs, economic, social and public policy impact, and research environment (Sweeney, 2009). The REF will consist of a single unified framework for the funding and assessment of research across all subjects. The REF will make much more use of quantitative measures of assessment, such as bibliometrics analysis (e.g. average citation counts per unit), other metrics based on research funding and postgraduate research training, as well as using the more qualitative peer review process where this is more appropriate, particularly in the humanities areas, creative arts and design (Adams, 2008a; Boston, 2008;

Sweeney, 2009).

Bibliometric measures involve the determination of the number of citations to journal articles published by academics within institutions. These then need to be normalised to the average worldwide citation count for different subject areas. The normalisation strategy will affect the outcome (Adams, 2008a). Some fields cite more often than others. Researchers specialise in sub-disciplines that are very small and younger researchers with a smaller publication record will be penalised because their citation rates in these sub-disciplines cannot be adequately normalised (Smith, 2008).

Further, bibliometric indicators only measure conventional published output. In the case of REF, data derived from citations of articles indexed in the Web of Science and Scopus database. However, bibliometric indicators measure impact rather than quality (Smith, 2008). Impact can be affected by a range of non-quality factors.

In sum, the policy changes and the introduction of the RAE in the UK have definitely brought benefits but have also had some negative impacts. Over the past two decades the UK's RAE has been evaluated extensively. In light of the identified weaknesses and criticisms there have been continued improvements in the PBF model. 
The RAE 2008 has addressed some of the weaknesses with the previous RAEs, especially in terms of their quality ratings and funding systems. Nevertheless, the lesson learned from the UK's PBF model is that there is dissatisfaction, and a limit to improvement to the RAE model was reached, as shown by the UK's decision to replace the RAE in the future. The devil is in the detail - there are difficulties with all the available bibliometric and non-bibliometric performance indicators, but some indicators are better proxies for research quality than others (Adams, 2008a; Boston, 2008).

However, there is no guarantee that the REF will be a better model than the RAE, although it is assumed that the REF will minimise the administrative burden of the evaluation process. Possibly, there may be other problems associated with bibliometrics measures that may become apparent either in the short-term or longterm when the system is being fully implemented. The shift from the RAE to the REF will be a challenging process.

\subsubsection{Australia - Performance Indicator Model}

The core funding of Australian universities for research purposes is now almost entirely performance-based (Anderson, Johnson, and Milligan, 1996). The change to a performance-based approach came with the introduction of the Relative Funding Model (RFM) in 1990. Research support was initially measured by the "Research Quantum", based on success in winning Commonwealth competitive grants. As from 1995, the Research Quantum was allocated on the basis of weighted indicators known as the Composite Competitive Index. This places emphasis on the quantity of research outputs rather than the quality of research. In 2002, the Research Quantum was replaced by an Institutional Grants Scheme (IGS), but the funding approach was not changed significantly.

In 2004, the Australian government launched the Research Quality Framework (RQF) for evaluating the quality and impact of research in Australia's universities. In late 2007 the new Australian Labor government proposed introducing the Excellence in Research for Australia (ERA) Initiative. The recent Australian developments are discussed further in section 5.3.3.2. 
The Australian Government provides support for higher education research and research training through two funding schemes, namely, peer-reviewed competitive research and performance-based block research grants. Peerreviewed competitive research funding schemes are administered by a number of bodies. The two largest are the Australian Research Council and the National Health and Medical Research Council. Performance-based block research funding schemes are administered by the Department of Education, Science and Technology. Universities receive research block funding from three main schemes. These are the Research Training Scheme (RTS), the Institutional Grant Scheme and the Research Infrastructure Block Grants Scheme (Department of Education Science and Training [Australia], 2005). The IGS supports the HEls research and research training activities, and allows them to fund their activities in accordance with their own strategic judgements. This scheme absorbs the funding previously allocated under the Research Quantum and the Small Grants Scheme. Funding under the IGS is allocated on the basis of a formula that takes into account each institution's success in attracting external research income (60\%), research students (30\%), and research publications (10\%) (Department of Education Science and Training [Australia], 2005).

The RTS provides block grants to eligible higher education providers to support research training for students undertaking Doctorates and Masters degrees by research. The objectives of the RTS are to enhance the quality of research training, improve the responsiveness of institutions to the needs of their research students, and to enhance the efficiency and effectiveness of research training. The allocation of funds to institutions under the RTS is based on a performance-based formula comprising higher degree by research completions (including international students) weighted at $50 \%$, research income weighted at $40 \%$, and research publications weighted at 10\% (Department of Education Science and Training [Australia], 2005).

The Scheme aims to improve the quality of the research training environment, and improve the completion times of student completion rates. These measures were regarded by those who designed the schemes as proxies for the quality of a research education environment. 


\subsubsection{Evaluation of the Performance Indicators Model}

It is interesting to note that, according to Taylor (2001), empirical evidence of the performance indicators impact on the work of university academics is limited and most of the studies on their effects are based on anecdotal evidence and personal observation. There are only a limited number of evaluations undertaken on the Australian model as it has evolved over the past decade.

\section{(i) Failure to enhance quality}

The current system for assessing research in Australian higher education places more emphasis on rewarding quantity than on assessing quality. Rewards are distributed more on the basis of research degree completions and grant income than for publications (Gale, Gilbert, Seddon, and Wright, 2005). The emphasis has been placed on the volume of publications, not their quality (Chubb, 2006; Taylor, 2001).

The application of quantitative performance indicators has contributed to a quantity-over-quality culture as academics strive to maximise the number of their publications and external research grant applications. This is likely to have a detrimental impact on the quality of research in the long run (Taylor, 2001). Several techniques have also been used to increase the number of publications. The most evident is the splintering of research into several publications and some academics publishing in less prestigious journals than previously.

\section{(ii) Priorities between research and teaching}

It is claimed that, in Australia, the fact that the Government has tied performance indicators to research funding with no similar scheme for teaching might lead to a focus on research at the expense of teaching. Taylor (2001) reported that most academics in his study admitted to shifting from teaching towards research because of the rewards attached. Some respondents stated that their teaching had deteriorated because of their focus on research.

As a result of this concern, at the University of Sydney "an institution-wide strategic approach to improving teaching and learning has been adopted, with a multi-level system of rewards and recognition for teaching as a scholarly activity in parallel with traditional research" (Asmar, 2007, p. 28). 


\subsubsection{Recent Developments}

The apparent failure of the RTS to achieve the primary objective of enhancing the quality of research training provision in Australia has led to the development of the Research Quality Framework (Chubb, 2006).

The government seems committed to the development of a consistent and comprehensive approval process to assess quality and ensure that resources are directed to areas of research excellence and public benefit. In 2004, the Australian government set up the Expert Advisory Committee to design and implement the Research Quality Framework for assessing the quality and impact of research in Australian's universities. The rationale for the Research Quality Framework is to validate the quality of research that is being undertaken in universities and to establish the value of the public investment in research. The elements of the Research Quality Framework assessment include research quality, research impact, and research training outcomes (Australian ViceChancellors' Committee, 2005). The basis for the research quality and research impact assessments for a Research Group is as follows:

\begin{tabular}{|c|c|}
\hline Quality Assessment & Impact Assessment \\
\hline $\begin{array}{l}\text { - the four best Research Outputs for } \\
\text { each researcher in the group } \\
\text { - the full list of Research Outputs for } \\
\text { the Group produced in the six- } \\
\text { year assessment period, and } \\
\text { - the evidence of research quality } \\
\text { provided as part of the Context } \\
\text { Statement }\end{array}$ & $\begin{array}{l}\text { An Impact Statement of up to } 10 \text { pages, } \\
\text { including: } \\
\text { - an evidence-based statement of } \\
\text { claims for the Group against } \\
\text { generic and panel-specific impact } \\
\text { criteria, including verifiable } \\
\text { indicators in support of those } \\
\text { claims } \\
\text { up to four case studies that } \\
\text { illustrate the Group's claims of } \\
\text { impact, and } \\
\text { details of end users who can be } \\
\text { contacted by Assessment Panels } \\
\text { to verify the Research Group's } \\
\text { Claims }\end{array}$ \\
\hline
\end{tabular}


Any appraisal of this scheme will need to consider whether the research impact assessment is undertaken consistently, accurately and fairly in order for the scheme to be successful.

Reporting research will be in the form of aggregations of individual work, rather than reports of research quality and of the impact attributable directly to individual researchers (Gale, et al., 2005). The new funding mechanism will replace the existing Australian Institutional Grant Scheme and Research Training Scheme in 2008/09. However, with the change in government in 2007, the Australian Labor Party has announced the Excellence in Research for Australia (ERA) Initiative. A consultation paper was released by the Australian Research Council in June 2008. The objectives of the new framework (ERA) are as follows:

- To identify excellence across the full spectrum of research activity

- To compare Australia's university research effort against international benchmarks

- To create incentives to improve the quality of research

- To identify emerging research areas and opportunities for further development

Other important considerations that ERA should recognise are to:

- Promote collaboration between institutions and between university researchers and end users

- Encourage efficient use of research infrastructures and resources

- Facilitate interdisciplinary research

- Minimise the burden on individual researchers, institutions and expert assessors (Australian Research Council, 2008, p. 5).

The proposed scheme will assess research carried out in HEls using measures of research activity and intensity; indicators of research quality; and indicators of excellent applied research and translation of research outcomes. Evaluations will take place in eight discipline clusters. 
The unit of evaluation for ERA will be "research disciplines within institution, classified by the Australian and New Zealand Standard Research Classification (ANZSRC) Field of Research (FoR) codes at both two-digit (22 Divisions) and four digit (157 Groups) level where relevant" (Australian Research Council, 2008, p. 6). ERA will not influence the allocation of research block grants until the Government considers and implements any new mechanism. This implies that the results of ERA will not be linked with funding of research grants as in the UK and NZ systems.

\subsubsection{New Zealand - Mixed Model}

The Tertiary Education Advisory Committee (TEAC) was set up in April 2000, "to develop a strategic direction for tertiary education in New Zealand" (Tertiary Education Commission [New Zealand], 2000, p. 6). The development of the PBRF was based on the recommendations of the TEAC in its Fourth Report Shaping the Funding Framework.

TEAC reviewed the available policy options including the performance indicator model (as used in Australia and Israel) and the peer review model (as used in United Kingdom and Hong Kong). The advantages, disadvantages, and implications of the performance indicator and peer review models were analysed and enumerated in the TEAC report. It was concluded that neither of the models would be ideal for New Zealand conditions. As a result, TEAC recommended a "mixed model", which is a combination of peer review and performance indicators, namely the Performance-Based Research Fund (Boston, Mischewski, and Smyth, 2005; Goldfinch, 2003; Tertiary Education Advisory Commission [New Zealand], 2001, p. 7).

Under the proposed model, the research "top up" component of tuition fees would be placed in a separate fund and allocated via a new PBF formula:

- $50 \%$ of the available funds would be allocated on the basis of results of periodic quality assessments by expert panels of the eligible staff in participating TEOs; 
- $25 \%$ would be based on the number of research degree completions (cost weightings and research component weightings for different types of research degrees); and

- $25 \%$ would be based on the amount of external research income.

Following the TEAC recommendations, the government approved the broad concept of the PBRF in mid-2002. In July 2002, a PBRF Working Group was established to provide further details of the PBF regime. In December 2002, on the advice of the PBRF Working Group, the government made a number of changes to the scheme recommended by TEAC.

This involved quality evaluation of researchers by external peer review panels and an evaluation of the performance of researchers, based on Evidence Portfolios (EP) prepared by eligible staff. The weighting placed on the peer assessment component (known as the 'quality evaluation') was increased to $60 \%$, while the weighting of the external research income was reduced to $15 \%$. In accordance with the Working Group's recommendation, the first 'quality evaluation' of research in the tertiary education sector was conducted in 2003, with a second in 2006 (Ministry of Education [New Zealand], 2006; Ministry of Education and Transitory Tertiary Education Commission [New Zealand], 2002).

To date, there have been two PBRF rounds (2003 and 2006) and modifications were made for the 2006 round on the basis of evaluations of the first funding round in 2003. The PBRF 2006 was partial, allowing exemption for those who scored well in 2003 and who desired to retain their grade until its normal 6 year cycle in 2012. The key modifications for 2006 will be highlighted at the end of the section.

\subsubsection{Key features of PBRF - Phase one (2003)}

The primary role of PBRF is to allocate research funds to TEOs on the basis of their results for the quality assessment of researchers, research degree completions and external research income. In general, the PBRF is designed to achieve a number of related objectives: to enhance the incentives for research excellence; encourage greater specialisation and concentration of research effort; and increase transparency and public accountability. 
The key features of the PBRF round are as follows below:

- The Unit of Assessment for quality rating purposes is the individual researcher. The choice of individual researcher as the unit of assessment will be discussed in more detail under the section on the strengths and weaknesses of PBRF.

- Evidence Portfolios (EPs) are a key component of the PBRF and form the basis of the quality evaluation. EPs comprise three key elements: (i) research outputs (RO weighted at $70 \%$ ), Peer Esteem (PE weighted at $15 \%$ ) and Contribution to Research Environment (CRE weighted at 15\%). This is a holistic system of assessment. Staff members are required to nominate up to four research outputs which they consider their best work and originally up to 50 (now 30 ) 'other' research outputs.

- The Assessment Panels consist of nominees from TEOs, professional groups, learned societies and industry (Goldfinch, 2003). There are 12 panels based around various subject-area groupings (Boston, et al., 2005).

- The PBRF is managed by the TEC. The new funding mechanisms were phased-in between 2004 and 2007 (Tertiary Education Commission [New Zealand], 2004b).

\subsubsection{Points of Similarity and Difference with the UK Performance-Based System}

The main similarities with the UK RAE are as follows:

- Both are PBF mechanisms for research activities.

- Both rely heavily on the use of peer review. Both use quality assessments that are undertaken periodically (i.e. every three-six years).

- Both have formula-driven funding mechanisms, which include volume measures.

The main differences are as follows:

- Under the PBRF, the performance indicators for the number of research degree completions and for external research income are not integrated into the quality assessment but are used separately and applied at the institutional level. However, the UK model includes performance indicators as part of the peer review process. 
- Under the mixed model, the individual is the unit of assessment for quality rating purposes, whereas under the UK RAE academic units linked to subject areas are the unit of assessment.

- Under the mixed model, the quality assessments are undertaken by multidisciplinary expert panels rather than by disciplinary panels, as in UK, but the RAE 2008 round will include multidisciplinary panels.

\subsubsection{Evaluations to date}

There is growing body of literature ${ }^{9}$ evaluating the PBRF. These evaluations variously suggest a number of strengths and weaknesses in the design and implementation of the New Zealand PBRF.

The strengths and weaknesses of the PBRF system can be analysed under the following headings:

- The individual as the unit of assessment

- Quality rating system

- Funding formula

- The reporting framework

- Teaching-research nexus

- Administrative and compliance costs

- Game-playing

Each of these is discussed in turn below.

(i) The Individual as a Unit of Assessment

During the design process, the TEAC and the PBRF Working Group considered three options for the unit of assessment (UoA): the institution as a whole; disciplinary-based groups or academic units; and individual researchers (Boston, 2002; WEB Research, 2004).

9 Boston, 2002, 2004; Boston, et al., 2005; Codd, 2005, 2006; Dalziel, 2005; Goldfinch, 2003; Hall and Matthews, 2006; Hazeldine and Kurniawan, 2006; Jesson, 2005; Small, 2005; Smart, 2005; R. Smith, 2005; WEB Research, 2004; White, 2006 
The institution as a whole, and academic units were not adopted as UoA because there were concerns about the capacity of multidisciplinary panels to judge the relative performance of aggregations of researchers in the context of small numbers. Moreover, there would be problems of rating disciplines in a small system, in which many disciplinary fields have only two to three providers. Therefore, the government, on advice, approved individual researchers as the preferred unit of assessment. This UoA is possible in NZ because there are only eight universities. There were 8,671 PBRF-eligible staff from the TEOs who participated in the 2006 PBRF (Cinlar and Dowse, 2008) as opposed to the UK with $160 \mathrm{HEls}$ where academic units are the UoA.

The arguments in support of the individual researcher as UoA were specified in a number of the studies [see in particular, (Boston, 2002, 2004)]. These arguments include: (i) simplicity and lower compliance costs; (ii) potential for self assessment, thereby reducing the burden of external assessment panels; (iii) more flexibility; (iv) more consistency with the growing importance of multidisciplinary research; and (v) appropriateness for the framework of the mixed model PBRF.

However, the individual researcher as a UoA has also been a matter of controversy in the tertiary education sector. The unintended consequences have been that the assessment process has placed considerable stress on staff in departments with low ratings, influenced the reputations of those directly affected, and jeopardised academics' careers and self esteem.

Further, it is said that "individual assessment is affecting the recruitment of new researchers and may thereby detrimentally affect sustainability and is being used as a substitute for proper staff development, in appraisal” (Adams, 2008c, p. 62). In addition, according to Middleton (2008, p. 133), "good scores are being used in promotion, job and grant applications".

Most of the studies critical of the individual as the UoA were undertaken by academic researchers who were directly involved in the regulatory regime (Codd, 2005, 2006; Dalziel, 2005). Their concerns and the criticisms raised about the UoA have been taken into account by the TEC in making continued improvements in future PBRF rounds. The criticisms have not led to the abandonment of the individual as the UoA. 
The PBRF independent reviewer maintains that the individual should remain the unit of assessment for PBRF 2012 because it would create unnecessary shortterm cost if it were modified at this stage (Adams, 2008c). One evaluation commented that: "international members of peer review panels interviewed praised the design and method of individual assessment and noted its advantages over their own experiences" (WEB Research, 2004, p. 44).

There is further evidence that academics support using the individual as the UoA provided that TEOs do not use the quality categories for managerial purposes, promotion and remuneration policies (WEB Research, 2004). Furthermore, the PBRF provides strong incentives for individual researchers and TEOs to improve their performance and in turn to be rewarded by increased funding (Boston, 2004).

\section{(ii) Quality Rating System}

One fundamental design issue which has been criticised in various studies is the quality rating system, including the scoring system (quality categories), the treatment of new and emerging researchers, and the internal assessment by TEOs. In the quality rating system one of the most obvious endeavours is to quantify such measures as Research Output, Peer Esteem and Contribution to Research Environment, although the PBRF 2003 assessment was of research quality, not quantity.

The scoring system (quality categories) has also been identified as a weakness in the design of PBRF. The TEAC proposed that academics would be classified, using various criteria, into four categories: international excellence, national excellence, research-active, and research-inactive (Tertiary Education Advisory Commission [New Zealand], 2001). Nevertheless, "there is no quality category in the PBRF labelled national or international excellence" (Dalziel, 2005, p. 4).

The TEC has described its four quality categories as " $A$ " (signifies research of a world-class standard), "B" (signifies very good quality research), "C" (signifies good quality research), and "R" (signifies that the EP did not meet the requirements for a "C") (Tertiary Education Commission [New Zealand], 2004b). "TEC (2003a para 12) estimates that up to 20 per cent of eligible staff were of international excellence" (Dalziel, 2005, p. 4). However, the overall results of the 2003 Quality Evaluation, indicated that only $5.7 \%$ of PBRF eligible staff were assigned category " $A$ ” (Boston, et al., 2005). 
According to Middleton (2005), of the 35 volunteers interviewed from seven TEOs who disclosed their PBRF scores, two were rated A, 10 as B, 12 as $C$, and 11 in the $\mathrm{R}$ category. Therefore, there is the possibility that the panels applied the criteria too tightly or the criteria themselves were too tight.

Another controversial issue has been the treatment of new and emerging researchers (Dalziel, 2005; E. Davies, Craig, and Robertson, 2005; Small, 2005; WEB Research, 2004). The concern focuses on new researchers, the way their research is evaluated, the negative effect on their status and career advancement, and the potential for exclusion of younger staff from institutions (Adams, 2008c). The failure to introduce a separate category for these researchers resulted in a high proportion of such staff receiving a low quality category (i.e. "R").

As shown in the study by Boston et al. (2005) the "R" category includes a large number of new and emerging social scientists. In the 2003 assessment, 39.9\% of eligible researchers were placed in this "R" category (Dalziel, 2005). The 3,273 staff who received an $R$ in 2003 included a significant proportion of younger staff members (Cinlar and Dowse, 2008). It was apparent from the 2003 PBRF round that new researchers were certainly disadvantaged in terms of peer esteem and contribution to research environment compared with more established researchers. Such individuals had not had the opportunity to acquire a substantial measure of peer esteem and make major contributions to the research environment. The categorisation of new researchers as " $R$ " was possibly the most challenged aspect of the PBRF.

In response, the PBRF moderation panel recommended that an additional category should be included to cover new and emerging researchers who are active but have not yet had the opportunity to build substantial EPs. The quality categories " $\mathrm{C}(\mathrm{NE})$ " and " $\mathrm{R}(\mathrm{NE})$ " for new and emerging researchers were introduced for the PBRF 2006 assessment (Tertiary Education Commission [New Zealand], 2006a). However, "the NE label does not fully solve the problem" (Adams, 2008c, p. 53). 
Having the TEO ratings was a great help to the TEC in the 2003 round as it served as a benchmark for comparisons. Nevertheless, the internal assessment by TEOs in 2003 was seen by many as unnecessary and costly. As a result, the internal assessment by TEOs for assigning quality categories was abolished for the 2006 round.

\section{(iii) Funding Formula}

It is generally accepted that under a PBF model, such as the PBRF, the quality evaluation should represent the majority of the funding allocated to tertiary institutions because funding is linked to the quality of research. The funds allocated between disciplinary areas are based mainly on two factors: (i) a volume measure based on the number of research-active academic staff included in the quality exercise; and (ii) the results of the quality rating exercise.

The decision to incorporate research degree completions (RDC weighted 25\%) and external research income (ERI weighted 15\%) in the funding formula was justified by TEC as a "proxy for research quality" (Hazeldine and Kurniawan, 2006; Tertiary Education Commission [New Zealand], 2004a, pp. 65-67). As a result, funds are allocated based on completions of research degrees rather than simply equivalent full time student enrolment. According to (Smart, 2006), a study of the seven-year completion rate of doctoral students revealed that both Australia (53\%) and the UK (59\%) are well above the NZ figure of $41 \%$ for the 1998 starting cohort.

The introduction of RDC as a performance measure is likely to encourage recruitment of students better able to complete degrees, and also to provide substantial financial incentives for TEOs to reduce completion times. TEOs may become more selective. According to Cinlar and Dowse (2008), in 1998, 402 doctorates were completed. This increased to 552 in 2003 and 639 in 2006. However, this measure is only applicable and beneficial to those TEOs offering research degrees. Thus, those that do not offer research degrees will be at a disadvantage and fail to score on the PBRF count. There is also the risk that the number of taught-only postgraduate programmes will decline or stabilise. 
There is no doubt that some TEOs have gained from the PBRF exercise by receiving funding additional to that which they would have received under the former equivalent full time student based system, but this is inevitable given the greater research focus of some TEOs. Furthermore, funding based on the amount of external research income may favour those organisations which are well established, and with long histories of research activities. For instance, a fairly small proportion of ERI is currently generated by social scientists and the patterns are unlikely to change in future (Boston, et al., 2005). Nevertheless, the system may also encourage TEOs to generate funding on different research projects from both local and overseas institutions.

According to Hazeldine and Kurniawan (2006), the subject-area weightings and the funds allocated under the component of RDC and ERI are also aspects of the funding formula which need to be revisited. There was some thought that the "RDC component is possibly weighted rather high when there is no clear link to a quality indicator associated with research degrees" (Adams, 2008c, p. 72). The subject area weighting favours expensive areas relative to the UK and other relativities. Another issue is that, because supervision of research students and external funding are included as part of CRE, there may be some double counting but, if so, it is modest. The RDC and ERI are included in the funding formula because the PBRF is a mixed model and these two indicators serve as proxies for research quality. The funding allocations through the PBRF were fully implemented in 2007.

The PBRF funding formula appears to be a well devised scheme, as opposed to the UK RAE, because the funding scheme is disaggregated and there is a quality mechanism for the system as a whole. The funding formula for RDC and ERI are applied at the institution level. With this funding, the possibility of TEOs not having any funding is minimal. The funding cliffs in the UK model have led to the major changes in the RAE 2008 rating system. Based on the UK experience of inadequate funding, Boston (2002) has suggested that contingency plans should be made available for additional PBRF funds in case there is an improvement in research quality. 


\section{(iv) The Reporting Framework}

The reason for reporting results is to ensure public access to a wide range of information pertaining to the research performance and activities of the participating TEOs, and to increase accountability at various levels. Another important objective is to improve the capacity of relevant stakeholders in the tertiary sector (including students, research funders, providers and the government) to make informed decisions.

The principles underpinning the reporting of PBRF results, as agreed by the TEC, include the need to protect the confidentiality of individuals' quality categories, to minimise incentives for game-playing by TEOs, to maintain the confidence and cooperation of the academic community, and to adopt a consistent reporting framework over two or more rounds in order to facilitate comparisons over time (Tertiary Education Commission [New Zealand], 2004a, 2005). The results of the 2003 Quality Evaluation were reported at four levels: individual TEOs, peer review panels, subject areas at TEO level, and nominated academic units.

The PBRF creates league tables where rankings of institutions are disclosed to the public at large. On the league tables, the TEO that is ranked first (with the highest quality score weighted on FTE basis) may be seen as the most prestigious. Such league tables may be simultaneously beneficial and harmful since this obviously has the potential to influence the reputation and status of those NZ universities directly affected, and with implications for students. League tables may provide powerful incentives for individual researchers and TEOs to improve their research performance, quality ratings and rankings for future Quality Evaluations.

Nevertheless, several controversial issues have been identified. These include the comprehensiveness of the reporting framework, the issues of confidentiality regarding individual quality categories, the disaggregation and reporting of the results of small academic units, and the granularity of levels of distinction (numerical, alphabetical or decimal places). The issue of how the results were reported was one of the most controversial aspects of the 2003 Quality Evaluation because there were several TEOs where all or virtually all staff had received the same Quality Category. 
Although the TEC agreed that there would be no public release of the results for quality categories assigned to individuals, it was not possible to avoid situations in which quality categories of many staff could be inferred by those with relevant additional information. "Although confidentiality of individuals' scores is protected in policy it was not always in fact” (Middleton, 2008, p. 133). The privacy and confidentiality of academic staff was not maintained because the results were sent to their employing TEOs but not directly to individual researchers.

The TEOs results were finally published alphabetically but also with rankings and quality scores have been calculated to one or two decimal places and not presented as whole numbers (as was previously specified) for more accurate distinctions in performance and to enhance transparency. The reporting of the results is vital to enhance greater accountability and increase transparency, therefore, the TEOs results have to be publicly disclosed. It is a real challenge to balance the two issues of transparency and confidentiality.

It may be right that, from an academic's perspective, confidentiality and privacy should be maintained, and that, as agreed by the TEC, individual results for quality categories should not be made public. However, from a policy perspective, accountability and transparency are important considerations under a PBF model.

\section{(v) Teaching-Research Nexus}

As in the UK and Australia, the relationship between teaching and research is another important concern which has been discussed in the literature. The main concerns have been that the PBRF would push teaching and research apart (Goldfinch, 2003; Jesson, 2005; Small, 2005; Smith, 2005). A critical concern of many academics is that under the PBRF staff will be directed to research at the expense of maintaining and enhancing the quality of teaching (Smith, 2005).

Furthermore, there are fears that departments will hire short-term contract teachers, and junior staff members will be burdened with teaching loads to allow active researchers to devote more time to generating research outputs.

One study noted that both heads of schools and post-graduate students acting as tutors agreed that staff perceived teaching as less valued than research (Hall and Matthews, 2006). There is increasing concern that the PBRF will disconnect the teaching and research relationship and that de facto there will be a separation between teachers and researchers in some departments (Goldfinch, 2003). 
However, according to White (2006) the PBRF has the potential to strengthen the link between teaching and research because it encourages the recruitment of teachers who are research-active, especially in the universities that are characterised by research-led teaching. White further predicts that preliminary evidence to support this view will be provided in the future by an increase in the recruitment and retention of research-active staff, and a decrease in teaching-only support staff, at least in universities.

Nevertheless, there is at present a lack of empirical evidence to show that the PBRF has had a negative impact on teaching or weakened the research-teaching nexus. To assess the impact of PBRF on the research-teaching nexus, further empirical investigations are required.

\section{(vi) Administrative and Compliance Costs}

Based on a comparison of the British and Hong Kong systems, it was anticipated during the design process of the PBRF that using individuals as the UoA would reduce compliance costs and be administratively simpler, because TEOs would be required to submit less information and documentary evidence to the Peer Review Panels (Boston, 2002). However, this claim proved to be incorrect. One reason was that the PBRF Working Group greatly increased the complexity of the scheme and the amount of information required to be submitted by TEOs. The estimated total costs of implementing the PBRF 2003 ranged between \$21 and \$28 million (WEB Research, 2004) and the TEC noted that they were a great deal higher than system operating on a per-head basis.

Instead of being cheaper to administer and simpler, the New Zealand model has proved to be fairly complex and costly. However, the total costs as a proportion of the total funds allocated for the period 2007-2012 are predicted to fall from a range of $12 \%$ to $17 \%(2004-2006)$ to a range between $1.5 \%$ to $2 \%$ for $2007-2012$ (Hazeldine and Kurniawan, 2006; WEB Research, 2004). 
(vii) Game-Playing

One important aspect of the PBRF is that the risks of game-playing are lower than under the UK RAE. Under the PBRF, the eligibility to participate in the quality evaluation process is clearly defined. The staff-participation criteria used to identify which staff members are employed by a TEO are PBRF-eligible as opposed to the UK where departments can decide the researchers to be included in the submissions.

\subsubsection{Key Modifications to the PBRF Round 2006}

Based on evaluations of the PBRF 2003, the key modifications for the PBRF round in 2006 were:

- The requirement for TEOs to conduct a full internal assessment and assign quality categories was abolished.

- The number of 'other' research outputs to be included in the EP was reduced to a maximum of 30 (from 50 ).

- The quality categories of " $\mathrm{C}(\mathrm{NE})$ and $\mathrm{R}(\mathrm{NE})$ " were introduced for assessing the new and emerging researchers. The weightings of RO (70\%), PE (15\%) and CRE (15\%) only apply when a new and emerging researcher's EP is being considered for the assignment of an " $A$ " or " $B$ " Quality Category. Otherwise, only the research outputs are considered. 


\subsection{Performance-Based Funding Models for Teaching}

Among the OECD countries, Denmark and Sweden are two countries which have implemented a PBF model for teaching activities since 1990s. This section describes the performance-based teaching funding models used in Denmark (Taximeter) and Sweden (FTE Study Results). The section includes the rationale for choosing these two jurisdictions for study, the development and key elements of their models, noting the significant differences between the two funding models, and evaluations of the systems.

Although the United States introduced PBF for teaching first, the United States has not been chosen for this study because the budgeting systems known as PBF and performance budgeting take two similar but distinct forms (Burke and Minassians, 2003). These differences may be cumbersome and not practical for evaluating the systems.

Denmark and Sweden have been selected mainly because their PBF models are long-lasting and well-established. The two countries have standard funding models which are employed at the national level for all TEOs. Furthermore, there have been several appraisals of the systems from which lessons can be drawn.

\subsubsection{Higher Education System, Reforms and Funding (Denmark and Sweden)}

Higher education in Denmark is characterised by a large number of institutions. There are 12 universities, 21 institutions that offer long-term and medium-cycle courses, 55 non-research based institutions which offer a variety of shorter and medium-term courses, and 22 state sector research institutions (Rushforth, Arbo, Puukka, and Vestergaard, 2006). However, in 2007 several universities were merged with sector research institutions, so from 2007 there are only eight universities. Further, the major part of the medium-cycle higher education programmes are consolidated in seven professional higher schools, while the short-cycle higher education programmes are combined in ten vocational academies (Ministry of Education [Denmark], 2008). In the past few decades, the demand for higher education in Denmark has increased considerably and this has resulted in substantial increases in the public expenditure allocated to HEls as they are primarily funded by the state. 
In 2005, 198,900 students were enrolled in a higher education programme. Of these, more than $55 \%$ studied in a university programme, $34 \%$ in a professional Bachelor programme and $9 \%$ in a short-term cycle programme. The number of students in the university education programme increased by $9 \%$ from 2000 to 2005 , increase of $5 \%$ in the professional Bachelor education programmes, whereas short cycle education got $5 \%$ fewer of the students in that period (Ministry of Education [Denmark], 2008).

Until the end of the 1960s, the budgets of HEls were based on their own proposals negotiated with the Ministry of Education. Budgets for teaching and research were integrated. In the 1970s and 1980s the government attempted to balance the output of the higher education system (in terms of graduates) with the current and future needs of the labour market, reflecting this in the funding model. The Danish higher education sector was reformed drastically in 1992. The primary aim of the 1992 reform was to put the main stress in governance on the individual university's goals and results instead of on resource consumption and budgetary ties.

The main changes were: (i) the introduction of a new funding mechanism called the taximeter system; (ii) the establishment of the Danish University Act in 1993; and (iii) the introduction of four-year agreements on the total number of study places per institute. The University Act 1993 introduced economic decentralisation for the universities, which has been further emphasised in the most recent University Act 2003. The objective of the decentralisation is to "promote economic responsibility and make better use of the resources" (IMHE and OECD, 2006).

There are no tuition fees in Denmark for higher education courses. In 2004, public expenditure on higher education accounted for $4.6 \%$ of the total public expenditure in Denmark. This places Denmark over the corresponding OECD average of $3.1 \%$ but only New Zealand (4.9)\% and Norway (5.3)\% spend larger shares on higher education than Denmark (Ministry of Education [Denmark], 2008). From the beginning of the period 1994 until 2003, the total public expenditure on education in relation to the gross domestic product (GDP) increased from $7.4 \%$ to $8.2 \%$.

The expenditure on higher education in total increased by DKK 8.2 billion, or 31.0\%, between 1994 and 2003. It did, however, drop between 1996 and 1997 (Ministry of Education [Denmark], 2005). 
The 2006 total expenditure on education amounted to DKK 126.6 billion, corresponding to $7.7 \%$ of the GDP. In the year 2006, the expenditure on higher education increased by $2.3 \%$ from 2000 to 2006 and a total of DKK 25.6 billion was spent on higher education (Ministry of Education [Denmark], 2008). The fact that Denmark spends a large proportion of its national budget on education is a sign that education is given high priority.

In Sweden there are 36 government-funded HEls which comprise 14 universities, 7 independent colleges of fine, applied or performing arts and 15 university colleges. In addition to these, there are 13 private institutions (Swedish National Agency for Higher Education, 2008). The number of students rose from 170,000 in the autumn semester of 1990 , to 337,400 in the autumn semester 2004 (Klemming, 2005). In 2007, the student population involved 278,200 FTE's, with an average cost per student at the higher education institutions of SEK 74,300 (Swedish National Agency for Higher Education, 2008).

In the past higher education finance in Sweden was centralised and funding flowed from the central government to institutions through line-item budget appropriations based on input-oriented goals and detailed planning efforts (Salerno, 2002). The Swedish educational system has undergone a continuing series of transformations since the 1950s. Similar to Denmark, the Swedish higher education system was reshaped by two significant reforms: one in 1977 and the other in 1993 (Johansson, 2004). The main objective of the 1977 reform was to restructure the admissions system and combine all post-secondary education, whereas the 1993 reform aimed to improve the higher education system through decentralisation and enhanced efficiency. The traditional system of appropriations based on expenditures was replaced in 1993 by a system linked primarily to performance. Higher education, except for doctoral studies, is financed almost entirely by state grants.

A new Higher Education Act and Higher Education Ordinance came into force in 1993. This legislation introduced a deregulation of the system, a greater autonomy for individual institutions of higher education and a wider choice for students. As from 1993, a system of management by objectives and results was introduced for higher education, with the Government and Riksdag (Swedish Parliament) setting the objectives and HEls being assigned the task of meeting objectives with given parameters. 
The most important objectives approved in 1993 were: (i) to substantially enhance the freedom of universities and university colleges with regard to the Government and Riksdag; (ii) to improve the quality of operations and make efficient use of resources, (iii) increase the number of students completing their educational programmes; and (iv) to harmonise the supply of educational programmes in higher education with student demand (Sarback, 2004).

In 2001, the government allocated nearly SEK 47.2 billion of funding to HEls, representing nearly $2.2 \%$ of Sweden's 2001 GDP (Salerno, 2002). In 2007, Sweden's expenditure for the higher education sector amounted to SEK 58 billion, which corresponds to $1.9 \%$ of the GDP. Of this expenditure, student finance cost SEK 10.3 billion in 2007 (Swedish National Agency for Higher Education, 2008). Similar to Denmark, Sweden does not charge tuition fees for higher education programmes.

\subsubsection{Denmark Taximeter Model}

The key rationales of the taximeter model are to promote efficiency and to stimulate HEls to become more results oriented; to link the allocation of grants to educational production so that institutions with more students and better results were rewarded accordingly; to implement a system that is simple, fair and transparent; and to avoid the erosion of standards (Canton and van der Meer, 2001; Kaiser, et al., 2001).

The main elements of the taximeter system are as follows:

- The taximeter system is primarily output-based, linking funding directly to the number of students who pass their exams (Cheung, 2003; Maassen, 2000). The key variable is the completion rates.

- Universities do not receive compensation for students who fail or do not take their exams.

- The taximeter system is not operational for postgraduate students because the yearly performance is not measured. Therefore, funds are allocated on the basis of actual number of students, limited to a three-year period for each student. 
- The tariff paid per passed exam, the 'taximeter', varies substantially between different fields of study.

- The tariff includes the cost of teaching and equipment, joint costs (administration, buildings and maintenance), and costs for practical training.

\subsubsection{Sweden FTE (Students) and FTE Study Results}

Sweden's new funding system for teaching is based on an educational task contract negotiated between the Ministry and each university and university college. In these contracts the three-year objectives of the institutions are stated. "Educational task contracts" contain the following objectives: the minimum number of degrees, the minimum total number of FTE students, the fields of study in which the number of students is to increase or decrease and the follow-up of an annual report (Maassen, 2000).

Under the new regime, as from 1993/94, the grants voted by the Riksdag for higher education are calculated on the number of FTE students ${ }^{10}$ and the FTE study result, using special revenues decided by the Government. One FTE student is a student who has been registered for courses adding up to 40 credits points. This is because the Swedish academic year consists of 40 weeks, therefore in one year a student can accumulate 40 credit points. The appropriation for higher education consists of what is known as a "ceiling amount". Higher education institutions can earn, at most, revenues for FTE students and FTE study results equivalent to the ceiling amount. To give institutions flexibility between fiscal years, institutions can save FTE study results on the non-utilised ceiling amount, until the following year, of up to $10 \%$ of the ceiling amount.

The key features for the Sweden FTE (students) and FTE (study results) are as follows:

- One FTE study result has been achieved if the student has earned 40 credit points during the year, while a student who has earned 30 credit points has achieved a 0.75 FTE study result.

\footnotetext{
${ }^{10}$ The Full-Time Equivalent /FTE for the Sweden University is the number of students enrolled in a course, both first time enrolees and repeat enrolees, multiplied by the course's point total during a certain period divided by 40 . Students who withdraw less than three weeks after the course's start are not included in the calculation.
} 
- Unit subsidies vary from field of study and are set by the government annually. The unit subsidies are designed to cover all kinds of costs, including costs for premises and borrowing costs for fixed assets (Salerno, 2002).

- The total grant is calculated at the end of the financial year on the basis of the results reported. If an institution does not reach its planned ceiling, it does not receive the full funding and if it enrols more students than is allowed for in the ceiling amount, no additional compensation is paid.

\subsubsection{Significant differences between Denmark and Sweden Funding Models}

To supplement the evaluation of the performance-based teaching funding mechanism for Denmark and Sweden the significant differences are highlighted. The main distinctions are as follows:

- Denmark's funding model for teaching is entirely output-driven, while for Sweden it incorporates a mixture of input and output variables.

- The teaching funding formula for Denmark incorporates the tariff for teaching and overhead cost per active student, the tariff for practical training, and the tariff (teaching and overhead) for postgraduate students, be it laboratory or non-laboratory subjects. Sweden's funding formula includes the tariff (direct teaching costs and overhead) per full time student and the performance tariff.

- The budget period for Denmark is 1 year transferable, for Sweden there is an annual budget with three-year contracts.

Despite the disparities between the systems and lack of empirical evidence on the models, the funding mechanisms for both countries are still in operation more than a decade after their establishment. Based on the goals of the Danish and Swedish funding systems, the possibility of adopting PBF for teaching can be considered for SIDS. 


\subsubsection{Evaluation of the Taximeter System}

Unlike the UK RAE and New Zealand PBRF, there is only a limited amount of material and research assessing the Danish taximeter system (Canton, et al., 2001; IMHE and OECD, 2006; Kaiser, et al., 2001; Ministry of Education [Denmark], 2000).

\section{(i) Safeguarding the quality of higher education}

The Danish Ministry of Education acknowledges that an output-based funding system could give rise to quality problems. Under the taximeter system institutions may be stimulated to lower quality standards and tempted to let students pass their exams to increase revenues (Canton and van der Meer, 2001; Vossensteyn, 2003). Therefore, the Ministry established an evaluation centre in 1992, namely the Danish Evaluation Institute (EVA), which performs regular evaluations of educational programmes (IMHE and OECD, 2006; Thune, 2001). The EVA is an independent body which has the main task of evaluating the quality of study programmes and publishing these evaluations.

Moreover, there is a system of external examination put in place to uphold the academic quality standards. Both the EVA and the Ministry of Education consider the system of external examiners too costly to maintain (Vossensteyn, 2003). The external examiners are to ensure a fair and equal treatment of all students, monitor the quality standards, advise the institutions on the quality of programmes; and submit a report to the institutions (IMHE and OECD, 2006). Although a number of evaluations have been performed in the period from 1995 to 2005, no negative trends in the level of academic quality could be found. Rather the EVA report shows that the reform has resulted in greater focus on students' needs and teachers' "professional ethic" (IMHE and OECD, 2006). Therefore, it appears that the taximeter system is effective.

However, despite the costs, the mechanisms of the Quality Assurance Agency and system of external examiners in place may be essential to safeguarding the quality of teaching. 
The taximeter model is transparent in the sense that the 'tariff' for higher education is determined by the government annually and institutions receive funds based on the number of students who pass the relevant exams. Hence, the budget of the institutions depends on the results of their students. Moreover, the policy for funding is clear as the mechanism is output-oriented. It is inevitable that institutions will want to maximise their funding. Therefore, although the system is transparent, it encourages a more selective approach by institutions to recruit motivated and qualified students who pass their exams and complete their studies in the prescribed time period. This selective approach may pose problems for other institutions if they are not able to attract the best students since this may lead to low completion rates and finally result in less funding.

\section{(iii) Enhance autonomy}

With the implementation of the taximeter system and the University Act 1993, Danish universities are becoming more entrepreneurial. The institutions receive funds as block grants and they are free to decide how to distribute this funding among different activities (Vossensteyn, 2003). Furthermore, the institutions have gained significant powers, including making decisions on the free intake of students to specific programmes and the planning and organisation of the teaching activities and other transactions. As a result, there is an increased focus on value for money (Canton and van der Meer, 2001). Nevertheless, one can also have this kind of autonomy under a bulk-funded input-based system.

As with any model, there is no model which is perfect. The taximeter model as well has a few weaknesses. These comprise fiscal risk, quality-differentiation and internal allocation of funds.

\section{(iv) Fiscal risk}

One of the main weakness of the taximeter system is its open-ended character (at least in the short run), which can lead to fiscal risks (Canton and van der Meer, 2001). With this system, the exact funding to be paid by government cannot be forecast as it is not possible to calculate accurately the number of successful students. If more students pass exams, more resources are made available to the institutions. 
As a result, the actual expenses may exceed the budget of the Ministry of Education and the latter has to request additional funds from the Ministry of Finance. Nevertheless, pass rates are not likely to change very much from year to year. This reduces the fiscal risk involved.

\section{(v) Quality-differentiation}

Another argument against the taximeter model is that it has encouraged qualitydifferentiation across institutions. Entry standards vary between universities. Some opt for a high-quality strategy and have rigorous entry criteria; other institutions accept all applicants. The system does not allow for measuring the value added by an institution. In addition, it favours those institutions attracting the best students as funding is linked to completion rates.

\section{(vi) Internal allocation of funds}

Furthermore, the taximeter principle is used by most Danish universities for the internal allocation of funds over the various faculties. The internal application of the taximeter principle suggests that a department with reduced student performance would receive less money. Thus, this may lead to insufficient funds for such departments to meet their operating costs and give rise to budget relocations.

\subsubsection{Future Direction of the Taximeter System}

The Danish Government has recently presented the Globalisation Strategy in which a number of recommendations are focussed on the existing funding system (IMHE and OECD, 2006). One of the recommendations is that the Government intends to modify the taximeter system significantly but apart from a proposal to charge greater tuition fees (for foreigners), and stronger allocations from the State Educational Grant and Loan Scheme, few details of the modifications have been provided. 


\subsubsection{Evaluation of the FTE (students) and FTE study results}

It is important to note that to date there has been no comprehensive evaluation of the new funding regime. Nevertheless, the goals inherent in the Sweden's performance-based model are similar to those of Denmark. The Swedish system of funding for teaching activities displays some of the same merits, such as enhanced efficiency, greater autonomy, and promoting quality.

With regard to teaching quality, the greater emphasis on FTE study results (i.e. completion rates in the funding formula) might encourage HEls to pass more students, thereby lowering the required standards. To uphold the quality of higher education, the National Agency for Higher Education in Sweden conducts continuous quality evaluations of higher education including doctoral studies (National Agency for Higher Education [Hogskoleverket], 2005). The Swedish quality assurance system consists of two main procedures. One is the programme evaluation for accreditation and the other, more important one, is the regular audit of universities by the independent state agency (Maassen, 2000).

As an audit system, the aim for the evaluation is not the quality as such in programmes, but the nature and implementation of HEls quality enhancement activities. This investigation of quality involves both self-evaluation by the institutions concerned and assessment by external teams (Sarback, 2004).

The implementation of a new quality assurance system by the National Agency started in 2007. The aim has been to combine experiences from the preceding system with the new ideas about quality assurance and quality development that have lately been suggested in various national and international contexts. The new quality assurance system comprises five components that relate and support each other. These mostly include: (i) audits of the quality assurance mechanisms at HEls; (ii) evaluation of programmes; (iii) appraisal of entitlement to award degrees; (iv) thematic evaluations and studies; and ( $v$ ) distinguishing centres of educational excellence (Swedish National Agency for Higher Education, 2008).

Aside from its strengths, one of the main weaknesses which have been acknowledged by the Swedish government is that the performance-based teaching funding system does not work when setting up new HEls. This has become obvious during the implementation of the new funding mechanism. 
The Government stated in the "Open University" bill, that "allocations must initially be based on more than the present resource allocation system" (Sarback, 2004 p.42). In these cases resources should be allocated using methods other than a performance-based system.

To substantiate further the evaluation of PBF teaching models, the views of a UKbased PBF expert Dr Jonathan Adams were considered although he has less experience in teaching than research assessment. Adams (2008b) maintained that it is very challenging to carry out effective teaching evaluations as there are few indicators that are relevant. He stated that one possible indicator for a teaching assessment model might be student performance, the assumption being that if students do well then this is likely to reflect the quality of the teaching they have received.

However, Adams noted that there is a problem that one institution may have a different catchment to another institution. Those institutions which attract highly capable students from secondary school tend to produce quality graduates but the value added by the institutions may be very small. By contrast, in another institution the students may start at a much lower level, the value added may be much greater, but the graduates are still performing at a lower level than in other institutions. The respondent commented that the added value may give some indication of whether the teachers are teaching effectively. Nevertheless, he believed that a single indicator (e.g. student performance) is insufficient for teaching evaluations; there is also a strong need for the involvement of peer review. 


\subsection{Conclusion}

This chapter has provided a detailed overview of the different PBF models for funding higher education adopted by Australia, Denmark, New Zealand, Sweden and the United Kingdom. PBF has evolved gradually since the early 1980s and is still continuing and spreading to new regions in the world with new forms and shapes, largely influenced by NPM doctrines, which place strong focus on output and deliverables, and the importance of indicators to measure performance.

The PBF models which were surveyed clearly demonstrate that such mechanisms have been, to some extent, effective in enhancing technical efficiency, promoting quality, improving research performance and increasing greater accountability in the tertiary education sector. As discussed, the UK peer review and the NZ mixed models have definitely provided incentives to improve research performance and research quality. Similarly, the Danish and Swedish PBF models also aim at maintaining and safeguarding the quality of teaching in their higher education systems, which, not surprisingly, has resulted in the birth of evaluation agencies or institutes. Nevertheless, the Australian indicator model has, to date, failed to enhance quality, as it primarily focuses on rewarding quantity of publications.

It has become apparent from the evaluation of these performance-based research funding systems, that the various models (peer review, indicator, and mixed) have some weaknesses and unintended consequences. Some of the weaknesses are specific and related to the design and funding of the model, whereas others are of general nature. As discussed earlier, in relation to research funding models, in the United Kingdom, the RAE ratings and funding weights have been revised a number of times, mainly because of the general increase in quality rating. More specifically, the improved grades for the RAE 2001's assessment could not be totally funded by the funding councils, which resulted in the scale used in RAE 2001 being replaced by quality profiles for the RAE 2008. In New Zealand, the individual as a unit of assessment and quality rating system (e.g. quality categories and treatment of emerging researchers) resulted in unintended consequences, which led to improvements in the PBRF round 2006. Further, high administrative and compliance costs are a common weakness for both peer review and mixed models. 
Prioritising research at the expense of teaching activities is also a major concern, but there is little empirical evidence that research-based PBF has affected teaching quality.

Even for teaching models, although Denmark (taxi-meter) and Sweden (FTE Study Results) have slightly different models, one output-oriented and the other a mixed of inputs and outputs variables, both are flawed in some way. For instance, the Swedish model does not apply when establishing a new higher education institution, whereas the Danish model can lead to fiscal risks and does not gauge the added value of an institution. Further, performance criteria are hard to define for teaching, as individual institutions have varying missions. These two countries have implemented quality evaluation agencies to ensure that competition does not result in a lowering of standards as quantitative criteria are introduced. As a result, this increases the total costs of introducing such models.

Against this background, there is certainly no ideal PBF model. Each scheme has undergone revisions over the past decades, and there will likely be more changes in the future. If developed countries, which have a relatively large number of higher education institutions, sufficient financial resources and human capabilities, are experiencing such issues when implementing PBF schemes, SIDS are likely to face even more problems. SIDS should proceed with caution in deciding whether to adopt a PBF model, either for research or teaching or to seek alternative solutions to enhance TEls' performance, given SIDS' limitations in terms of population, size of the tertiary education sector and resources available.

The literature review clearly demonstrated that, amongst others, capacity and capability for rewarding improved performance for any kind of PBF schemes, large administrative burden and high costs, the choice of unit of assessment, the establishment of performance criteria, and the expenditure for setting up evaluation bodies are the important factors for determining the introduction and development of a PBF model in the tertiary sector. If developed countries, such as the UK, Denmark, NZ and Sweden, which have the necessary conditions for implementing PBF models have experienced such problems, it is likely that SIDS will have more difficulties due to their smallness, financial constraints, and limited human resources. Therefore, policymakers in SIDS need to give serious consideration to all the factors that may risk the development of PBF systems. 


\section{CHAPTER SIX: NECESSARY CONDITIONS FOR PBF SYSTEMS}

\subsection{Introduction}

The primary aim of this research is to examine the opportunities and challenges associated with the development and implementation of performance-based funding (PBF) models for tertiary education in SIDS - with particular reference to Mauritius. Thematic analysis is used in this study because it offers a flexible and useful research tool, which can provide a detailed and rich account of qualitative data (Braun and Clarke, 2006). The empirical analysis and the findings are presented in this chapter and in chapter seven.

This chapter describes the process of empirical analysis and explains how the empirical analysis for the 38 interviews undertaken for this research has been carried out. Further, chapter six covers the underlying conditions that emerged, both through the process of empirical materials collection and analysis and through the assessment of the strengths and weaknesses of the PBF systems undertaken as part of the literature review for this research. The four baseline conditions comprise policy objectives and outcomes for tertiary education in Mauritius, the present policy settings, the level of understanding and comprehension of PBF systems among the different stakeholders, and the objectives and drivers of PBF systems.

\subsection{Process of Empirical Materials Analysis}

As highlighted in chapter two, thematic analysis is used for this research. Thematic analysis is an approach that involves the creation and application of 'codes' to data. The 'data' being analysed might take any number of forms - interview transcripts, field notes, policy documents. The phases of thematic analysis outlined in Table 6.1 represent the different processes that have been carried out in analysing the empirical materials generated through the interviews with the 38 respondents in Mauritius. 
Table 6.1 Phases of Thematic Analysis

\begin{tabular}{|c|c|}
\hline Phase & Description of the Process \\
\hline $\begin{array}{l}\text { 1. Familiarisation with the } \\
\text { data }\end{array}$ & $\begin{array}{l}\text { Conducting all interviews in English. Transcribing } \\
\text { data verbatim which is an excellent way to start } \\
\text { becoming familiar with the data. Reading and } \\
\text { highlighting the data, and noting down initial ideas. }\end{array}$ \\
\hline 2. Generating initial codes & $\begin{array}{l}\text { Producing initial codes from the data, collating data } \\
\text { relevant to each code. }\end{array}$ \\
\hline 3. Searching for themes & $\begin{array}{l}\text { Coding and pulling data together, with different } \\
\text { codes sorted into potential themes derived from the } \\
\text { strong and weak points of the PBF systems. }\end{array}$ \\
\hline $\begin{array}{l}\text { 4. Reviewing and refining } \\
\text { themes }\end{array}$ & $\begin{array}{l}\text { Two levels of reviewing and refining the themes. } \\
\text { Level one involves reviewing the coded data } \\
\text { extracts for each theme, and considering whether } \\
\text { they appear to form a coherent pattern. } \\
\text { Level two involves a similar process, but in relation } \\
\text { to the entire data set. }\end{array}$ \\
\hline $\begin{array}{l}\text { 5. Defining and naming } \\
\text { themes }\end{array}$ & $\begin{array}{l}\text { Ongoing analysis to refine the specifics of each } \\
\text { theme. A detailed analysis is written, identifying } \\
\text { the story that each theme tells in relation to the } \\
\text { research question. }\end{array}$ \\
\hline 6. Producing the report & $\begin{array}{l}\text { Final analysis and write-up of the findings. The } \\
\text { write-up provides a concise, logical and non- } \\
\text { repetitive account of the narrative the data tell } \\
\text { within the themes, with evidence of data extracts } \\
\text { and examples. The extracts are embedded within } \\
\text { an analytic narrative which illustrates the story } \\
\text { about the data and makes an argument in relation } \\
\text { to the research question. }\end{array}$ \\
\hline
\end{tabular}

Source Adapted: Boyatzis, 1998; Braun and Clarke, 2006 
In general, a theme is an implicit or recurrent idea. According to Boyatzis (1998, p. 161), a theme is defined as "a pattern in the information that at minimum describes and organizes the possible observations and at a maximum interprets aspects of the phenomenon". The research revealed important themes in relation to the key research questions which both informed the interview schedule and which were further refined in the light of transcript data. Four themes are presented in this chapter and the others will follow in chapter eight. These particular themes cover the background conditions that will enable the development and implementation of PBF systems:

(i) policy objectives and outcomes for tertiary education in Mauritius;

(ii) present policy settings;

(iii) the level of understanding and comprehension of PBF systems by interviewees; and

(iv) the objectives and drivers of PBF systems.

Each of these themes will be discussed in turn.

\subsection{Policy Objectives and Outcomes for Tertiary Education in Mauritius}

The main policy objectives and outcomes that emerged from the empirical analysis are: (i) the increasing access for students to tertiary education, thus ensuring greater equity for educational prospects and improving quality towards knowledgebased economy; (ii) the enhancement of research culture; and (iii) the development of alternative sources of funding. These objectives and outcomes are essential for building human resource capacity, improving the socio-economic needs and quality of life, meeting labour market demands, and lessening the burden of government funding on tertiary education.

\subsubsection{Access, Equity and Quality Improvement}

Human capital is a significant social and economic resource and it has a critical role to play in the political, social and economic development for Mauritius. The first challenge to both the government of Mauritius and TEls is to support the knowledge-based economy by providing the necessary human capital. 
The majority of the respondents reported that equitable access and quality improvement are the primary policy objectives for tertiary education. A number of the respondents commented that increasing access to post-secondary and tertiary education and promoting equity for educational opportunities, are important goals for capacity building. Respondents R1 and R16 noted that increasing the participation rate, such as GTER ${ }^{11}$, and focusing on the numbers of students with degree qualifications from the TEls are the main policy outcomes. The following quotes from R6 and R9, both policy makers, illustrate the above statement:

To make Mauritius a knowledge hub, increase student access, increase quality, and promote equity. Education for all, life-long learning is a priority for Mauritius (R6.Q1)

To increase access we are also working towards the setting up of an open university, it would be a distance university. We have objective to reach GTER of $40 \%$ in 2010 and would like to achieve $45 \%$ by 2015 so as to be at par with countries which at a similar stage of development [is] something which we are not now (R9.Q1)

Respondents R15, R26, and R32, all senior officials, commented:

The issue of the access to tertiary education which I think should be a primary objective. In terms of equity, those who cannot afford to pay we need to have support programs (R15.Q1)

Increase access for students. There should be equity and fairness, those who have the potential for higher education but not affordable (R26.Q1)

More "democratise" the system so that more students and people can join university (R32.Q1)

In addition, of the 38 respondents, a clear majority (24) described quality

enhancement as a major policy objective for tertiary education taking into account the emerging challenges for building capacity for a knowledge-based economy, and in coming to terms with the challenges of globalisation. Some respondents viewed quality in two dimensions, namely: (i) relevance and employability; and (ii) international recognition.

\subsubsection{Quality as Relevance and Employability}

Many respondents emphasised that there must be strategies to improve quality in terms of the employability of students emerging from the TEls. They claimed this is because Mauritius has quite a number of university graduates who are either unemployed or underemployed.

\footnotetext{
${ }^{11}$ Gross Tertiary Enrolment Ratio
} 
Respondents also noted a skills mismatch between the kind of people produced and the kind of people required, since those who have acquired tertiary education are not necessarily finding suitable openings in the job market. These views are illustrated in the following quotes, all from academic staff:

Tertiary education system should aim at producing people particularly young people, to fit the job market demands in Mauritius (R14.Q1)

To produce graduates for relevant employment. We are churning out graduates but unfortunately many of them are underemployed (R19.Q1)

Universities these days are supposed to produce the human capital that has [are] required by the economy (R29.Q1)

One respondent, a senior official, commented:

There is quite some work to do in terms of producing graduates but producing them in the fields that we need them and also with the kind of quality that we require from them (R8.Q2)

And another respondent, a representative of the TEls staff association, observed that:

By quality I mean the types of courses which will make these people employable. Also to meet the general education requirements other than employable skills (R24.Q1)

A similar view was taken by a chief executive of an organisation representing tertiary education:

... [It] should be employability that means responding to the needs of the industry in terms of human resources (R31.Q1)

Most of the respondents indicate that policy should be geared towards equipping young people with the skills and knowledge that will enable them to obtain employment in the public and private sectors.

\subsubsection{Quality as International Recognition}

Some respondents revealed that international benchmarking is also another consideration in terms of quality. Quality of a recognised international standard is significant because people are living in a global world and both institutions and students should be able to benchmark themselves with other students from overseas. One respondent, an academic, noted that:

Main policy objectives should be looking at standardisation in terms of different TEls in Mauritius so as to provide branding of the tertiary education level and recognition in the region and internationally (R17.Q1)

Other respondents had similar views:

Our vision is to provide quality education of international standard (R16.Q1) 
We need to upgrade our quality of tertiary education and achieve world class education (R26.Q1)

Additionally, a few respondents argued for quality in terms of responsible citizenship. Other respondents expressed their concerns about the quality levels of tertiary education and the brain drain.

\subsubsection{Responsible Citizens and Brain Drain}

A few respondents mentioned that people acquire tertiary education to enhance the quality level of the citizenship of the country and society. This entails contributing towards having a society with more educated, informed and cultured people. To quote R16 and R21, both policy makers:

Quality in terms of responsible citizenship - we don't want people to go to universities [to] acquire education just for work but also responsible citizens (R16.Q1)

We should ensure the knowledge they get to become good citizens and to be able to earn a living (R21.Q1)

The phenomenon of a brain drain was also noted by a number of respondents. This is a common feature in small island states where, instead of remaining within the domestic labour force, the highly skilled go overseas, and often, once abroad, remain there in order to find better and well-paid employment. This leads to a lack of skilled labour force and qualified people to sustain the development needs of the country and to meet the challenges of emerging sectors. One respondent commented that:

This is also a national problem, a lot of qualified staff, or experienced people are constraints in terms of opportunities available locally they leave the country to go elsewhere (R2.Q1)

Some respondents also expressed dissatisfaction about the quality of education at the tertiary level:

Policy objectives obviously we have a lot in place in my opinion we are not ensuring the quality itself. (R25.Q1)

I wonder how far we are really meeting the quality criteria (R28.Q2)

The preceding analysis implies that, although access, equity and quality improvement is the main policy objective for tertiary education in Mauritius, the most crucial element for tertiary education in SIDS is the quality of education at all levels. 
Quality is an important challenge for Mauritius as it seeks to compete in the world since human resources are the predominant asset of the small island states. The overall view of the respondents interviewed for this research is that explicit mechanisms have to be developed and implemented to maintain and enhance the quality of the tertiary education system. One respondent commented:

I am very fearful not just me.... I speak on behalf of my colleagues that the quality will suffer due to cost cutting and the unwillingness by government to fund TEls (R37.Q2)

This undoubtedly indicates that there is an urgency to get the funding mechanism right.

\subsubsection{Enhancement of a Research Culture}

Despite the emphasis on quality, the research identified that there is a lack of a research culture in the tertiary education sector in Mauritius, even though academic promotion depends on research. A number of respondents commented on the significance of knowledge creation in small island states and its role in the national development of the economy.

Respondents from different stakeholder groups claimed that there is a need to strengthen and promote research by investing in collaborative research projects, creating an Excellence Park, and enhancing the body of knowledge in subjects that are interesting and relevant to the economy and society. One respondent, an academic, in commenting on knowledge creation observed:

The first goal is to focus on research, pure and applied. Under this goal there is a list of strategies that we think should be actively pursued in order to achieve the objectives: (i) Encourage team research,(ii) Create Excellence Park (iii) Research enterprise of the university; [and] (iv) Invest in collaborative research projects (R2.Q1)

Two other respondents, one a policy maker (R7), and the other, a chief executive from a tertiary education organisation (R31), commented:

In terms of the output of the research most of it has gone in publications but the application of the research findings has not been evident (R7.Q1)

It should also cater for those who would like purely to enhance body of knowledge in any subject matter that they would find interesting (R31.Q1) 
Further, some of the respondents questioned the contribution of research to national needs and the extent to which research outputs are being applied to the local context and in particular national economic development requirements.

The following comments from a policy maker illustrate this point:

\begin{abstract}
Research based towards publications in scientific, local and international journals and has not been enough emphasis as I said earlier on to what extent that research output is being applied to the local context and to what extent it is adding to the economic growth of the country (R7.Q2)
\end{abstract}

It was also claimed that research and development levels remain very low and there is a lack of proper equipment and resources available to undertake specific research.

Another academic respondent commented:

Research and Development levels remain very low in this country [Mauritius] I don't know the exact figure ...when compared with Singapore and Korea ...on that indicator [research output] we fail miserably (R29.Q2)

A senior state official responded in a similar manner:

In terms of the research itself, the problem that we are facing is in terms of equipment is not easily available locally but still has a lot to invest in research in getting the proper equipment and funding (R28.Q3)

The above comments illustrate the importance of research activities in Mauritius for the advancement of the economy, applicability of the research, improvement for quality teaching and enhancement of knowledge.

\title{
6.2.3 Development of Alternative Sources of Funding
}

Many respondents indicated that the government would not be able to sustain its funding for tertiary education on the scale it has been doing in the past. TEls are facing increased competition from other public services for scarce financial resources. Alternative sources of funding for TEls are a crucial issue at the moment. The main sources of funding mentioned by respondents are private participation in the provision of tertiary education, external research funds for TEls, and the introduction of tuition fees. These are the gateways for exploring alternative sources of funds.

The following extracts from interview transcripts of a chief executive of a TEI (R1) and two policy makers (R5 and R9), indicate support for alternative sources of funding through external funds for research activities and private participation. 
Researcher is so successful that he or she can bring in funding to be more self financing and to finance the institution (R1.Q1)

We want to get the support and encourage private sector to step in because government not going to provide all funds for tertiary. We want to improve the number of tertiary institutions in Mauritius and do it fast to attract as many as possible (R5.Q2)

Encourage private partnership first by encouraging brand name institutions from abroad to set up campuses. A new legislation passed since 2005 to that effect (R9.Q2)

Another important issue raised by this research is that the government needs to adopt cost sharing measures for all TEls. One respondent, a chief executive, made the following observation:

I wonder. Without generating funding you won't be able to expand the university, there must be a way of re-looking the system and introduce some kind of funds without forgetting there will always be some needy students which will need some incentives like scholarships (R10.Q4)

Although cost sharing measures are becoming an important concern for government, a senior state official noted that:

At the level of the Government...the government does not seem to have on its agenda the introduction of fees (R28.Q2)

The preceding discussion suggests that there is a strong sense of the need for reform in the tertiary education sector. The demands on tertiary institutions to enhance quality of education, promote research culture, increase access and equity, and develop sources of funding are the main public policy objectives. The drive to develop human capacity is being met by increasing access to tertiary education, although the brain drain is still reported to be one of the greatest obstacles to development. To achieve these desired objectives the government has to review the way TEls are funded. Respondents support evidence in the literature (Vossensteyn, 2003) that quality is a crucial aspect of PBF systems. Thus, the development of PBF mechanisms may possibly contribute to the improvement of quality in tertiary education. Further, to undertake research, people need to be equipped with the necessary resources. Therefore, a funding mechanism for research activities is a critical element which policy makers need to consider in order to achieve the policy objective of promoting a research culture. 
The introduction of a performance-based research funding model may be a possible option for creating an environment conducive to research in Mauritius and promoting research capacity and capability. However, the amount of money matters too.

In sum, the policy objectives and outcomes highlighted earlier by the respondents in Mauritius are part of the strengths of the PBF systems adopted by the developed countries.

\subsection{Present Policy Settings}

This section considers the present policy settings identified in light of the transcript data, including the responses on the extent to which the tertiary education system is producing outcomes such as increasing student access, ensuring greater equality of educational opportunity, and improving quality.

The respondents have mixed views as to the extent to which the tertiary education system is producing those outcomes. Respondents mentioned that happens mainly because each government that comes into power has its own policies and outlook on the development of the country. Further, there is lack of training needs analysis and there is still a skills mismatch between what is produced by the tertiary education sector and what is required of it.

Respondents were asked: "To what extent is the tertiary education system producing those outcomes? If it is, what is the present policy mix that is producing those outcomes? - If it is not, what are the impediments to those outcomes being produced?".

The following quotes illustrate the views of academics:

In a sense yes because we are providing young people and mature students with the necessary qualifications, training etc. But at the same time the lack of the Training Needs Analysis (TNA) at different levels although it specifies at certain a point in time that TNA are carried out that government publishes a list of priority areas to be trained to fit in the different sectors. (R14.Q2)

Well it is to a certain extent yes producing those outcomes because there [are] some graduates finding the relevant employment (R19.Q2)

Mauritius as a whole has a very small output of graduates as compared to many other countries of similar levels of income and therefore it goes to show that, as it is, the system is not producing enough graduates... Is it producing the right kinds of graduates for the kinds of emerging knowledge economy? (R29.Q2) 
One respondent, a senior state official, observed:

I believe [the policy settings] meet only one third of those [policy objectives and] outcomes (R26.Q2)

In addition, respondents felt that the tertiary education system is not producing teaching outcomes to the required level. Some suggested that the tertiary education system is too focused on basic skills and competencies such as literary skills and little different from the secondary school system. Other respondents noted that teaching loads are high and academics do not have sufficient time to conduct research activities.

One respondent, an academic, commented:

Education that they receive seems to be very textbook oriented. If you see the number of contact hours it is heavily loaded, 18 hours of contact per week and it is just teaching. There is so far no room for tutorials (R3.Q3)

And another respondent, a policy maker, noted that:

To a great extent I have the feeling that the university is sort of an extension of secondary school (R36.Q2)

A similar view was taken by $R 24$, a representative of the TEls staff association:

The overburden in terms of teaching, it's like mass production. Staff cannot conduct proper research to develop value added programs (R24.Q2)

Other respondents noted that there is a quality audit system put in place by the Tertiary Education Commission (TEC) with the objective of maintaining and improving the quality of teaching. One respondent expressed the view that, for public institutions, peer review and people from overseas are employed to conduct the quality audits but for private institutions it is the TEC that undertakes the quality review process.

The preceding discussion confirms that the respondents from the different stakeholder groups are not fully satisfied with the extent to which tertiary education in Mauritius is achieving the outcomes of increased student access, greater equality of educational opportunity, and improved quality which policymakers require. While the present policy mix includes the provision of free tertiary education to school leavers, and only a nominal fee is paid for general administration, in practice there is no consistent tuition fee policy. 
This inconsistency in the policy mix arises from one university (University of Mauritius) not charging tuition fees while the other university (University of Technology, Mauritius) charges tuition fees for school leavers.

Two respondents, one a senior official (R26), and the other, a representative of TEls association (R37), observed:

There is only one free university and the second is partly subsidised (R26.Q2)

We don't mind that government do not give us money ... [they] let us charge fees and generate our income (R37.Q2)

Further, one respondent mentioned that the present policy mix is one which keeps on changing because there are regular changes in government with each election (normally every five years). Once another party comes into power there is no guarantee of follow up in terms of government policies. To quote R12, a policy maker:

We have a system of government where we have a five years rotational type and any outcome in an education system is one from childhood to primary cycle it takes seventeen years minimum to generate graduate or postgraduate what comes in tertiary education. This cycle keeps on being disturbed (R12.Q2)

Another respondent revealed that it is very difficult to get all the resources available put at the disposal of tertiary education sector. The following comments from a senior official support this:

The budget allocated to tertiary sector around 3\% of the GDP goes to tertiary education sector or in terms of education budget is around 12 to $13 \%$ ( $R$ 28.Q2)

The above findings imply the necessity for government to review the present policy mix. In addition, respondents believed that the introduction of fees is one of the key issues which government has to consider.

Other significant issues raised by the respondents are that funding constraints, resistance to change, lack of expertise and human resources, and limited number of seats in TEls are the main impediments to providing quality tertiary education. The majority of respondents mentioned that funding constraints are a key barrier. They further indicated that the cost of higher education and lack of funds to purchase equipment, infrastructure and human resources, and space to expand campuses are the other impediments to growth of the tertiary education sector. 
Two respondents, both academics (R4 and R13), and a chief executive of a TEI (R33) commented:

Its inability to recruit [the] number of academic staff required, lack of funds to purchase equipment and to increase the documentation facilities (R4.Q4)

There is a lack of funding from the Government (R13.Q 2)

The impediments are in trying to get more and more resources in terms of pedagogical materials, infrastructure, and human resources (R33.Q2)

Respondents also argued that TEls are not able to recruit the number of academic staff required. One policy maker observed that in most of the TEls the ratio of support staff to academic staff is higher than it needs to be.

Further to that, some respondents noted that resistance to change is another impediment in achieving the policy objectives and outcomes in Mauritius. The tertiary education system is one where people's level of understanding is likely to be highest, yet there are many people's mindsets to be changed. A policy maker supported this view:

Changing mindset is the second issue especially when you are moving [from] government funding to private funding for education. The issue of using key performance indicators is a new concept and meets a lot of resistance to change (R21.Q2)

One respondent, a policy maker, mentioned that there is a lack of expertise and qualified human resources for producing the desired outcomes:

It will not be a very easy task for the tertiary education sector because of the problem of financial resources.... whether we have the real physical and human capacity to be able to respond rapidly to these emerging challenges (R35.Q2)

Additionally, one academic staff member indicated that there is an inefficient use of human capital. The respondent claimed that the low outputs of the schooling system which then become the inputs of the tertiary system highlight the wastage that goes on within the education system in Mauritius.

The respondent commented:

About $40 \%$, of course I am exaggerating a little bit, but the reality is that it is not exaggerated because when you look at those who even pass the Certificate of Primary Education they can be considered as failures because two years [later] they fall out of the secondary school system. So if we have such a large wastage of human capital at the age of $10+$ we are already eliminating a good portion of our student population. Then when you go up the ladder and you look at the pyramid ... you find a very small percentage making it [into the tertiary education sector]. So that in itself is an impediment when you are wasting so much human capital (R29.Q2). 
The above views indicate that the tertiary education outcomes are only being partly achieved and suggest that the government will need to review the present policy settings if the policy objectives or outcomes for equitable access, employability, and quality improvement are to be attained.

\subsection{Understanding and Comprehension of PBF Systems}

Respondents provided a lot of views on PBF systems and answered the questions according to their own understanding of the terms "performance" and "performance-based funding" rather than from any familiarity with models in practice. The level of understanding and comprehension of the various PBF systems varies among the respondents. Some respondents viewed PBF as a system which is linked to performance criteria and indicators, whereas for other respondents it acts as a financial reward for teaching and research achievements. Only two respondents indicated that they viewed PBF as an output-based system.

Of the 38 respondents, 17 considered PBF as a funding system which is related to performance criteria or indicators. Respondents were not fully aware of all the different indicators for teaching and research activities but had some knowledge of the common ones, such as number of graduates produced, publications in refereed journals, and successful PhD supervisions. Three respondents, all policy makers, commented:

\footnotetext{
We are moving towards performance-based budgeting. PBF is right planning, right targets, deliverables and performance indicators be it a faculty /cohort tied to outcomes (R6.Q3)

It is essentially a funding system which is based with key performance indicators in the system (R9.Q3)

Well I believe that we need to have clearly established performance indicators (R16.Q3)
}

Similarly, two academics, responded:

Performance indicator that may be related to performance based funding system may be, for example, number of students admitted, number of graduates produced per year, number of publications established by staff, number of MPhil and PhD graduates (R4.Q3)

Criteria need to be set against which the performance of TEls will be measured (R13.Q3) 
In addition, (R26) a senior state official and a TEI chief executive (R34), had the same views:

PBF system means that funding will be based on the performance and attached with key performance indicators (R26.Q3)

We should have very clear cut and measurable performance indicators (R34.Q3)

The responses revealed that performance indicators are regarded as one of the most important elements in the PBF system and the key performance indicators must be measurable and easily quantifiable.

One third of the respondents (13) mentioned that PBF is a funding system that depends on performance, with financial rewards attributed for teaching and research achievements. The respondents understood that "performance-based" is about how particular institutions are performing in terms of their teaching and research, and that funding will be allocated based on performance.

A chief executive of a TEI (R1), and a policy maker (R30) commented:

PBF system applies financial reward for achievements made in typically teaching or research work (R1.Q3)

PBF would be funding depending on the performance on the output and on the outcome. Therefore the one who needs more will get more rather than giving everybody the same amount which often leads to wastage (R30.Q3)

An academic responded in a similar manner:

PBF system is according to outcomes. Funding will be according to the number of people we produce with qualifications (R19.Q3)

A policy maker (R7) expressed the view that PBF relies heavily on the teaching and research outputs achieved:

In the funding system we have to ensure that different outputs have met the target that was envisaged there (R7.Q3)

Further, a senior state official (R2) supported the above statement and commented that PBF is in the same line of philosophy or approach as Mauritius intended to implement under a Medium Term Expenditure Framework.

The above findings illustrate that most of the respondents from the different stakeholder groups have a general notion of the funding mechanisms but do not have a comprehensive understanding of how the systems work or operate in the tertiary education sector. 
A majority of the respondents have limited knowledge of specific PBF models for teaching and research activities. One respondent, a policymaker (R21), and another, a TEI chief executive (R22), commented:

I cannot tell you right away of which country and which models (R21.Q11)

I understand the philosophy. How it is functioning in detail I'm not conversant (R22.Q6)

The above views are further supported in the following quotes by a senior official (R2) and academic staff:

I would not say I have a deep knowledge of any PBF models but I'm quite familiar with how funds are being allocated in the UK based on the RAE. I'm not too sure as an instrument for allocation of funds (R2.Q11)

For teaching I don't know such a model that funding is correlated with performance (R4.Q11)

Well I have some difficulty with this term although I know that it is being used in the literature (R29.Q3)

And a representative of TEls staff association responded in a similar manner:

I don't understand PBF system (R24.Q3)

The preceding analysis suggests that the PBF system is a fairly new concept in the context of Mauritius. Despite the responses from the stakeholders, it is clear that there is a lack of understanding of the various PBF models and systems. The strengths and weaknesses of the PBF models for research (UK and New Zealand) and teaching (Denmark and Sweden) revealed in the literature review suggest that the current level of understanding and comprehension among key stakeholders may well be an important challenge and constraint for the development and implementation of PBF systems in SIDS. As is evident from the discussion of the academic literature in chapter five the choice of performance indicators is critical.

\subsection{Objectives and Drivers of PBF Systems}

This section focuses on the objectives and drivers of PBF systems. On the basis of the literature reviewed in chapter five this appears to be a key issue and so was canvassed with stakeholders through interviews. The three key objectives are improving efficiency and value for money, promoting quality, and enhancing accountability. 
Although the interviewees were not well conversant with PBF models in practice, the following questions were asked: "What specifically might/should a PBF system seek to achieve in Mauritius? Who, if anyone, is advocating a PBF and why?" in order to ensure better understanding of PBF systems. Respondents claimed that overseas funding agencies, policy actors and domestic participants are the major drivers for advocating a PBF system. A significant number of the respondents (14) expressed the view that efficiency and value for money is a vital objective for PBF systems.

They stated that PBF should seek to better manage resources and eliminate inefficiencies and wastage. Further, the system should focus on value for money because government has financial constraints, and other priority areas, such as health services and social security, are competing equally for these financial resources from the state. Four respondents, all policy makers, commented respectively:

PBF system should seek to achieve value for money, and to better manage resources i.e. eliminate inefficiencies and wastage (R6.Q4)

Tertiary education is presently funded at the level of almost one billion rupees a year. Are these 1 billion rupees well used? Is the use efficient? (R9.Q4)

PBF system will enable us to assess the efficiency of the system (R16.Q4)

PBF should aim at ensuring that the little amount of money that we spent on tertiary education in this country is used efficiently and above all decrease the wastage in the system (R30.Q4)

Another, a TEI chief executive, responded:

I think the PBF system as I said is good. It will allow us to measure our achievements this will relate to its usefulness and the efficiency of the system (R34.Q4)

Two senior state officials had similar views:

I think it will improve efficiency of institutional activities performance in that it will force the institutions to plan the activities upfront and to monitor the outputs during implementation. To increase expenditure in activities which are proving to be beneficial while at the same time curtail expenditure in activities which are not bringing results (R2.Q4)

Reducing inefficiencies or wastages in the system and attaining our objectives with our limited funding that is where money should go first (R8.Q4) 
The responses described above demonstrate that majority of the respondents are of the similar belief that the development and implementation of a PBF model will increase accountability, efficiency and enhance value for money.

As it was pointed out earlier, quality has been seen to be one of the most crucial factors for tertiary education to keep abreast of the emerging challenges of globalisation and the knowledge-based economy. Some respondents indicated that PBF systems will motivate staff to develop high levels of excellence in both teaching and research activities. Two respondents, both policy makers, commented further on quality issues:

We want students to get the highest quality education in terms of programs, teaching and learning (R5.Q4)

PBF system should seek to achieve quality and excellence in the work that is being done and most of all the applicability of the results of the work in terms of the social and economic development (R7.Q4)

Another comment from an academic staff member supports that statement:

The PBF system is about the quality of students that they are producing. It will look at indicators like the employability of the students. Also now in terms of research output, what type of research they are undertaking, where their research published, is they in top rank journals (R3.Q4)

The extracts from the interviews illustrate that a variety of stakeholders are aware of the need for PBF systems in order to improve quality in tertiary education teaching and research. In general terms, respondents believe that such a funding mechanism will increase greater accountability to taxpayers, students and the public at large.

The respondents maintained that TEls have to be responsible for whatever resources are provided to them. Two policy makers made the following observations:

We cannot afford to waste any resources or to use our resources liberally and we have to be accountable for whatever we are using in the tertiary education (R7.Q6)

PBF will introduce more rigour, more accountability and will ensure that people at all levels feel accountable. PBF is certainly a new model that will ensure accountability across the whole system (R16.Q6) 
A senior state official (R15) and another respondent (R31) commented:

PBF system would put the honest (onus?) on the institutions to demonstrate that they are delivering the outcomes and this would increase their accountability to the population at large and more specifically to those who are providing funding (R15.Q6)

To increase public accountability and identify the low performing tertiary education institutes (R31.Q4)

The preceding analysis supports the arguments reviewed earlier in the literature that the quest for efficiency, quality and accountability are the underlying principles for PBF systems.

In addition, other important drivers of the PBF system have been raised by this research. Forty two percent of respondents indicated that overseas funding agencies such as World Bank, IMF and EU are potential drivers for PBF systems. This is because these overseas agencies provide additional externally generated funding for certain critical government projects where domestic funding is scarce. On the one hand, these funding agencies want to know how the funds are used at the government level and want to ensure greater accountability. On the other hand, these agencies typically impose certain terms and conditions for the grants disbursed so that they can measure the achievements and outcomes.

Three policy makers commented:

The idea is being rightly brought in and enforced by international agencies because of the budgetary situation of the country (R7.Q5)

We seek financial support from external agencies such as the World Bank, the EU and others it is only clear that these funding agencies.... monitor whether the funding which they are giving is rationally used (R9.Q5)

Financing agencies also have imposed such conditionality to measure success and achievements in terms of resources as compared to outcomes (R12.Q5)

Two other respondents, both senior state officials, had similar views:

Overseas agencies as well World Bank, ADB, various European agencies as well have explicitly told the government that they have to put more order in their financial management systems because money is going in and we are not sure that the money are used in an optimal manner (R2.Q5)

If ever there is PBF system coming to Mauritius I would rather believe that it will be coming from overseas rather than local actors (R27.Q5) 
Only $18 \%$ of the respondents argued that policy actors (Ministers, Members of Parliament, advisors) are advocates for a PBF system while $26 \%$ mentioned that the drive mainly comes from the domestic participants (chief executives of government agencies and TEls, senior state officials). Two of the TEls chief executives commented:

I should say it is the policy actors (R22.Q5)

Generally they are the policy actors influenced very strongly by overseas agencies (R33.Q5)

The domestic participants were also emphasised by academics R4, R14, and R20.

The respondents mentioned that both policy actors and domestic participants are in favour of such schemes because resources are scarce and they want people to deliver the results and achieve the set targets. Moreover, $14 \%$ of the respondents claimed that the drivers of PBF systems are a mix of overseas agencies, policy actors and domestic participants.

One respondent, a policy maker, observed:

Policy actors / domestic participants as well as overseas agencies too have exercised a pressure in the system to deliver because at the end of the day when we say PBF the activity part of it is government but the outcome or the beneficiaries is the people (R12.Q5)

One respondent, an academic, made the following observation:

I think it's a mix of all three at a very minimum level (R29.Q5)

Another academic staff member commented:

I don't think really there is any one advocating for the PBF in education sector (R3.Q5)

The preceding analysis indicates that overseas funding agencies are likely to have an important influence in shaping any government funding mechanism as the former are the primary providers of funds for small island states.

Further, the interviewees' responses illustrate that both policy actors and domestic participants are anticipating making better use of their funding through performance-based measures and ensuring that the necessary conditions set by the funding agencies are met. 


\subsection{Summary Findings}

The empirical analysis and findings from the different stakeholders interviewed for this research reveal that increasing access for students, ensuring greater equality of educational opportunity, promoting excellence, enhancing the research culture, and developing alternative sources of funding are the key policy objectives or outcomes for tertiary education in Mauritius. The respondents constantly stressed the need for quality in tertiary education because human capital is regarded as the most valuable resource for SIDS to become knowledge-based societies and to compete in the global environment. Of those interviewed, some respondents (including policy makers and academics) argued that relevance and employability, international recognition, and the broader issue of ensuring responsible citizen engagement in governance are other issues which pertain to the quality of tertiary education. According to the literature, quality is one of the main arguments in favour of the introduction of PBF schemes.

The need for revamping the research culture in Mauritius is significant in terms of the improvement in teaching quality, knowledge creation, and socio-economic development. Alternative sources of funding, such as the introduction of tuition fees, are essential because the government of Mauritius has scarce financial resources. By and large, the different stakeholder groups (policy makers, TEI chief executives, senior officials, academics and representatives of the TEI staff association) shared similar views on the tertiary education policy objectives and outcomes in Mauritius.

The present policy settings suggest that the tertiary education policy objectives and outcomes in Mauritius - such as (i) increasing student access GTER and number of graduates with degree qualifications, (ii) enhancing quality in terms of employability rates and relevancy, and (iii) fostering greater equality of educational opportunity - are moderately realised in the tertiary education sector.

Of those interviewed, senior officials and representatives of the TEls staff association claimed that the present policy mix in relation to tertiary education funding is not consistent across the TEls. For instance, it was noted that the leading university (UoM) does not charge fees for school leavers, whereas the newly established university (UTM) has introduced tuition fees for full-time students. 
Most of the stakeholders who participated in this research highlighted that the lack of government funding and human capital, the difficulty in managing resistance to change in the tertiary sector and the few places available in TEls are the foremost impediments to realising the tertiary education outcomes in Mauritius.

The different stakeholder groups interviewed for this research demonstrated a general understanding of the nature of PBF systems - i.e. that under such approaches, funding is linked to performance, financial rewards are attributed for teaching and research achievements, and PBF is an output-oriented system. However, few of those interviewed had a detailed understanding of current PBF systems elsewhere in the world or how precisely funding and performance is, or should be, related. Of those interviewed, those with the best understanding of PBF systems were policy makers and academics. By contrast, it was evident that TEI chief executives, senior officials, and the representative of the TEI staff association had only a minimal understanding of such systems for both teaching and research. Overall, the interview data confirmed that because PBF systems are not used in Mauritius there would be only a limited understanding of their nature, design and likely impacts of the systems.

On the basis of the interviews conducted, it was repeatedly stressed by most of the respondents that enhancing efficiency and value for money, increasing public accountability and promoting quality for tertiary education are the key objectives for funding systems. Of the different stakeholder groups interviewed, primarily the policy makers placed considerable emphasis on all three objectives. Nevertheless, senior state officials and TEI chief executives commented on reducing inefficiencies and increasing greater accountability for government money generated from students' fees, taxpayers and the public at large. Similarly, academics supported the PBF objectives of improving efficiency in TEls and enhancing quality for both teaching and research activities.

The interview data clearly demonstrate that the opinions vary in terms of the respondents' roles in various sectors. This is because stakeholders have different goals, beliefs and perceptions in terms of their status. Policy makers and chief executives of TEls will focus more on national and broad strategies and their impacts on tertiary education while academics and other stakeholders will concentrate on operational issues that may have an effect on their achievements, reputation, performance and workload. 
In general, the empirical findings from the relevant people interviewed concurred with the rationale for PBF systems as discussed in the literature review, in chapter five.

Equally, many of those interviewed thought that overseas funding agencies, such as World Bank, IMF and EU, are the significant drivers for advocating PBF systems as they are the main external providers for financing SIDS projects. By and large, the TEls chief executives interviewed were of the opinions that the drive comes mainly from policy actors, including Ministers, Members of Parliament, advisors, chief executives of the Ministries and Departments involved, and Chairmen of TEls.

However, it was clear from the interview data that the academics considered that domestic participants are also drivers for PBF systems. Academics believed that chief executives of TEls and senior state officials have their on own reasons for supporting the overseas funding agencies and policy actors. By contrast, very few of the respondents maintained that the driver of PBF systems is a mix of all three (i.e. overseas funding agencies, policy actors and domestic participants).

The overall conclusion that can be reached on the basis of the analysis and findings is that the views on tertiary education policy objectives and outcomes by the different stakeholder groups in Mauritius are similar and appear to be reasonable for SIDS in order to meet the challenges of globalisation, and the need to build knowledge societies and human resource capabilities. The analysis also concurs with what Crossley and Holmes (2001, 2004), Bray and Kwo (2003), and Pillay and Elliot (2005) found in their work, namely that small island states have to reconceptualise educational policies, focus on educational research and quality issues, and invest in human capital.

The inconsistency in policy mix, government budgetary constraints and the attitudes of stakeholders towards change in Mauritius may create problems for realising those objectives and outcomes as discussed earlier. The interview data revealed that most stakeholders lack familiarity with the PBF models which developed countries have put in practice. 
Moreover, the preceding discussion on the objectives of PBF systems by the various respondents is consistent with the key arguments in favour of PBF systems as evidenced in the literature (Boaden and Cilliers, 2001; Boston, 2006; Burke and Modarressi, 2000; Evans and Quigley, 2006; Guena and Martin, 2003; Serban, 1998). This implies that although stakeholders have a lack of understanding on the different PBF models they are sufficiently informed about the underlying principle of PBF systems.

The empirical analysis of policy issues, understanding and drivers of PBF systems provides evidence that there is a strong drive for tertiary education reforms in Mauritius. The introduction and development of PBF systems are viewed by many stakeholders as being both relevant and desirable, particularly taking into account the opportunities for promoting quality and efficiency in the tertiary education sector, enhancing research culture and developing alternative sources of funds. Chapter seven continues with presenting the empirical analysis and focuses specifically on the opportunities and challenges for the development and implementation of PBF systems in Mauritius. Additionally, chapter seven analyses the secondary data extracted from the official documents and annual reports of TEls, the TEC, and the MRC. 


\section{CHAPTER SEVEN: OPPORTUNITIES AND CHALLENGES FOR PBF SYSTEMS}

\subsection{Introduction}

This chapter explores the applicability and desirability of PBF systems in Mauritius. Particular attention is given to capacity constraints and/or opportunities, implementation issues, and the political acceptability and administrative feasibility of PBF systems. The analysis of the interview data highlights a number of particular challenges and constraints facing Mauritius. These include the small size, limited resources, and relatively greater vulnerability to natural calamities, together with issues associated with the multi-ethnic and multi-cultural nature. In relation to the potential problems of implementing PBF systems in Mauritius, the interview data raise a number of specific issues, including the lack of the necessary human resources, the lack of appropriate training, the difficulties of managing change in the tertiary education system, and a general lack of consultation with key stakeholders about new policy issues. It was evident from the interviews with stakeholders in Mauritius that the implementation of PBF systems would pose some significant challenges and risks for policy makers. Amongst these are the likelihood of resistance to change on the part of many academics and tertiary institutions, potentially high implementation costs, the difficulty of selecting appropriate performance indicators, the problem of finding people with the necessary expertise to implement such schemes, and the potential for PBF systems to have negative impacts on either teaching or research (depending on the kind of scheme being implemented).

In order to examine further the applicability of PBF systems in SIDS, this chapter supplements the interview data with secondary evidence drawn from Mauritius comprising data concerning tertiary education budgets, the number of researchers, student completion rates, higher degree research student enrolments, and the number of publications.

Such data further highlights some of the challenges facing PBF systems in Mauritius and suggests that some PBF systems are likely to be more appropriate than others. 


\subsection{Applicability and Desirability of PBF Systems}

The interview data demonstrated that the perceptions on the applicability and desirability of PBF systems vary among the different stakeholder groups. Of those interviewed, a majority of the respondents commented that PBF systems are appropriate for SIDS. Those respondents comprise eight policy makers, five academics, five senior state officials, two TEls chief executives, and one representative of the TEl's staff association. However, other respondents have opposite and mixed views and were not sure whether PBF will work in the context of Mauritius.

Those respondents who thought that a PBF system might be applicable in Mauritius indicated that such system will help tertiary institutions to improve their teaching or research outputs, achieve the level of performance set by indicators and increase transparency in the management of funds. Other respondents argued that none of the governments in the world would be prepared to put in resources without any accountability, or any sort of assessment. Two respondents, both policy makers, made the following comments:

A PBF is appropriate for Mauritius. We want to get value for money; whatever we spend we want to get the highest outputs and returns (R5.Q6)

We are a small country. We have about $50 \%$ of our enrolment in government funded institutions and... we have got a lot of problems about use of that funding which goes to public funded institutions where we have seen the way the funds are used is not transparent. There is very little accountability (R21.Q6)

Another respondent, a policy maker (R16), supported the above views and noted that a small country like Mauritius may require a major change to adjust and remodel the funding system. By contrast, a few respondents mentioned the need to describe and thoroughly explain the concept of PBF systems. This statement is illustrated in the following quotes - both from senior officials:

PBF system is appropriate for tertiary education in Mauritius. However, we need to define properly what these concepts are [and] what are the criteria to be used. Such a system definitely will be a more scientific, transparent and judicious use of funds to achieve national objectives (R11.Q6)

PBF is appropriate for TES. However, it needs a bigger reform in the system for it to work (R15.Q6). 
An academic staff member (R25) commented that it is definitely desirable for the tertiary education system, as currently funding is not related to research and teaching performance or outputs. The respondent further indicated that applied research is much more appropriate for the socio-economic development of the economy and the performance indicators for research should be cautiously chosen.

Further, a representative of the TEI staff association noted that:

It is appropriate. We have to ensure that the mode of assessment is a transparent and fair system, then it will work ... to ensure quality education (R37.Q6)

Nevertheless, a number of respondents (TEI chief executives, academics and senior officials) argued that a PBF system is not suitable in the context of Mauritius for various reasons. This is primarily because the government budget for tertiary education is not enough and there are a very small number of universities.

Additionally, there were many who thought that PBF systems may have likely impacts on the quality of graduates produced.

One respondent, a TEI chief executive (R33), and the other, an academic (R19), observed:

In my view, there will be pressure on the education system to produce graduates on a mass scale and this may affect quality of graduates produced, especially at this time when the budget for education is not enough (R19.Q6)

PBF system does not apply to an education system. It applies to industries, enterprises which produce quantifiable goods. Students are not goods (R33.Q6)

Another respondent, a senior official, indicated that a PBF system would be less desirable if there is a lack of political support:

It would not be appropriate as such because Mauritius is very small and [has] two universities. Only one of them is fully funded by the government. It will be less desirable because there is no political willingness and commitment. I mean in Mauritius we tend to have change in government every five years. There is no continuity for policy development and implementation (R23.Q6)

Of those interviewed, the respondents who have mixed views are mainly academics. One of the respondents (R3) mentioned that PBF systems are a very fair system but such a system (teaching or research) may be inappropriate because the tertiary institutions in Mauritius are not on the same playing field. 
Another respondent (R4) noted that a PBF system is desirable as it will assist tertiary institutions to progress. However, it may be inapplicable as the sum of money allocated to the tertiary education sector is very low compared to that of developed or OECD countries.

The above analysis illustrates that a majority of the respondents believed that a PBF system is applicable and desirable for SIDS. In view of the nature of SIDS, evidently there are changes that may be required in order to adapt PBF systems. But the opportunities for developing and implementing PBF models are already present.

Additionally, the analysis of the interview data demonstrates that SIDS do have some specific features which have to be taken into account in the development and implementation of PBF systems in Mauritius. These features were enumerated by many respondents from the different stakeholder groups. These include: (i) small size; (ii) limited resources and vulnerability to natural calamities; and (iii) multi-cultural and multi- ethnic nature. Although larger democracies and developed countries are increasingly multi-ethnic, this makes a difference for SIDS because multi-cultural and multi-ethnic have a much more influence on government's decisions in SIDS.

Of the 38 respondents, $39 \%$ claimed the small size of SIDS is a specific feature that may pose difficulties in the applicability of PBF systems. The respondents stated that the small market and remoteness of the islands, closeness of people in family and religious groups, and familiarity among the academic community are other SIDS particular characteristics which cannot be compared to larger developed economies.

Further, a few respondents raised the issues of smallness of such states, maintaining that the influence of pressure groups and proximity between the leaders and people may create problems for policy makers in the decision making process.

One respondent, a TEI chief executive, observed:

The features of PBF models on SIDS that make them more difficult to implement are caused by the smallness of the island, the closeness of the people in family groups and religious groups and therefore a difficulty in being able to exercise completely independent judgements (R1.Q6) 
Another respondent, a senior official, noted that:

SIDS has got some structural limitations... because of the smallness of the society and proximity between rulers and the common people, the decisionmaking process has been less effective, which has resulted in postponement of bold decisions and, in some cases, inaction (R15.Q6).

Further, a policy maker argued that the familiarity among academics is another significant concern for the applicability of a PBF system:

In a small country..., Mauritius, where everybody knows everybody else, so the individual assessment becomes a rather complex exercise that sometimes has to assess people who are rather close to you or related to you or a friend of your friend and so on. A PBF model for a small country has to take that into account how to make it impartial. (R10.Q6)

The preceding analysis reveals that the small size of such a state and the closeness and familiarity among people have to be considered seriously when developing and implementing PBF systems. About one fifth of the respondents stated that developed economies have more financial resources compared to SIDS.

One respondent, a policymaker (R9), commented:

I do agree that, in the context of small island states where resources are scarce, in that respect the question therefore arises as to how are we going to fund the public education system, the more so the higher education system (R9.Q6)

Another respondent, an academic staff member (R25), supported the above view.

The extracts from interview transcripts emphasise that most of the SIDS are vulnerable to natural calamities such as drought, floods, storms and cyclones. Most of these features are specific to SIDS, such as Mauritius. In the context of natural calamities, a policymaker noted that:

As far as the SIDS is concerned they are vulnerable to all sorts of calamities like, in Mauritius, cyclones (R30.Q6)

In addition, some respondents indicated that the basic difficulties for SIDS are their multi-ethnic and multi-cultural communities. The respondents claimed that introducing changes in the tertiary sector may be slow as there are different groups of people who are powerful in the decision making processes in Mauritius. 
The following observations from two policymakers illustrate this point:

We also have to ensure that in this multi-ethnic community there is an equitable share of resources and that we are able to meet the aspirations of the people as much as possible. It is this multi-ethnicity which is the distinguishing feature of this island (R7.Q6)

The problem of minorities, different pressure groups, ethnic differences, and religious differences do have a certain influence on the decision-making process in our country....I believe if we put a lot of effort we get the support of good intentioned people. I think if all social conditions are united we will be able to succeed (R35.Q6)

The preceding analysis implies that there is a strong desire to opt for PBF systems. However, many of those interviewed have concerns about SIDS' own characteristics, such as small size, limited resources, familiarity among the academic community, and vulnerability to natural calamities by placing additional demands on government expenditure. In this regard, it was emphasised repeatedly that PBF models will have to be adapted to suit the needs of such states.

Further, the size of TEls, the political commitment, and budget allocation to the tertiary education sector are other critical aspects which have to be taken into account by policymakers for the development and implementation of PBF systems. The analysis from the interview data demonstrates that the specific issues for SIDS raised by this research are consistent with the evidence in the literature (Campling, 2006; Carment, et al., 2004; Tigerstrom, 2005).

\subsection{Capacity Constraints and Opportunities for PBF Systems}

This section depicts the capacity constraints and opportunities emerging from the analysis of the interview data for the development and implementation of PBF systems. A majority of the respondents, including policy makers, the TEls' chief executives, senior officials and academics, considered that the most important element for PBF systems to be successful is political commitment.

Two respondents, a policy maker (R9), and a senior state official (R2), made the following comments:

It's always a difficult political decision...the policy platform is coming in. It will constitute general agreement on what must be the way forward in funding [and] policy measures in tertiary education. I would say the platform for policy measures is coming in. We are in the process of building that policy platform (R9.Q7) 
I think the platform can be created if it does not exist and, in the local context, the platform that has been created for implementing the Medium Term Expenditure Framework would be easily extended to the application or implementation of a PBF model (R2.Q7)

Further, a senior state official (R8) claimed that political support is the very basis for a robust platform. Importantly, the participation and cooperation all other stakeholders concerned are a prerequisite to create that platform.

As well as political will, of the 38 respondents, a clear majority (26) argued that the current policy platform is not sufficiently robust for developing and introducing a PBF system. This is because of the likelihood of resistance to change and lack of communication and consultation at the level of all stakeholders.

Respondents maintained that the collaboration within and among TEls is poor. Many indicated the difficulties in managing change are mostly on the part of academics and people involved in the tertiary education sector. There is much fear and uncertainty whenever a new system is introduced. Further, it was emphasised by the respondents interviewed that people will have to change their attitudes and mindsets if a performance-based framework were to be introduced.

The following quotes from the policy makers illustrate the above views:

I will not say we have a robust policy platform. As I said initially there will be a lot of misgivings, a lot of resistance, but I think the commitment is there as it is a policy decision; we have to go for the system of performance-based (R16.Q7)

Well, we cannot say that there is right now a robust platform. I think we can build up the platform with all actors concerned and ultimately try to get the collaboration of all concerned to be able to bring these new changes and build up the robust platform (R35.Q7)

One respondent, a senior official, commented on the difficulties posed:

The main obstacle will be the resistance to the change to a new system. Whenever you introduce any new system it brings a lot of fear about the future, and the new working environment (R11.Q9)

An academic responded in a similar manner:

I would say that there is not a sufficiently robust platform. Because introducing it would [require] the approval of unions and we know that unions are very reluctant to change (R4.Q7) 
Moreover, another academic (R20) observed that civil servants wish to maintain their privileges and not be losers in a new system. A TEI chief executive (R34) supported the view expressed above but indicated that, if the key stakeholders understand the rationale and the objectives for introducing PBF systems, then it should be feasible to accomplish.

One respondent, a TEI chief executive (R 33), expressed the view that there is "lack of consultation with the principal stakeholders" and suggested that communication and consultation will be necessary.

Similarly, an academic maintained that consultation among different players in the sector is essential:

There should be some work done at the institutional level. There should be collaborations among departments, various units and schools. For the moment we don't have a good collaboration in terms of TEls exchange (R3.Q7)

In the light of these issues, the interviews from stakeholders in Mauritius specified the key elements in the present policy and institutional mix which might contribute to the platform. These include clear policy directions for the tertiary education sector, consistency in policies for all TEls, consultation with key stakeholders and effective information management systems.

One policy maker (R35) mentioned that the Ministry of Education and Human Resources has produced a number of policy papers, announcing policy decisions to reform the tertiary education sector. This initiative might contribute to the introduction of PBF systems.

A senior state official highlighted the importance of uniformity in policy across the sector:

There should be a uniform policy. In other words what applies to institution A must also apply to institution B, unless there are specific explicit justifiable reasons for doing otherwise (R2.Q7)

Another policy maker indicated that access to information and reliable data and appropriate software for data capture and reporting are also critical and noted that:

It will also require systemic changes for e.g. many of our ministry's, procedures and processes have to be computerised because access for information and flow of communication is essential for PBF (R16.Q7) 
The preceding discussion illustrates that high-level issues, such as political willingness and clear, consistent policies, are important aspects that policy makers have to look into. Moreover, other issues, for instance building up a robust policy platform, managing change and creating effective information systems need to be addressed in order to introduce PBF systems in Mauritius.

Nevertheless, many of those interviewed expressed concerns about the principal capacity gaps associated with the introduction of PBF systems. A majority of the respondents (30) maintained that one of the primary deficits is human capacity. The respondents claimed that there is a lack of human resource capacity in terms of the required expertise, and relevant training at the institutional and organisational levels.

One respondent, a policy maker, observed that there is a shortage of high calibre professionals at the level of tertiary education:

The question whether we have the real capacity at the university and tertiary level people who have got the sufficient expertise to be able to bring these changes right now and this is the major weakness. (R35.Q7)

Another respondent, a TEI chief executive officer, made the following observation:

To develop the PBF model at both teaching level and research level it is essential to bring in overseas experts to help with this until local Mauritian staff has had a few years experience and implementation of it (R1.Q7)

An academic (R3) and two other respondents, both senior officials (R23 and R26), shared the same view that lack of expertise is the principal gap and experienced people from overseas will need to be recruited to implement such a system.

The preceding findings indicate that limited human resource capability is regarded as one of the main challenges that Mauritius will face in introducing PBF systems. The principal capacity gaps specified by the respondents highlight the need for policy makers to consider well in advance the strategies required in order to develop and introduce funding mechanisms in the tertiary sector. Among the respondents, there were many who thought that training is a fundamental tool in developing human resource capacity. Some respondents identified that there are insufficient guidelines and limited information provided to implement changes. 
A policy maker mentioned that the concept of PBF systems is very often new to those people involved and that training would be beneficial:

These ideas are to a great extent new to the operators, especially the people who are in the tertiary institutions. But in the present context it is likely to get easy acceptance, provided we have people who are trained in that area to enforce it (R7.Q7)

A senior official observed:

My feeling is that there are no sufficient guidelines again. There is insufficient training because if you want to implement any change people should be prepared to accept that change. It should be at the level of each and every individual concerned with the system (R28.Q7)

Two other respondents, both senior state officials, pointed out that there is a particular need for appropriate training on new mechanisms to be introduced:

No, there is not a robust platform. We are developing the platform having people to be trained. Train trainers to explain [to] people about the systems (R32.Q7)

I believe it is not sufficiently robust. There is the need to ...create awareness among people in the TEls and the stakeholders. Provide training for implementation (R26.Q7)

Two academics advanced similar views with regard to training issues. In particular, there is need to organise workshops and hire people who have the potential and experience in PBF systems. Further, all stakeholders in the tertiary education sector directly involved with PBF systems should be trained and provided with guidance.

The above analysis illustrates that training is an imperative issue that has to be taken into account in introducing PBF schemes. The respondents considered that training can be seen as one way to create the robust platform for all the stakeholders involved and to facilitate the implementation process. However, in addition to training, they acknowledged the necessity for comprehensive guidelines.

The interview data highlight that there are opportunities for developing and implementing PBF systems in Mauritius. In order to make PBF systems (whether teaching or research schemes) successful, there is a need for political commitment and support for the creation of a robust policy platform and the introduction of effective information management systems. 
A robust policy platform means that government should engage different stakeholder sector groups in the development of new policy issues, create a forum for debates so that people can express their views, and participate in the policymaking process. However, the analysis demonstrates a number of constraints and challenges facing Mauritius.

In relation to these challenges, particular attention needs to be given to the human resource capability (i.e. lack of expertise and high calibre people), provision for relevant training from experienced people, establishment of comprehensive guidelines, and the difficulties in managing resistance to change in the tertiary education sector.

\subsection{Focus of PBF}

The interviews with stakeholders in Mauritius indicate about three quarters of the respondents (71\%) agree that PBF systems should focus on both teaching and research. The respondents from the different stakeholder groups claimed that improving teaching quality and promoting research culture are the two imperatives for producing world-class quality graduates. Moreover, they stressed that the mission of a university is for both teaching and research and these two activities are complementary.

Two respondents, both policy makers, made the following comments:

In higher education, we cannot dissociate teaching and research. It has to be both. So I would not say it has to be a uniform approach but it has to be balanced in terms of the areas / disciplines where we want this to happen. It is easier to measure and quantify research activities in science and technology whereas in the social sciences it is very difficult (R16.Q8).

I think [a PBF system] should focus on both of them. For teaching it will be a different kind of model in terms of outputs and outcomes. For research it is more abstract for Mauritius because the research element in Mauritius is still being created. People are not aware what research entails (R21.Q8).

R1, a TEl chief executive, and R8, a senior state official, supported the view that PBF systems should focus on teaching and research activities:

The excellence of teaching is needed to produce world class quality graduates who can enable Mauritius to operate in the face of international competition. Research likewise should be assessed to help the government of Mauritius in its key areas of economic or social development (R1.Q8)

Both have their own specificities and contribution. Teaching is just production of graduates, but research is more than that. It has a lot more value added, especially applied research (R8.Q8) 
An academic staff member responded in a similar manner:

I would say both teaching and research because what is important is how academics can reach excellence when transferring their know how through teaching (R17.Q8)

R4, R13, and R20, who are all from the academic community, shared the same views.

Another respondent, a representative of the TEI staff association, commented:

Research has developed very significantly over the last few years and it is only done [on a] quantity basis but not quality basis. Because of this being new, still at an infancy stage, I believe that both research and teaching can be considered (R37.Q8)

The above findings imply that the majority of respondents have a strong view that PBF systems should concentrate on both teaching and research as this will enhance the quality of teaching and research culture. The respondents also indicated that, although teaching and research are interlinked, two different PBF models should be developed.

By contrast, $16 \%$ of the respondents maintained that PBF systems should focus on research only, while $8 \%$ mentioned teaching only, and $5 \%$ did not make any comments. Some respondents who supported research only were of the view that there is a lack of research culture and research funding in Mauritius. They believed the introduction of a PBF system for research will be beneficial for the socioeconomic development of the economy, enhancing knowledge and improving quality for teaching.

Two respondents, both policy makers commented:

PBF should be geared towards producing a research which is truly beneficial to the needs of the country (R9.Q8)

Research is very often a leap in the dark and I don't think anybody, whether the state or the private sector, can just blindly continue to fund research. We need guidelines, benchmarks here. I think we need performance-based. I think it should focus on research, in general the economic applicability of research (R36.Q8)

Another respondent, a TEI chief executive, expressed the view that:

In terms of research that could be measurable in terms of number of papers one produces, the impact factor of these research papers and journals in which they [are] published.... Again we have to mobilise sufficient resources but resources are constrained. It is very difficult to introduce performance indicators (R33.Q8) 
An academic noted that:

The question of research is something that has to be taken very seriously. If we were to develop and implement a PBF in Mauritius it should be on research. Up to now, I have not seen anyone defining or giving a real definition of research, what it entails to start research. I think it is important for us to lay a lot of emphasis on research by creating a really well-structured research institute (R14.Q8)

On the other hand, it was emphasised by quite a few respondents that PBF should focus on teaching only because they considered that strengthening the human resource capability is crucial for Mauritius. They maintained that research is too expensive and requires a substantial commitment of financial resources on the part of the government.

Two senior state officials observed:

\begin{abstract}
A PBF would need to be on teaching for some time because we need to develop human resources to service the main economic pillars. The gap between the TEls in Mauritius and those in far more advanced countries is so high in the field of research that I do not feel we have a competitive advantage (R15.Q8)

For Mauritius, I mean it would be teaching only because doing research requires funding. Being a small island state, we do not have the necessary funding. If academics want to do research they can do it in collaboration with developed countries (R23.Q8)
\end{abstract}

The preceding discussion illustrates clearly that a majority of those interviewed from the various stakeholder groups desire to have PBF systems for both teaching and research. However, the literature on PBF systems reveals that developed countries which have implemented such mechanisms have adopted a single PBF model, either for teaching or for research activities, but not for both although New Zealand has talked of a teaching PBF system.

\title{
7.4 Implementation Issues
}

It is evident from the analysis of interview data that there are opportunities for developing and introducing PBF systems for the tertiary education system in SIDS. However, the interviews with stakeholders in Mauritius highlighted certain risks for the policy makers for implementing PBF regimes. 
Amongst these risks is the challenge of stakeholders' resistance to change, the difficulty of choosing the relevant performance indicators, the likelihood of high administrative and implementation costs, the problem of obtaining the right people (experts) to implement PBF systems, and the likely negative effects on either teaching or research activities. A majority of the respondents viewed the complexity of managing resistance to change in the tertiary education sector and government ministries and agencies as the major challenge for policy makers for implementing PBF schemes. The respondents stressed that it takes time for people to accept new developments and this change management process is very important for PBF systems to be successful.

Two respondents, both policy makers (R12 and R21), and a senior state official (R23) commented:

\footnotetext{
...There is a political cycle v/s an education cycle which does not converge. Currently there is risk which is real and ...the perception that is being imposed that would say it is a repulsion type of risk (R12.Q9)

\begin{abstract}
One major risk... is the acceptability of the system [by] the present staff. We have tried in the past to introduce similar systems where there will be more accountability, more transparency and better governance, but we have met with a lot of resistance (R21.Q9)

Possibly resistance to change and lack of commitment of the different stakeholders as well (R23.Q9)
\end{abstract}

These statements were also supported by another respondent (R22), a TEI chief executive.

The preceding analysis implies that resistance to change would cause some significant problems and this issue has to be taken seriously in order to develop and implement PBF schemes. The justifications for changes should be clear to the stakeholders concerned and make them ready to accept.

A number of the respondents (12) indicated the potential risk of selecting an appropriate set of performance indicators for PBF systems either for teaching or research activities. Of those interviewed, a few respondents further argued that the weight attached to performance indicators may put institutions at a disadvantage, with some of them being more favoured than others. 
One respondent, a policy maker, made the following observation:

I think we have to be very careful when we use indicators especially for research and teaching. In terms of publications... most of the time top institutions like Harvard, and Cambridge etc. will have more publications by academics than a small university in Mauritius... because the facilities there are more appropriate, they are better equipped and the networking is much better. We have to be very cautious so that we do not copy indicators (R21.Q11)

Two other respondents, both academics, expressed similar views:

When it comes to implementation stage it will heavily depend on the weight given to the indicator on which the institution will be assessed. Take the research component -- some institutions have better research facilities, some institutions do not. So if we are putting, let's say weight on research, some institutions will be at an unfair position (R3.Q6)

The principal risk is when the targets of performance indicators have been wrongly spelt out and the targets of performance indicators may not be attained especially if funding is inadequate (R4.Q9)

Of those interviewed, a policy maker (R16) suggested that in tertiary education there may be certain sectors which are important for the overall growth of society. But with the introduction of PBF systems these sectors may be neglected as they are not economically viable. From the policy angle, tertiary education needs to be looked at from an overall perspective and special consideration given to certain sectors even though the standards associated with PBF do not necessarily apply.

The analysis of the interview data clearly indicates that the respondents' main concerns about the PBF systems are the selection of the performance indicators, the weight attached to these indicators, and the financial resources available for the tertiary education sector. As identified in the literature review chapter five, performance indicators are critical for PBF systems, both for research or teaching.

It was repeatedly mentioned by a few respondents that there is the possibility of high implementation costs. The respondents raised a number of particular issues, including the time taken to document PBF systems, compile information by academics, and prepare and collect institutional data in a standardised format. They further argued that PBF systems will increase the administrative burden and require investment in appropriate software packages for data exchange. Further, the respondents claimed that the services of independent overseas experts would be crucial in SIDS to avoid favouritism and make the system more credible and transparent. This will undoubtedly increase the total costs. 
Two respondents, both policy makers, observed:

Unfortunately external expertise is expensive. If we have to look for external experts to come and put such a system in place it will be very expensive (R9.Q9)

I think it is very important to ensure that it does not just add another administrative layer in the educational system especially for small island states. We need to ensure that the regulatory burdens are not too high (R35.Q4)

A TEI chief executive, made the following comments on the potentially high implementation costs for PBF systems:

Firstly it is time consuming... Using local subject panels coupled with involvement of independent subject specialists from overseas. This latter can be expensive in terms of travel cost, fees and time taken (R1.Q9)

Likewise, R29, an academic, and R37, a representative of the TEI staff association, observed:

In small places where everybody knows everybody there is a lot of patronage and nepotism going on. It happens in big states as well but certainly it is perhaps more visible and inherent in small island states (R29.Q9)

The elements of transparency and fairness I think even for any institutions especially here. The assessment should be done by a third party or external to the institution because there is always this element of bias. It is human nature. If it was to be done by a third and external party that would be fine (R37.Q9)

It is true that small-scale raises the cost of transparency as external people are involved but such external moderation and audit is important to deal with the problems of a tightly-interrelated society.

The preceding discussion implies that the high implementation costs are an important element which policy makers have to consider before developing and introducing PBF systems in Mauritius. The administrative and implementation costs have to be reasonable in relation to the budget allocated to teaching and research for TEls. However, evidence from the literature (WEB Research, 2004) as discussed in chapter five, has revealed that the financial costs and human efforts in implementing PBF models have tended to be relatively high compared to the amount of money invested in tertiary education. 
Further, some respondents claimed that in Mauritius where human resources are scarce, there is the difficulty of finding people with the necessary skills at government and TEls levels to implement PBF systems.

Two policy makers made the following observations:

The risks will be less if we have enough people qualified in this area. That is our major risk (R7.Q9)

The risk in Mauritius being a small country where human resource itself is scarce.... Do we have local expertise to drive this project? (R9.Q9)

Similarly, one academic (R13) and a senior state official (R23) supported the above views.

So it is necessary that we have only very highly skilled and qualified people in the area (R13.Q9)

It will be a human resources aspect because I do not know if we have the appropriate qualified staff to do the implementation of such a system (R23.Q9)

As discussed earlier, in the view of the respondents, the lack of technical capabilities in SIDS is a significant issue which should be given due attention by policy makers for the development and introduction of PBF systems.

In addition, a few respondents indicated that there is the possibility for PBF systems to have negative impacts on TEls' activities. If a PBF system is introduced for research activities, institutions may concentrate on research at the expense of maintaining and enhancing the quality of teaching. At the same time, if a PBF system is developed for teaching, a potential impact is that research may be ignored at the expense of teaching. Further, the analysis of the interview data stressed that there is a current lack of supporting academic staff that could provide assistance for teaching and research.

An academic staff member commented:

Let's say the focus is on teaching, then the risks will be that the institutions will be focussing on a lot of teaching and they will neglect research. But, however, if funding is flowing because of research staff, then there is a risk that staff will be focusing on research rather than teaching. They don't have facilities here to employ tutors and research assistants as in other universities (R3.Q9)

Further, respondent R30, a policy maker, maintained that implementing such a system at tertiary level, especially for research, is likely to discourage people from embarking on innovative and creative products. 
The above analysis supports the evidence in the literature (Sharp and Coleman, 2005) that with the introduction of a PBF model for research there is a perception that teaching will be neglected and more teaching assistants will be required to relieve researchers.

\subsection{Political Acceptability and Administrative Feasibility of PBF Systems}

The interviews with different stakeholder groups clearly demonstrate that of the 38 respondents, the majority (25) support the development and introduction of PBF systems for tertiary education in Mauritius. Of those interviewed, few have negative views on the acceptability and feasibility of PBF systems, while five of the respondents have mixed opinions. Those who are in favour of PBF systems claimed that Mauritius has to achieve the policy objectives of enhancing quality of education, increasing access of students to post secondary education, promoting equality of educational opportunity, enhancing research culture, and developing alternative sources of funding. Some respondents stressed that, with limited financial resources for tertiary education, a new funding mechanism has to be set up in order to eliminate wastage and inefficiencies in the sector.

One policy maker (R30) indicated that, as the percentage of the Mauritius budget going to tertiary education is very low compared to secondary education, there is a need to make judicious use of the resources. Another policy maker commented:

I would strongly support the implementation of such a system in Mauritius. If we want to justify both human and financial resources that we put in any system it is important that we have to introduce [such] a system.... Also being a SIDS, resources are very scarce in different areas. We are committed to bring this required change whatever the difficulty we face (R35.Q10)

Further, a senior official responded in a similar manner:

I would support it ... I am of the view that implementing PBF systems at least would be able to remove those inefficiencies gradually, and be more focused on what [we] need to achieve (R28.Q10)

Respondents R11 and R15, both senior state officials, and R2, an academic, supported the above statement. 
Additionally, there are some who thought that PBF systems would be an important mechanism as they enhance efficiency, increase accountability and transparency, and improve quality. Two respondents, one a policy maker (R21), and the other, a senior official (R26), made the following observations:

If government would continue to fund tertiary education it has to be on a performance-based system. The time of giving money to institutions blindly has gone. It is very important... to have more transparency, to make institutions more accountable and to have good governance (R21.Q10)

I would support a PBF system for tertiary education. It will enhance efficiency, and accountability. It will enable the use of scarce resources more efficiently [and] effectively and eliminate wastage (R26.Q10)

In addition, two other respondents R31 and R32 support the PBF system because they believed that the system will motivate TEls to achieve their outputs.

One respondent, a TEI chief executive, commented:

It is clear that a PBF system would be in the interest of everybody and the country. We cannot say that we would not like to support it (R34.Q10)

An academic staff member (R4) commented that PBF would mean providing additional funding to those institutions which perform better. However, the respondent emphasised that the basic funding, with a minimum quantum, should be given to each institution with or without a PBF system.

Further, a policy maker (R16) supported the introduction of PBF systems on condition that necessary precautions need to be taken for those sectors which may require more attention and flexibility, as education is a complex sector. The respondent claimed that PBF systems would be undoubtedly very beneficial because they will bring about "greater rigour in planning, implementation, monitoring, transparency and accountability". Another policy maker (R5) shared a similar view.

The interview data demonstrates that a few respondents oppose the development and implementation of PBF systems because Mauritius has a limited number of universities. Moreover, the respondents thought that such mechanisms may affect newly established tertiary institutions. They also believed that PBF systems may create frustration and pressures for academics and additional administrative responsibilities for people working in the tertiary education sector and government agencies. 
Two respondents, both senior officials, observed:

Institutions which are just starting are not adequately resourced and experienced and, if one starts imposing performance on a small baby [institution, it will] reduce tangible outputs which may be more damaging than anything else (R2.Q10)

I would oppose such a system in Mauritius. I mean Mauritius is a very small country as you can see there are only 9 [public funded institutions and out of which 2 universities] (R23.Q10)

In addition, one respondent, a policy maker (R36), noted that:

I hold a different view on research. Given all the constraints... there is no way that it would be fair and good for the medium and long term social and economic development for the country to have a PBF being introduced in the tertiary education sector (R36.Q10)

Those respondents who have mixed views argued that Mauritius is not ready for PBF systems because such schemes will be unfair to other TEls which are not on the same playing field. Further, the respondents maintained there is a need to draw on the experience of countries which have implemented PBF systems, although they recognised that this could be a very costly undertaking for SIDS.

One respondent, an academic, made the following observation:

I am not opposing the PBF system but I feel that Mauritius is not ready for such a system. It's going to penalise a lot of institutions, given that, for example, one leading tertiary institution will be attracting the best researchers, best teachers and highly qualified persons, while the others ... will be left with lecturers not having PhDs (R3.Q10)

However, another academic, R 29, recognised that PBF systems do have advantages, such as helping to enhance and improve the tertiary education landscape. Such schemes will encourage academics to produce more research outputs and improve teaching quality because there will be indicators and milestones to meet. The respondent further argued that funding tertiary education only in relation to performance based on indicators might be beneficial but cannot be used alone because Mauritius is still at a level of development where state intervention is needed.

The preceding analysis suggests that the majority of the respondents from the different stakeholder groups are in favour of introducing and developing PBF systems. 
The interview data underline that PBF systems were considered desirable because they are expected to eliminate inefficiencies, promote judicious use of public funds (taxpayers' money), motivate tertiary institutions to improve their performance and increase accountability. However, some respondents who support PBF systems expressed concern that the implementation process would need to be managed with care and give due regard to academic disciplines which are at a disadvantage. Those who oppose PBF systems argued that they would privilege leading institutions to the detriment of newly established TEls, which may lack financial and human resources.

The key findings from the primary data derived from the interviews conducted with policy makers, TEls chief executives, senior state officials and academics on the applicability and desirability of PBF models for tertiary education in SIDS are summarised in Table 7.4 . 


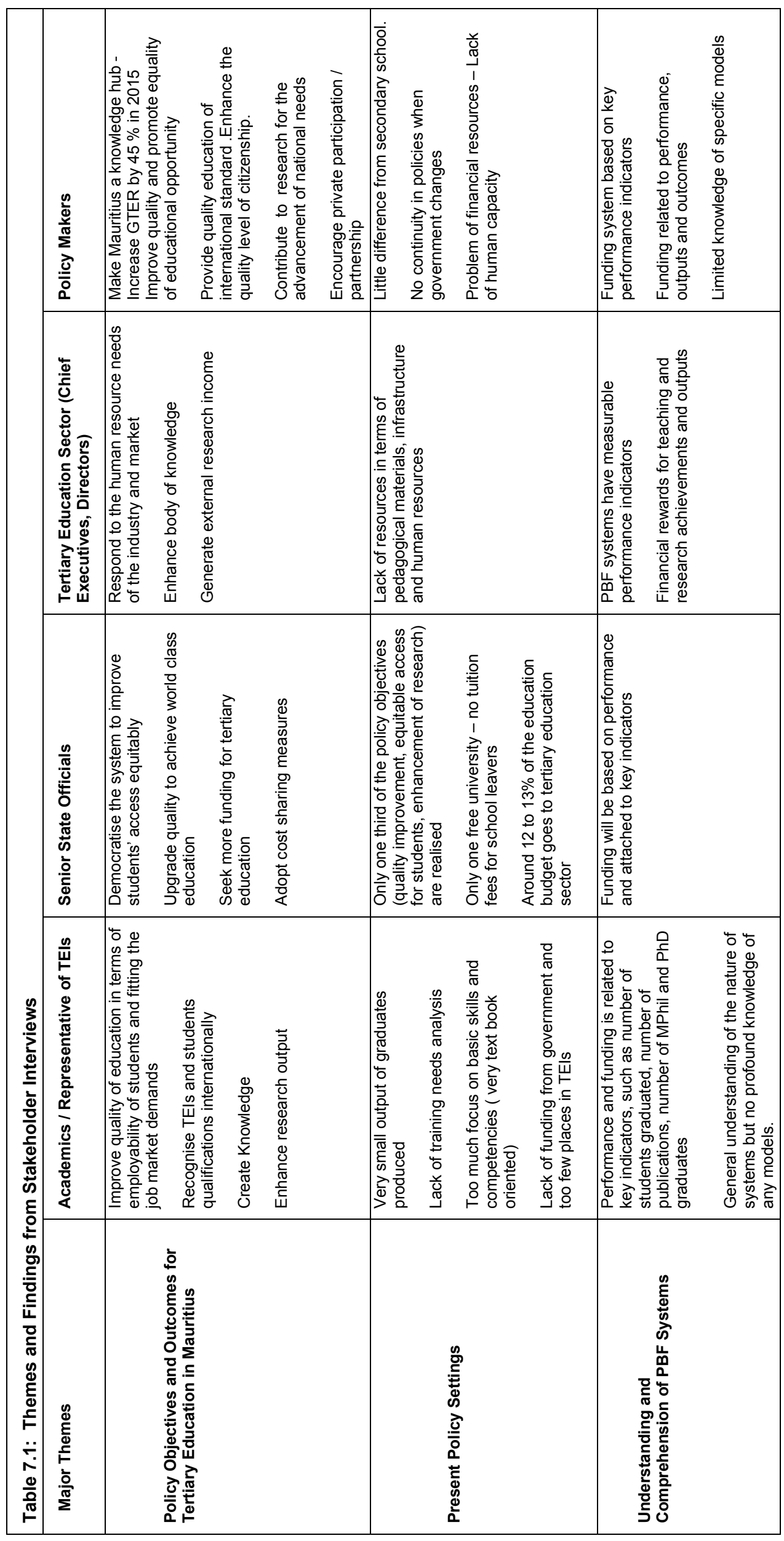




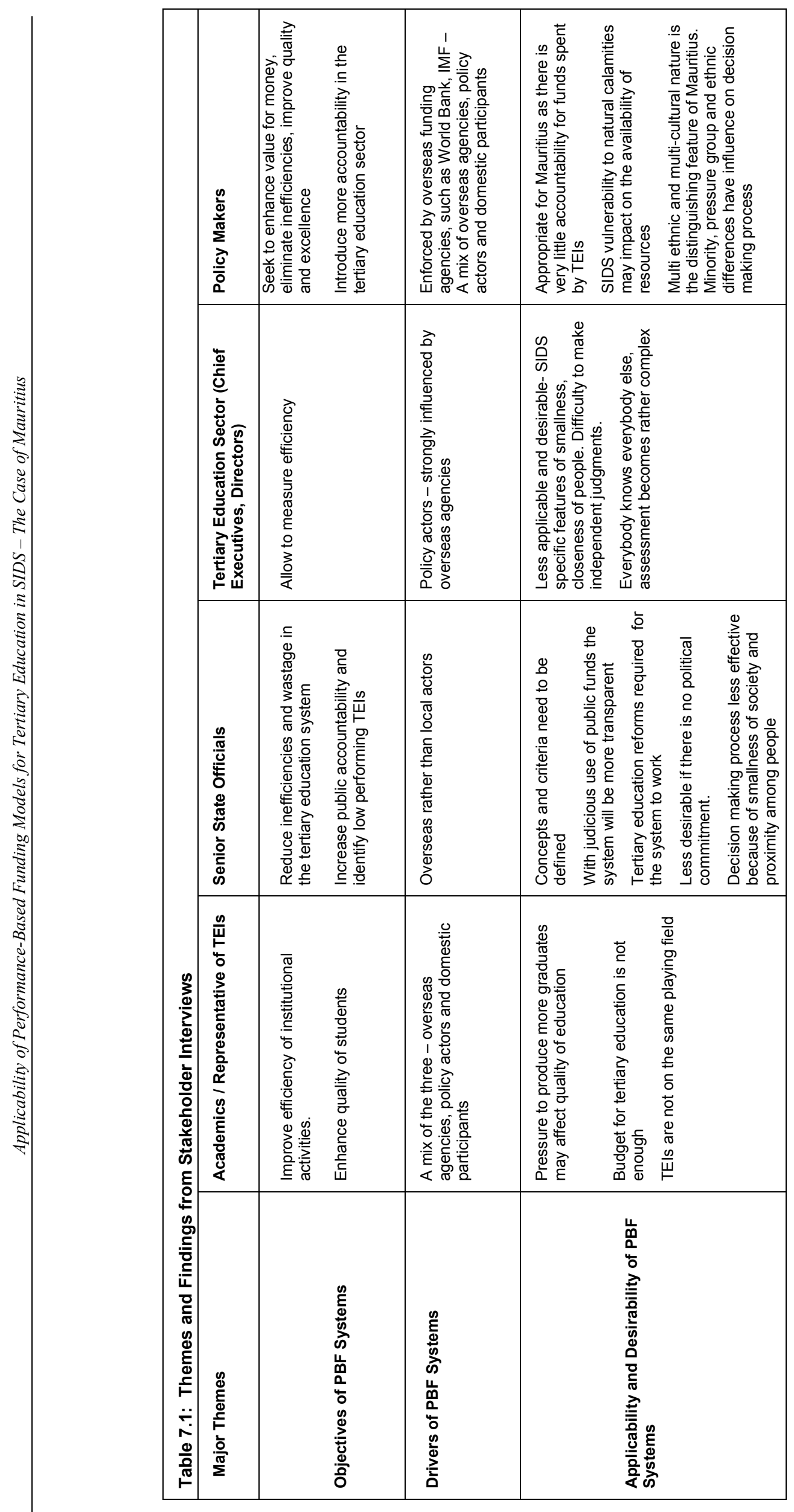




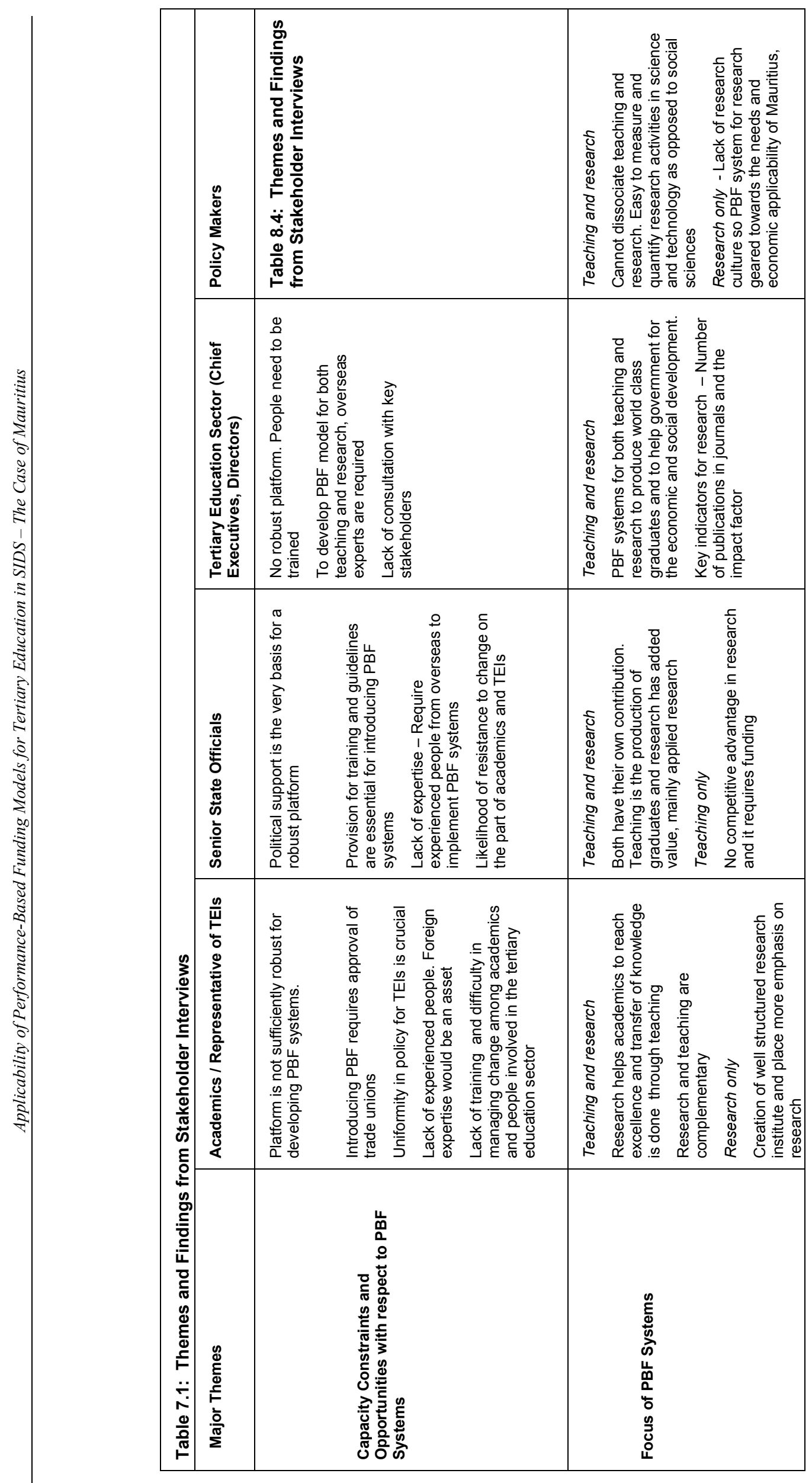




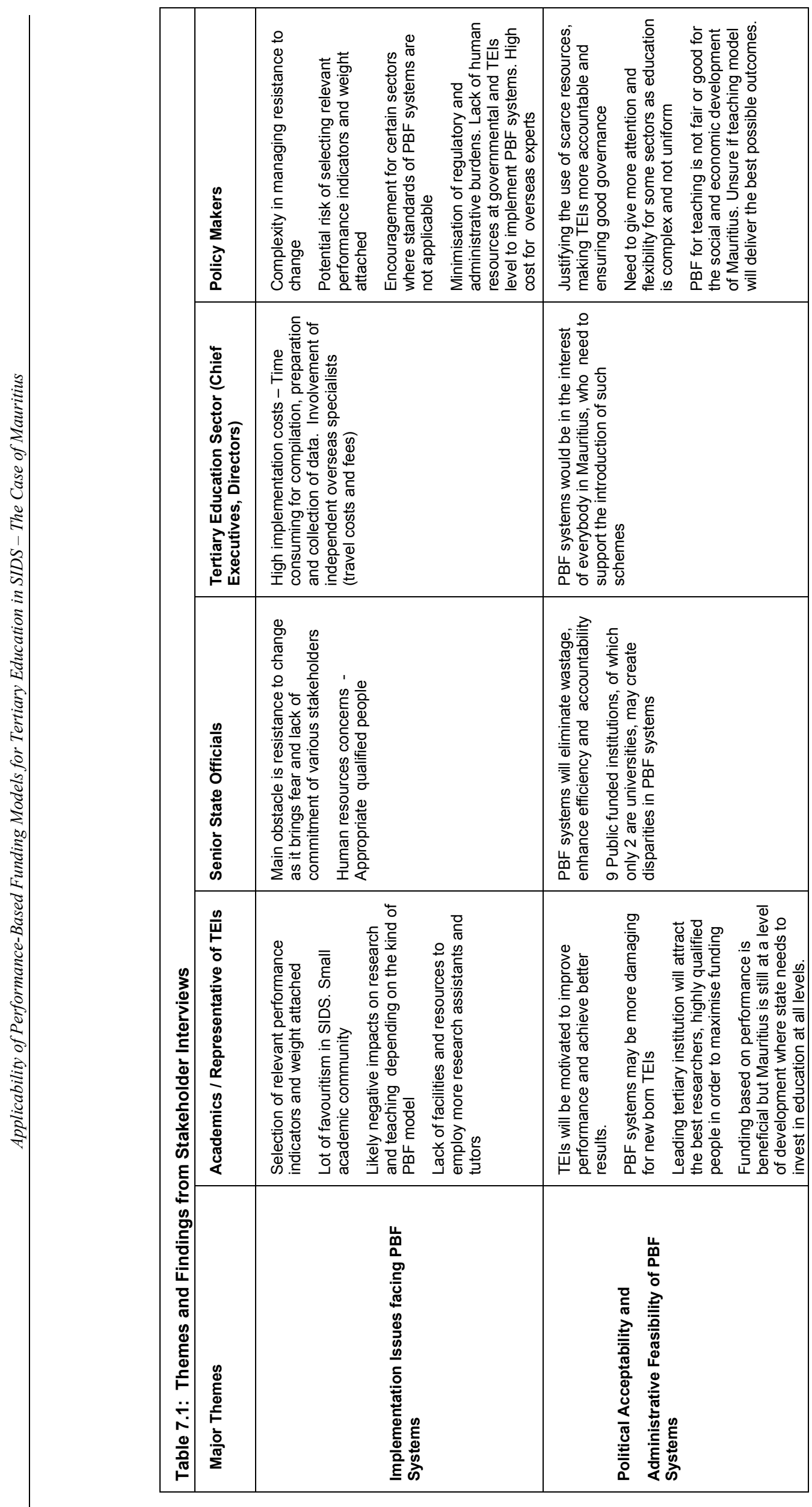




\subsection{Secondary Data Analysis}

Secondary data analysis is the analysis of preexisting data, usually for purposes that differ from those originally intended when the data was collected. The major advantage of working with secondary data is economy, because the researcher does not have to devote resources to collect and organise the data. However, one main disadvantage of using secondary data is that the data were not collected to answer specific research objectives. Thus, particular information relevant to one's study may be missing (Boslaugh, 2008).

But secondary data do provide a mechanism by which the researcher can combine data sets in order to answer questions of a comparative nature (Thorne, 2007). The contribution of secondary data analysis in this research is for crossvalidation and augmentation. The existing data sets extracted from annual reports and official documents are employed to confirm, compare, and triangulate the primary data collection findings. Using distinct 'lenses' to collect data on the same phenomenon reduces the possibility of misinterpretation of data, thus increasing the reliability and validity of the research. Secondary data can also contribute detail (such as funding trends) that not directly elicited in interviews. Further, it may cross-validate interview data re "small size" and the like, but also adds details (numbers).

This section discusses the secondary data, such as tertiary education budgets, number of academic staff, student enrolment and output, higher degree research student enrolment and publications, extracted from the annual reports of TEls, official documents of Tertiary Education Commission [Mauritius] and Central Statistical Office [Mauritius].

\subsubsection{Tertiary Education Budgets}

As pointed out earlier in chapter three, in Mauritius the budgets for teaching and research activities are integrated and disbursed to TEls as a block grant on the basis of a funding formula, using the FTE system. The tertiary education budgets for the past six years from 2002/2003 to 2006/2007, and the latest financial year available (July to June) 2007/2008, are presented in Table 7.1. 
The currency used is the Mauritian Rupee (MRU) and the exchange rate one US dollar is equivalent to MUR 27.70 as at 30 June 2008.

Table 7.2 Mauritius Education Budget for Tertiary Sector (in millions)

\begin{tabular}{|l|l|l|l|l|l|l|}
\hline & $\mathbf{2 0 0 2 / 0 3}$ & $\mathbf{2 0 0 3 / 0 4}$ & $\mathbf{2 0 0 4 / 0 5}$ & $\mathbf{2 0 0 5 / 0 6}$ & $\mathbf{2 0 0 6 / 0 7}$ & $\mathbf{2 0 0 7 / 0 8}$ \\
\hline & MUR & MUR & MUR & MUR & MUR & MUR \\
\hline $\begin{array}{l}\text { Total Recurrent Budget } \\
\text { (Nationwide) }\end{array}$ & 35456.7 & 39698 & 40490 & 40563.6 & 47628 & 51494 \\
\hline Total Budget of Education & 4573.7 & 5119 & 5840.7 & 6098.1 & 6195.5 & 7390 \\
\hline Tertiary Education Budget & 671.8 & 698.8 & 796.7 & 684.9 & 700 & 785.4 \\
\hline $\begin{array}{l}\text { Tertiary Education Budget as } \\
\text { a \% of Total Recurrent Budget } \\
\text { of Education }\end{array}$ & 15.4 & 13.9 & 14.2 & 11.2 & 11.5 & 11.3 \\
\hline
\end{tabular}

Source: Central Statistical Office [Mauritius], 2008

In 2002/2003 the tertiary education budget amounted to MUR 671.8 million. This implies that $15.4 \%$ of the total education budget was allocated to tertiary education compared with $14.2 \%$ (MUR 796.7 million) in $2004 / 2005$ and $11.3 \%$ (MUR 785.4 million) in 2007/2008 as illustrated in Figure 7.1:

Figure 7.1 Tertiary Education Budget as a Percentage of Total Education Budget

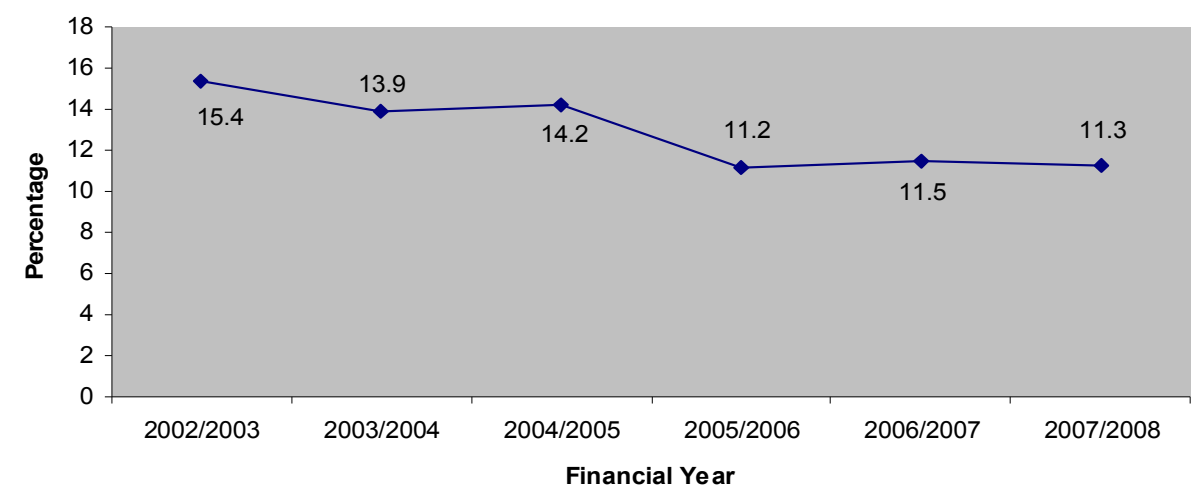

Source: Central Statistical Office [Mauritius], 2008

The analysis indicates that government financing for tertiary education as a percentage of the total education budget has decreased over the period $2002 / 2003$ to $2007 / 2008$, except with slight increases of $0.3 \%$ in the years 2004/2005 and 2006/2007. 
Table 7.3 Allocation of Funds to Tertiary Education Institutions (in millions)

\begin{tabular}{|l|l|l|l|l|l|l|}
\hline Budget Allocation to TEls & $\begin{array}{l}\mathbf{1 9 9 9 /} \\
\mathbf{2 0 0 0}\end{array}$ & $\begin{array}{l}\mathbf{2 0 0 0 /} \\
\mathbf{2 0 0 1}\end{array}$ & $\begin{array}{l}\mathbf{2 0 0 2} \\
\mathbf{2 0 / 0 3}\end{array}$ & $\begin{array}{l}\mathbf{2 0 0 3 /} \\
\mathbf{2 0 0 4}\end{array}$ & $\begin{array}{l}\mathbf{2 0 0 5 /} \\
\mathbf{2 0 0 6}\end{array}$ & $\begin{array}{l}\mathbf{2 0 0 7 I} \\
\mathbf{2 0 0 8}\end{array}$ \\
\hline & MUR & MUR & MUR & MUR & MUR & MUR \\
\hline University of Mauritius (UoM) & 193.5 & 207.6 & 230 & 250 & 255 & 270 \\
\hline Mauritius Institute of Education (MIE) & 80 & 81.3 & 96 & 108 & 117 & 127 \\
\hline Mahatma Gandhi Institute (MGI) & 103 & 110.2 & 129.2 & 165 & 207 & 245 \\
\hline Mauritius College of the Air (MCA) & 47 & 54.7 & 58 & 65 & 63 & 62 \\
\hline $\begin{array}{l}\text { University of Technology, Mauritius } \\
\text { (UTM) }\end{array}$ & 1.4 & 21.7 & 7 & 10 & 9 & 3 \\
\hline Rabindranath Tagore Institute (RTI) & 0 & 0 & 0 & 0 & 2.2 & 4.5 \\
\hline \begin{tabular}{l} 
Open University Mauritius (OUM) \\
\hline
\end{tabular} & 0 & 0 & 0 & 0 & 0 & 5 \\
\hline
\end{tabular}

Source: Central Statistical Office [Mauritius], 2008; Tertiary Education Commission [Mauritius], 2003a, 2004, 2005, 2006a, 2007, 2008a

The allocation of funds to TEls totalled MUR 716.5 million in 2007/2008 representing an increase of $9.7 \%$ compared to $2005 / 06$. In the financial year 2005/2006 the budget to UoM amounted to MUR 255 million compared to MUR 117 million for Mauritius Institute of Education, MUR 207 million for Mahatma Gandhi Institute, MUR 63 million for the Mauritius College of the Air, MUR 9 million for University of Technology Mauritius, and MUR 2.2 million for Rabindranath Tagore Institute as shown in Table 7.2.

Figure 7.2 Budget Allocations for TEls

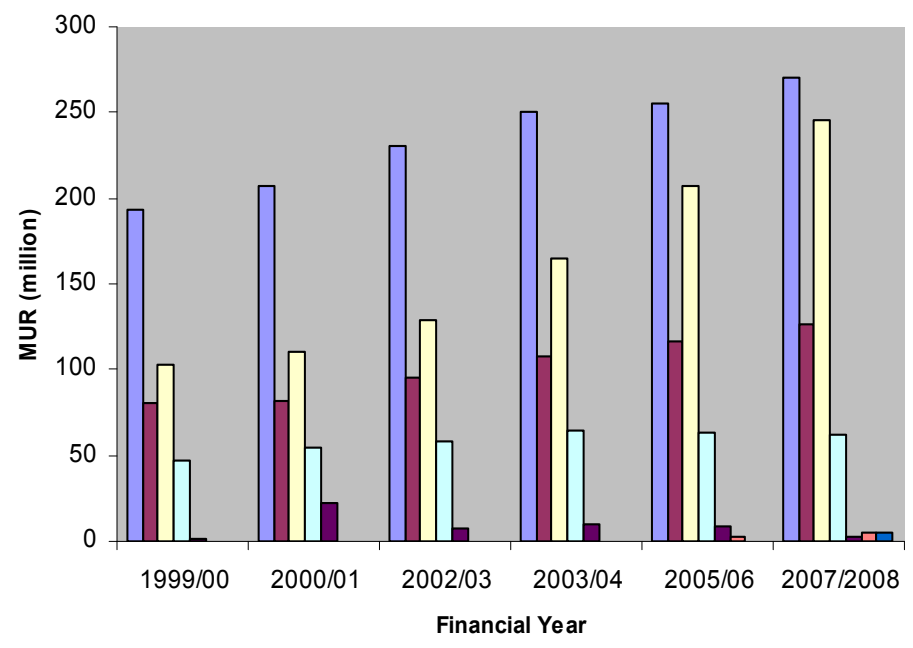


Over the past six years, there has been an upward trend in the budget disbursed to TEls. The data on allocation of funds to TEls clearly demonstrate that UoM, MIE, and MGI are the three institutions which obtained the highest share of government funding as illustrated in Figure 7.2. Generally funds are allocated after deducting the income generated from fees. UoM does not charge tuition fees for school leavers: "The decision to abolish fees at University of Mauritius in 1976 was made in the wake of political decision of the then government, taken on the eve of the December 1976 general elections, to introduce free secondary education in Mauritius. Fees were, however, reintroduced in June 1980, to be abolished again in 1988" (Mohadeb, 2006, p. 39). UTM charges tuition fees for students enrolled both on a full-time and a part-time basis. The other TEIs (UoM, MIE, MGI and MCA) charge fees for part time students only.

The preceding secondary analysis suggests that the key constraints on introducing PBF systems in Mauritius are the low level of budget allocated to the tertiary education sector and the integrated budget system for teaching and research activities compared to the larger developed economies. This evidence strengthens the primary data collected through qualitative interviewing (political elites and representatives of the tertiary education sector) where many respondents claimed that only a small percentage of the available funding is spent on the tertiary education sector. This is so because a large proportion of the budget education goes for secondary education as Mauritius is at a developing stage and there is need to build up the human resources capacity to service the economy and to meet the emerging challenges.

\subsubsection{Number of Researchers (Academic Staff)}

In the interviews conducted with stakeholders in Mauritius, a significant number of respondents indicated that in Mauritius there is a lack of human capacity and relevant expertise, the academic community is too small and there is a lot of familiarity among people at the tertiary level. In Mauritius there are few researchers and only two universities and four institutes compared to a substantial research community and numerous institutions in large developed economies. 
For instance, in the UK for the $2001 \mathrm{RAE}, 2,598$ submissions were received from 173 HEls, listing the work of almost 50,000 researchers (RAE, 2001) whereas for the PBRFeligible staff in 2003 was approximately 8,018 (Tertiary Education Commission [New Zealand], 2006b).

According to the UoM, UTM, MIE, and TEC reports ${ }^{12}$, in Mauritius the total number of academic staff in the TEls for the financial year 2006/2007 was 497 compared to 451 in 2002/2003 and 416 in 2000/2001. The leading university UoM had 244 academics in 2006/2007 and 225 in 2003/ 2004 (Tertiary Education Commission [Mauritius], 2006d). The data exclude the RTI as it is not yet operational and data are not available for the MIH prior to $2006 / 2007$.

\subsubsection{Student Enrolment and Output}

In 2006/2007, 15,464 students enrolled in public-funded institutions in Mauritius. ${ }^{13}$ The total number of students enrolled in tertiary education, both locally and overseas, was 33,230, of which 9,293 were enrolled with distance education and private providers and 8,473 overseas. The total number has increased to 34,332 in the year 2007/2008, including 15,880 students in PFIs (Central Statistical Office [Mauritius], 2008; Ministry of Education and Human Resources [Mauritius], 2008). ${ }^{14}$ The student output (graduates) from the PFls over the past 12 years is shown in Figure 7.3.

\footnotetext{
12 University of Mauritius, 2001, 2002, 2003, 2004, 2005, 2006, 2007; University of Technology Mauritius, 2005; Mauritius Institute of Education, 2006; Tertiary Education Commission [Mauritius], 2003a, 2004, 2005a, 2006a, 2006b, 2007)

${ }^{13}$ Total number of students enrolled in Public Funded Institutions UOM 7370; UTM 1620; MIE 3981; MGI 650; MCA (Distance Education) 415; MIH 104; SDIM 626; IST 285; IVTB 413 (Central Statistical Office [Mauritius] 2008)

14 Total number of students enrolled UOM 7662; UTM 1839; MIE 3959; MGI 575; MCA (Distance Education) 478; MIH 97; SDIM 562; IST 330; IVTB 378; Distance Education / Private Providers 9,612; Overseas 8,840 (Central Statistical Office, [Mauritius]; Tertiary Education Commission [Mauritius], 2008)
} 
Figure 7.3: Outputs (Graduates) from the Publicly-Funded Institutions, 1995/1996 2006/2007

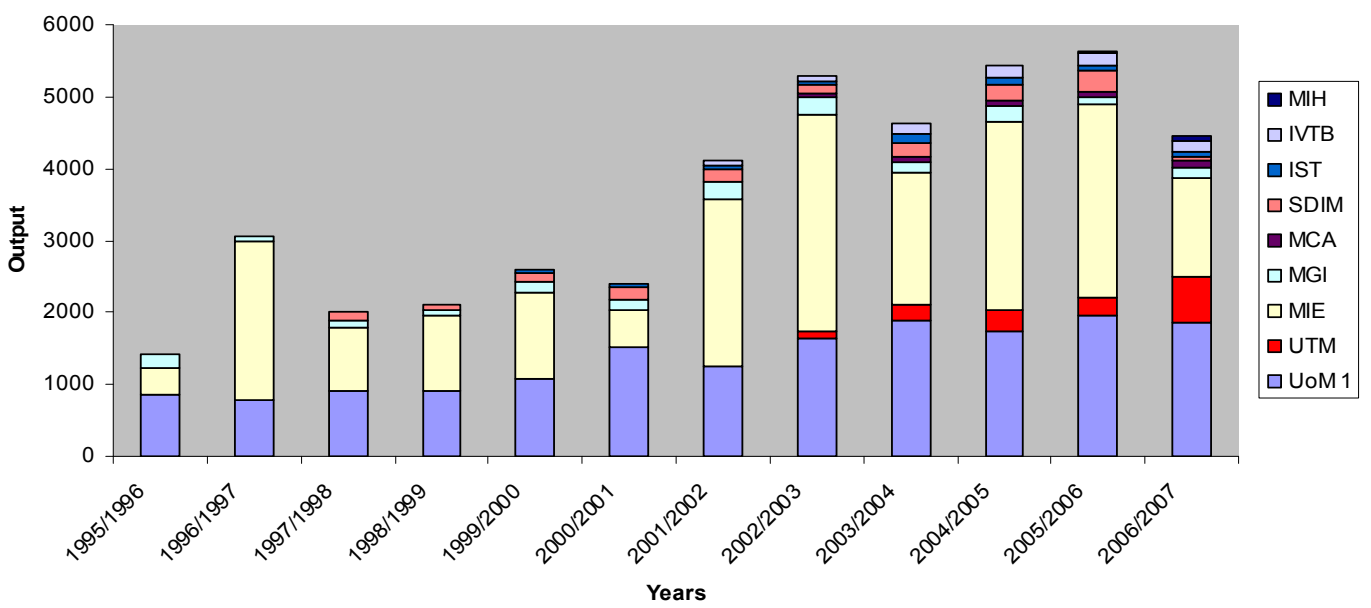

Source: Central Statistical Office [Mauritius], 2008; Ministry of Education and Human Resources [Mauritius], 2008

The student output as a percentage of student enrolment in 2003/2004 for Mauritius was $36 \%$, while it was $46 \%$ in $2004 / 2005$, $42 \%$ in $2005 / 2006$, and $29 \%$ in $2006 / 2007$.

There has been a relative fall in the output of local tertiary institutions. This is because students registered with distance education and private providers and those overseas have increased more substantially than the increase in domestic students over the past seven years (2000 to 2007). The two main institutions which have the highest student outputs for the consecutive years 2006 and 2007 were MIE and UoM respectively.

\subsubsection{Higher Degree Research Student Enrolments}

The number of scholarships/fellowships for M/Phil and PhD studies has been raised by the TEC in order to strengthen the research capability of Mauritius. This is imperative for socio-economic development in the new era of globalisation. In terms of supporting research and capacity building in the sector, of the PFIs, TEC has funded scholarships for only the two universities UoM and UTM: 26 for fulltime MPhil, 7 fellowships for PhD and 32 bursaries for part-time MPhil/PhD students (Tertiary Education Commission [Mauritius], 2006b). Enrolments in doctoral degrees increased substantially over the last decade. 
UoM has witnessed a significant rise in the number of postgraduate researchers at both the MPhil and PhD levels. These went up from 26 in 1991/1992 to 78 in 1996/1997, 122 in 2001/2002, 167 in 2003/2004 and 177 in 2004/2005 (Tertiary Education Commission [Mauritius], 2006b). Figure 7.4 presents the UoM higher degree research student enrolments by faculty as at 31 July 2007, a total of 197 students:

Figure 7.4 Faculty-wise Distribution of Students Registered for MPhil or PhD Degree

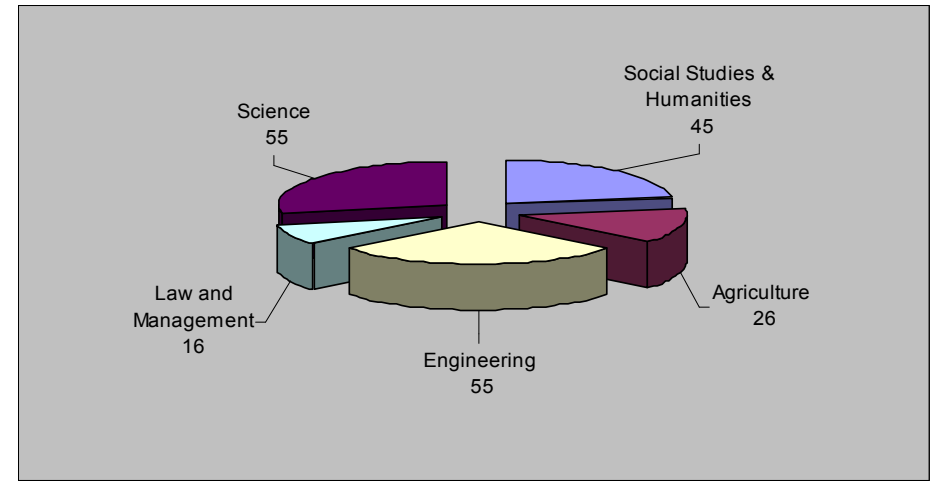

Source: University of Mauritius, 2008

This rise occurred in response to the TEC research funding policy for TEls and also as a result of incentives provided by TEls to encourage research.

For instance, in UoM the Research Promotion Scheme and Academic Staff Development Scheme were revisited to encourage research of national and regional relevance.

In institutions which are relatively new, such as UTM, "activities are concentrated exclusively on teaching and they have yet to build up the capability to undertake research work" (Tertiary Education Commission [Mauritius], 2003b, p. 5). The number of PhD enrolments for UTM was 12 in 2005/2006, compared to 4 in 2003/2004. As UTM's enrolment of research students is relatively small compared to UoM, the data available were not allocated by faculties.

The secondary data analysis shows growth in the enrolment numbers for research degree students. Further, this indicates that there is an increased focus on research. 


\subsubsection{Publications}

The data on publications have been taken from the annual reports of UoM which is the leading tertiary organisation. There are no data available for UTM. The publications consist mainly of international journal articles, books/book chapters and conference proceedings. The analysis for the publications is important in order to assess in which subject areas research is focused. It reveals that, over the past seven years, the Faculty of Science has the highest publications rate, followed by the Faculty of Engineering for the years 2001/2002, 2002/2003, and 2003/2004. It was the Faculty of Agriculture which ranked second in 2000/2001 and $2004 / 2005$. In 2006/2007 the Faculty of Science still ranked first with a total of 42 publications and followed by the Faculty of Social Studies and Humanities with 14 publications.

It is likely that a complete set of data was not available from the Faculty of Social Studies and Humanities as it appears that the publications from this faculty were not recorded in the annual reports. The performance of the faculties in terms of publications is illustrated in Table 7.3.

Table 7.4: UoM Publications by Faculties

\begin{tabular}{|c|c|c|c|c|c|c|c|}
\hline Faculties & $\begin{array}{l}2000 / \\
2001\end{array}$ & $\begin{array}{l}2001 / \\
2002\end{array}$ & $\begin{array}{l}2002 l \\
2003\end{array}$ & $\begin{array}{l}2003 / \\
2004\end{array}$ & $\begin{array}{l}2004 / \\
2005\end{array}$ & $\begin{array}{l}2005 / \\
2006\end{array}$ & $\begin{array}{l}2006 / \\
2007\end{array}$ \\
\hline Faculty of Agriculture & 15 & 7 & 3 & 0 & 22 & 5 & 3 \\
\hline Faculty of Engineering & 12 & 22 & 11 & 36 & 8 & 2 & 12 \\
\hline Faculty of Law and Management & 4 & 0 & 9 & 2 & 1 & 1 & 6 \\
\hline Faculty of Science & 39 & 40 & 27 & 56 & 37 & 35 & 42 \\
\hline $\begin{array}{l}\text { Faculty Social Studies and } \\
\text { Humanities }\end{array}$ & 0 & 4 & 0 & 4 & 0 & 13 & 14 \\
\hline
\end{tabular}

Source: University of Mauritius, 2001, 2002, 2003, 2004, 2005, 2006, 2007, 2008

Further, the University of Mauritius Research Journal aims at creating opportunities locally for University academics and students to publish quality articles.

The first issue of the University of Mauritius Journal was published in March 1999 in three volumes: two volumes of Science and Technology and one volume combining Law and Management and Social Sciences and Humanities. 
A total of 26 papers, all internationally refereed, appear in the three volumes (University of Mauritius, 2001). Nine volumes for Science and Technology and four volumes for Law, Management and Social Sciences have been published to date (University of Mauritius, 2004). During the period 2004-2005 volumes 10 and 11 of the University of Mauritius Research Journal devoted to Science and Technology were published.

The preceding analysis suggests that the secondary data, such as tertiary education budgets, number of researchers, student output, higher degree research student enrolments, and publications, strengthen and validate the findings from the primary data elicited from the respondents of different stakeholder groups. The secondary data analysis above is vital for designing and implementing PBF models for research or teaching, and identifying the available performance indicators that may be employed to suit the needs of SIDS.

\subsection{Summary Findings}

To summarise, primary data from interviews with policy elites and representatives of the tertiary education sector and secondary data from official documents and TEls annual reports were collected for this research.

The secondary data analysis has been used to substantiate and triangulate the conclusions from the primary data. The nine themes emerging from the primary data analysis and findings of this research have been categorised as the background conditions and opportunities and challenges for the introduction and development of PBF models in Mauritius.

In the interviews almost all the stakeholders in Mauritius agreed on the policy objectives and outcomes of tertiary education: to provide quality education of international standard and recognition, increase equitable access for students, ensure employability of graduates, encourage private funding provision, and generate external funds. With regard to research, the respondents emphasised knowledge creation, the Excellence Park, and its contribution to the national socioeconomic needs of the economy. 
Of those interviewed the majority of the policy makers, senior officials, and academics are of the opinion that PBF systems are appropriate and desirable for SIDS. The respondents thought that with the introduction of PBF systems there would be improvements in performance at the institutional level, both in teaching and research activities. Additionally, there would be enhanced efficiency, increased transparency and better public accountability. However, a few respondents, TEls chief executives and academics, argued that PBF systems are not appropriate because of the insufficient budget allocation for TEls, the possible impacts on quality of education, and the small number of universities.

Further, the interview data illustrate that PBF systems might be less feasible and practicable without political willingness and commitment. Additionally, the different stakeholder groups constantly maintained that many SIDS, including Mauritius have specific characteristics which may impact on the viability of PBF systems, such as the small size, culture and ethnicity differences (multi-ethnic communities, religious differences and pressure groups), limited financial and human resources, and vulnerability to natural calamities. These are critical issues which policymakers should consider for introducing PBF systems (either for teaching or research) for SIDS.

The interview data illustrate that there are opportunities for PBF systems in Mauritius. However, $68 \%$ of the respondents emphasised that the existing policy platform is not adequately robust for developing and implementing PBF schemes. This is due to certain constraints, including the lack of capable human resources and training, the difficulty for managing change in the tertiary education sector and lack of communication and consultation with key stakeholders. Capacity building, such as the need for people of high expertise and competence, is regarded as the primary constraint and major challenge.

The views on whether the policy platform was sufficiently robust to introduce PBF systems were consistent for the majority of respondents from the various sectors and in different roles. The interview data highlight that the main elements that might contribute to the robust policy platform comprise political will, uniformity in TEls' policies, provision for training, communication and consultation with key people involved in TEls and government agencies, and managing change. 
Many of those interviewed indicated that there will be some risks involved in the implementation of any kind of PBF systems. These risks include the likelihood of resistance to change, high administrative and implementation costs, the lack of expertise and high calibre people and the negative impacts on either teaching or research. Policymakers and academics have expressed their concern about the selection and weight attached to performance indicators, as PBF systems may favour some institutions or departments at the expense of others.

Both policy makers and TEls chief executives believed that the collection of information by TEls, and hiring the services of overseas experts for assessment panels would definitely increase the administrative burden and implementation costs for Mauritius. The lack of technical capability in Mauritius may be a major risk in implementing PBF systems. Further, academics indicated that there is also a risk that teaching may be affected, at the expense of research, if a research funding model is introduced. To achieve the prescribed level of performance, researchers might focus on research activities and neglect teaching.

Moreover, a few respondents expressed concerns that PBF systems may have a negative effect on recently established tertiary institutions. This might create pressures and frustration for academics to enhance their level of performance and be unjust to other TEls which are not on the same playing field. However, around $66 \%$ of the various stakeholder groups supported the development and introduction of some form of PBF system for the tertiary education sector. The respondents indicated that, as opposed to a line budgeting system, PBF schemes would contribute better to the policy objectives and outcomes of increasing equitable access for students, enhancing excellence and research culture, and generating external sources of funding. TEls might have powerful motivations to achieve the set of performance indicators identified and provide extra funding to those who perform, but the basic minimum funding should be provided to all TEls.

With the emerging challenges of a knowledge society and accommodating the rapid growth in tertiary education while addressing quality, efficiency, accountability, human resource needs and financial constraints in most of the SIDS, the preceding analysis indicates that in all quarters there is a strong desire to move from an input-based funding system to performance-based system. 
Although capacity constraints, administrative feasibility and implementation are important issues, it appears from the different stakeholder groups' responses that the development and implementation of PBF systems would be beneficial to Mauritius.

The research findings, implications of the different PBF systems (peer review, performance indicator and mixed model) and the policy options for a particular model that suits the specific features and needs for SIDS will be discussed in the following chapter. 


\section{CHAPTER EIGHT: DISCUSSIONS AND IMPLICATIONS FOR SMALL ISLAND DEVELOPING STATES (SIDS)}

\subsection{Introduction}

This chapter discusses the research findings presented in chapters six and seven, and considers the implications of PBF models for SIDS, based on the findings in the Mauritius case. In so doing, it examines whether a PBF model might be applicable in SIDS and, if so, what kind of PBF would be most appropriate (whether it would be preferable to introduce a performance-based regime for research or teaching, or perhaps both, and what method for assessing performance - whether a peer review, indicator, or mixed model - is most appropriate).

The broad conclusion emerging from this analysis is that extensive or comprehensive PBF models are not applicable for most SIDS, including Mauritius, at least in the short term, because of SIDS' distinctive features - these typically include the relatively small size of the tertiary system in SIDS and limited financial and human resources. Accordingly, this chapter concludes with an examination of other policy options other than comprehensive PBF regimes that could be employed in the short term, and that are designed to enhance research performance, promote quality and efficiency, and increase public accountability. Three particular options are considered: (i) monitoring and reviewing the research performance of TEls by an independent body; (ii) conducting a quality assurance assessment via an independent body; and (iii) conducting a review of the impact of the research being carried out within the tertiary education sector via an independent body. Option (i) focuses only on research and research training, option (ii) on teaching and research, and option (iii) on research outcomes. It is argued that first of these options would be best in the short term. Over the longerterm, however, it is suggested that the best way forward for SIDS with at least two TEls would be to develop an indicator model for funding research. 


\subsection{Discussions of Research Findings}

This section highlights what was particularly important or significant about the findings in relation to the main research questions, and links the key findings to the literature review. The primary research objective was to investigate the opportunities and challenges associated with the development and introduction of PBF models for tertiary education in SIDS.

In this regard, a substantive evaluation of PBF systems in a number of countries (in particular, Australia, Denmark, NZ, Sweden and the UK) was undertaken to assess both research and teaching funding models. Further, Mauritius was employed as a case study in order to explore the applicability and desirability of PBF systems for tertiary education in SIDS.

PBF schemes have been introduced in a number of jurisdictions, and for both research and teaching activities. Australia, NZ and the UK have implemented PBF models for research, and Denmark, and Sweden for teaching activities. Chapter five provided a review of the range of different PBF models that have been introduced. Drawing on the substantive assessment of these models, there is clearly much that Mauritius and other SIDS or developing states can learn from the experiences of these countries. Studies on the application and impacts of PBF systems in tertiary education have been by and large focused on American states ${ }^{15}$ and developed countries ${ }^{16}$. There is a lack of literature on PBF systems with relevance for SIDS.

The level of understanding of PBF systems is limited in Mauritius because the concepts of PBF are relatively recent and such systems have not yet been explored in the context of the tertiary education systems and wider policy environment within SIDS. Nevertheless, of those interviewed for the purposes of this research, policy makers and academics had a better understanding of PBF systems than other stakeholders.

\footnotetext{
${ }^{15}$ Ashworth, 1994; Burke, 1998; Burke and Modarressi, 2000; Layzell and Caruthers, 1995

${ }^{16}$ Adams and Smith, 2006; Boston, 2002, 2006; Boston, Mischewski, and Smyth, 2005; Codd, 2005; IMHE and OECD, 2006; Kaiser, Vossensteyn, and Koelman, 2001; Roberts, 2003; Taylor, 2001
} 
The respondents interviewed in Mauritius (the Minister of Education and Human Resources Development, Members of Parliament, TEI chief executives, senior state officials, academics and representatives of the TEI staff association) stressed that the key objectives for any new funding mechanism should be promoting excellence, enhancing efficiency and increasing greater accountability.

The results reported in this study, while they relate to Mauritius in particular, with extension to SIDS in general, are consistent with the literature from developed country experiences, and the objectives that interviewees identified for a PBF regime are akin. Kaiser et al.(2001), for example, found that in Denmark the key argument for the reform of the funding mechanism was to enhance efficiency and promote competition among TEls. Hare (2002) concluded that the UK's RAE system has also led to some improvements in the efficiency of university research. Further, the results are consistent with those of Guena and Martin (2003), who recognised that the main advantages of PBF are rewarding success and improving quality, providing public accountability for government funds invested in research, and enhancing individual as well as institutional performance.

In larger developed countries the PBF systems have typically been focussed either on research or teaching, but not both. There are, however, some risks to introducing PBF in only one of the two areas. As highlighted in the literature review, introducing a PBF system only for teaching or research might encourage academics to direct their effort only towards those goals measured, rewarded and funded by performance indicators. Overall, more countries have applied PBF systems to research than teaching. However, most of those interviewed in Mauritius tended to support the introduction of PBF models for both teaching and research to achieve policy objectives and outcomes, such as increasing access for students, ensuring greater equality of educational opportunity, enhancing the research culture, promoting excellence and developing different sources of financial support. Having a PBF model for both might seem to enable good researchers to devote more time to produce research outputs and good teachers to focus on enhancing student performance. 
Experiences from overseas countries demonstrate that PBF systems have been applied either for research or teaching. As outlined in the literature review, Australia (Institutional Grant and Research Training Schemes ), New Zealand (Performance-Based Research Fund), and the United Kingdom (Research Assessment Exercise) have introduced different PBF models for research only, whereas Denmark (Taximeter) and Sweden (FTE Study Results) have adopted models for teaching. If these developed countries have not yet implemented PBF systems for both teaching and research, this clearly suggests that having both is not desirable. This may be explained by various reasons.

The first reason is that PBF policies are not generally popular among key stakeholders within the tertiary education sector, and typically involve significant compliance costs. Having one PBF system may be manageable; having two could become unmanageable. Therefore, there is a high probability that it would prove politically unacceptable to fund both research and teaching via PBF systems. Changing the entire funding mechanism for tertiary education will definitely create disturbance, confusion, unhappiness and resistance to change on the part of academics and other people involved in the sector. Accordingly, a strategy of implementing two PBF models at the same time may have detrimental effects on the popularity of any government.

Second, having both PBF systems may not be cost-effective or affordable because of the high transaction costs and the risk of the government being unable to reward improvements in performance. As discussed in chapter five, the introduction of one PBF scheme has imposed relatively high administrative costs on tertiary institutions. In financial terms, although the UK RAE 2001 represents roughly $0.8 \%$ of the sum of money allotted over seven years, the NZ PBRF has proved to be quite costly, with the total costs amounting between $12 \%$ and $17 \%$ of the total funding allocated only during 2003-2006. Between 2006-2012 the administrative and compliance costs are likely to be less than $2 \%$ of the funds allocated. Moreover, as outlined in section 5.3.2.2 (under grading and funding systems) the RAE 2001 results could not be fully funded. This implies that, if PBF models were implemented for both teaching and research, the need for additional public funding in the tertiary sector would be even higher. 
Third, there is a potentially high risk of losing academic staff because the funding mechanisms can be demoralising and frustrating for academics. There may be a shift of capable people from the tertiary education sector to other areas of employment if they have better working conditions and less pressure to perform. Thus, there would be an increasing risk of a brain drain if academics are being assessed simultaneously via two different performance measures.

Finally, since larger developed democracies such as the UK, Australia and NZ, are still refining and enhancing their PBF systems for only one particular model, there would undoubtedly be more problems associated with implementing both research and teaching evaluations at the same time. This also implies that SIDS should draw some lessons from on-going overseas experiences before introducing any kind of PBF model in the short term.

At present, none of the developed countries have implemented more than one PBF model. Therefore, it would prove imprudent and impossible for SIDS to attempt to introduce two models at once. Their small size and remoteness, limited government funding for tertiary education, lack of human resource capability and relatively small number of tertiary institutions would make this impracticable.

Additionally, this study has focused on the risks associated with the implementation of any kind of PBF model, including those that need to be addressed by policymakers. Issues around the choice of performance indicators, along with the possible high administrative and compliance costs discussed above, were the most important risks identified by the stakeholders interviewed in Mauritius.

Other implementation issues included the complexity of managing resistance to change among academics and other people involved in the tertiary education sector, the difficulty of acquiring local and overseas expertise at the government and TEls levels, and the likely negative impact on teaching and research activities. Certainly, the implementation risks will be a greater challenge for SIDS in developing PBF systems as compared to larger economies because their small size, limited resources and exposure to natural calamities hinder their capacity to absorb implementation failures. 
The interviews with stakeholders in Mauritius were necessarily limited to hypothetical reflections on the desirability of PBF. It is thus informative to consider these findings in light of the views of Dr Jonathan Adams, a UK-based PBF expert. Adams (2008b) argues that three policy objectives and some country-specific features are essential considerations in introducing a new PBF in a SIDS. The three objectives Adams singled out are transparency, signalling and formative information. The first policy objective is simply to produce a metric that feeds directly and transparently into a funding formula to distribute money. Because funding is distributed in relation to performance, there is a need for a performance measurement system that gives a quantitative index which provides for the funding model.

Adams' opinions on metrics-based on peer review versus indicators are valuable. Indicators may not accurately reflect research activity, quality or outcomes or be properly linked to funding. Many of the indicators that are used conventionally in international assessment are going to have potentially less relevance to SIDS because the model is based on a fairly traditional western scientific paradigm and involves inputs, activity, outputs and outcomes. In order to build confidence in the system in SIDS, there would have to be independent peer review to moderate the outcomes. However, Adams claims that peer review is subject to major constraints and risks of bias in a small community where there is not enough comparison. SIDS may need to develop a different model as their research environment differs from countries such as Australia, NZ, UK and South Africa.

Second, the signalling effects and social and national value of PBF systems are crucial. This view was one that did not come through in the interviews or literature. Adams, however, sees value in calculating a quality factor and publishing the results. These results can be made available in a report and thereby inform the government and public at large how the institutions are performing. Further, Adams noted, what matters is not just excellent research as judged by a peer researcher but also the merit of its outcomes and their value to the economy and society in SIDS (e.g. in terms of the health and housing systems and quality of life). 
The merit review is meant to be a "relevance" test. The key criterion is the potential value and interest that stakeholders are likely to derive from the outcomes of a research project. The relevancy test could be undertaken by a Review Committee which would comprise members who can fairly and comprehensively evaluate research outcomes.

The third policy objective is to provide formative information to assist decision makers and staff to improve performance and encourage improvements in this performance. Since under PBF, research resources would be allocated more selectively to the institutions which deliver better research performance, information from PBF assessment could feed into effective changes in behaviour for individuals and their institutions, research culture and awareness, and the priority given to research activity. In NZ, for example TEOs are responding to the PBF regime by changing their way of managing activities, establishing senior management with specific responsibility for research activity, and improving performance by better deployment of resources, better assessment of staff, and better focus on strategic objectives. The formative influence is notable at the level of the academic unit where each unit thinks more clearly about what sort of activities it should be doing and makes choices between different activities in a planned way to maximise future performance.

Looking at the overall country factors, a successful PBF system in a SIDS would need features that are different from those in developed countries. First, the system should not only reward performance but also support improvement. If a PBF is employed solely to distribute money to tertiary institutions, this may have negative effects as many SIDS are still at a stage where institutions doing less well need to be encouraged to move forward. Moreover, the small size of SIDS needs to be taken into account. SIDS are small communities with small groups of experts, a small number of institutions and everybody knows everybody else. It follows, Adams noted, that it is not desirable to have a PBF model that creates a very steep gradient between the good and the bad. A key issue is to focus on how to use the information that comes out of a PBF system to support institutions to perform better, and to concentrate on managing what they do to enhance the overall outcome for the state. In this way the formative policy objective may be primary in SIDS. 


\subsection{Key Lessons from Overseas Experience for SIDS}

As there is the desire to improve teaching quality and promote research culture within SIDS, consideration might be given to an appropriate PBF model which could be implemented over the longer-term for SIDS, thereby managing some of the risks identified earlier in this chapter. At present, SIDS comprise 52 separate states: 21 of them do not have any university, 16 have one university and only 15 have two or more universities (Catalogue of World Universities, 2008).

There is obviously a great deal that SIDS can gain from the know-how of developed economies, especially Australia, Denmark, New Zealand and Sweden, and the United Kingdom, for introducing PBF systems either for research or teaching. SIDS can draw a number of key lessons from overseas experience. These include political acceptability and commitment, the size of the tertiary education sector, the choice of a PBF model, and the transaction costs associated with PBF systems. In addition to transferable lessons, this research has found some SIDS-specific constraints that would influence PBF arrangements such as the adequacy of tertiary education budget, the technical capability at government and TEI levels, the reliability and quality of data, and leadership from TEls and staff association participation.

\subsubsection{Political Acceptability and Commitment}

Experiences from developed countries where PBF models have been implemented indicate that such countries are politically relatively stable, which creates a conducive environment for introducing and implementing new policies so as to enhance performance, improve efficiency and increase accountability in various sectors. However, in most SIDS there is greater political instability than in developed countries. Mauritius, for example, while not affected by rebellions or coups, typically experiences changes in government every five years. Therefore, governments of SIDS may face greater difficulties in developing PBF schemes for tertiary education than in economies which have more favourable political conditions. In addition, there tends to be a lack of policy continuity in many SIDS. This may imply less commitment on the part of policy makers to maintain a particular policy determined by the previous government. Each government wishes to put its own stamp on policy and this could result in frequent changes in systems. 


\subsubsection{Size of the Tertiary Education Sector}

As outlined in chapter five, sections 5.3.1 and 5.4.1, the size of the tertiary education sector in the developed democracies where PBF systems for research and teaching have been implemented is relatively considerable. For instance, the UK had 109 universities in August 2008, Australia 37 public universities in 2007, and, in 2007, New Zealand had eight universities. Similarly, Denmark has eight and Sweden 14 universities. Moreover, these developed countries have the necessary critical mass of student enrolments and academics so as to implement PBF systems.

This indicates clearly that the number of tertiary institutions is critical for introducing comprehensive PBF systems. However, in many SIDS there are only a few TEls. The small number of TEls will undoubtedly limit the degree of competition in the tertiary education sector and reduce the potential for PBF schemes to increase differentiation (to the extent that this is a policy objective) or enhance performance (either with respect to research or teaching). This institutional context might also affect the kind of PBF schemes that would be suitable or even feasible.

Forming independent, high-quality peer review panels may be difficult in most fields in many SIDS because of a lack of relevant academic expertise and research communities. Furthermore, in view of SIDS' smallness, most members of their academic communities are familiar with each other and there is likely to be networking and knowledge sharing among them. There is also the possibility that this familiarity may lead to a conflict of interests and a risk of favouritism if panel members are recruited locally.

\subsubsection{Choice of a PBF Model}

Overseas countries' experiences suggest that PBF models should be developed either for research or teaching but not both. Although many of those interviewed in Mauritius for this research believed that PBF systems should concentrate on both research and teaching, it would be virtually impossible and almost certainly undesirable for SIDS to implement both systems simultaneously. Policymakers will have to make a choice in order to determine which one of the two funding systems to introduce first. 
Further, policy makers should be aware that the development and implementation of any kind of PBF scheme will have some negative impacts either on research or teaching activities, and some tertiary education providers will lose funds if they are not performing well and others will be favoured.

While in developed countries such effects are desirable, and held to improve overall efforts and quality, there is no single optimal way to assess research or teaching performance in order to allocate funding. Every approach has certain strengths and weaknesses, and may generate unintended consequences. In the context of SIDS, it is important to balance the advantages and disadvantages of any particular PBF model in order to minimise the potential negative impacts.

\subsubsection{Transaction Costs associated with PBF systems}

On the basis of the literature review, it is acknowledged that those PBF systems which involve some element of peer review are likely to be more costly to implement than indicator models. Of those transaction costs associated with a PBF system, some of these costs arise irrespective of the scope and scale of the model i.e. fixed costs for developing and implementing the model. Other costs will depend on the size of the system i.e. the number of TEls, academic staff etc.

If the fixed costs are broadly the same irrespective of the size of the tertiary system or the amount of money being allocated, other things being equal, the transaction costs will represent a higher proportion of the funds available in a small tertiary system with a small budget for research or teaching. Accordingly, the transaction costs of PBF systems in SIDS are likely to be a higher proportion of the funding available than in larger systems.

This is evident when one compares the transaction costs of the UK RAE (which operates in a large tertiary system) with those in the NZ PBRF (which operates in a relative small system). In the UK, the transaction costs related to PBF system represent about $0.8 \%$ of the total funds allocated over seven years, where as for NZ it is estimated to be between $1.5 \%$ and $2 \%$ for 2007-2012 (WEB Research, 2004). 
Therefore, the transaction costs of implementing PBF systems as a proportion of the limited total funds allocated in SIDS are likely be even higher than NZ. This will make policymakers in Mauritius reflect on whether it is cost-effective and feasible to introduce PBF systems.

\subsubsection{Adequacy of Tertiary Education Budget}

As evident in the academic literature, the developed countries have invested significant levels of money for the introduction of PBF systems either for research or teaching activities. For instance, in the UK, the RAE 2001 generated funding problems (McNay, 2003; Roberts, 2003) as the funding councils were unable to compensate for the significant improvement in research quality, as measured by the 2001 assessment. If such a case could arise in a large economy like the UK, there is a high probability that SIDS may face the difficulty of finding extra funding, due to budgetary constraints, to support the results of a performance-based system.

The risk of an inability to provide additional money is clearly greater in SIDS than in developed democracies, given the kinds of constraints that typically apply in the area of fiscal policy. As illustrated in section 7.61, the small size of the budget for tertiary education in Mauritius may pose problems for policymakers in rewarding performance and providing additional new money.

Since the budget is fixed, the question that arises is whether an effective incentive can be designed for allocating a small capped sum. The danger is that if the first PBF round rewards past performance, there may be no real scope for the incentives to improve future performance. Further, if there is no new money for funding, then any PBF can only redistribute existing funds. This will be demoralising for academics and frustrating for those institutions which overall have obtained improved results.

Given such considerations, the size of the budget allocation is of critical importance for the development and introduction of PBF systems in SIDS. In the case of an improvement in TEls' research or teaching performance (depending on the kind of model developed and implemented), governments must be able to make provision for additional funds in real terms, not just once, but on an ongoing basis if performance continues to improve. 
This suggests that, under these circumstances, governments of SIDS should be very cautious about implementing PBF schemes. SIDS should have a contingency plan, such as a separate fund under the Ministry of Finance vote item, to reward performance under PBF systems. However, if SIDS' governments feel unable to provide extra money then it may not be sensible or reasonable to adopt PBF schemes in the first place except as a redistributive tool perhaps.

\subsubsection{Technical Capability at Government and TEI Levels}

A significant technical capability at both government and TEI levels is a vital prerequisite for the implementation of PBF models which are typically complex and demanding. The results from interviews carried out with the different stakeholder groups in Mauritius indicated that there is a lack of technical capability such as trained and knowledgeable personnel at the government and TEI levels to implement such models. As a result, the government will require the expertise of foreign consultants to develop PBF systems in Mauritius or any other SIDS. Both Australia and NZ - developed industrialised countries - have drawn on foreign expertise to implement their models.

In the case of SIDS, there will undoubtedly be a need for an even heavier reliance on overseas experts. However, most SIDS would face financial constraints in securing such assistance, and would be reluctant to become dependent on overseas experts of this kind.

\subsubsection{Reliability and Quality of Data}

Reliable high-quality data are not only crucial for PBF systems in larger economies but especially in SIDS because the data input could be wrongly captured, processed and coded, or not entered in the proper fields due to lack of appropriate information management skills, knowledge and trained people. Further, SIDS might encounter problems surrounding the accurate measurement of publications if they are not recorded properly. Thus, the establishment of PBF schemes in SIDS would certainly require a control mechanism (auditing system) and/or that management information system software be put in place to ensure the reliability and quality of data. Given capacity and funding constraints, this may limit the feasibility of developing, implementing and monitoring certain kinds of PBF models in SIDS. There is also the risk that potential quantitative measures may create distortions and generate gaming. 


\subsubsection{Leadership from TEIs and Staff Association Participation}

As highlighted in the literature, developed countries' experiences demonstrate that TEls have changed their management style (e.g. Denmark's universities have become more entrepreneurial than previously). In New Zealand, as per Adams (2008c), TEOs have changed their management activities, delegating specific responsibilities to look at research activity so as to maximise future performance. The introduction of a PBF system in SIDS will certainly have a major influence on the management of tertiary institutions and the culture of academics. The PBF system will increase pressure on the academic community to perform, and change the distribution of resources between tertiary education providers.

Further, a PBF for research will have an effect on the recruitment process of postgraduate students because tertiary providers are likely to select the best candidates so as to maximise their funding under PBF schemes.

As in many developed countries, the staff culture is also unionised in SIDS. Policy makers require the support, inputs and views of staff associations for any policy formulation and implementation. Efforts should be made to consult the academic community and encourage their participation in the development of any PBF systems.

Otherwise, the academics may use the bargaining powers of the staff association to hinder the process. They may believe that this funding system is pressuring them to achieve tertiary education objectives, making them more accountable, and questioning the professional integrity of academia.

In sum, the key lessons drawn from overseas countries clearly showed that Mauritius, or any other SIDS will need to consider all the issues discussed above before introducing any kind of PBF system.

\subsection{Applicability of PBF Models for SIDS}

Previous sections cast doubt on whether PBF systems make sense for SIDS. At best, the conclusion is that a new system would need to be introduced very cautiously, over a relatively long time frame with a clear monitoring and contingency plan. Assuming a plan was to go ahead, which PBF model might be best? 
The findings of this research demonstrate that SIDS would certainly encounter potential problems in developing and implementing a PBF assessment for teaching or research activities. There are strong grounds for believing that no PBF model, whether based on peer review, indicators or both and whether for teaching or research, would be applicable to, or feasible for SIDS in the short term. Each of these models is discussed later in this section, together with the main reasons why they are not applicable in SIDS.

\subsubsection{PBF for Teaching - Why Not Applicable?}

Respondents in Mauritius revealed that the key challenges for SIDS are to promote the quality of tertiary education, increase students' access and improve equity. The priorities identified through the interviews conducted for this research are consistent with the kinds of policy objectives associated with the PBF models discussed in the literature reviewed in earlier chapters. The clear policy challenge for Mauritius (and arguably other SIDS) is the need to enhance teaching standards and student performance.

However, conducting a successful PBF assessment of teaching activities in SIDS would be difficult because of the risks associated with the use of completion rates as an indicator of performance, the high costs of setting up an independent quality agency, and the choice of funding formula to calculate the annual teaching budget. Generally, there are very few objective measures that are relevant for teaching performance. Of the available measures, the most widely used is completion rates of students.

In Mauritius, PBF for teaching will not be effective if funding is based on the number of students who pass their exams because this may create difficulties for other TEls which have low completion rates. This performance measure may lead TEls to lower quality standards so as to let students complete their studies. For instance, in 2007/2008 the student enrolments for UoM were 7,794, whereas for UTM they were 1,839 (Central Statistical Office [Mauritius], 2008; Ministry of Education and Human Resources [Mauritius], 2008). On the basis of the enrolment data, UoM will probably be at an advantage compared to UTM. 
Further, the use of completion rates may act as a disincentive for TEls to recruit weak students. In addition, the disadvantaged TEI may run the risk of not obtaining sufficient funds to cover its fixed operating costs if such a performance measure is employed.

Thus, this funding policy will be difficult to implement for achieving the government's goals for tertiary education in Mauritius. Moreover, completion rates are only a very rough proxy for teaching quality. Using only one indicator (e.g. student performance) is inadequate for assessing teaching performance and does not allow for gauging the value added for an institution (Adams, 2008b).

Further, the introduction of a PBF model for teaching would require governments in Mauritius or other SIDS to institute an independent quality assurance agency of some kind (as in Denmark and Sweden) in order to safeguard the quality of tertiary education. The agency would need to conduct extensive evaluations of the TEls' educational programmes, develop new mechanisms (auditing techniques) for assessing the quality of teaching in order to ensure that academics have delivered good learning outcomes, and publish the results of the evaluations.

However, the implementation of such quality mechanisms would be very expensive. This is a clear example of additional costs for SIDS which already face budgetary constraints. The formulas employed for calculating the annual teaching budget in the Danish (taximeter) and Swedish (FTE study results) models are fairly complex and it would be necessary to develop a less complicated teaching budget formula for implementation in SIDS which generally have limited technical capabilities. In addition, with this funding system, a decline in student demand will have a direct effect on the income of the TEI.

This may have a negative effect on TEls as they have long-term financial commitments with regard to staff costs and other administrative overheads. In addition, in Sweden, the teaching budget is based on projections of student numbers, funding is on three-year contracts and the appropriation consists of a ceiling amount. Funding on a three-year contract-basis as used in Sweden may encourage wastage and inefficient use of resources in SIDS because of their lack of good governance practices. 
The lessons drawn from developed economies and the findings from this research provide sufficient evidence to conclude that the introduction of a PBF system for teaching in Mauritius, or any other SIDS would not be applicable, politically feasible or acceptable.

\subsubsection{PBF for Research (Peer Review or Mixed Model) - Not Applicable}

The introduction of a systematic assessment of research performance based on a pure peer review system or a mixed model would be problematic and undesirable to introduce in SIDS. The judgment that a peer review or mixed model would not be applicable for SIDS is based on a number of different considerations.

\subsubsection{Choice of Performance Indicators for Research}

Inappropriate performance indicators were one of the most important risks identified by the stakeholders interviewed in Mauritius. It was argued by the respondents that the choice of good performance indicators is imperative if PBF systems are implemented. With the experience from overseas (Australia, NZ and the UK), research publications, research degree completions, and external research income are the three principal indicators that are currently being used. However, even in these developed countries, it is recognised that every potential indicator of research performance has certain disadvantages, and might generate undesirable impacts. The performance indicators for research depend on whether one measures the volume or the impact of publications. If volume of publications is measured, the most commonly used indicator is internationally refereed and local journal articles, book chapters, books, and conference proceedings.

As outlined earlier, the risk with using the volume of publications as a measurement is that it may lead academics to focus on quantity rather than quality. The impact of publications is most readily measured in terms of citations (representing a connection between two published articles). The citation measures are possible in developed countries but the question is whether they are reliable and appropriate. There is no doubt that a high number of citations can indicate that an author or document has had a major impact in the field, or that a work has high value. 
However, it is crucial to bear in mind that publication and citation rates vary widely from field to field. Other factors that need to be taken into account include the extent and nature of self-citation; whether citations are concentrated around a few papers; the extent to which citations are cross-disciplinary or international; and the quality and impact of journals from which citations derive (Institute for Scientific Information, 1998). Further, not all academic or professional journals are included in the relevant indices and the number of citations can be increased by journals encouraging academics' self-citation.

Even though a citation-based system has some problems, the UK and Australian governments are placing an increased reliance on bibliometric evidence of the number of citations to journal articles published by academics within institutions. However, in the context of SIDS, the problems associated with the impact of publications could be greater because many local journals are not included or registered on international citation databases. Moreover, there may be good public policy reasons for researchers - particularly those working in applied fields - to want to publish in local rather than international journals. What is significant for researchers in SIDS is not just outstanding research or publications in internationally reputable journals or high citation rates but the merit of the research outcomes and the value to the economy and public at large.

For many SIDS, the research outcomes of a particular project are an important criterion which is employed to disburse funds for research projects. For instance, the Mauritius Research Council allocates research grants according to state priorities.

The limited number of researchers in Mauritius (497 in 2006/2007) compared to New Zealand (PBRF-eligible staff 8,671 in 2006) and relatively small number of articles and citations that produced by Mauritian researchers would skew the results. Under a citation-based system, if a TEI (e.g. UoM) has research subjects (such as biomedical sciences, and engineering) which are highly cited there might be a tendency for UoM to get much more money compared with others. It is obvious that if one TEI (UoM) gets more, the others will get less. Thus, the use of citation measures may not be desirable for Mauritius because UTM has less research capability at present compared to UoM. 
Using volume measures would equally pose problems for SIDS but probably not to the extent of citation measures. There might be a tendency for academics to place more emphasis on research topics which are easily publishable in local journals rather than overseas journals or proliferating versions of the same article in order to increase quantity of publications.

To summarise, publication measures such as citation rates for rewarding research performance under PBF schemes would not be desirable for SIDS because of the small size of the tertiary education sector and their low research intensity and capability. Although using volume as a measure to assess performance has disadvantages, it would nevertheless provide incentives for SIDS' academics to improve research outputs and create international networking.

\subsubsection{Peer Reviewers and Composition of Panel Members}

The experience of the United Kingdom and New Zealand suggests that in a peer review system the composition of the panels and the quality of the reviewers are critical. Even in the United Kingdom, institutions believed that there was a lack of transparency in the composition and recruitment of panel members for the RAE 2001. This would be a problem in the context of SIDS as there are likely to be few domestic reviewers. Further, there is the possibility of favouritism and conflicts of interest if panels are mainly composed of local academics. Therefore, panels should comprise high-calibre academics in the various disciplines in order to build trust and confidence in the system.

For instance in NZ, which is a small state, approximately $23 \%$ of the panel members in 2006 were from overseas (Tertiary Education Commission [New Zealand], 2006a). In the case of SIDS, a higher proportion of the panel members (probably over $50 \%$ ) would need to be from overseas which would certainly increase the implementation costs. However, there is also the risk that international peer reviewers may lack knowledge of Mauritius, so it may be difficult for overseas academics to review publications in the local journals.

\subsubsection{Affordability (Administrative and Compliance Costs)}

If PBF mechanisms entail high transaction and compliance costs for UK and NZ there is no doubt that a peer review model would cost more for SIDS relative to the size of funds being allocated, since there are no economies of scale. 
A peer review model would definitely involve high administrative and implementation costs. These costs would include overseas travel, payment of fees to peer reviewers, compilation of data by TEls, investment in software packages and recruitment of additional supporting staff. Further, there would be the administrative costs of funding bodies to design the scheme and handle and manage the peer review process.

Given that the costs of implementing PBF models based on a peer review process are likely to be high relative to the total funds available for allocation in a small tertiary system, there might be little willingness by policymakers and other main stakeholders to develop a pure peer review or mixed model for research in Mauritius or any other SIDS.

\subsubsection{PBF for Research (Indicator Model) - Possibly applicable in the long-term but not short-term}

As outlined in chapter one, quality and educational research challenges have been regarded as the primary issues for SIDS. Most of the respondents interviewed for this research repeatedly stressed that there is a real necessity for the governments of SIDS to improve the quality of tertiary education and build up research capability to meet development needs. Introducing an indicator model would possibly help in improving the quality of education and research performance. However, human capacity at governmental and TEls levels would be important for implementation. The overall assessment of an indicator model suggests that such a PBF scheme would probably be applicable in the long-term in some SIDS if it were based on the volume of research publications, higher research degree completions, and external research income.

Publication measures for assessing research in Australia's higher education system have been considered as problematic because they give incentives for academics to place emphasis on the quantity, rather than quality, of publications. In the context of SIDS, the use of publication measures will probably pose similar problems. There is the likelihood that the academic community will simply create new publishing vehicles (e.g. internet or local journals, etc.), thereby increasing the quantity of research outputs and neglecting the quality aspect. Nevertheless, this volume-based indicator model would give TEls strong incentives to increase research outputs in all areas, and improve research culture in SIDS. 
The use of RDC and ERI may also pose some problems in an indicator model. For instance, newly established institutions would be at a disadvantage in terms of securing research funding over the short-to-medium term, if the funding measure is shifted from enrolments to completions.

If available external research funds from different sources are concentrated in a limited number of disciplinary areas, certain tertiary institutions would inevitably benefit from PBF incorporating an ERI measure. This indicator may therefore accentuate the differences in performance between universities. For instance, in most jurisdictions, the biomedical sciences and the other sciences and technologies (e.g. engineering) have access to greater research funding from the public sector, private sector, and overseas funding sources compared to the social sciences and humanities. Thus, those institutions focussing in areas for which there are only limited external research funds might be likely to undergo a decline in their share of the available research resources.

Currently, in Mauritius, the ERI is highly skewed in favour of specific disciplines and government priorities in terms of socio-economic development. The external research funds from the Mauritius Research Council for different projects were allocated as follows in 2008: (i) Biomedical and Biotechnology MUR 14.3 million (MUR 11.8 m in 2005); (ii) Marine Resources MUR 19.1 million (MUR $7.4 \mathrm{~m}$ in 2005); and (iii) Social and Economic MUR 25.3 million (MUR 19.2 m in 2005) (Mauritius Research Council, 2008).

The number of doctoral programmes and thus the number of postgraduate research students are very low in SIDS compared to Australia, New Zealand or the UK. In Mauritius, in 2007 the number of MPhil and PhD students at UoM was 197 whereas UTM had only 17. Further, the total number of postgraduate students was 2,181 in the year 2007/2008 (Ministry of Education and Human Resources [Mauritius], 2008) compared to 18,473 for New Zealand (Wensvoort, 2008). Therefore, the use of RDC as an indicator for PBF systems in SIDS might create difficulties because of the limited number of tertiary institutions offering postgraduate programmes. 
There is no doubt that RDC and ERI measures encourage TEls to make sure that students' research projects are well supervised and completed in a timely manner, and that they thus enhance research performance and provide more incentives for TEls to generate external research funds.

It is clear that there is no perfect PBF model. All PBF models, whether for research or teaching, regardless of the indicators used have their own strengths and weaknesses.

However, performance indicators such as publications (journal articles, book chapters, books and conference proceedings), RDC and ERI may be used as measures for monitoring and reviewing research outputs and performance in SIDS in the short term. By using these indicators to enhance performance, over time policymakers might have a better idea whether it would be feasible in the long term to employ a research indicator model which is linked with the research funding.

\subsection{Policy Options for SIDS}

"Policy is about the future, not about the past or present, but we can never be really certain about how the future will unfold, not even if we engage it with the best of intentions and the most thoughtful of policy designs" (Bardach, 2000, p. 27). A policy is regarded to be in the "public interest if the benefits to the public exceed the costs, taking into account who enjoys the benefits and incurs the costs" (Ledbury, Miller, Lee, Fairman, and Clifton, 2006, p. 2).

Aside from the challenges surrounding the development and implementation of PBF systems, there are both policy and operational issues to which policymakers and implementers need to give specific attention in developing a PBF system for the tertiary sector in SIDS. A majority of those interviewed for this research $(66 \%$ of respondents) were in favour of introducing PBF systems.

However, the rest opposed PBF systems, citing the fact that Mauritius has only two universities and that PBF system could create frustrations and pressures for academics, and an extra administrative burden for academics and everyone involved in the tertiary sector. 
In terms of rewarding performance, the majority considered PBF to be desirable even though Mauritius and other SIDS are still developing human resource capabilities for socio-economic development needs. Nevertheless, the minority view, however, reflects a realistic awareness of the constraints that would operate on a PBF system, rendering it inapplicable.

As the PBF models are not considered relevant for SIDS in the short term, other policy options need to be considered. Possible options are: (i) improved monitoring and reviewing of research performance; (ii) the introduction of a quality assurance system; and (iii) the conduct of a research outcome review.

\subsubsection{Monitor and Review Research Performance of TEIs}

The first option is to monitor and review research performance of TEls. The key features would be to focus only on research and research training. The tasks would be undertaken by an independent body set up by the government or Tertiary Education Commission to conduct on-going monitoring and reviewing of research performance on a three-year cycle. TEls would submit required performance data to an independent body e.g. performance indicators publication measures, RDC and ERI. The results would be published in an official document.

The rationale for this option is essentially to enhance the quality of information on TEI research performance, provide incentives to improve research performance and increase the accountability of TEls through the simple device of collecting and publishing comparable data. Under this option, the sources of evidence would be performance indicators, e.g. research outputs - publication in a peer-reviewed journal, book, book chapter, edited book, and conference proceedings - number of Masters' theses and Doctoral theses awarded, and external research income generated by TEls.

The main strengths of this approach are that it would encourage TEls to increase research outputs and provide incentives for academics to generate external research income and improve postgraduate students' completion rates. Further, it would provide detailed performance data at departmental and institutional levels and entail relatively low administrative costs and less burden for TEls than a funding regime. 
The weaknesses are that it would likely focus on the quantity of publications rather than quality, neglect teaching at the expense of research, and lack a peer review element.

This option would give policymakers and others a clear indication of the research performance and intensity in different TEls and academic units. It would provide incentives for TEls to enhance their potential research capability. The examination of RDCs as a measure would motivate TEls to ensure that higher degree research students have good supervision and complete their studies within the agreed timeline. ERI as a measure would probably promote added competition among TEls in those disciplinary areas where larger amounts of funds are available. However, under this option, the performance indicators are not being proposed as a funding measure but rather as useful data to provide evidence of performance and trends.

\subsubsection{Quality Assurance System}

The second option is to set up a quality assurance system for tertiary education. This option could apply to both teaching and research activities. The quality assurance assessment would be conducted by an independent body such as the Tertiary Education Commission on a three-to-six year cycle. It is designed primarily to promote the quality of teaching and research by applying internationally recognised quality assurance processes. The quality of teaching would be assessed by a quality assurance agency and the quality for research would be assessed by a peer review system comprising local and overseas reviewers.

The quality assurance system for teaching would aim to provide a minimum benchmark for the quality of the learning outcomes for students. It would focus on the systems and processes that support delivery of learning by TEls. As sources of evidence, TEls would be requested to submit reports on their quality assurance system and there would be site visits by an independent body. The audit results should be made publicly available in an official report.

The evaluation for research would be carried out by a peer review system to assess the quality of research outputs submitted by academics. Peer review is a substitute for 'quality control'. Similar evidence for research outputs would be required as in Option (i). 
However, option (i) differs from option (ii) as in the former there is no peer review mechanism for quality assessment. Therefore, option (i) would be less likely to encourage research quality. Another important issue with option (ii) is that a quality assurance system would involve a high administrative burden and significant transaction costs.

The main advantages of this option are enhancing academics' understanding of quality assurance processes, maintaining and safeguarding the quality of teaching activities in TEls, and promoting research excellence and individual research performance. Further, the quality assurance system would filter good from less good, misleading or bad, authenticate the work and assure quality. The disadvantages are that it is likely to be very costly to set up and administer an independent quality agency. In terms of research quality, there are possible difficulties for recruiting panel members in different disciplines and compiling information for submission to peer reviewers.

\subsubsection{Research Outcome Review}

The third option is the research outcome review. Many of those interviewed in Mauritius considered that what matters most for them are the broader outcomes in terms of social and economic results derived from a research project. The research outcome review would be undertaken by an independent body, appointed by the Ministry of Education and Human Resources, which would establish a methodology to assess the research outcomes of a particular project.

Further, a Review Committee would comprise decision makers and researchers to determine the review cycle and submit a report to government. Sources of evidence would be research outputs related to the research outcomes of the project. This option is not aimed primarily at improving research quality but at assessing whether the research outcomes have met the socio-economic needs or other goals set by government.

The main strength of this alternative is to assess the potential benefits that stakeholders in the wider economy and society are likely to gain from the outcomes of a research project. The major weaknesses are that a research outcome review is not a common system and it is likely to be difficult and complex to measure research impacts, whether over the short-term or long-term. 
Nevertheless, this measure could potentially enhance the research outcomes which are imperative for SIDS' socio-economic advancement by encouraging academics to focus on applied research projects. The success of the outcome review process would particularly depend whether there is any plausible evidence to determine whether a particular project has had impacts on the society or economy. However, there is the possibility that a review by an independent body might involve high costs and take a considerable period of time to carry out within the tertiary education sector. Moreover, for the success of such an option, it would be crucial to establish effective terms of reference for the outcome review.

To summarise, there are three policy options, all of which will involve changes in the tertiary education sector if introduced. However, there are other matters that are worth considering before deciding the best option.

Option (iii), a research outcome review, has relatively few disadvantages, but might be difficult to introduce in Mauritius as it is not popular in the developed countries from which lessons can be drawn. Further, due to the lack of human resource capability in Mauritius, introducing such a complex option may pose problems for policymakers.

Option (ii), the quality assurance system, appears to be a good alternative to the option of a research outcome review as it enhances both teaching and research performance in the tertiary sector. However, this option cannot be implemented fully in Mauritius for two reasons. First, it would be very expensive. Second, the problems associated with the peer review system for SIDS, as discussed earlier in section 8.3.2.2, would create possible difficulties in recruiting panel members, and involve high administrative and transaction costs.

Out of the three alternatives, option (i), monitoring and reviewing research performance, is likely to be the cheapest and simplest mechanism. Although it has the major drawback of focusing on quantity rather than quality, it provides detailed data on research performance.

In order to meet the policy objectives for promoting the quality of tertiary education, improving research performance, and increasing efficiency and accountability, the establishment of simple and cost-effective performance-based measures is essential for SIDS. 
Therefore, a combination of option (i), monitoring and reviewing research performance, and option (ii) quality assurance systems for teaching is considered to be the best approach for enhancing performance in the tertiary education sector.

In the context of Mauritius, as TEC has already established a Quality Assurance and Accreditation Division to monitor and strengthen the quality assurance mechanisms in TEls, as discussed in chapter three, there is a real potential to introduce a system for enhancing research performance in the short-term. Therefore, option (i) - monitoring and reviewing research performance - is probably the most appropriate new policy initiative for Mauritius.

\subsection{A Way Forward}

If a country like Mauritius introduced a monitoring system for research alongside its existing quality assurance system for teaching - as overseen by the Tertiary Education Commission - it could be used to prepare for the eventual introduction of a PBF system. Other SIDS with at least two TEls could follow. With the lessons to be drawn from the design, implementation and evaluation of PBF systems for research in developed countries, SIDS governments will have adequate time to reflect on an indicator model with publications, research degree completion rates (Masters, M.Phil and PhD), and external research income as performance measures.

However, this research also confirms certain preconditions which are vital in developing and implementing a research assessment model in Mauritius or any other SIDS. These comprise: (i) stable policy settings and political commitment; (ii) capacity and capability; and (iii) separate budgets for research and teaching.

\section{(i) Stable Policy Settings and Political Commitment}

In larger developed economies where PBF models for teaching or research activities have been implemented the political conditions are typically stable and favourable. However, the problem faced by many SIDS is that the political environment may be less stable, there may be a lack of political commitment and there may be a lack of any consensus within the political leadership. Additionally, there is a tradition of policy turnover when new governments are installed, which can happen frequently (typically every five years in Mauritius). 
Government policies clearly attempt to direct the community towards economic and social goals such as greater efficiency, increased productivity, and social cohesion. In short, policy reflects government objectives. To implement a public policy initiative in SIDS, such as a PBF model for research, it is necessary to reach an agreement across all sector groups. This could be achieved by engaging in a national education debate (consultation with both the government and the opposition members) to reach a policy consensus that will lay the basis for the development of any tertiary education strategies. This is evidently desirable in order to avoid the dangers of constant changes in educational policies whenever there is a change in the government.

Political support, a consensus among elected members, and a clear set of policy objectives are the main requirements to build up a robust policy platform. This could be achieved through circulation of policy papers, a forum and open dialogue with people from TEls and the government agencies. It is also essential to inform all stakeholders of the general policy decisions as this would assist to create a strong policy platform to achieve government educational objectives. Further, there is clear indication that in Mauritius there is a lack of stakeholders' awareness of the current PBF models employed by developed economies. Therefore, in order to introduce a PBF research model in SIDS, it is imperative to educate those involved in the tertiary sector and in government agencies on the concept of PBF systems, how the systems operate and how funding is linked to performance. Thus, for SIDS to introduce a PBF model, the government has to ensure that the policy platform is sufficiently robust.

\section{Capacity and Capability}

In many SIDS there is a shortage of human capacity (high-calibre professionals), and the difficulty of acquiring the right people with the necessary know-how to implement a research funding model - in short there are capacity and capability constraints. Availability of specific expertise would be necessary for the introduction and development of a research funding model in SIDS. This would undoubtedly require the services of policy experts and also other academics from overseas. 
These experienced people would advise the government on the detailed design issues of the proposed model, and what can be done to meet the particular needs of SIDS. It is very likely that accessing foreign expertise would prove to be costly. Nevertheless, overseas expertise and experience are essential for implementing such a PBF model. The funding agencies (World Bank, IMF and EU), which are regarded as the potential drivers for performance-based systems, could possibly finance the costs of foreign experts to introduce a PBF research model in SIDS in order to encourage greater autonomy and effective financial management systems.

Further, there is a need to build up the human capacity and provide training at various levels if such a model is to be introduced. With the assistance of foreign experts, in the case of Mauritius, a group of people from the Ministry of Education and Human Resources, the Ministry of Finance and Economic Development and any other relevant agencies should be trained to act as 'trainers' to explain the rationale for a new research funding mechanism and how it would operate to people in the tertiary institutions and government agencies.

The introduction of a new research funding system in Mauritius or any other SIDS would certainly lead to the potential challenge of stakeholders' resistance to change. Policymakers and implementers would have to ensure that effective change management mechanisms were established. A lack of commitment on the part of the principal stakeholders from the tertiary education sector and academics might jeopardise the policy initiative. Thus, a participatory approach should be adopted to mitigate difficulties with the change process. This could be accomplished by government consultation with the various stakeholders.

\section{(iii) Separate Budgets for Research and Teaching}

Another important precondition for the introduction of a PBF scheme in SIDS is that the government budget for tertiary education should be allocated independently for teaching and research activities as in most developed economies. This is essential because it enables the government to see how the funds are distributed to different TEls and makes institutions become more accountable and use their funds efficiently and effectively. 


\subsection{Conclusion}

In carrying out this research it has been observed that most of the academic literature for PBF models focuses on developed countries. This study has contributed new knowledge by exploring the applicability and desirability of PBF schemes for SIDS.

First, the results from this research demonstrate that, even though the stakeholders in Mauritius are unfamiliar with the specific PBF models adopted in various jurisdictions, their main objectives for PBF schemes are consistent with those identified in the academic literature: to enhance quality of tertiary education, promote research culture and increase students' access. However, their desire to implement a PBF model simultaneously for both teaching and research is not supported by the literature or existing models elsewhere.

Second, this chapter has also addressed the question of whether a PBF system for teaching or research would be applicable and desirable in the tertiary education sectors for SIDS. It is clear from the evidence that a PBF model for teaching would not be suitable or politically acceptable because of SIDS' particular characteristics, such as human resource constraints, restricted capacity for government to reward performance, and the possible difficulties in terms of the reliability of potential quantitative measures and quality of data.

Further, the research funding models (peer review and mixed) would not be feasible in the short-term because of the substantial administrative and compliance costs, and the difficulties that SIDS would have with the use of conventional indicators and peer reviewers. However, one of the central recommendations arising out of the present research is that a performance indicator model for research might be appropriate for Mauritius in the long-term, particularly given that $66 \%$ of the respondents interviewed for this research indicated some measure of support for performance-based systems. This suggests that there is a desire to implement PBF systems and, as opposed to the peer-review or mixed models, a research-indicator model could find support among a majority of stakeholders in Mauritius. 
Third, this research has confirmed other studies' findings that there is no one perfect model. Each model has its strengths and weaknesses, including risks of unintended consequences. Those jurisdictions, such as, Australia, New Zealand and the UK, which have implemented PBF systems in relation to research, are either in the process of improving them or shifting to other research funding models. In developed states the policy environment is both fluid and evolving. Fourth, in the short-term, rather than introducing any form of PBF model, SIDS' governments should consider introducing uncomplicated and cost-effective performance-based measures for monitoring and assessing performance to achieve their tertiary education objectives and outcomes. As discussed earlier, out of the three proposed options, a mixture of option (i) - monitoring and reviewing research performance - and option (ii) - quality assurance systems for teaching would be best for SIDS in the short term. Of course, this option will definitely depend on the current tertiary education conditions prevailing in different SIDS. Finally, a way forward for those SIDS which have at least two TEls would be to explore the option of a performance-indicator research funding model in the longer term, provided the key preconditions outlined earlier are met, in order to address the $21^{\text {st }}$ century challenges such as knowledge-based economy, globalisation, efficiency and accountability of public funds. 


\section{CHAPTER NINE: CONCLUSION}

This thesis has examined the applicability and desirability of PBF models for tertiary education in SIDS, with particular reference to Mauritius. The study has provided an in-depth investigation of the necessary conditions that are required for, and the opportunities and challenges associated with, the development and implementation of PBF models for tertiary education in SIDS. Such an examination is informed by the opinions and perceptions of political elites and representatives of the tertiary education sector in Mauritius and by an analysis of the features of PBF in practice and in theory.

This chapter gives a brief outline of the thesis and brings together the key conclusions obtained from this research. This thesis has critically evaluated the different PBF models currently adopted in developed countries as well as their potential for enhancing the performance of tertiary education systems in developing countries, including SIDS. Further, this research has explored the necessary conditions under which a PBF model might be applicable in Mauritius, and if these conditions are met, which particular model either for research or teaching might be appropriate. Given that such necessary conditions may not be present, this thesis has also investigated possible alternative policy options for enhancing the performance of tertiary education in SIDS. Finally, it provides recommendations for further research.

Chapter one set out the context within which this research has been undertaken. An analysis of the specific issues and challenges for SIDS has provided a clear understanding of the objective of the study. As explained in chapter two, a qualitative approach has been adopted to address the research questions. Semistructured interviews were used to form the primary data whereas secondary data were collected from published annual reports and official documents. Chapter three gave an overview of the tertiary education system in Mauritius, including the TEls, the institutional arrangements, participation at the tertiary level, and funding systems for teaching and research. Finally, the current issues and challenges for tertiary education in Mauritius were described. 
The discussion in chapter four gave insights into the historical perspective of funding mechanisms from the $19^{\text {th }}$ century up until the end of the $20^{\text {th }}$ century, highlighted the strengths and weaknesses of negotiated and input-based funding systems, provided definitions for PBF, and outlined its underlying principles. Chapter five set out the background to the developments of PBF systems, and reviewed the literature on the PBF concepts, and the application of different models for research (Australia, New Zealand, United Kingdom) and teaching (Denmark and Sweden) implemented in these jurisdictions. A substantive assessment of the different research funding models (peer review, indicator and mixed) and teaching funding models (Danish taximeter system and Swedish FTE Study Results) was carried out.

Chapters six and seven presented the empirical analysis and findings, described and analysed the key themes that emerged from this research, and illustrated these with quotations from respondents to substantiate the results. Finally, chapter eight discussed the research findings, the implications for SIDS, and the applicability and desirability of PBF models in Mauritius or any other SIDS.

This research offers three contributions to knowledge. First, this research contributes to an understanding of PBF models. It reviews the key principles of new public management that led to tertiary education funding reforms, and the application of different PBF models in selected countries - Australia, Denmark, Sweden, New Zealand, and the United Kingdom. It notes that previous studies of PBF systems have focused particularly on comparative analyses, impacts and implications for teaching and research activities in OECD countries and American states. Since it appears that no previous research has been carried out on the desirability and applicability of PBF models for tertiary education in SIDS, this empirical work and subsequent discussion adds to the PBF literature.

Second, as the literature makes clear, country-specific aspects of tertiary education reforms show that PBF systems adapt to specific conditions. Overall, the main concerns associated with input-based funding systems, the doctrines of new public management, and accounting for results, have steered governments in various jurisdictions to review funding mechanisms so as to enhance technical efficiency, promote quality and increase accountability for public expenditures. 
This general trend has been shown to hold in Mauritius and, hence, by extension may be a likely pattern in other SIDS, although a shift to PBF will not occur immediately.

Various countries have learned from their experiences that each PBF model has its own strengths and weaknesses, and generates unintended consequences. There is definitely no 'right' or 'ideal' model. Another lesson learned by the selected countries is that PBF models place a large administrative burden on the tertiary sector and entail high transaction costs as a percentage of the total funds allocated but not compared with competitive bidding processes. Further, PBF models have generated funding concerns, encouraged game-playing, and may have had a negative effect upon interdisciplinary fields and on young emerging scholars. Therefore, there are on-going changes being made to improve the current PBF models in the different jurisdictions assessed to further reduce the administrative burden, minimise costs, and make use of more quantitative performance measures. Funding capacity for rewarding performance is essential for governments to implement any kind of PBF scheme otherwise the scheme may act as a disincentive for TEls and academics. Moreover, investment in quality assurance mechanisms is crucial for maintaining and safeguarding quality.

Third, from the in-depth review of the PBF models undertaken for various jurisdictions, it appears that no jurisdiction has introduced a PBF model simultaneously for both research and teaching. Applying PBF systems for both teaching and research is not desirable because it would be administratively unmanageable, costly and unfeasible, and place undue pressure on TEls and academics.

On the basis of the evidence provided in chapters six and seven, four major conclusions can be drawn. First, notwithstanding the numerous problems associated with PBF systems, there is a surprisingly high level of support for such systems among the different stakeholder groups in Mauritius. Moreover, in Mauritius, arguably a bellwether SIDS, there is a desire by the majority of respondents to implement PBF systems for teaching and research simultaneously, so as to achieve the desired policy objectives and outcomes. However, the analysis in this research shows this desire to be unachievable, certainly in the short-term. 
Second, respondents in Mauritius have a good understanding of the capacity constraints that would arise when introducing and developing PBF systems in Mauritius or any other SIDS. This understanding is consistent with the analysis of the literature. Many of those interviewed expressed concerns about SIDS' distinctive characteristics that need to be considered by policymakers such as small size, limited resources, vulnerability to natural calamities, and the close of relationships amongst the academic community. Moreover, respondents perceived that political commitment, the creation of a robust policy platform, overseas expertise and good management information systems are essential building blocks for PBF systems.

Third, respondents interviewed in Mauritius also recognised the key implementation issues that might impact on the success of PBF systems for tertiary education in SIDS. The implementation issues identified in this research were these: the potentially high administrative burden and compliance costs; the lack of technical capability within the government and TEIs; the limited number of TEls; the small number of researchers; the complexities of managing change in the tertiary education sector; and the negative impacts on research and teaching, depending on the kind of PBF model. This means that for PBF systems to be successfully implemented in Mauritius or any other SIDS, governments of the SIDS in question need to give particular attention to these issues.

Fourth, in terms of implications as discussed in chapter eight, a key argument advanced is that the small size of the budget allocation for tertiary education may limit the capacity for policymakers to reward performance if PBF models are introduced in SIDS. Therefore, provision for additional funds is required to reward performance, not only once, but on an on-going basis if there is to be continual improvement in performance. Similarly, the reliability of quantitative measures and quality of data may be problematic without an improvement in human resource capability.

This research has sought to provide a clearer understanding of PBF systems in OECD countries, and their potential desirability and applicability in SIDS. In doing so, the policy implications for SIDS and policy options in the short-term to enhance performance in the tertiary education sector have been explored, and a recommendation for the long-term has been advanced. 
In the short-term there appear to be three policy options: more active monitoring and reviewing the research performance of TEls, establishing better quality assurance systems, undertaking a research outcome review, or some combination of the three options.

The key conclusion arising from this research is that PBF systems for either teaching or research are neither desirable nor feasible for SIDS, at least in the short term. This conclusion applies irrespective of the kind of PBF system that might be considered (i.e. whether it is based on peer review assessments or the use of performance indicators, or some combination of the two). The reasons for reaching this conclusion have been explained in detail in the preceding chapters, but can be summarised as follows. First, all PBF systems, whatever their technical features and specifications, entail relatively high implementation costs relative to input-based funding models. These costs are especially high in the case of both a peer review and a mixed model.

Second, there is a high probability that the implementation costs of a PBF model, whether for teaching or research, will comprise a significant proportion of the funding available for these activities in a relatively small tertiary system (which of course is the norm in SIDS). Third, specific PBF models have well-recognised weaknesses and limitations. For instance, models based on the use of performance indicators are likely to have distortionary effects on funding allocations between TEls, and these are likely to cause harm to specific TEls and/or subject areas (sometimes for utterly arbitrary reasons). Similarly, any PBF system that requires peer review will impose substantial additional costs on the tertiary system, not to mention the difficulty of recruiting suitable peer reviewers. If, for the reasons outlined, PBF systems are unlikely to achieve the policy objectives for tertiary education desired by SIDS, such as Mauritius, other options need to be considered. Of the options discussed in chapter eight, in my view, the best approach in the short-to-medium term - at least in relation to Mauritius - would be to improve the monitoring and reviewing of research performance, and enhance the existing quality assurance system for teaching. 
Over the longer-term, it might be possible to consider the implementation of a PBF system in a SIDS like Mauritius. Of the currently available options, it is likely that a performance indicator model would be most appropriate, but only if certain conditions are met. These include stable policy settings and political commitment, capacity and capability, and the separation of budgets for research and teaching.

Were an indicator model to be seriously considered, it would be desirable to proceed with caution and, in the first instance, to allocate only a modest proportion of the available funding via such a system. In this way, the effects of the new policy framework can be monitored and assessed. If the overall consequences of the new scheme are deemed to be positive (and, in particular, if there is no evidence of significant distortionary impacts), then the scheme could be expanded. Choosing which particular indicators to employ will depend, amongst other things, on the nature and quality of the data available, the number of TEls and researchers, and other relevant considerations.

\section{Recommendations for further research}

This research has reviewed the desirability and applicability of PBF models for tertiary education in SIDS, particularly Mauritius. No attempt was made to incorporate other developing countries into this study. This research suggests an area of further investigation would be a comparative study of the potential for PBF systems in other developing countries. This would expand the usefulness of the study and contribute to improved quality education so as to empower developing nations to meet the goals of knowledge-based society, globalisation and socioeconomic needs.

Another possible area for further investigation would be to undertake a quantitative study to test the feasibility of the PBF indicator model for research in SIDS with a limited number of TEls. 


\section{APPENDIX A}

\section{List of Small Island Developing States (SIDS)} (UN Members)

\begin{tabular}{|c|l|l|l|}
\hline 1 & Antigua and Barbuda & 20 & Federated States of Micronesia \\
\hline 2 & Bahamas & 21 & Mauritius \\
\hline 3 & Bahrain & 22 & Nauru \\
\hline 4 & Barbados & 23 & Palau \\
\hline 5 & Belize & 24 & Papua New Guinea \\
\hline 6 & Cape Verde* $^{*}$ & 25 & Samoa \\
\hline 7 & Comoros $^{*}$ & 26 & São Tomé and Principe \\
\hline 8 & Cuba & 27 & Singapore \\
\hline 9 & Dominica & 28 & St. Kitts and Nevis \\
\hline 10 & Dominican Republic & 29 & St. Lucia \\
\hline 11 & Fiji & 30 & St.Vincent and the Grenadines \\
\hline 12 & Grenada & 31 & Seychelles \\
\hline 13 & Guinea-Bissau & 32 & Solomon Islands* \\
\hline 14 & Guyana & 33 & Suriname \\
\hline 15 & Haiti* & 34 & Timor-Lesté \\
\hline 16 & Jamaica $^{*}$ & 35 & Tonga \\
\hline 17 & Kiribati* & 36 & Trinidad and Tobago \\
\hline 18 & Maldives & 37 & Tuvalu* \\
\hline 19 & Marshall Islands & 38 & Vanuatu* \\
\hline
\end{tabular}

\section{List of Small Island Developing States (SIDS) (Non-UN Members)}

\begin{tabular}{|l|l|l|l|}
\hline 1 & American Samoa & 8 & Guam \\
\hline 2 & Anguilla & 9 & Montserrat \\
\hline 3 & Aruba & 10 & Netherlands Antilles \\
\hline 4 & British Virgin Islands & 11 & New Caledonia \\
\hline 5 & Commonwealth of Northern Marianas & 12 & Niue \\
\hline 6 & Cook Islands & 13 & Puerto Rico \\
\hline 7 & French Polynesia & 14 & U.S. Virgin Islands \\
\hline
\end{tabular}

* Also Least Developed Countries (LDCs)

Source: United Nations, 2009 


\section{APPENDIX B}

\section{Number of Interviewees from Different Organisations and Stakeholder Groups}

\begin{tabular}{|c|c|c|c|c|c|c|}
\hline Organisation & $\begin{array}{l}\text { Policy } \\
\text { Makers }\end{array}$ & $\begin{array}{l}\text { Chief } \\
\text { Executives }\end{array}$ & $\begin{array}{l}\text { Senior } \\
\text { State } \\
\text { officials }\end{array}$ & Academics & $\begin{array}{l}\text { TEIS } \\
\text { Staff } \\
\text { Association } \\
\end{array}$ & $\begin{array}{l}\text { Number of } \\
\text { Interviews }\end{array}$ \\
\hline $\begin{array}{l}\text { Ministry of } \\
\text { Education and } \\
\text { Human Resources }\end{array}$ & 4 & & & & & 4 \\
\hline $\begin{array}{l}\text { Ministry of } \\
\text { Economic Finance } \\
\text { and Development }\end{array}$ & 1 & & 4 & & & 5 \\
\hline National Assembly & 1 & & & & & 1 \\
\hline $\begin{array}{l}\text { Tertiary Education } \\
\text { Institutions }\end{array}$ & 1 & 4 & 2 & 10 & 2 & 19 \\
\hline $\begin{array}{l}\text { Government } \\
\text { Agencies } \\
\text { responsible for } \\
\text { Tertiary Education }\end{array}$ & 3 & & 4 & & & 7 \\
\hline $\begin{array}{l}\text { Private Provider } \\
\text { and others }\end{array}$ & 1 & 1 & & & & 2 \\
\hline Total & 11 & 5 & 10 & 10 & 2 & 38 \\
\hline
\end{tabular}




\section{APPENDIX C}

\section{Interview Schedule}

1. What specific policy objectives or outcomes should be sought from the tertiary education system?

2. To what extent is the tertiary education system producing those outcomes? If it is "What is the present policy mix that is producing those outcomes? - If it is not "What are the impediments to those outcomes being produced?"

3. What do you understand by the notion of a performance-based funding system, particularly in tertiary education?

4. What specifically might/should a performance-based funding system seek to achieve in Mauritius?

5. Who, if anyone, is advocating a PBF and why? (policy actors, domestic participants, overseas agencies)

6. Is a PBF system appropriate for the tertiary education system in Mauritius? Why and why not?

Are there features of SIDS that make PBF models more, or less, applicable /desirable than in larger developed economies?

7. Given the present political, policy and institutional context in Mauritius is there a sufficiently robust platform on which to develop and introduce a PBF?

What are the elements in the present policy/institutional mix might contribute to that platform? Where are the principal capacity gaps or deficits?

8. If a PBF were to be developed and implemented for Mauritius should it focus on teaching, research, or both; why?

9. If a PBF were to be developed and implemented, what in your assessment would be the principal risks in terms of the implementation of such a system?

10. Given what you know about PBF systems for tertiary education, on balance would you support or oppose the development and implementation of such a system for Mauritius; why? 


\section{APPENDIX D}

(On University Letter head)

\section{Information Sheet for a Study of the Applicability of Performance-Based Models for Tertiary Education for Small Island Developing States-The Case of Mauritius}

Researcher: Siamah Kaullychurn, PhD student in Public Policy, School of Government, Victoria University of Wellington.

\section{Purpose and Benefits of the Project}

The purpose of this project is to explore the desirability and applicability for Small Island Developing States (SIDS), such as Mauritius, of a move towards performance-based funding models for tertiary education. Empirical studies to date have been largely confined to developed countries. However, there is a lack of literature on performance-based funding models with regard to developing countries, including SIDS. This study will attempt to remedy this gap in literature. Furthermore, this study will provide insights for the Governments of Mauritius and other Small Island Developing States about the arguments for and against the introduction of a performance-based funding model for tertiary education, and assist policymakers in the development and implementation process.

\section{Ethical Approval}

The University requires that ethics approval be obtained for research projects involving human participants. As semi-structured interviews will be conducted, Human Ethics Committee approval has to be granted before data collection can begin.

\section{Procedures and Duration}

Participation is entirely voluntary. The researcher will carry out a face-to-face interview with the respondents during which the interviewees will be asked to respond to questions and to provide insights based on their own understanding and views. All interviews will be tape recorded and transcribed by the researcher. In addition to taping the interviews, notes will be taken to capture important points made by the respondents. The duration of the interview is expected to be one and one and half hours. 


\section{Confidentiality}

In the consent form there is an undertaking to keep personal details of the participants confidential. The interview notes and all written materials will be kept in a locked file, all electronic information will be kept in a password-protected file and access will be restricted to the researcher. All written materials will be destroyed five years after the conclusion of the research and any audio recordings will be electronically wiped.

\section{Publication of Results}

The results of the data collected will be part of the thesis and deposited in the University Library and also used for publications in academic or professional journals and conference presentations.

\section{Feedback}

A covering letter from the researcher with an executive summary of the completed study will be provided to participants within four months of the completion of the doctoral programme.

\section{Contact Details}

If participants have any questions or would like to receive further information about the project, please contact Professor Jonathan Boston, Institute of Public Policy, School of Government Victoria University of Wellington, New Zealand, phone number: +64 4463 5456 DDI and email: jonathan.boston@vuw.ac.nz. 


\section{APPENDIX E}

\section{CONSENT FORM}

\section{Applicability of Performance-Based Funding Models for Tertiary Education in Small Island Developing States-The Case of Mauritius}

Objective of the study: To explore the desirability and applicability for Small Island Developing States, such as Mauritius, of a move towards performance-based funding models for tertiary education.

I have read the information about the applicability of performance-based funding models for tertiary education and I understand why the research is being undertaken.

I understand that:

\section{No}

- I will be interviewed.

- My participation is entirely voluntary.

- The interview will be tape recorded.

- The information I give will be seen only by the interviewer and her supervisors.

- The information will be used in a study that the interviewer is undertaking for her PhD thesis.

- I may withdraw from the study, by advising the researcher or her Supervisor, at any time up to three months after the interview date and any information provided by myself will be destroyed.

- The information I provide may be attributed to me with the option of "general consent" or "specific consent for particular attributions"

Yes 


\section{REFERENCES}

ACP/83/012/06 (2006). Brussels Declaration on Education for Sustainable Development in ACP States. Retrieved March 18, 2007, from http://www.acp-edulink.eu.

Adams, J., Cook, N., Law, G., Marshall, S., Mount, D., Smith, D., et al. (2000). The Role of Selectivity and the Characteristics of Excellence: Report to the Higher Education Funding Council for England: A consultancy study within the Fundamental Review of Research Policy and Funding Available from http://www.evidence.co.uk/downloads/selectivity-report.pdf

Adams, J. (2008a). The Future of the British RAE. Paper presented at the Measuring Research Performance: What are the Options? Retrieved November 25, 2009, from http://ips.ac.nz/events/downloads/2008/

Adams, J. (2008b). Personal Communication on Performance-Based Funding Systems for SIDS.

Adams, J. (2008c). Strategic Review of the Performance-Based Research Fund: The Assessment Process. Retrieved October 28, 2008, from http://www.tec.govt.nz/upload/downloads/pbrf-report-2008-review.pdf

Adams, J., and Smith, D. (2006). Evaluation of the British Research Assessment Exercise. In L. Bakker, J. Boston, L. Campbell \& R. Smyth (Eds.), Evaluating the Performance-Based Research Fund. Wellington, N.Z.: Institute of Policy Studies.

Anderson, D., Johnson, R., and Milligan, B. (1996). Performance-Based Funding of Universities (Commissioned Report No.51): Australia Higher Education Council, National Board of Employment, Education and Training.

Asian Development Bank (2000). A Pacific Strategy for the New Millennium.

Ashworth, K. H. (1994). Performance Based Funding in Higher Education: The Texas Case Study. Change, 26(6), 8.

Asmar, C. (2007). Strategies to Enhance Learning and Teaching in a ResearchExtensive University. International Journal for Academic Development, 7(1), 18-30. 
Auerbach, C. F., and Silverstein, L. B. (Eds.). (2003). Qualitative Data: An Introduction to Coding and Analysis. New York: New York University Press.

Australian Research Council (2008). Consultation Paper: Excellence in Research for Australia (RE) Initiative (No. 978-0-9581800-2-3). Retrieved October 1, 2008, from http://www.arc.gov.au/pdf/ERA-ConsultationPaper

Australian Vice-Chancellors' Committee (2005). Enhancing Australia's Core Research Capacity - Developing a Research Quality Framework: The AVCC Proposal.

Bailey, P. H. (1997). Finding Your Way Around Qualitative Methods in Nursing Research. Advanced Nursing, 25, 18-22.

Ball, D. F., and Butler, J. (2004). The Implicit Use of Business Concepts in the UK Research Assessment Exercise. R \& D Management, 34(1), 87-97.

Banta, T. W., Rudolph, L. B., Dyke, J. V., and Fisher, H. S. (1996). Performance Funding Comes of Age. Tennessee. Higher Education, 67(1), 23-45.

Bardach, E. (2000). A Practical Guide for Policy Analysis: The Eightfold Path to More Effective Problem Solving. New York: Chatham House Publishers of Seven Bridges Press, LLC.

Barnett, R., and Bjarnason, S. (1999). The Reform of Higher Education. London: Jessica Kingsley.

Barr, N. A. (2004). Higher Education Funding. Oxford Review of Economic Policy, 20(2), 264-283.

Barzelay, M., and Gallego, R. (2006). From "New Institutionalism" to "Institutional Processualism": Advancing Knowledge about Public Management Policy Change. Governance: An International Journal of Policy, Public Administration, and Institutions, 19(4), 531-557.

Bauer, M. W., and Gaskell, G. (2002). Qualitative Researching with Text, Image and Sound: A Practical Handbook. London: Sage.

Bence, V., and Oppenheim, C. (2004). The Influence of Peer Review on the Research Assessment Exercise. Journal of Information Science, 30(4), 347-368. 
Blaikie, N. W. H. (2000). Designing Social Research: The Logic of Anticipation. Malden, MA: Polity.

Boaden, R. J., and Cilliers, J. J. (2001). Quality and the Assessment Exercise: Just One Aspect of Performance. Quality Assurance in Education, 9(1), 513.

Borland, K. W. (2001). Qualitative and Quantitative Research: A Complementary Balance. New Directions for Institutional Research, 112, 5-13.

Boslaugh, S. (2008). Secondary Data Sources for Public Health - A Practical Guide. Cambridge: Cambridge University Press.

Boston, J. (2002). Designing a Performance-Based Research Fund for New Zealand. Wellington, N.Z.: Transition Tertiary Education Commission.

Boston, J. (2004). The Future of the Performance-Based Research Fund: Issues and Options. Paper presented at the Paper for Royal Society Forum: 'Evaluating the Assessment Framework'.

Boston, J. (2006). Rationale for the Performance-Based Research Fund: Personal Reflections. In L. Bakker, J. Boston, L. Campbell \& R. Smyth (Eds.), Evaluating the Performance-Based Research Fund. Wellington, N.Z.: Institute of Policy Studies.

Boston, J. (2008). Enhancing the PBRF: Options for Post 2012. Paper presented at the Measuring Research Performance: What are the Options? Retrieved November 15, 2009, from http://ips.ac.nz/events/downloads/2008/

Boston, J., Martin, J., Pallot, J., and Walsh, P. (1996). Public Management: The New Zealand Model. Auckland: Oxford University Press.

Boston, J., Mischewski, B., and Smyth, R. (2005). Performance-Based Research Fund: Implications for Research in the Social Sciences and Social Policy. Social Policy New Zealand(24), 55-85.

Boyatzis, R. E. (1998). Transforming Qualitative Information. Thousand Oaks, California: Sage.

Boyd, W. L. (1982). Zero-Base Budgeting: The Texas Experience. Higher Education, 53(4), 429-438.

Braun, V., and Clarke, V. (2006). Using Thematic Analysis in Psychology. Qualitative Research in Psychology, 3, 77-101. 
Bray, M., and Kwo, O. (2003). Higher Education in Small Territories: Political Transition and Development in Macau. Higher Education Policy, 16, 413432.

Bryman, A. (2001). Social Research Methods. New York: Oxford University Press.

Burke, J. C., and Minassians, H. (2001). Linking State Resources to Campus Results: From Fad to Trend, Fifth Annual Survey. New York: Nelson A. Rockefeller Institute of Government.

Burke, J. C. (1998). Performance Funding: Present Status and Future Prospects. New Directions for Institutional Research, 97, 5-13.

Burke, J. C., and Shahpar, M. (1999). Performance Funding and Budgeting: Popularity and Volatility, Third Annual Survey. New York: Nelson A. Rockefeller Institute of Government.

Burke, J. C., Rosen, J., Minassians, H., and Lessard, T. (2000). Performance Funding and Budgeting: An Emerging Merger? Fourth Annual Survey New York: Nelson A. Rockefeller Institute of Government.

Burke, J. C., and Minassians, H. (2002). Performance Reporting: The Preferred "No Cost" Accountability Program, Sixth Annual Survey. New York: Nelson A. Rockefeller Institute of Government.

Burke, J. C., and Minassians, H. (2003). Performance Reporting: "Real" Accountability or Accountability "Lite", Seventh Annual Survey. New York: Nelson A. Rockefeller Institute of Government.

Burke, J. C., and Modarressi, S. (2000). To Keep or Not to Keep Performance Funding. Higher Education, 71(4), 432-453.

Campling, L. (2006). A Critical Political Economy of the Small Island Developing States Concept: South-South Cooperation for Island Citizens. Developing Societies, 22(3), 235.

Canton, E., Richard, V., Jongbloed, B., Jos, K., van der Meer, P., and Vossensteyn, H. (2001). Higher Education Reform: Getting the Incentives Right. Netherlands: CPB Netherlands Bureau for Economic Policy Analysis, CHEPS. 
Canton, E., and van der Meer, P. (2001). Public Funding of Higher Education: The Danish Taximeter-Model Higher Education Reform: Getting the Incentives Right. Netherlands: CPB Netherlands Bureau for Economic Policy Analysis, CHEPS.

Carment, D., Prest, S., and Samy, Y. (2004). Assessing Small Island Developing State Fragility. In L. Briguglio \& E. J. Kisanga (Eds.), Economic Vulnerability and Resilience of Small States. Malta: Islands and Small States Institute.

Catalogue of Universities (2009). Retrieved March 25, 2009, from http://www.webometrics.info/

Central Intelligence Agency (2009). The World Fact book. Country Comparisons GDP Per Capita (PPP). Retrieved March 24, 2009, from www.cia.gov/library/publications/the-world-factbook/rankorder

Central Statistical Office [Mauritius] (2008). Trends in Enrolment and New Admissions on Tertiary Education Level Programmes Retrieved May 15, 2008, from http://www.gov.mu//portal/goc/cso

Cermáková, Z., Holda, D., and Urbánek, V. (1994). Changes in Funding of Higher Education in the Czech Republic. European Journal of Education, 29(1), 75-83.

Cheung, B. (2003). Higher Education Financing Policy: Mechanisms and Effects. Essays in Education, 5.

Chubb, I. (2006). The Future of Research Education (in the research quality framework). Paper presented at the Quality in Postgraduate Research Conference, Glenelg.

Cinlar, N., and Dowse, J. (2008). Human Resource Trends in the Tertiary Academic Workforce - A Working Paper Contributing to the Independent Strategic Review of the Performance-Based Research Fund. Wellington, NZ: Tertiary Education Commission [New Zealand].

Codd, J. A. (2005). The PBRF as Ideology: Lessons from the British RAE. In R. Smith \& J. Jesson (Eds.), Punishing the Discipline - The PBRF Regime. Auckland, N.Z.: Auckland University of Technology, University of Auckland. 
Codd, J. A. (2006). The Performance-Based Research Fund and the Production and Commodification of Knowledge. In L. Bakker, J. Boston, L. Campbell \& R. Smyth (Eds.), Evaluating the Performance-Based Research Fund. Wellington, N.Z.: Institute of Policy Studies.

Cohen, B. B. (2006). Basics of Outcome Model Construction. Retrieved January 15, 2009, from www.health.state.mn.us/ommh/grants/ehdi/forgrantees/outcomemodel.pdf

Cowan, J. (1985). Effectiveness and Efficiency in Higher Education. Higher Education, 14, 235-239.

Cross, P. K., and Valley, J. R. (1974). Planning Non-Traditional Programs: An analysis of the Issues for Post-Secondary Education. San Francisco: Jossey-Bass.

Crossley, M., and Holmes, K. (2001). Challenges for Educational Research: International Development, Partnerships and Capacity Building in Small States. Oxford Review of Education, 27(3), 395-409.

Crossley, M., and Holmes, K. (2004). Whose knowledge, Whose Values? The Contribution of Local Knowledge to Education Policy Processes: A Case Study of Research Development Initiatives in the Small State St Lucia. Compare, 34(2), 197-213.

Dalziel, P. (2005). Rewarding Individual Research Excellence in the PBRF. New Zealand Journal of Tertiary Education Policy, 1(2), 1-9.

Davies, E., Craig, D., and Robertson, N. (2005). Is the Performance Based Research Fund in the Public Interest? New Zealand Journal of Tertiary Education Policy, 1(2), 1-5.

Davies, P. (2001). Spies as Informants: Triangulation and the Interpretation of Elite Interview Data in the Study of the Intelligence and Security Services. Politics, 21(1), 73-80.

De Boer H (2000). Institutional Governance: Consequences of Changed Relationships between Government and University. Paper presented at the IMHE Seminar, Tokyo.

Denzin, N. K., and Lincoln, Y. S. (2005). Qualitative Research (3rd ed.). London: Sage. 
Denzin, N. K., and Lincoln, Y. S. (2008). The Landscape of Qualitative Research (3rd ed.). London: Sage

Department of Education, Science and Training [Australia] (2005). Higher Education Report 2004-05.

Department of Education, Science and Training [Australia] (2007). Annual Report 2006-07. Retrieved January 30, 2008, from http://www.dest.gov.au/annualreport/2007/

Desmond, M. (2004). Methodological Challenges Posed in Studying an Elite in the Field. Area, 36(3), 262-269.

Douglass, J. A. (2004). A New Cycle of UK Higher Education Reforms: New Labour and New Fees May Foster Mission Differentiation: Center for Studies in Higher Education, California.

Education and Training (Miscellaneous Provisions) Act (2005). Amendments to Education, MQA and TEC Acts. Retrieved January 30, 2006, from http://www.gov.mu/portal/goc/mqa/file/eduact.doc.

Elkin, J. (2002). The UK Research Assessment Exercise 2001. Libri, 52, 204-208..

Evans, L., and Quigley, N. (2006). The Performance-Based Research Fund and the Benefits of Competition between Universities. In L. Bakker, J. Boston, L. Campbell \& R. Smyth (Eds.), Evaluating the Performance-Based Research Fund. Wellington, N.Z.: Institute of Policy Studies.

Fereday, J., and Muir-Cochrane, E. (2006). Demonstrating Rigor using Thematic Analysis: A Hybrid Approach of Inductive and Deductive Coding and Theme Development. International Journal of Qualitative Methods, 5(1), 1-11.

Field, R. (2008). Students Are Well Supported - Our Universities Are Not. Dominion Post, .June 30, 2008.

Friedman, L. (1979). Performance Budgeting in American Cities. Public Productivity Review, 3(4), 50-62.

Gale, T., Gilbert, R., Seddon, T., and Wright, J. (2005). The RQF and Educational Research in Australia: Implications and Responses across the Research Community. Paper presented at the Australian Association for Research in Education, Sydney. 
Gerristen, J. (2008, May 16). More Funding, More Difference. New Zealand Education Review.

Goldfinch, S. (2003). Commentary: Investing in Excellence? The PerformanceBased Research Fund and its Implications for Political Science Departments in New Zealand. Political Science.

Gubrium, F. J., and Holstein, J. A. (2002). Handbook of Interview Research Context \& Method. London: Sage.

Guena, A., and Martin, B. R. (2003). University Research Evaluation and Funding: An International Comparison. Minerva Kluwer Academic Publishers, 41, 277-304.

Hall, C., and Matthews, K. M. (2006). Impact of the Performance-Based Research Fund on Teaching, and the Research-Teaching Balance: Survey of New Zealand University. In L. Bakker, J. Boston, L. Campbell \& R. Smyth (Eds.), Evaluating the Performance-Based Research Fund. Wellington, N.Z.: Institute of Policy Studies.

Hare, P. G. (2002). The UK's Research Assessment Exercise Impact on Institutions, Departments, Individuals. Paper presented at the OECD Conference on Higher Education Incentives and Accountability: Instruments of Change in Higher Education, Paris.

Hazeldine, T., and Kurniawan, C. (2006). Impact and Implications of the 2003 Performance-Based Research Fund Research Quality Assessment Exercise. In L. Bakker, J. Boston, L. Campbell \& R. Smyth (Eds.), Evaluating the Performance-Based Research Fund. Wellington, N.Z.: Institute of Policy Studies.

Henkel, M. (2006). The Modernisation of Research Evaluation: The Case of the UK. Higher Education, 38(1), 105-122.

HERO (2001). 2001 Research Assessment Exercise: The Outcome. RAE 4/01. Retrieved February 23, 2007, from http://www.hero.ac.uk/rae/pubs Higher Education Funding Council for England (2000). Better Accountability for Higher Education: A Review for the HEFCE by PAQ Consulting. Bristol. 
Higher Education Funding Council for England (2005). Higher Education in the United Kingdom. Retrieved March 30, 2007, from www.hefce.ac.uk/pubs/hefce/2005/05

Higher Education Funding Council for England (2006). Funding Higher Education in England. Retrieved June 15, 2007, from http:www.hecfe.ac.uk

Higher Education Funding Council for England (2008a). Recurrent Grants for 2008-09. Retrieved May 14, 2008, from http://www.hefce.ac.uk/pubs/hefce

Higher Education Funding Council for England (2008b). Research Excellence Framework. Retrieved September 30, 2008, from http://www.hefce.ac.uk/Research/ref

Higher Education Statistics Agency (2008). Universities Celebrating 90 years 1918-2008: Higher Education in Facts and Figures. Retrieved 4 November, 2008, from

http://www.universitiesuk.ac.uk/Publications/Bookshop/Documents/Stats20 08.pdf

Hoenack, S. A. (1982). Pricing and Efficiency in Higher Education. Higher Education, 53(4), 403-418.

Hood, C. (1991). A Public Management for All Seasons? Public Administration 69, 3-19.

House of Commons Select Committee on Science and Technology (2002). Merits of the Research Assessment Exercise, Second Report. Retrieved December 15, 2006, from http://www.publications.parliament.uk/pa Howe, K. R. (1998). The Interpretive Turn and the New Debate in Education. Educational Researcher, 27(13), 12-20.

Human Development Report, 2009. Human Development Index 2007. Retrieved November 15, 2009, from http://hdrstats.undp.org/en/countries / country fact sheets/

IMHE and OECD (2006). Funding Systems and Their Effects on Higher Education Systems - Country Study Denmark: The Danish Centre for Studies in Research and Research Policy, University of Aarhus. 
Institute for Scientific Information (1998). What Are Citation Indexes and What Are Their Benefits? Retrieved November 12, 2008, from http://zatoka.icm.edu.pl/sci/wos man/citindhp

Jenkins, A. (1995). The Research Assessment Exercise: Funding and Teaching Quality. Quality Assurance in Education, 3(2), 4-12.

Jensen, L. (1998). Interpreting New Public Management: The Case of Denmark. Australian Journal of Public Administration, 57(4), 54-65.

Jesson, J. (2005). The PBRF and Education: A state created Standards Body for Governmentality of our Own. In R. Smith \& J. Jesson (Eds.), Punishing the Discipline: The PBRF Regime. Auckland: Auckland University of Technology, University of Auckland.

Johansson, M. (2004). The Swedish Model for Capital Expenditure in Higher Education from a Lifelong Learning Perspective. Stockholm: Institute of International Education.

Jongbloed, B., and Vossensteyn, H. (2001). Keeping up Performances : An International Survey of Performance-Based Funding in Higher Education. Higher Education Policy and Management, 23(2), 127-145.

Kaiser, F., Vossensteyn, H., and Koelman, J. (2000). Public Funding of Higher Education: A comparative Study of Funding Mechanisms in Ten Countries: CHEPS, Netherlands.

Kaiser, F., Vossensteyn, H., and Koelman, J. (2001). Public Funding of Higher Education: A Comparative Study of Funding Mechanisms in Ten Countries. Netherlands: CHEPS.

Kettl, D. F. (1997). The Global Revolution in Public Management: Driving Themes, Missing Links. Policy Analysis and Management, 16(3), 446-462.

Klemming, Y. Z. (2005). Swedish Universities \& University Colleges Short Version of Annual Report: National Agency for Higher Education.

Koelman, J., and Venniker, R. (2001). Public Funding of Academic Research: The Research Assessment Exercise of the UK. Netherlands: CHEPS, CPB Netherlands Bureau for Economic Policy Analysis. 
Lauth, T. P. (1978). Zero-Base Budgeting in Georgia State Government: Myth and Reality. Public Administration Review, 38(5), 420-430.

Layzell, D. T. (1998). Linking Performance to Funding Outcomes for Public Institutions of Higher Education. The U.S European Journal of Education, 33, 103-111.

Layzell, D. T., and Caruthers, J. K. (1995). Performance Funding at the State Level: Trends and Prospects. Paper presented at the Annual General Meeting of the Association for the Study of Higher Education, Orlando, Florida.

Layzell, D. T., and Mckeown, P. M. (1992). State Funding formulas for Higher Education: Trends and Issues. Paper presented at the Annual Meeting of the Association for the Study of Higher Education.

Leathers, C. G. (1979). "Language Barriers" in Public Productivity Analysis: The Case of Efficiency and Effectiveness. Public Productivity Review, 3(4), 6368.

Ledbury, M., Miller, N., Lee, A., Fairman, T., and Clifton, C. (2006). Understanding Policy Options. Retrieved 10 November 2008, from http://www.hmtreasury.gov.uk

Leininger, M. (1994). Evaluation Criteria and Critique of Qualitative Research Studies. In J. M. Morse (Ed.), Critical Issues in Qualitative Research Methods. London: SAGE.

Lilleker, D. G. (2003). Interviewing the Political Elite: Navigating a Potential Minefield. Politics, 23(3), 207-214.

Lincoln, Y. S., and Guba, E. G. (1985). Naturalistic Inquiry. London: SAGE.

Maassen, D. P. (2000). Models of Financing Higher Education in Europe: Center for Higher Education Policy Studies (CHEPS), University of Twente.

Mahoney, P. (2006). Higher Education Funding - Overseas Models. NZ Parliamentary Library.

Mason, J. (2002). Qualitative Researching. London: Sage. 
Mauritius Chamber of Commerce and Industry (2006). Discover Mauritius: Basic

Data. Retrieved February 26, 2007, from http://www.mcci.org/discover

Mauritius Research Council (2002). Annual Report 2000/2001. Rose Hill.

Mauritius Research Council (2004). Annual Report 2001/2002 and 2002/2003.

Rose Hill.

Mauritius Research Council (2005). Annual Report 2003/2004. Rose Hill.

Retrieved February 20, 2009, from

http://www.mrc.org.mu/Documents/AR0304.pdf

Mauritius Research Council (2006a). About Mauritius Research Council. Retrieved January 10, 2007, from http://www.mrc.org.mu

Mauritius Research Council (2006b). Annual Report 2004/2005. Rose Hill.

Mauritius Research Council (2008). Annual Report 2006/2007. Rose Hill.

Retrieved April 28, 2009, from

http://www.mrc.org.mu/Documents/AR0607.pdf

May, T. (2001). Social Research: Issues, Methods and Process: Buckingham: Open University.

Mayan, M. J. (2001). An Introduction to Qualitative Methods. Edmonton, Alberta: International Institute of Qualitative Methodology.

McEvoy, J. (2006). Elite Interviewing in a Divided Society: Lessons from Northern Ireland. Politics, 26(3), 184-191.

McGee, D. G. (2007). The Budget Process: A Parliamentary Imperative. London: Commonwealth Parliamentary Association.

McKeown-Moak, Mary, P. (1999). Higher Education Funding Formulas. New Directions for Higher Education, 1999(107), 99-107.

McKeown, Mary P (1996). State Funding Formulas for Public Four-Year Institutions: State Higher Education Executive Officers Association.

McLaughlin, M. (2003). Tertiary Education Policy in New Zealand: lan Oxford (New Zealand) Fellowships in Public Policy Retrieved July 15, 2008, from www.fulbright.org.nz/voices/axford/docs/mcLaughlin.pdf 
McNay, I. (1997). The Impact of the 1992 Research Assessment Exercise in English Universities. Higher Education Review, 29, 34-43.

McNay, I. (2003). Assessing the Assessment: An Analysis of the UK Research Assessment Exercise, 2001, and its Outcomes, with Special Reference to Research in Education. Science and Public Policy, 30(1), 1-8.

Middleton, S. (2005). One Flew over the PBRF: Disciplining the Subject of Education. In R. Smith \& J. Jesson (Eds.), Punishing the Discipline: The PBRF Regime. Auckland: Auckland University of Technology, University of Auckland.

Middleton, S. (2008). Research Assessment as a Pedagogical Device: Bernstein, Professional Identity and Education in New Zealand. British Journal of Sociology of Education, 29(2), 125-136.

Miles, M. B., and Huberman, A. M. (1994). Qualitative Data Analysis. London: Sage.

Miller, J. L. (1964). State Budgeting for Higher Education: The Use of Formulas and Cost Analysis. Ann Arbor: Institute of Public Administration, University of Michigan.

Ministry of Education [Denmark] (2000). Financing of Education in Denmark. Ministry of Education [Denmark] (2005). Facts and Figures 2005. Retrieved July 27, 2006, from http://pub.uvm.dk/2005/facts/

Ministry of Education [Denmark] (2008). Facts and Figures 2007. Retrieved November 6, 2008, from http://pub.uvm.dk/2008/facts/

Ministry of Education [New Zealand] (2006). OECD Thematic Review of Tertiary Education. Wellington.

Ministry of Education [New Zealand] (2007). Profile and Trends 2006: New Zealand's Tertiary Education Sector. Wellington.

Ministry of Education and Human Resources [Mauritius] (2008). Education Statistics: Post-Secondary Education. Retrieved May 13, 2008, from http://www.gov.mu/portal/goc/cso/report/natacc/educa07 
Ministry of Education and Scientific Research [Mauritius] (2004). The Development of Education: National Report of Mauritius. Retrieved December 20, 2007, from http://www.ibe.unesco.org/International/ICE47/

Ministry of Education and Scientific Research [Mauritius] (2005). Developing Mauritius into a Knowledge Hub and a Centre for Higher Learning, from www.gov.mu/portal/goc/educationsite/file/coverkh.pdf

Ministry of Education and Transitory Tertiary Education Commission [New Zealand] (2002). Investing in Excellence, The Report of the PerformanceBased Research Fund Working Group. Wellington.

Ministry of Finance and Economic Development (2008a). Budget Speech 2008/2009. Retrieved June 30, 2008, from http://www.gov.mu/portal/goc/mof/files/bud0809.pdf

Ministry of Finance and Economic Development (2008b). National Budget 20082009. Retrieved November 26, 2008, from http://www.gov.mu/portal/site/MOFSite

Mohadeb, P. (2006). Student Loan Schemes in Mauritius: Experience, Analysis and Scenarios: UNESCO, International Institute of Educational Planning.

Mohamedbhai, G. (2006, 18-20 June 2006). Quality Assurance in Tertiary Education in Mauritius, Sevres, France.

Moore, J. W., Newman, J. R., Sloane, J. P., and Steely, D. J. (2002). Productivity Effects of Research Assessment Exercises: University of Aberdeen.

Moore, S. (2006). Mauritius at a Glance: Overview. Retrieved February 18, 2007, from http://www.morestephends.mu

Moss, C. E., and Gaither, G. H. (1976). Formula Budgeting: Requiem or Renaissance? Higher Education, 47(5), 543-563.

National Agency for Higher Education [Hogskoleverket] (2005). The Internationalisation of Higher Education in Sweden. Stockholm.

National Assembly [Mauritius] (2006). The National Assembly. Retrieved September 3, 2006, from http://www.gov.mu/portal/site/Assembly

Nel, D. J. P., and Com, D. (2007). Epistemology versus Ontology. 1-13. Retrieved June 13, 2008, from http://www.mentornet.co.za/files/documents 
O'Sullivan, E., Rassel, G. R., and Berner, M. (2008). Research Methods for Public Administration. London: Pearson Education.

ORCA [Mauritius] (2006). Doing Business in Mauritius. Retrieved November 30, 2006, from http://www.ocra-mauritius.com/local/mauritius

Organisation for Economic Co-operation and Development [OECD] (2008).

Education at a Glance 2008. Retrieved January 22, 2009 from http://hera.ugr.es/doi/17676551.pdf

Orr, D. (2003). Can Performance-Based Funding and Quality Assurance Solve the State vs Market Conundrum? Higher Education Policy, 18(1), 31-50.

Osborne, D., and Gaebler, T. (1992). How the Entrepreneurial Spirit is Transforming the Public Sector: Reading: Addison-Wesley Publishing Company.

Patton, M. Q. (2002). Qualitative Research \& Evaluation Methods. London: Sage.

Pelling, M., and Uitto, J. I. (2001). Small Island Developing States: Natural Disaster Vulnerability and Global Change. Environmental Hazards, 3, 4962.

Peters, M. (1992). Performance and Accountability in 'Post-industrial Society': The Crisis of British Universities. [Journal]. Higher Education, 17(2), 123-139.

Pillay, H., and Elliott, B. (2005). Looking Through Old Lenses to Understand The Emerging New World Order: Implications for Education Reform in Small Island States. Research in International Education, 4(87), 87-106.

RAE 2008: Initial Decisions by the UK Funding Bodies (2004). Retrieved October 20, 2008, from http://www.rae.ac.uk/Pubs/2004/01

RAE (2001). 2001 Research Assessment Exercise: The Outcome. Retrieved 3 June 2008, from htpp://195.194.167.103/Pubs/4_01/section2.asp

Research Assessment Exercise 2008: The Outcome (2008). Retrieved January 30, 2009, from http://www.rae.ac.uk/pubs/2008/01/

RAE 2008: Quality Profiles. Retrieved January 22, 2009, from http://www.rae.ac.uk

Roberts, S. G. (2003). Review of Research Assessment. Retrieved January 21, 2007, http://www.hefce.ac.uk/pubs/hefce/2003/03 22.htm\#exec 
Rourke, F. E., and Brooks, G. E. (1966). The Managerial Revolution in Higher Education. Baltimore: Johns Hopkins.

Rubin, H. J., and Rubin, I. S. (2005). Qualitative Interviewing. London: Sage.

Rushforth, J., Arbo, P., Puukka, J., and Vestergaard, J. (2006). Supporting the Contribution of Higher Education Institutions to Regional Development Peer Review Report Jutland-Funen in Denmark: Organisation for Economic Co-operation and Development (IMHE).

Sadlak, J. (1978). Efficiency in Higher Education - Concepts and Problems Higher Education, 7, 213-220.

Salerno, C. (2002). Higher Education in Sweden (No. C2CS519). Netherlands: CHEPS.

Salmi, J., and Hauptman, A. M. (2006). Innovations in Tertiary Education Financing: A Comparative Evaluation of Allocation Mechanisms: World Bank's Tertiary Education Thematic Group.

Sarback, S. (2004). Financial Management and Governance in HEIS: Sweden: OECD IMHE-HEFCE.

Serban, A. (1997). Performance Funding for Public Higher Education : Views of Critical Stakeholders. Paper presented at the AAHE Assessment and Quality Conference, Miami Beach.

Serban, A. (1998). Precursors of Performance Funding. New Directions for Institutional Research, 97, 15-23.

Serban, A. (2000). Newcomers to Performance Funding: A Comparison of California's Partnership for Excellence to Other Performance Funding Programs. Paper presented at the Annual Forum of the Association for Institutional Research (AIR), Cincinnati.

Sewell, M. (2002). The Use of Qualitative Interviews in Evaluation. Retrieved June 23, 2008, from http://ag.arizona.edu/fcs/cyfernet/cyfar/Intervu5

Sharp, S., and Coleman, S. (2005). Ratings in the Research Assessment Exercise 2001 - the Patterns of University Status and Panel Membership. Higher Education Quarterly, 59(2), 153-171. 
Silverman, D. (2001). Interpreting Qualitative Data: Methods for Analysing Talk, Text and Interaction. London: Sage.

Silverman, D. (2004). Qualitative Research Theory, Method and Practice. London: Sage.

Small, D. (2005). The PBRF - Some Risks of Research Rankings. In R. Smith \& J. Jesson (Eds.), Punishing the Discipline - the PBRF Regime. Auckland: AUT University and The University of Auckland.

Smart, W. (2006). Performance-Based Research Fund: Analysis of the Incentives for Research Degree Completion. In L. Bakker, J. Boston, L. Campbell \& R. Smyth (Eds.), Evaluating the Performance-Based Research Fund - Framing the Debate. Wellington, NZ: Institute of Policy Studies.

Smith, R. (2005). Counting Research in Education: What counts under the Sheriff of Nottingham-style funding redistribution. In R. Smith \& J. Jeson (Eds.), Punishing the Discipline - The PBRF Regime: AUT University and The University of Auckland.

Smith, V. (2008). Research Excellence Framework. Retrieved September 30, 2008, from http://vsmith.info/REF

Sorlin, S. (2007). Funding Diversity: Performance-Based Funding Regimes as Drivers of Differentiation in Higher Education Systems. Higher Education Policy, 20, 413-440.

Steier, F. A. (2003). The Changing Nexus: Tertiary Education Institutions, the Marketplace and the State. Higher Education, 57(2), 158-180.

Swedish National Agency for Higher Education (2008). Swedish Universities and University Colleges: Short Version of Annual Report 2008.

Sweeney, D. (2009). The Research Excellence Framework UK Research: The Changing Policy Landscape. Retrieved April 15,2009, from www.universitiesuk.ac.uk/Events/Documents/David\%20Sweeney\%2010.1 0\%20-\%2010.30.ppsx

Talib, A., and Steele, A. (2000). The Research Assessment Exercise: Strategies and Trade-Offs. Higher Education Quarterly, 54(1), 68-87. 
Taylor, J. (2001). The Impact of Performance Indicators on the Work of University Academics: Higher Education Quarterly, 55(1), 42-61.

Temple, C. M., and Riggs, R. O. (1978). The Declining Suitability of the Formula Approach to Funding Public Higher Education: Rationale and Alternatives. [Issues and Trends in American Education]. Peabody Journal of Education, 55(4), 351-357.

Tertiary Education Advisory Commission [New Zealand] (2001). Shaping the Funding. Fourth Report of the Tertiary Advisory Commission. Wellington.

Tertiary Education Commission [Mauritius] (2003a). Annual Report and Accounts 2000/2001. Reduit.

Tertiary Education Commission [Mauritius] (2003b). Annual Report and Accounts 2001-2002. (Reduit?)

Tertiary Education Commission [Mauritius] (2004). Annual Report and Accounts 2001/2002. Reduit.

Tertiary Education Commission [Mauritius] (2005). Annual Report and Accounts 2003/2004. Reduit.

Tertiary Education Commission [Mauritius] (2006a). Annual Report and Accounts 2004/2005. Reduit.

Tertiary Education Commission [Mauritius] (2006b). Annual Report and Accounts 2005/2006. Reduit.

Tertiary Education Commission [Mauritius] (2006c). Participation in Tertiary Education 2005. Reduit.

Tertiary Education Commission [Mauritius] (2006d). Report on Tertiary Education 2003/2004. Reduit.

Tertiary Education Commission [Mauritius] (2007). Annual Report and Accounts 2005/2006. Reduit.

Tertiary Education Commission [Mauritius] (2008a). Annual Report and Accounts 2006/2007. Reduit. Retrieved April 20, 2008, from http://tec.intnet.mu/PDF\%20downloads/TEC\%20Annual\%20Report\%20200 6-2007.pdf 
Tertiary Education Commission [Mauritius] (2008b). Participation in Tertiary Education 2007. Reduit.

Tertiary Education Commission [New Zealand] (2000). Shaping a Shared Vision: Initial Report of the Tertiary Education Advisory Commission. Wellington.

Tertiary Education Commission [New Zealand] (2004a). Performance-Based Research Fund - Evaluating Research Excellence: the 2003 Assessment.

Tertiary Education Commission [New Zealand] (2004b). Performance-Based Research Fund - Evaluating Research Excellence: the 2003 Assessment: Overview and Key Findings. Wellington.

Tertiary Education Commission [New Zealand] (2005). Performance-Based

Research Fund Guidelines 2006. Retrieved April 10, 2007, from

http://www.tec.govt.nz

Tertiary Education Commission [New Zealand] (2006a). Performance-Based Research Fund - Evaluating Research Excellence: the 2006 Assessment. Wellington.

Tertiary Education Commission [New Zealand] (2006b). Performance-Based Research Fund - Evaluating Research Excellence: the 2006 Assessment. Wellington.

Theisens, H. (2003). Higher Education in the United Kingdom. Netherlands: CHEPS.

Thorn, K., Holm-Nielsen, L., and Jeppesen, J. S. (2004). Approaches to ResultsBased Funding in Tertiary Education. World Bank Policy Research Working Paper, (3436), Retrieved April 30, 2007, from http://econ.worldbank.org

Thorne, E. S. (2007). Secondary Analysis of Qualitative Data

Encyclopaedia of Social Science Research Methods Retrieved May 12, 2008, from http://www.sage-ereference.com/socialscience/Article n895

Thune, C. (2001). Quality Assurance of Higher Education in Denmark

Tigerstrom, B. V. (2005). Small Island Developing States and International Trade: Special Challenges in the Global Partnership for Development. Melbourne Journal of International Law, 6, 402-436. 
Tucker, H. J. (1982). Incremental Budgeting: Myth or Model. The Western Political Quarterly 35(3), 327-338.

Turner, D. A. (1994). Formula Funding of Higher Education in the Czech Republic: Creating an Open System. Studies in Higher Education, 19(2), 139-150.

UNESCO (2005). EFA Global Monitoring Report: The Quality Imperative. Paris.

United Nations Economic and Social Commission for Asia and the Pacific (UNESCAP) (2009). What is Good Governance?. Retrieved November 15, 2009, from http://www.unescap.org/pdd/prs/ProjectActivities/Ongoig lgg/governance.asp

United Nations (2005). Special Challenges Facing SIDS in Trade and Economic Development. Paper presented at the International Meeting to Review the Implementation of the Programme of Action for the Sustainable Development of Small Island Developing States, Port Louis, Mauritius.

United Nations (2009). List of Small Island Developing States. Retrieved January 29, 2009, from http://www.un.org/special-rep/ohrlls/sid/list.htm

United Nations Report (2003). Small Island Developing States Network Retrieved October 15, 2006, from http://www.sidsnet.org University of Mauritius (2001). Annual Report 1999/2000. Reduit. University of Mauritius (2002). Annual Report 2000/2001. Reduit. University of Mauritius (2003). Annual Report 2001/2002. Reduit. University of Mauritius (2004). Annual Report 2002/2003. Reduit. University of Mauritius (2005). Annual Report 2003/2004. Reduit. University of Mauritius (2006). Annual Report 2004/2005. Reduit. University of Mauritius (2007). Annual Report 2005/2006. Reduit. University of Mauritius (2008). Annual Report 2006/2007. Reduit. Vos, R. (1996). Educational Indicators: What's To Be Measured? NDES Working Papers. Washington, DC: Inter-American Development Bank. World Bank: (2000).

Vossensteyn, H. (2003). Higher Education in Denmark. Netherlands: CHEPS. 
WEB Research (2004). Phase 1 Evaluation of the Implementation of the PBRF and the Conduct of the 2003 Quality Evaluation.

Weiler, H. N. (2000). State, Markets and University Funding: New paradigms for the reform of higher education in Europe. [Journal]. Compare, 30(3), 333339.

Wensvoort, M. (2008). Tertiary Education Enrolments - 2007: Tertiary Sector Performance Analysis and Reporting Strategy and System Performance, Ministry of Education [New Zealand].

White, K. G. (2006). Impact of the Performance-Based Research Fund on Staffing in Tertiary Education Institutions. In L. Bakker, J. Boston, L. Campbell \& R. Smyth (Eds.), Evaluating the Performance-Based Research Fund.

Wellington, N.Z.: Institute of Policy Studies.

Willmott, H. (2003). Commercialising Higher Education in the UK: The State, Industry and Peer Review. Studies in Higher Education, 28(2), 129-141.

World Bank (1998). Public Expenditure Management Handbook: The International Bank of Reconstruction and Development / The World Bank.

World Bank (2000). Higher Education in Developing Countries Peril and Promise. Washington (DC?).

World Bank (2002). Constructing Knowledge Societies: New Challenges for Tertiary Education. Washington (DC?).

Ziderman, A., and Douglas, A. (1992). Financing Universities in Developing Countries. Education \& Employment Division Population and Human Resources Development.

Ziderman, A., and Douglas, A. (1995). Financing Universities in Developing Countries Washington D.C.: Falmer. 